\title{
Stem cell organization in Arabidopsis: from embryos to roots
}

Jos R. Wendrich 
Thesis committee

\section{Promotor}

Prof. Dr D. Weijers

Personal chair at the Laboratory of Biochemistry

Wageningen University

\section{Co-promotor}

Dr B. De Rybel

Researcher, Laboratory of Biochemistry

Wageningen University and VIB, Ghent University

\section{Other members}

Prof. Dr B.J.G. Scheres, Wageningen University

Prof. Dr T. Beeckman, Ghent University, Belgium

Dr R. Offringa, Leiden University

Dr H. Robert-Boisivon, CEITEC Brno, Czech Republic

This research was conducted under the auspices of the Graduate School of Experimental Plant Sciences 


\section{Stem cell organization in Arabidopsis: from embryos to roots}

\section{Jos R. Wendrich}

\section{Thesis}

submitted in fulfilment of the requirements for the degree of doctor at Wageningen University

by the authority of the Rector Magnificus

Prof. Dr A.P.J. Mol,

in the presence of the

Thesis Committee appointed by the Academic Board

to be defended in public

on Friday 3 June 2016

at 1.30 p.m. in the Aula. 
Jos R. Wendrich

Stem cell organization in Arabidopsis: from embryos to roots, 192 pages.

PhD thesis, Wageningen University, Wageningen, NL (2016)

With references, with summaries in English and Dutch

ISBN: 978-94-6257-735-0

DOI: $10.18174 / 370659$ 


\section{Contents}

\section{Chapter 1}

Introduction

\section{Chapter 2}

Ligation Independent Cloning for plant research

\section{Chapter 3}

In vivo identification of plant protein complexes using IP-MS/MS

\section{Chapter 4}

A set of domain-specific markers in the Arabidopsis embryo

\section{Chapter 5}

IQ-domain proteins connect auxin and calcium signaling during

Arabidopsis development

\section{Chapter 6}

Organization of the Arabidopsis root meristem by opposing transcriptional gradients

\section{Chapter 7}

General Discussion

English Summary

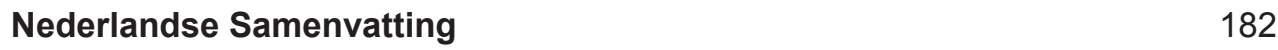

$\begin{array}{ll}\text { Acknowledgements } & 184\end{array}$

$\begin{array}{ll}\text { Curriculum Vitae } & 188\end{array}$

$\begin{array}{ll}\text { Publications } & 189\end{array}$

$\begin{array}{ll}\text { Education Statement } & 191\end{array}$ 



\section{Chapter 1}
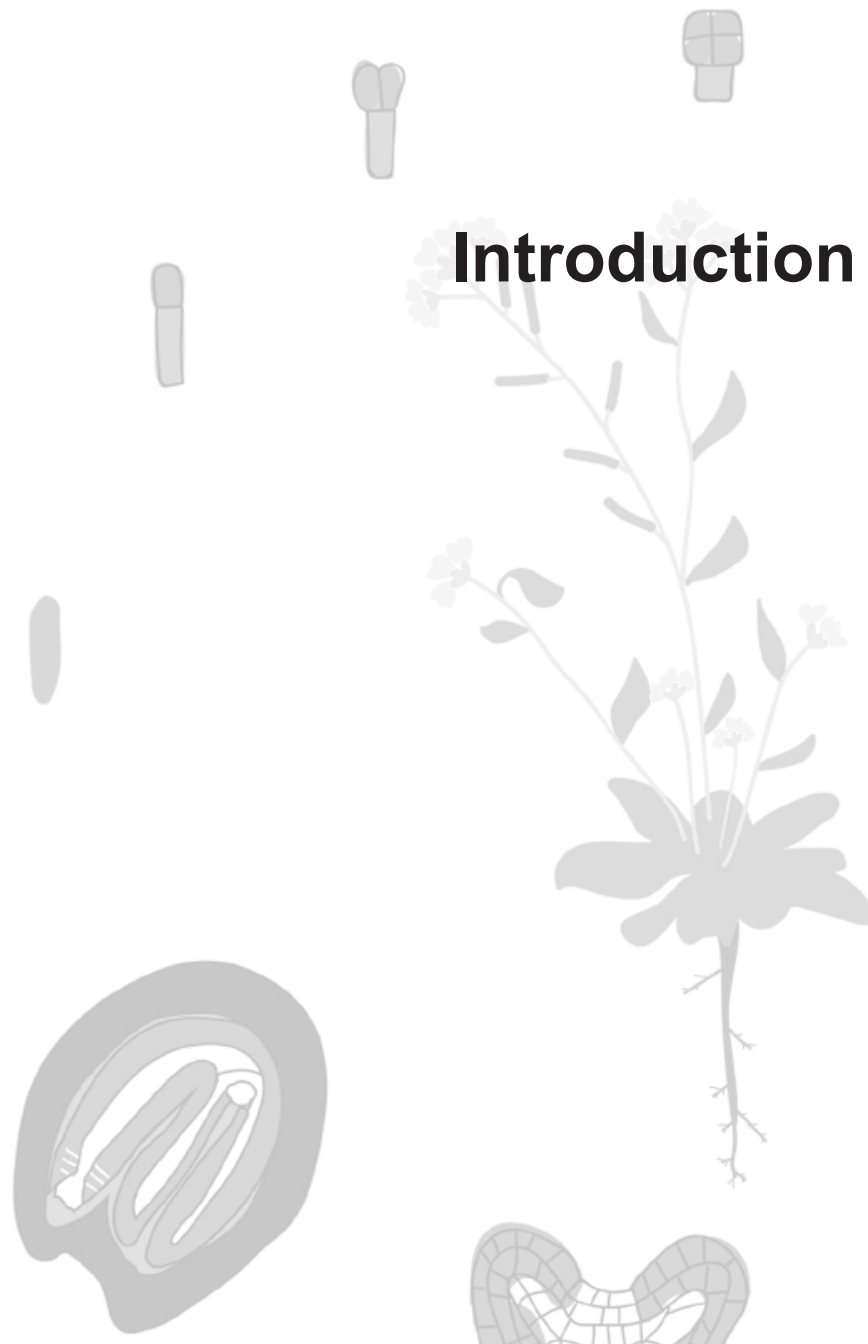

\section{Introduction}

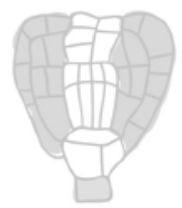

A part of this introduction was published as: Wendrich J.R. and Weijers D. (2013) The Arabidopsis embryo as a miniature morphogenesis model. New Phytol 199:1425. doi:10. 1111/nph.12267 



\section{Summary}

Development of multicellular organisms depends on the continuous and coordinated renewal of tissues and, in the case of plants, formation of new organs. This renewal is only possible through the action of stem cells that deliver new differentiating cells to the growing tissue, while staying undifferentiated, themselves. Furthermore, development often occurs in a strictly controlled manner ensuring proper morphogenesis. Four basic ingredients of morphogenesis, oriented cell division and expansion, cell-cell communication and cell fate specification allow plant cells to develop into a wide variety of organismal architectures. A central question in plant biology is how these cellular processes are regulated and orchestrated. Here, the advantages of the early Arabidopsis embryo as a model for studying the control of morphogenesis are presented. All ingredients of morphogenesis converge during embryogenesis, and the highly predictable nature of embryo development offers unprecedented opportunities for understanding their regulation in time and space. In addition, de novo specification of stem cells during this stage of development provides a great tool to study this process. This chapter further describes the morphogenetic principles underlying embryo patterning and discusses recent advances in their regulation. Morphogenesis is under tight transcriptional control and most genes that were identified as important regulators of embryo patterning encode transcription factors or components of signaling pathways. There exists, therefore, a large gap between the transcriptional control of (embryo) morphogenesis and the cellular execution. This thesis describes efforts made to start bridging this gap and provides new insights into the organization of stem cells in the Arabidopsis root, using the embryo as model and starting point. 


\section{Ingredients of plant morphogenesis}

Morphogenesis occurs throughout plant life, and generates the enormous variety of shapes observed in the plant kingdom. No matter how complex the eventual plant morphology, whether a structurally simple moss or a highly branched tree, a small set of cellular processes underlie all shapes. Hence, an understanding how diversity in plant shapes, structures and functions is controlled requires knowledge of the basic cellular principles underlying morphogenesis. Among these are cell division, the process where a cell divides into two daughter cells, either with the same properties (symmetric) or with different properties (asymmetric) (both orientation and rate of cell division strongly contribute to morphogenesis) and (directional) cell expansion, the process whereby a cell expands its volume in either a random or a directional fashion. This occurs primarily through turgor pressure from the vacuole, guided by the cell wall (Sanchez-Rodriguez et al., 2010). These two processes (division and expansion) are cell-intrinsic features that define shape and growth direction. As such properties are uniquely controlled in different cell types, a third important component of morphogenesis is cell fate specification. Finally, considering its vital importance for plant morphogenesis, we consider a fourth key process that coordinates cellular decisions in time and space: cell-cell communication (both short- and long-range). Short-range cell-cell communication mostly occurs using small signal molecules that diffuse either through the cell membrane or channels or are secreted to the apoplast and recognized by membrane receptors in adjacent cells (Nakajima et al., 2001; Hirakawa et al., 2008). Long-range communication is typically established by the use of hormones that work as either a ligand for membrane receptors or as an active compound within the cell (Ubeda-Tomas et al., 2012).

Whereas cell migration plays a key role in morphogenesis during animal development, for example in gastrulation (Lim \& Thiery, 2012), cell migration does not occur in plants, because of the presence of rigid cell walls. Since morphogenesis is strongly genetically controlled, development can be viewed as the sum of the transcriptional control of individual cell properties, combined with cell-cell signaling that connects cells. In this chapter, we discuss the use of the early embryo as a model that is excellently suited to study these processes and their interconnections. Early embryogenesis is interesting, not only because morphogenesis occurs in a very controlled manner (see below), but also because the tissues, the cell types that populate them, and the stem cell systems that maintain them are specified de novo.

During plant development, several niches of stem cells (discussed below) are established. These niches, or meristems, are established as early as the globular 

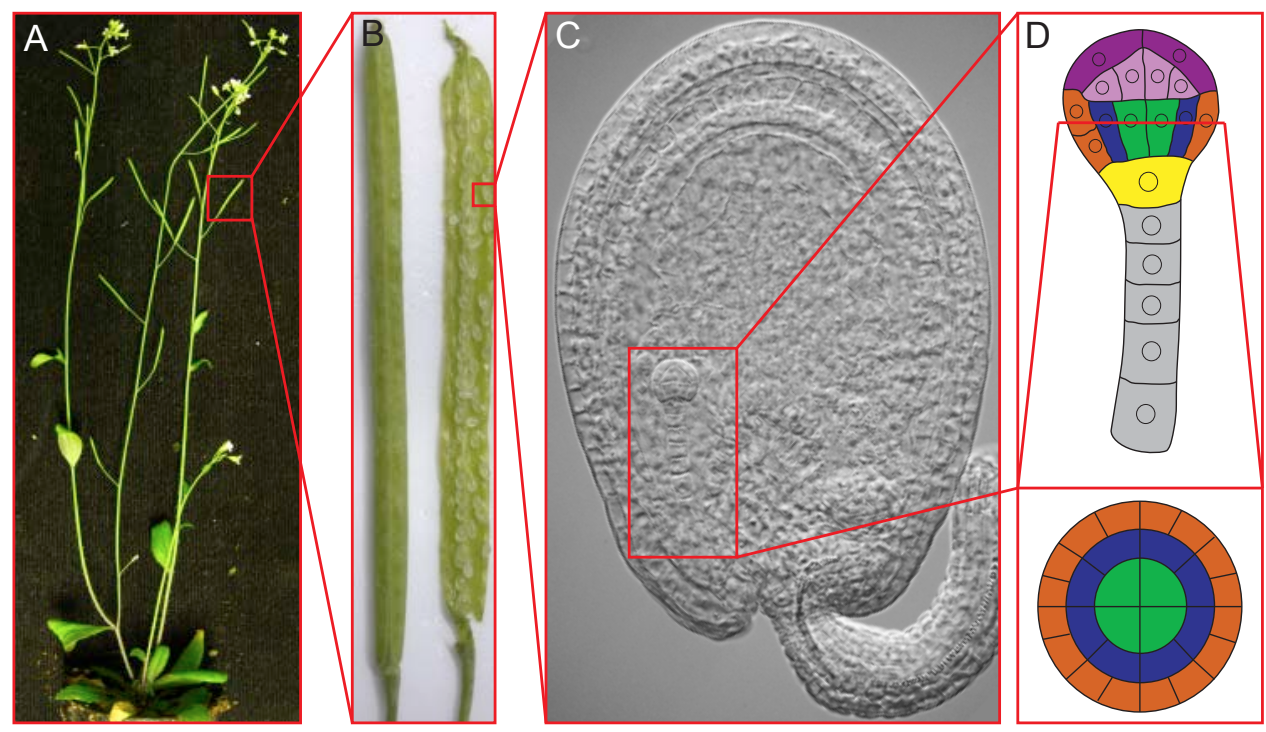

Figure 1: The Arabidopsis embryo. Embryos are deeply embedded in maternal structures. Siliques on the stem (a) contain developing seeds (b) that harbor the embryo (c). (d) Schematic representation of a longitudinal (top) and transverse (bottom) cross-section of a globular stage embryo. Different colors represent unique cell types.

stage of Arabidopsis embryo development, are maintained throughout the life of a plant and function to establish the new tissues and organs (Weigel \& Jurgens, 2002). Although much has been learned about meristem function and maintenance from studies of postembryonic development (Liu etal., 2009; Terpstra \& Heidstra, 2009), the exact processes underlying the initiation of stem cells and their meristems are still poorly understood. One of the many challenges of developmental biology is to separate genetic control from environmental control on the tissue that is studied. As both can play a major role in the development of an organism, the ability to separate these two factors is of great importance. The challenge in doing this lies mainly in the fact that both factors are often interdependent and respond to each other (Hsu \& Harmer, 2012). Particularly because organogenesis is a highly plastic process on which many environmental factors converge, postembryonic development is not entirely predictable at the cellular level. The early embryo, by contrast, is resilient to environmental influences, as the same body pattern is generated under various conditions. Despite its simplicity (Figures 1 and 2), the few first days of plant life produce an embryo in which all ingredients of morphogenesis combine to generate the main tissues, cell types and meristems. Although different plant species can differ greatly in the final product of embryo development (Johri et al., 1992), the same basic principles apply, as in all cases a species-specific robust pattern with 
comparable pattern elements is formed. Since most research has been performed on the development of the Arabidopsis embryo, we will mainly focus on this model in this chapter. We will discuss the key steps in embryonic pattern formation and recent insights into their regulation. We will consider future directions and challenges in revealing the molecular and cellular basis for plant morphogenesis using the embryo as a model.

\section{Arabidopsis embryo development: an amalgamation of morphogenetic processes}

There have been many reports and reviews describing the sequence of divisions during Arabidopsis embryogenesis (e.g. De Smet et al., 2010; Peris et al., 2010; Nodine et al., 2011). Here, we would like to take a slightly different approach to describe and visualize this. In order to fully understand the processes that play a role during embryo development, one must look not only at what happens to the embryo while it develops, but also at the different cellular processes necessary to achieve these steps. One important characteristic of early Arabidopsis embryogenesis is that the sequence and order of morphogenetic events, including the precise arrangements of cell division planes, is virtually invariant. This characteristic installs a large degree of predictability that allows the deconstruction of complex development into individual steps. In this section, and highlighted in Figure 2, we break down embryo development into the necessary cellular processes that need to be controlled for developmental progression to occur. When discussing these precisely controlled morphogenetic events, one should bear in mind that the regularity displayed in the Arabidopsis embryo may be idiosyncratic. Most postembryonic organs are composed of many more cells, and may not require such a high degree of control at the individual cell level. Furthermore, regenerative properties allow patterning from alternative cellular templates. Nonetheless, the regularity of cellular behavior in the early Arabidopsis embryo is a strong asset in the study of mechanisms that underlie the cellular basis of pattern formation.

Before fertilization, the egg cell appears as a highly polar cell, with its nucleus localized in the apical region of the cell (Figure 2). Directly after fertilization, this polarity is lost, the cell depolarizes and the nucleus moves to the center of the cell (Christensen et al., 2002; Faure et al., 2002; Ueda et al., 2011). The polarity is then re-established and the zygote elongates, before dividing asymmetrically to form a small apical cell and a larger basal cell containing more vacuole than the apical cell (Figure 2; Zhang \& Laux, 2011). The basal cell will divide symmetrically 

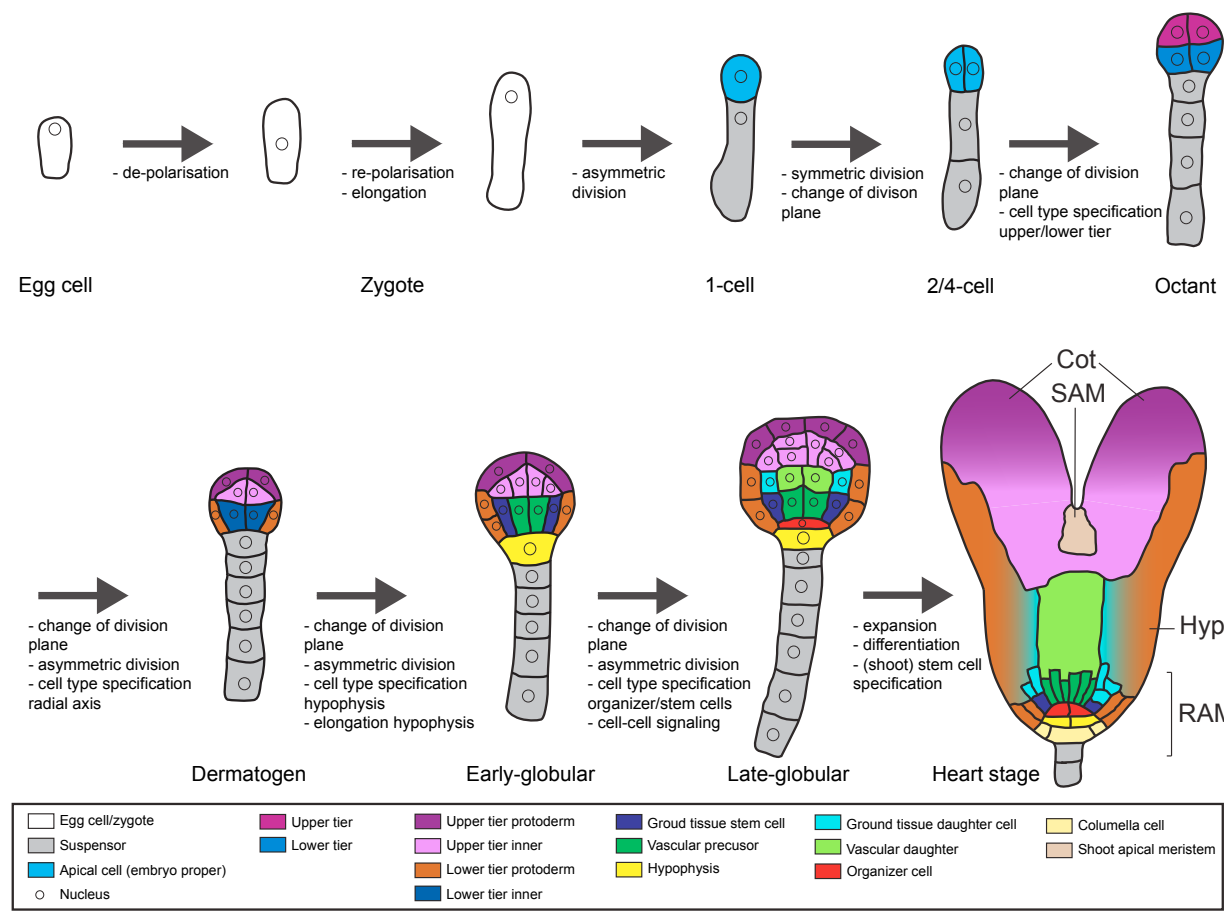

Figure 2: Morphogenetic processes during Arabidopsis embryogenesis. Schematic overview of Arabidopsis embryogenesis from the egg cell to the heart stage embryo, highlighting the morphogenetic processes required to progress from one stage to the next. The colors represent cells of (essentially) the same type (see color legend), based on marker gene expression and lineage analysis. Cot, cotyledon ; SAM, shoot apical meristem; Hyp, hypocotyl; RAM, root apical meristem.

and in the same direction until the globular stage, forming the connective tissue called the suspensor. The apical cell will change its division plane and seems to divide symmetrically. Another change of division plane results in the formation of the upper and lower tiers, also called the apicobasal axis of the embryo proper. The step from octant to dermatogen stage again requires a new direction of division (the cells divide almost diagonally) and this results in the establishment of another axis, the radial axis. The outermost cells are the so-called protodermal cells, which will undergo several rounds of symmetric cell divisions and later establish the epidermal tissue. During the following step to the early-globular stage, the first internal tissues are specified. Through a round of asymmetric cell divisions, the inner cells form the precursors of the vascular and ground tissue. Also during this step, the hypophysis is specified from the most apical suspensor cell, which then protrudes (and is incorporated) into the embryo. The steps taken to form the late-globular embryo may be regarded as some of the most essential steps during the development of 
the embryo. During the transition from the early- to the late-globular stage, the hypophysis divides asymmetrically to form the small apical lens-shaped cell and the larger basal cell. These are known as the root organizer (in later stages called the quiescent center [QC]) and columella stem cells, respectively. Cell-cell signaling has been shown to be crucial for hypophysis specification to occur properly (Hamann et al., 1999; Schlereth et al., 2010). Also during this stage, the stem cells for the vasculature and ground tissue are specified and divide once to form apical daughter cells that will further divide and differentiate. In later stages, more cell expansion and differentiation take place, together with the specification of the shoot apical meristem cells.

As will be detailed below, all the earlier-mentioned processes are under tight genetic control, as mutations in key components lead to specific defects. Furthermore, the different cell identities as described here are often marked by specific gene expression markers (Figures 2, 3, and 5).

\section{Regulation of morphogenetic processes during embryogenesis}

Even though embryogenesis is a continuous process, and all patterning processes depend on appropriate prior patterning, we will here consider the regulation of the critical morphogenetic processes during embryo development individually, with an emphasis on recent findings that have shed light on the mechanisms involved.

\section{Development before and directly after fertilization}

During the very first stages of embryo development, the zygote, right after fertilization, loses its polarity, which is later re-established. To our knowledge, there have so far been only three reports showing the depolarization and subsequent repolarization of the zygote after fertilization (Christensen et al., 2002; Faure et al., 2002; Ueda et al., 2011), and in all cases the phenomenon has been descriptively reported. Therefore, it remains unknown why this happens, what mechanisms are involved in the process and the precise function of the depolarization. Before fertilization of the egg cell, a high degree of polarity can be observed, but the factors that are important for this polarity are not well understood. One can speculate about the meaning of this polarity and, perhaps more importantly, the meaning of the depolarization. It is conceivable that during development of the female gametophyte, the cells surrounding the egg cell produce signals that determine egg cell polarity and that, after fertilization, these signals are no longer produced or available, resulting in depolarization of the egg cell. It is also possible that the subsequent availability 


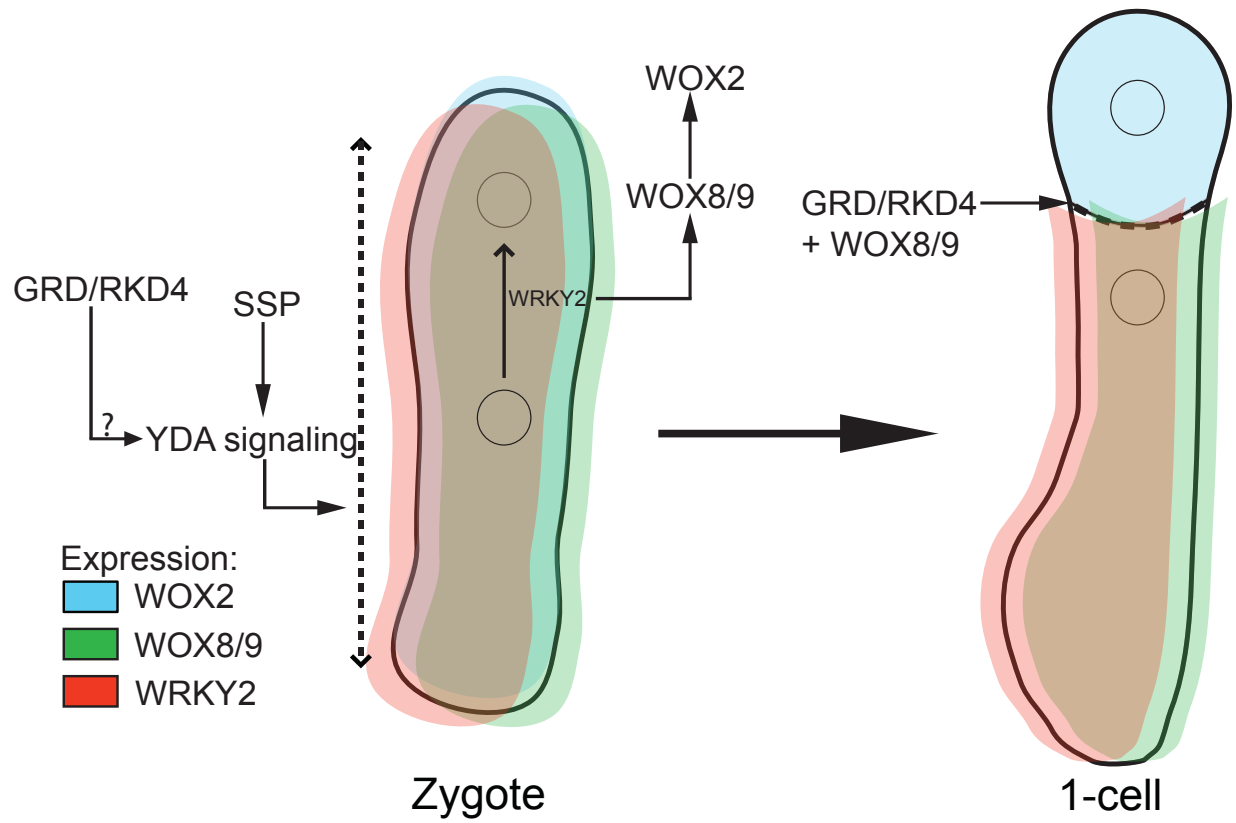

Figure 3: Regulation of zygote elongation and asymmetric division in Arabidopsis. The expression of genes involved in the polarity of the zygote is shown in different colors. One of the first important steps, zygote elongation, is predominantly regulated by the YODA (YDA) signaling pathway, which is activated by paternally delivered SHORT SUSPENSOR (SSP). GRD/RKD4 also acts in zygote elongation, but the molecular connection to the YDA pathway is unknown. WRKY2 regulates repositioning of the zygote nucleus and activates WOX8/9 expression. WOX8/9 in the basal cell non-cell-autonomously induce the expression of WOX2 in the apical cell, and, together with GRD/RKD4, regulate the asymmetric division of the zygote.

of factors required for repolarization determines whether the first division of the zygote occurs symmetrically or asymmetrically. Some plant species have been shown to lack this characteristic asymmetric division seen in Arabidopsis (Johri et al., 1992). In Arabidopsis, the WRKY2 gene has been shown to be a factor required for repolarization of the egg cell after fertilization (Ueda et al., 2011). A large-scale study combining transcriptomic and physiological approaches comparing different plant species could potentially unravel the mechanisms that underlie the process of depolarization and subsequent repolarization and perhaps shed light on the biological function of these processes. In Arabidopsis, the WRKY2 gene, encoding a zincfinger transcription factor, was the first and so far the only genetic regulator of zygote repolarization to be identified (Ueda et al., 2011). WRKY2 was identified as a direct upstream regulator of WOX8 and WOX9 transcription (discussed below). Expression of WRKY2 in the early zygote is necessary for its activity in this process (Ueda et al., 2011; Figure 3). In the absence of WRKY2 activity, the polarity of the egg cell is lost 
after fertilization, similar to the wildtype. In contrast to the wildtype zygote, polarity is not re-established and the subsequent division seems to occur symmetrically rather than asymmetrically (based on cytoplasm density and the presence of vacuoles). Later divisions of the suspensor cells also occur erroneously, as the suspensor cells are very small and sometimes divide periclinally, resembling embryonic cells (Ueda et al., 2011). This indicates that WRKY2 also has a role in specification or maintenance of the suspensor identity. The role of WRKY2 in suspensor identity is most likely through regulation of WOX8/9 expression in the zygote. In the wkry2 mutant background, WOX 8 is severely down-regulated in the zygote and expression of the embryo-specific WOX2 gene is expanded to erroneously dividing cells of the suspensor (Ueda et al., 2011), which further indicates that these cells attain an embryo-like fate. Although WOX8 expression is greatly reduced in the zygote, this expression is regained by the two-cell stage, showing that other factors also control WOX8 expression and this is most likely the reason why the wrky2 mutant produces relatively normal mature embryos. In addition to regulation of WOX8 and WOX9 expression in the zygote, there seems to be another, as yet unknown, factor regulated by WRKY2, as the wox8 wox9 double mutant does not show a phenotype until after the one-cell stage, and expression of WOX8 in the wrky2 background cannot fully rescue the phenotype (Ueda et al., 2011). This suggests that there are factors yet to be discovered that play a role in the process of zygote polarity and the establishment of cell types in this early stage.

A further step is elongation of the zygote. Several factors have been found that influence zygote elongation and one of the main pathways is the so-called YODA (YDA)-signaling pathway (Figure 3). YDA encodes a mitogen-activated protein kinase kinase (MAPKK) that was first isolated through a mutant screen for defects in suspensor development (Lukowitz et al., 2004). In this screen, two other genes (SHORT SUSPENSOR [SSP] and GROUNDED [GRD]) were found to have similar phenotypes and, indeed, these were found to act in the YDA-signaling pathway. The YDA gene is ubiquitously expressed, but the effect on elongation seemed to be restricted to a specific developmental cue, as no significant effect on elongation was found in other cells (Lukowitz et al., 2004). YDA does have a broader function, perhaps unrelated to elongation, as it was shown to regulate stomatal development (Bergmann et al., 2004). In the yda mutant, elongation of the zygote is severely reduced, resulting in a very short suspensor and often-erroneous divisions in the suspensor at later stages. Interestingly, a hyperactive variant of YDA has an almost opposite effect on embryo development, resulting in excessive elongation of the suspensor, which was often found to contain more cells than normal (Lukowitz et 
al., 2004). More recently, the YDA-signaling pathway was found to be controlled by a member of the interleukin-1 receptor-associated kinase (IRAK)/Pelle-like kinase family of receptor-like kinases, called the SHORT SUSPENSOR (SSP; Bayer et al., 2009). Remarkably, this was one of the genes retrieved from the same screening that resulted in isolation of the YDA gene (Lukowitz et al., 2004). MAP kinase signaling pathways are, in both animals and plants, often under the control of receptor-like kinases that are activated by an external signal and this was also suggested to be the case for the YDA-signaling pathway (Lukowitz et al., 2004). Isolation of the SSP gene provided further supporting evidence for this hypothesis. Interestingly, the activity of this membrane-bound protein was shown to be under the control of a paternally derived transcript, which is translated only after fertilization and then able to activate the YDA-signaling pathway in both embryos and leaves (Bayer et al., 2009). This indicates that there must be some regulatory mechanism that blocks translation of SSP transcripts in the pollen.

The third gene found in the screen by Lukowitz et al. (2004), GROUNDED $(G R D)$, was recently found to encode a protein containing an RWP-RK domain (Jeong et al., 2011; Waki et al., 2011; here called RKD4). RWP-RK domain-containing proteins are found in the genomes of green algae (Ferris \& Goodenough, 1997), vascular plants (Schauser et al., 1999), and basal eukaryotes (Schauser et al., 2005), but interestingly not in animals, which indicates that these factors probably have a plant-specific function. The RWP-RK domain was predicted to form a basic helix-turn-helix secondary structure (Schauser et al., 2005), which implies a role for these proteins in DNA binding and regulation of transcription. Indeed, Waki et al. (2011) found that GRD/RKD4 could trigger embryo-specific gene expression upon overexpression, in some cases even resulting in the induction of somatic embryogenesis. Phenotypically, the grd/rkd4 mutants resemble the $y d a$ and $s s p$ mutants, with defects in zygote elongation and suspensor formation, and GRD/ RKD4 was shown to have a genetic interaction with the YDA-signaling pathway (Figure 3; Jeong et al., 2011). Although it is not a direct target of YDA signaling, as overexpression of GRD/RKD4 in a yda background does not suppress the $y d a$ phenotype, it is required for a functional YDA cascade, as the hyperactive yda mutant does not have an effect on the grd/rkd4 phenotype (Jeong et al., 2011). How this interaction occurs on a protein level is as yet unknown, although GRD/RKD4 could be regulating the expression of target genes active in the YDA-signaling pathway, either with the cooperation of the YDA cascade or completely independently. In addition to its function in the YDA-signaling pathway, GRD/RKD4 was found to act cooperatively with WOX8 and WOX9 in establishing embryo polarity (Figure 3). Embryos lacking 
all three genes stop developing very early on and never progress beyond the onecell stage (Jeong et al., 2011). This enhancement of both phenotypes (see below) indicates that there is a synergistic relationship between the WOX and the YDA pathway, strengthening both their roles in the development of the plant embryo.

WOX8/9 are part of the family of WUSCHEL RELATED HOMEOBOX (WOX) genes, which have been shown to be regulators of a whole range of developmental processes, including embryogenesis (van der Graaff et al., 2009). The founder of this gene family, WUSCHEL, regulates maintenance of the shoot apical meristem (Laux et al., 1996). Interestingly, the wus mutant is able to produce new meristems, but these are not maintained and soon terminate their growth. WUS expression can be found in the organizing center of the shoot apical meristem (Mayer et al., 1998), similar to a distant relative, WOX5, which is found in the quiescent center (QC) cells of the root meristem and is important for root meristem maintenance (Sarkar et al., 2007). Strikingly, the wus phenotype can be complemented by expressing WOX5 in the WUS domain (Sarkar et al., 2007), indicating that, although not closely related, these factors share similar functions in the maintenance of meristems. This is also consistent with phylogenetic data that shows there is a single common ancestor for all the WOX genes in green algae and a single WUS/WOX 5 homolog found in gymnosperms (Nardmann et al., 2009). This indicates that a subfunctionalization event occurred that kept meristem maintenance function in both genes, but diverged them into two different expression domains. The role of WOX genes in early embryogenesis becomes most apparent in the interplay between the WOX2 and WOX8/9 genes. Initially, these genes are coexpressed in the undivided zygote but they become restricted to the apical (WOX2) and basal (WOX8/9) cell after the first division, marking the separate cell lineages and also showing the asymmetric division on a molecular level (Haecker et al., 2004). Single mutants in WOX8 and WOX9 do not show any apparent morphological difference to the wildtype embryos, but when both WOX8 and WOX9 function is disrupted, several developmental defects can be observed (Breuninger et al., 2008). Up until the one-cell stage of development, the embryos resemble the wildtype phenotype, although subsequently the apical cell divides horizontally instead of vertically and the basal cells become enlarged and show aberrant division planes. These mutants also show defects on a molecular level, as they seem to lose the expression of several basal (e.g. WOX5) and apical (e.g. ZWILLE) markers and show an increased auxin response demonstrated by more, and ectopic, DR5 expression. In addition to this, the authors were able to show that WOX8 and WOX9 are positive regulators of WOX2 expression in the embryo (Breuninger et al., 2008). This indicates that the specification of the basal 
cell lineage is under the control of WOX8 and WOX9 and that this specification is very important, not only for the development of the basal cell lineage, but also for the apical cell lineage.

\section{Regulation of the two-cell stage to the dermatogen stage}

Many of the remaining questions concerning regulation of morphogenetic processes arise in relation to development from the two-cell stage to the dermatogen stage. During these stages, the basis of many cell types is established, through the process of axis and pattern formation. Both the apicobasal and radial axes are formed at this time, but how the formation of these two most important axes is regulated is still largely unknown. Although some important advances have been made, as will be discussed here (see also Figure 4), many gaps still remain.

In recent years, it has become increasingly clear that several patterning steps in the embryo strongly depend on the activity of the hormone auxin. The auxin signaling pathway is a relatively simple and short one that is involved in many developmental processes, including root growth and development, flowering, apical dominance, formation and organization of vascular tissue, fruit growth and development, and embryogenesis (Stewart \& Nemhauser, 2010). It consists of four main components: the SCF ${ }^{\text {TIR } 1 / A F B}$ ubiquitin ligase complex (Ruegger et al., 1998), Aux/IAA inhibitor proteins (Reed, 2001), DNA-binding AUXIN RESPONSE FACTORs (ARFs; Guilfoyle \& Hagen, 2007) and the phytohormone auxin. At low auxin concentrations, the Aux/IAA proteins bind to the ARFs and inhibit their function in regulating genes (Tiwari et al., 2001, 2003). When auxin concentrations increase, auxin binds to the TIR1/AFB1-5 subunit of the SCF ${ }^{\text {TRR } 1 / A F B}$ ubiquitin-ligase complex, increasing the affinity of this complex to the Aux/IAA proteins (Gray et al., 2001; Dharmasiri et al., 2005a; Kepinski \& Leyser, 2005). Upon ubiquitination, the Aux/ IAA proteins are degraded by the $26 \mathrm{~S}$ proteasome, releasing the ARFs from their inhibition and leaving them to perform their function as transcriptional regulators (reviewed by Lokerse \& Weijers, 2009). Several Aux/IAAs were shown to act in part by recruiting the corepressor TOPLESS (TPL; Szemenyei et al., 2008).

The amount of auxin present in a cell is tightly controlled. Owing to the relatively low $\mathrm{pH}$ in the apoplast, auxin becomes protonated and is able to diffuse passively through the cell membrane into the cell, where the higher $\mathrm{pH}$ results in deprotonation and blockage of passive diffusion through the cell membrane (Rubery \& Sheldrake, 1973). Export of auxin occurs actively through the PIN-FORMED protein family of auxin exporters (Grunewald \& Friml, 2010). These often polar- and membrane-localized proteins facilitate directional transport of auxin, and thus allow 


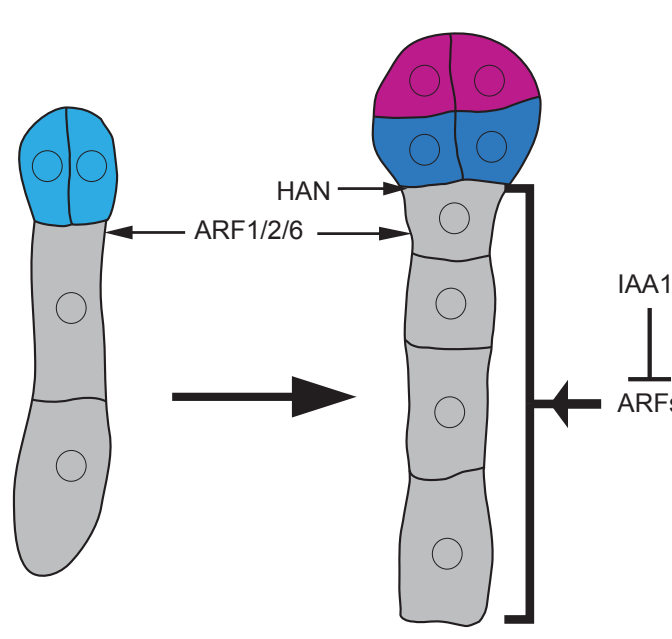

2/4-cell

Octant

Figure 4: Protoderm, suspensor and boundary specification in Arabidopsis. Suspensor identity is actively maintained by several redundantly acting AUXIN RESPONSE FACTORs (ARFs), which are inhibited by the auxin-labile IAA10 protein. The boundary between proembryo and suspensor requires activity of the HAN transcription factor. WOX2 is necessary for the correct division of the upper tier into protoderm cells and inner cells. The colors indicate the different cell types, as shown in Figure 2.

local maxima to be generated (Grunewald \& Friml, 2010). These auxin maxima have been shown to be important for maintenance and also the establishment of meristems. One of the main questions in auxin research is how a small molecule like auxin, triggering such a short and seemingly simple signaling pathway, can regulate so many different developmental processes and how the specificity of this pathway is regulated. The proteins involved in the auxin signaling are all part of larger protein families. The TIR1/AFB, Aux/IAA and ARF families consist of six, 29 and 23 members, respectively (Reed, 2001; Dharmasiri et al., 2005b; Guilfoyle \& Hagen, 2007), and different combinations of these members, through differences in availability and affinity, could account for some of the specificity in the signaling. Interestingly, Rademacher et al. (2011) showed there is a pre-pattern of ARF gene expression in the embryo, which could account for, or may at least contribute to, specific auxin responses in different cell types. As different cell types all have a distinct set of ARFs, they will respond differently to the same stimulus, which will result in a different developmental output. Conversely, cells that are supposedly the same, sharing the same set of ARFs, will respond in the same way. It is unclear how the pre-pattern of $A R F$ expression itself is established, but this mechanism at least involves the SSP gene (Rademacher et al., 2012). In support of the importance of 
the ARF pre-pattern, several mutants were identified where multiple ARFs, in the suspensor, were either knocked out or constitutively repressed using a stable Aux/IAA protein. Both these approaches lead to excessive proliferation of the suspensor, loss of suspensor-specific gene expression (e.g. IAA30) and a gain of embryo-specific gene expression (e.g. MONOPTEROS, SHOOT MERISTEMLESS, KNOLLE, and WUS); occasionally, suppression of the auxin signaling in the suspensor even leads to twin embryo phenotypes (Rademacher et al., 2011, 2012). This finding suggests that the ability of suspensor cells to develop into an embryo, which was recognized a long time ago (Schwartz et al., 1994), is actively suppressed by the signaling molecule auxin.

As becomes apparent from the information in the previous paragraph, maintaining suspensor identity is important for normal embryo development. The juxtaposition of two distinct cell identities (embryo vs suspensor), by definition, creates a boundary domain. Recently, the HANABA TARANU (HAN) gene was found to be maintaining this basal boundary in the early stages of embryogenesis (Figure 4; Nawy et al., 2010). This GATA transcriptional repressor (Zhang et al., 2013) was shown to regulate transcription of several genes in the lower tier of the embryo and, upon disruption of its function, their expression domains were expanded to more apical (e.g. SUCROSE TRANSPORTER3, WOX5, SHORT-ROOT) or lateral regions (e.g. PLETHORA1) (Nawy et al., 2010). Active auxin signaling, usually seen in the hypophysis descendant cells (Friml et al., 2003; Weijers et al., 2006), also shifted upwards (Nawy et al., 2010), which may be the consequence of a change in PIN1 and PIN7 expression. Where PIN1 is normally localized in the basal membrane of the inner cells of the embryo (Steinmann et al., 1999), directing auxin towards the base and the hypophysis, in the case of the han mutant, PIN1 accumulates mainly in the apical cells (Nawy et al., 2010). Similarly, in wildtype, PIN7 is localized in the apical membrane of the suspensor, marking the boundary between the suspensor and the embryo (Friml et al., 2003), but in the han mutant PIN7 is found mainly in the apical membrane of the basal cells of the embryo. Interestingly, the absence of a functional HAN protein results in an initially rootless embryo, though the root is later reinitiated and han seedlings do have a main root (Nawy et al., 2010). These findings underline the importance of this fate boundary, although the precise molecular and cellular definitions of this domain are unclear.

In addition to its function in zygote polarity specification, WOX2 has also been shown to act redundantly with the closely related WOX1 and WOX3 genes in the regulation of the protoderm-forming cell divisions in the upper tier (see Figure 4; Breuninger et al., 2008). In wox1/2/3 mutant embryos, division of cells in the 
upper tier often occurs periclinally, which occasionally results in seedlings with one cotyledon or 'rod-shaped' seedlings (Breuninger et al., 2008). Although this indicates the mechanism regulating the upper tier, it is still unclear how this change in division plane is regulated for the lower tier (Figure 4). It is possible that WOX9 could play a role in this, as it has a complementary expression pattern to WOX2. A phenotype could be masked by the more extreme phenotype of the wox8/9 double mutant (Breuninger et al., 2008), although this remains to be investigated. The mechanisms underlying the change of division planes in the two- cell and octant stages also remain elusive to date.

\section{Globular stage of development - stem cell and tissue specification}

A crucial step in development is the globular stage. It is during this stage (from earlyto late-globular) that the root tissues and their stem cells are specified (Figure 5). These are also the stages where most mutants show phenotypes (Lloyd \& Meinke, 2012). Perhaps one of the most well-known factors to play a role in specification of root cell types is the AUXIN RESPONSE FACTOR5/MONOPTEROS (MP) gene, as it has been shown to be a key regulator in hypophysis specification and specification of other cells that form the embryonic root (Berleth \& Jurgens, 1993; Hardtke \& Berleth, 1998; Weijers et al., 2006). Mutations in the MP gene result in misspecification of the hypophysis, which leads the cells in the basal tier to divide erroneously, eventually resulting in rootless seedlings (Berleth \& Jurgens, 1993; Hardtke \& Berleth, 1998). As with all members of the ARF family, auxin and the Aux/IAA family of transcriptional repressors regulate MP function, and Schlereth et al. (2010) recently revealed the mechanism by which MP regulates hypophysis specification. Using an inducible version of the Aux/IAA protein IAA12/BDL that cannot be degraded and induces an mp-like phenotype (Hamann et al., 1999; Hamann et al., 2002), MP function was briefly inhibited. After applying a microarray approach, they were able reveal a set of differentially expressed genes. Further characterization of target genes revealed several direct TARGET OF MONOPTEROS (TMO) genes. Two of these, TMO5 and TMO7, encode basic helix-loop-helix (bHLH) transcription factors and both are only transcribed in the basal inner cells of the proembryo (Schlereth et al., 2010; Figure 5). Interestingly, the TMO7 protein was shown to move from its transcribed region to the hypophysis. By addition of either a single or triple GREEN FLUORESCENT PROTEIN (GFP) molecule to the TMO7 protein, the authors were able to show that this movement is size-dependent and is also required for specification of the hypophysis. Moreover, TMO7 expression in the suspensor was found to partly rescue the $m p$ phenotype (Schlereth et al., 2010). Recently, TMO5 

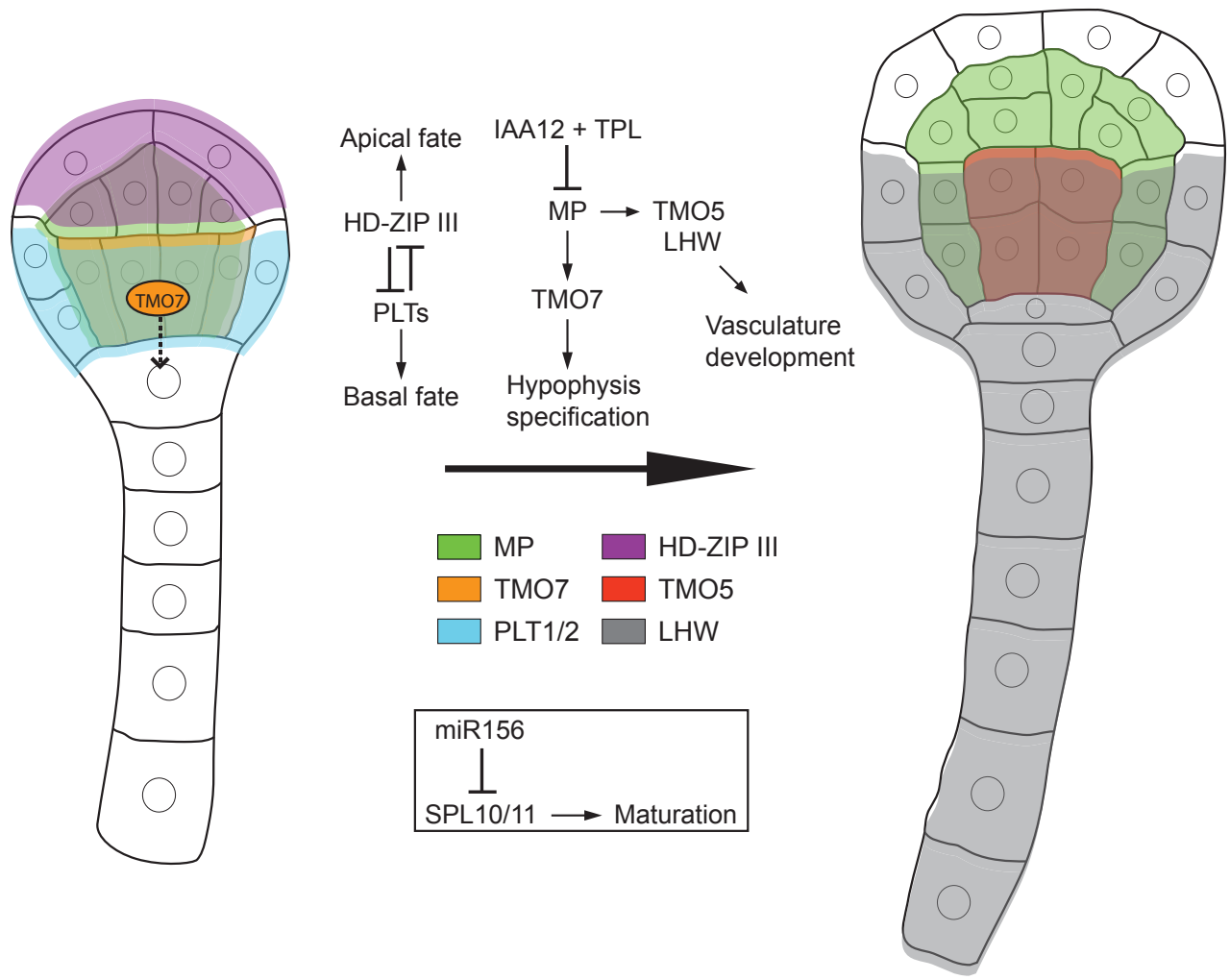

Early-globular

Late-globular

Figure 5: Cell type specification in the globular stage of development in Arabidopsis. During the early-globular stage of development, the uppermost suspensor cell is specified as the hypophysis, through MONOPTEROS (MP)-dependent expression and subsequent movement of the TMO7 protein from adjacent inner basal tier cells. MP activity is regulated by the IAA12 protein, which can recruit the TOPLESS (TPL) corepressor in order to inhibit MP function. The separation of apical (shoot) and basal (root) identity is mediated by the mutually exclusive and potentially cross-repressive expression of HD-ZIP III and PLT1/2 genes. During the transition to late-globular stage, maturation genes such as SQUAMOSA PROMOTER BINDING PROTEINLIKE10 (SPL10) and SPL11 are de-repressed by the down-regulation of miR156, which prevents maturation in earlier stages. In the late-globular stage, a dimer of TMO5 (whose expression is driven by MP) and LHW regulates the development of vascular tissue. The colors indicate the expression domains of different genes.

was shown to form a dimer with another member of the bHLH family, LONESOME HIGHWAY (Ohashi-Ito \& Bergmann, 2007), and as a dimer trigger oriented periclinal divisions during development of the vascular tissue in the early embryo (De Rybel et al., 2013). While TMO5 and LHW are critical for the divisions that 'make' the vascular tissue, little is known about what initially specifies the tissue. This is one of the major outstanding questions, and genetic approaches thus far have not revealed the critical components for embryonic vascular or ground tissue specification.

In addition to specification of stem cells and tissues, a different layer of 
information is generated at this stage of embryogenesis, namely that of regional identity. Cotyledons, shoot apical meristem and root all express unique sets of genes and have distinct organ identities (Long et al., 1996; Long \& Barton, 1998; Aida et al., 2004). The PLETHORA (PLT) transcription factors (Aida et al., 2004) seem to play an important role in specification of regional identity at this stage of embryogenesis. PLT1 and PLT2 are key regulators of root meristem maintenance and root 'fate' (Aida et al., 2004; Galinha et al., 2007). Removal of several PLT genes leads to rootless embryos (Galinha et al., 2007), while misexpression can induce the formation of ectopic root structures (Aida et al., 2004). It was recently shown that exclusion of PLT gene expression from the apical embryo domain is required for shoot formation (Smith \& Long, 2010). PLT expression was found to be inhibited by CLASS III HOMEODOMAIN-LEUCINE ZIPPER genes (HD-ZIP III; i.e. PHABULOSA, PHAVOLUTA, REVOLUTA, INCURVATA4 and ARABIDOPSIS THALIANA HOMEOBOX-8), which are expressed in the apical part of the embryo and regulated by MICRO-RNA165/166 (Emery et al., 2003; Mallory et al., 2005; Smith \& Long, 2010; Miyashima et al., 2013). Interestingly, ectopically expressing a microRNA-resistant version of any of the HD-ZIP III genes under the PLT2 promoter results in the opposite phenotype as found for the overexpression lines of the PLTs: a shoot in place of a root (Smith \& Long, 2010). This shows that root and shoot fates are mutually exclusive, and that part of the root or shoot program entails suppression of the alternative fate (Figure 5).

As shown by the regulation of the HD-ZIP III genes in the apical fate regulation, microRNAs control development of the Arabidopsis embryo. Indeed, systematic expression analysis of the MICRO-RNA165/166 gene family revealed an extended potential for regulation of HD-ZIP III accumulation by these factors (Miyashima et al., 2013). As microRNAs are involved in a wide range of processes in all organisms that carry them (Furuta et al., 2012), there is the distinct possibility that there are more, as yet unidentified, roles for these regulators in early plant embryogenesis. Such functions are easily missed in genetic screens, as only some mutations will alter microRNA efficiency (Schwab et al., 2005), and the microRNAs are often represented by gene families (Miyashima et al., 2013). Evidence for such novel functions in embryogenesis comes from analysis of the microRNA biogenesis mutant dicer-like1 (dcl1). Many developmental processes are disturbed in $d c / 1$ mutant embryos, including the loss of expression of several cell-lineage markers, such as WOX2, -5 and -8 , and expansion of the protoderm markers MERISTEM LAYER1 (ATML1) and PROTODERMAL FACTOR1 to the suspensor (Nodine \& Bartel, 2010). By sequencing the transcriptome of $d c / 1$ mutant embryos, it was 
shown that many late-embryogenesis genes are precociously active. This can be explained to a large degree by unchecked activity of SQUAMOSA PROMOTER BINDING PROTEIN-LIKE10 (SPL10) and SPL11 transcription factors. SPL10 and $S P L 11$ are both transcriptionally regulated by miR156 and their activity is required for the distinctive phenotypes in $d c / 1$ (Nodine \& Bartel, 2010). Further exploration of this and other microRNA mutants should reveal whether these regulators control aspects beyond embryo maturation and HD-ZIP III activity.

As indicated, this stage of embryogenesis can be considered the nexus where tissues, cell types, regions and stem cells are specified. The latter component, stem cell specification, remains a relatively underexplored area. Stem cells are the main engines behind maintenance and growth. During development of multicellular organisms, tissues are continuously renewed. This renewal ensures the maintenance of an organ or tissue by replacing old/dead cells with new cells, or can ensure growth by adding cells to the tissue and pushing the organ outwards. In plants, stem cells or stem cell properties also play a key role in generating new organs, a process that, in contrast to animals, occurs continuously (Weigel \& Jurgens, 2002). One of the main factors that enable stem cells to do this is their capability for self-renewal and the production of a differentiating daughter cell (Figure 6). Stem cells are often found in specialized compartments, called niches or meristems, which can usually be divided into several regions that contain cells with distinct properties. The first can be regarded as the organizing region/center, which contains organizer cells that rarely divide and are important for maintenance of the stem cell properties of the cells that surround them (Scheres, 2007). These surrounding cells form the second region of the meristem, the region containing the actual stem cells. The stem cells divide relatively often and give rise to the third region, containing the so-called highly proliferative or transit amplifying cells. These cells divide more regularly than the stem cells and give rise to the differentiating cells. Unlike the stem cells, the cells from the third region are not able to self-renew and also differentiate after a few rounds of cell division (Scheres, 2007). In early plant development, two distinct meristems are notable: the shoot meristem and the root meristem, situated at apical and basal ends of the plant, respectively. Later in development, other (lateral) meristems are established, such as the axillary, floral and lateral root meristems, which will give rise to new, lateral organs (Duclercq et al., 2011). Although the existence of cells with stem cell properties in plant meristems and their importance for sustaining growth are undisputed, there is no clear operational or mechanistic definition of such cells. While stem cells in mice or humans can be functionally defined by transplantation or clone formation assays (Huch et al., 2013), such experiments are extremely 


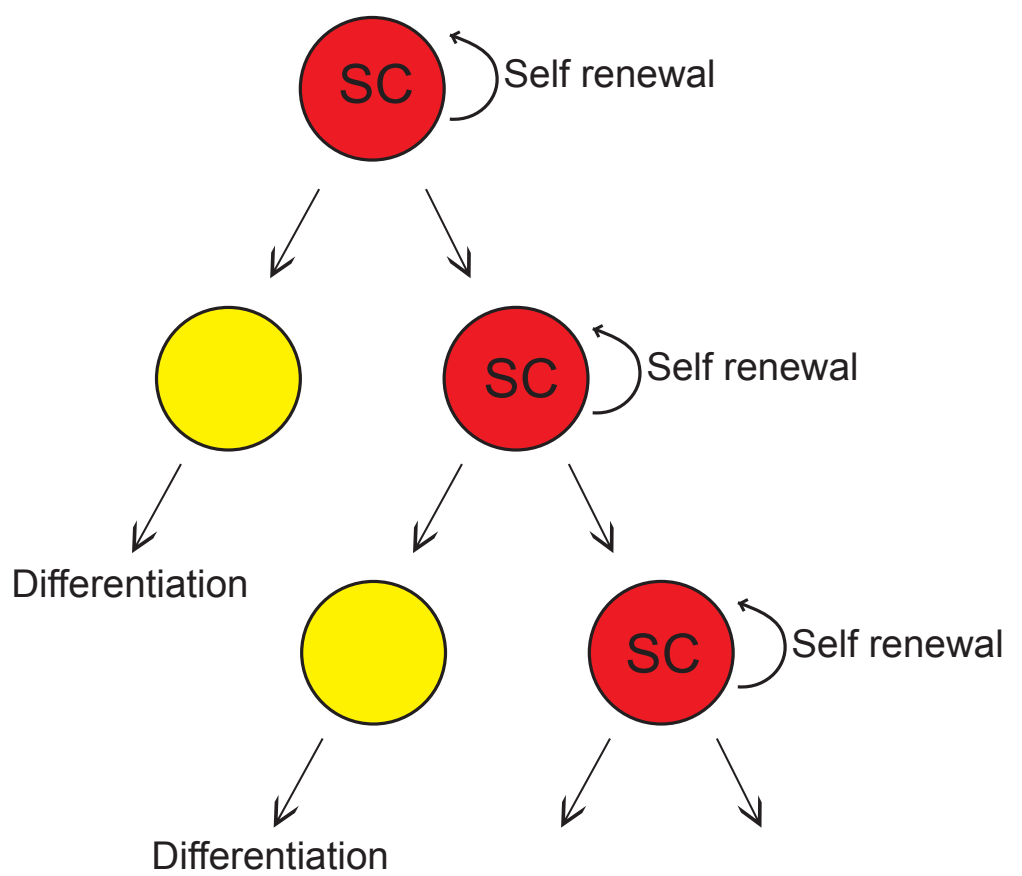

Figure 6: Typical self-renewing property of stem cells. Upon division, stem cells (SC) generate a differentiating daughter cell (yellow) and a new stem cell (red).

challenging in plants, as cells are usually respecified when they find themselves in a different context (Scheres, 2001). While molecular criteria exist for some animal stem cells (Barker et al., 2007), no markers for stem cells exist in plants. Finally, while a mix of proteins can induce stem cell-like properties in mice and humans (Takahashi \& Yamanaka, 2006; Yu et al., 2007), similar factors have not been reported in plants. Therefore, definition of stem cells remains somewhat difficult in many plant tissues, except for those such as the columella root cap, where a single (stem) cell layer separates the differentiated cells from the organizing center (Scheres, 2007). These difficulties extend to the problem of when exactly stem cells are first specified in the embryo. From lineage-tracing experiments (Scheres et al., 1994), it is clear that the cells that act as long-term stem cells in the root meristem can be traced to the basal tier cells of the globular stage embryo. Indeed, genes that mark the presumptive stem cell zone in the postembryonic root meristem are first activated at this stage of development (e.g. De Rybel et al., 2013). Hence, we anticipate that the globular stage embryo is a promising, yet largely unexplored model for identifying elusive stem cell factors in plants. 


\section{Genes to shape - cellular execution of transcriptional instructions}

All genes described in this chapter as key regulators of morphogenetic processes during early embryogenesis encode transcription factors, (receptor) kinases, hormones and microRNAs that, in turn, regulate transcription factors. These factors can collectively account for two key processes as defined earlier: cell specification and cell-cell communication. Yet, as discussed, the shape-defining morphogenetic drivers in plants are oriented and/or asymmetric cell division and (directional) cell expansion. A pressing question is therefore how unique cell identities, established as distinct cellular transcriptomes, are translated to reprogramming of the mechanisms underlying these two morphogenetic drivers. This is a challenge that has so far not been addressed in embryos, but, as outlined earlier, the embryo offers a compact and predictable model to study this problem. The key question is which genes need to be regulated for cell division rate or plane, or cell expansion rate or direction, to change. Many generic components in these processes have been identified, and these include many regulators of actin or microtubule cytoskeleton (Yang, 2008), cell wall composition or extensibility (Roppolo \& Geldner, 2012), cell cycle (Komaki \& Sugimoto, 2012), cell plate orientation (Torres-Ruiz \& Jurgens, 1994) and membrane trafficking (Lukowitz et al., 1996). Without exception, interfering with the function of these components causes dramatic defects at both the cell and tissue levels (Turner \& Somerville, 1997; Bao et al., 2001; Schnittger et al., 2003; Ambrose et al., 2007), but rarely are such defects limited to individual cells, which complicates connecting these factors to regulators of pattern formation. A few recent papers have started bridging the gap between pattern regulators and cell biological functions. The transcription factor SHORT-ROOT (SHR) controls asymmetric division of the initial cell that gives rise to endodermis and cortex in the postembryonic root (Helariutta et al., 2000), and in addition helps in specifying endodermis identity (Cui et al., 2007). Through transcriptomics approaches, a CyclinD6 gene was recently identified as a direct SHR target that is required for triggering the asymmetric (formative) division in this initial cell (Sozzani et al., 2010). This is a direct connection between a patterning factor and the machinery that executes cell division. A very interesting challenge will be to extend such findings to the embryo, and more generally link patterning to morphogenesis. 


\section{Concluding remarks and scope of this thesis}

Plants are among the most abundant and crucial organisms on the planet, as they provide food and oxygen for other inhabitants, including for mankind. To understand how plants are able to develop is of vital importance in an everchanging environment. Although much has already been learned about different aspects of plant development, many challenges remain in answering questions like how cells are able to know their identity and how different developmental cues are integrated. During plant development, several morphogenetic processes need to be tightly regulated, in order to ensure proper establishment of specific cell types and tissues. In this chapter we have highlighted what we consider to be the most important morphogenetic processes involved in the development of the Arabidopsis embryo and how these processes are regulated. Of central importance in plant development are groups or niches of stem cells that enable continuous establishment of new organs, and growth and renewal of the existing ones. It is therefore evident that studying stem cells and how these are established is of great interest. Although much effort has been invested in finding new factors that are important in the regulation of these processes, and indeed several pathways have been identified, many questions still remain to be answered. Owing to the inherent difficulties associated with the small size of embryos in Arabidopis, and their encapsulation in seeds within fruits (Figure 1), methods other than genetics have not been explored to their full potential. Although recent years have brought many methodological and technological advances, continued optimization and further improvement will be necessary to address important questions in this developmental system. Two such optimizations and improvements are described in Chapters 2 and 3. Chapter 2 presents an optimized and highly efficient cloning method. This method makes use of in vivo ligation of cloning fragments, rather than relying on more time consuming and often-expensive in vitro alternatives. A detailed step-bystep protocol is described that allows for reliable, semi-high-throughput generation of plant transformation-ready constructs within two to three days, which facilitates follow-up analysis in genome-wide approaches. Chapter 3 describes a protocol for an immunoprecipitation procedure followed by tandem mass-spectrometry. This method allows for unbiased determination of in vivo protein-protein interactions, which is vital to understand the biological function and relevance of a protein of interest. A detailed, optimized protocol is presented, describing a step-by-step procedure from starting material to data analysis and visualization. The methods described in Chapters $\mathbf{2}$ and 3 are accordingly used throughout the rest of this thesis. This thesis further addresses 
the following questions:

\section{- What defines individual cell types?}

As described in this chapter, cell and tissue identities are specified early during Arabidopsis embryogenesis, and a central question is how this is genetically controlled. As cell and tissue types express unique sets of transcripts, a powerful way to infer cell identity is through the analysis of transcriptional output. Chapter 4 presents a number of genetic "marker" lines in the embryo that label three different specific domains: developing ground tissue, stem cells and the shoot apical meristem. This set of marker lines is useful for example in genetic studies to infer domain identity in mutant backgrounds. In addition, the use of single-cell or cell type-specific transcript profiling approaches has the potential to provide genomewide views on molecular differentiation of cells. Such analysis will also be helpful to identify cell-specific functions and pathways. New techniques, such as Isolation of Nuclei TAgged in specific Cell Types (INTACT; Deal \& Henikoff, 2010) should help in obtaining transcriptomes at cellular resolution from embryos, through development and this will be discussed in Chapter 7 .

- What are the downstream mechanisms by which key morphogenesis regulators act?

As most analyzed factors, acting downstream of key morphogenesis regulators are transcriptional regulators, a major outstanding question is how these key morphogenesis regulators (often hormones and transcription factors) direct cellular processes that determine cell shape and function. In Chapter 5, we took a multidisciplinary approach, combining expression analysis, protein localization evaluation, protein complex determination, genetic disruption and misexpression studies, for in-depth characterization of a group of IQ-domain proteins. These proteins, acting downstream of MONOPTEROS, likely perform cellular functions involving both auxin and calcium signaling, forming a bridge between these two major signaling pathways.

\section{- How are stem cells organized in the root?}

As discussed above, the exact mode for the organization of stem cells in the Arabidopsis root meristem remains an open question. Although stem cells can be operationally defined, whether the plant makes a qualitative, molecular distinction between stem cells and other cells is still unclear. In Chapter 6, we re-evaluate the currently prevailing model for stem cell organization in the Arabidopsis (embryonic) root. Through a series of expression analysis, transcriptomic profiling and follow-up 
analyses we provide support for an extended model for the organization of stem cells in the root.

Finally, in Chapter 7, the findings of this thesis are discussed and placed in a broader perspective. In addition, Chapter 7 outlines directions for future research. 


\section{References}

Aida M, Beis D, Heidstra R, Willemsen V, Blilou I, Galinha C, Nussaume L, Noh YS, Amasino R, Scheres B. 2004. The PLETHORA genes mediate patterning of the Arabidopsis root stem cell niche. Cell 119: 109-120.

Ambrose JC, Shoji T, Kotzer AM, Pighin JA, Wasteneys GO. 2007. The Arabidopsis CLASP gene encodes a microtubule-associated protein involved in cell expansion and division. The Plant Cell 19: 2763-2775.

Bao Y, Kost B, Chua NH. 2001. Reduced expression of alpha-tubulin genes in Arabidopsis thaliana specifically affects root growth and morphology, root hair development and root gravitropism. Plant Journal 28: 145-157.

Barker N, van Es JH, Kuipers J, Kujala P, van den Born M, Cozijnsen M, Haegebarth A, Korving J, Begthel H, Peters PJ et al. 2007. Identification of stem cells in small intestine and colon by marker gene Lgr5. Nature 449: 1003-1007.

Bayer M, Nawy T, Giglione C, Galli M, Meinnel T, Lukowitz W. 2009. Paternal control of embryonic patterning in Arabidopsis thaliana. Science 323: 1485-1488.

Bergmann DC, Lukowitz W, Somerville CR. 2004. Stomatal development and pattern controlled by a MAPKK kinase. Science 304: 1494-1497.

Berleth T, Jurgens G. 1993. The role of the MONOPTEROS gene in organising the basal body region of the Arabidopsis embryo. Development 118: 575-587.

Breuninger H, Rikirsch E, Hermann M, Ueda M, Laux T. 2008. Differential expression of WOX genes mediates apical-basal axis formation in the Arabidopsis embryo. Developmental Cell 14: 867-876.

Christensen CA, Gorsich SW, Brown RH, Jones LG, Brown J, Shaw JM, Drews GN. 2002. Mitochondrial GFA2 is required for synergid cell death in Arabidopsis. The Plant Cell 14: 2215-2232.

Cui H, Levesque MP, Vernoux T, Jung JW, Paquette AJ, Gallagher KL, Wang JY, Blilou I, Scheres B, Benfey PN. 2007. An evolutionarily conserved mechanism delimiting SHR movement defines a single layer of endodermis in plants. Science 316: 421-425.

De Rybel B, Moller B, Yoshida S, Grabowicz I, Barbier de Reuille P, Boeren S, Smith RS, Borst JW, Weijers D. 2013. A bHLH complex controls embryonic vascular tissue establishment and indeterminate growth in Arabidopsis. Developmental Cell 24: 426437.

De Smet I, Lau S, Mayer U, Jurgens G. 2010. Embryogenesis - the humble beginnings of plant life. Plant Journal 61: 959-970.

Deal RB, Henikoff S. 2010. A simple method for gene expression and chromatin profiling of individual cell types within a tissue. Developmental Cell 18: 1030-1040.

Dharmasiri N, Dharmasiri S, Estelle M. 2005a. The F-box protein TIR1 is an auxin receptor. Nature 435: 441-445.

Dharmasiri N, Dharmasiri S, Weijers D, Lechner E, Yamada M, Hobbie L, Ehrismann JS, Jurgens G, Estelle M. 2005b. Plant development is regulated by a family of auxin receptor $\mathrm{F}$ box proteins. Developmental Cell 9: 109-119.

Duclercq J, Sangwan-Norreel B, Catterou M, Sangwan RS. 2011. De novo shoot organogenesis: from art to science. Trends in Plant Science 16: 597-606.

Emery JF, Floyd SK, Alvarez J, Eshed Y, Hawker NP, Izhaki A, Baum SF, Bowman JL. 2003. Radial patterning of Arabidopsis shoots by class III HD-ZIP and KANADI genes. Current Biology : CB 13: 1768-1774.

Faure JE, Rotman N, Fortune P, Dumas C. 2002. Fertilization in Arabidopsis thaliana wild type: developmental stages and time course. Plant Journal 30: 481-488.

Ferris PJ, Goodenough UW. 1997. Mating type in Chlamydomonas is specified by mid, the 
minus-dominance gene. Genetics 146: 859-869.

Friml J, Vieten A, Sauer M, Weijers D, Schwarz H, Hamann T, Offringa R, Jurgens G. 2003. Efflux-dependent auxin gradients establish the apical-basal axis of Arabidopsis. Nature 426: 147-153.

Furuta K, Lichtenberger R, Helariutta Y. 2012. The role of mobile small RNA species during root growth and development. Current Opinion in Cell Biology 24: 211-216.

Galinha C, Hofhuis H, Luijten M, Willemsen V, Blilou I, Heidstra R, Scheres B. 2007. PLETHORA proteins as dose-dependent master regulators of Arabidopsis root development. Nature 449: 1053-1057.

van der Graaff E, Laux T, Rensing SA. 2009. The WUS homeobox-containing (WOX) protein family. Genome Biology 10: 248.

Gray WM, Kepinski S, Rouse D, Leyser O, Estelle M. 2001. Auxin regulates SCF (TIR1)dependent degradation of AUX/IAA proteins. Nature 414: 271-276.

Grunewald W, Friml J. 2010. The march of the PINs: developmental plasticity by dynamic polar targeting in plant cells. EMBO Journal 29: 2700-2714. Guilfoyle TJ,

Hagen G. 2007. Auxin response factors. Current Opinion in Plant Biology 10: 453-460.

Haecker A, Gross-Hardt R, Geiges B, Sarkar A, Breuninger H, Herrmann M, Laux T. 2004. Expression dynamics of WOX genes mark cell fate decisions during early embryonic patterning in Arabidopsis thaliana. Development 131: 657-668.

Hamann T, Mayer U, Jurgens G. 1999. The auxin-insensitive bodenlos mutation affects primary root formation and apical-basal patterning in the Arabidopsis embryo. Development 126: 1387-1395.

Hamann T, Benkova E, Baurle I, Kientz M, Jurgens G. 2002. The Arabidopsis BODENLOS gene encodes an auxin response protein inhibiting MONOPTEROS-mediated embryo patterning. Genes \& Development 16: 1610-1615.

Hardtke CS, Berleth T. 1998. The Arabidopsis gene MONOPTEROS encodes a transcription factor mediating embryo axis formation and vascular development. EMBO Journal 17: 1405-1411.

Helariutta Y, Fukaki H, Wysocka-Diller J, Nakajima K, Jung J, Sena G, Hauser MT, Benfey PN. 2000. The SHORT-ROOT gene controls radial patterning of the Arabidopsis root through radial signaling. Cell 101: 555-567.

Hirakawa Y, Shinohara H, Kondo Y, Inoue A, Nakanomyo I, Ogawa M, Sawa S, Ohashi-Ito K, Matsubayashi Y, Fukuda H. 2008. Non-cell-autonomous control of vascular stem cell fate by a CLE peptide/receptor system. Proceedings of the National Academy of Sciences, USA 105: 15208-15213.

Hsu PY, Harmer SL. 2012. Circadian phase has profound effects on differential expression analysis. PLoS ONE 7: e49853.

Huch M, Dorrell C, Boj SF, van Es JH, Li VS, van de Wetering M, Sato T, Hamer K, Sasaki N, Finegold MJ et al. 2013. In vitro expansion of single Lgr5+ liver stem cells induced by Wnt-driven regeneration. Nature 494: 247-250.

Jeong S, Palmer TM, Lukowitz W. 2011. The RWP-RK factor GROUNDED promotes embryonic polarity by facilitating YODA MAP kinase signaling. Current Biology 21: 1268-1276.

Johri BM, Ambegaokar KB, Srivastava PS. 1992. Comparative embryology of angiosperms. Heidelberg, Germany: Springer Verlag.

Kepinski S, Leyser O. 2005. The Arabidopsis F-box protein TIR1 is an auxin receptor. Nature 435: 446-451.

Komaki S, Sugimoto K. 2012. Control of the plant cell cycle by developmental and environmental cues. Plant \& Cell Physiology 53: 953-964.

Laux T, Mayer KF, Berger J, Jurgens G. 1996. The WUSCHEL gene is required for shoot and floral meristem integrity in Arabidopsis. Development 122: 87-96. 
Lim J, Thiery JP. 2012. Epithelial-mesenchymal transitions: insights from development. Development 139: 3471-3486.

Liu C, Thong Z, Yu H. 2009. Coming into bloom: the specification of floral meristems. Development 136: 3379-3391.

Lloyd J, Meinke D. 2012. A comprehensive dataset of genes with a loss-of-function mutant phenotype in Arabidopsis. Plant Physiology 158: 1115-1129.

Lokerse AS, Weijers D. 2009. Auxin enters the matrix-assembly of response machineries for specific outputs. Current Opinion in Plant Biology 12: 520-526.

Long JA, Barton MK. 1998. The development of apical embryonic pattern in Arabidopsis. Development 125: 3027-3035.

Long JA, Moan El, Medford JI, Barton MK. 1996. A member of the KNOTTED class of homeodomain proteins encoded by the STM gene of Arabidopsis. Nature 379: 66-69.

Lukowitz W, Mayer U, Jurgens G. 1996. Cytokinesis in the Arabidopsis embryo involves the syntaxin-related KNOLLE gene product. Cell 84: 61-71.

Lukowitz W, Roeder A, Parmenter D, Somerville C. 2004. A MAPKK kinase gene regulates extra-embryonic cell fate in Arabidopsis. Cell 116: 109-119.

Mallory AC, Bartel DP, Bartel B. 2005. MicroRNA-directed regulation of Arabidopsis AUXIN RESPONSE FACTOR17 is essential for proper development and modulates expression of early auxin response genes. Plant Cell 17: 1360-1375.

Mayer KF, Schoof H, Haecker A, Lenhard M, Jurgens G, Laux T. 1998. Role of WUSCHEL in regulating stem cell fate in the Arabidopsis shoot meristem. Cell 95: 805-815.

Miyashima S, Honda M, Hashimoto K, Tatematsu K, Hashimoto T, Sato-Nara K, Okada K, Nakajima K. 2013. A comprehensive expression analysis of the Arabidopsis MICRORNA165/6 gene family during embryogenesis reveals a conserved role in meristem specification and a non-cell-autonomous function. Plant \& Cell Physiology 54: 375-384.

Nakajima K, Sena G, Nawy T, Benfey PN. 2001. Intercellular movement of the putative transcription factor SHR in root patterning. Nature 413: 307-311.

Nardmann J, Reisewitz P, Werr W. 2009. Discrete shoot and root stem cell- promoting WUS/ WOX5 functions are an evolutionary innovation of angiosperms. Molecular Biology and Evolution 26: 1745-1755.

Nawy T, Bayer M, Mravec J, Friml J, Birnbaum KD, Lukowitz W. 2010. The GATA factor HANABA TARANU is required to position the proembryo boundary in the early Arabidopsis embryo. Developmental Cell 19: 103-113.

Nodine MD, Bartel DP. 2010. MicroRNAs prevent precocious gene expression and enable pattern formation during plant embryogenesis. Genes \& Development 24: 2678-2692.

Nodine MD, Bryan AC, Racolta A, Jerosky KV, Tax FE. 2011. A few standing for many: embryo receptor-like kinases. Trends in Plant Science 16: 211-217.

Ohashi-Ito K, Bergmann DC. 2007. Regulation of the Arabidopsis root vascular initial population by LONESOME HIGHWAY. Development 134: 2959- 2968.

Peris Cl, Rademacher EH, Weijers D. 2010. Green beginnings - pattern formation in the early plant embryo. Current Topics in Developmental Biology 91: 1-27.

Rademacher EH, Lokerse AS, Schlereth A, Llavata-Peris Cl, Bayer M, Kientz M, Freire Rios A, Borst JW, Lukowitz W, Jurgens $G$ et al. 2012. Different auxin response machineries control distinct cell fates in the early plant embryo. Developmental Cell 22: 211-222.

Rademacher EH, Moller B, Lokerse AS, Llavata-Peris Cl, van den Berg W, Weijers D. 2011. A cellular expression map of the Arabidopsis AUXIN RESPONSE FACTOR gene family. Plant Journal 68: 597-606.

Reed JW. 2001. Roles and activities of Aux/IAA proteins in Arabidopsis. Trends in Plant Science 6: 420-425. 
Roppolo D, Geldner N. 2012. Membrane and walls: who is master, who is servant? Current Opinion in Plant Biology 15: 608-617.

Rubery PH, Sheldrake AR. 1973. Effect of $\mathrm{pH}$ and surface charge on cell uptake of auxin. Nature: New Biology 244: 285-288.

Ruegger M, Dewey E, Gray WM, Hobbie L, Turner J, Estelle M. 1998. The TIR1 protein of Arabidopsis functions in auxin response and is related to human SKP2 and yeast grr1p. Genes \& Development 12: 198-207.

Sanchez-Rodriguez C, Rubio-Somoza I, Sibout R, Persson S. 2010. Phytohormones and the cell wall in Arabidopsis during seedling growth. Trends in Plant Science 15: 291-301.

Sarkar AK, Luijten M, Miyashima S, Lenhard M, Hashimoto T, Nakajima K, Scheres B, Heidstra R, Laux T. 2007. Conserved factors regulate signalling in Arabidopsis thaliana shoot and root stem cell organizers. Nature 446: 811-814.

Schauser L, Roussis A, Stiller J, Stougaard J. 1999. A plant regulator controlling development of symbiotic root nodules. Nature 402: 191-195.

Schauser L, Wieloch W, Stougaard J. 2005. Evolution of NIN-like proteins in Arabidopsis, rice, and Lotus japonicus. Journal of Molecular Evolution 60: 229-237.

Scheres B. 2001. Plant cell identity. The role of position and lineage. Plant Physiology 125: 112-114.

Scheres B. 2007. Stem-cell niches: nursery rhymes across kingdoms. Nature Reviews Molecular Cell Biology 8: 345-354.

Scheres B, Wolkenfelt H, Willemsen V, Terlouw M, Lawson E, Dean C, Weisbeek P. 1994. Embryonic origin of the Arabidopsis primary root and root meristem initials. Development 120: 2475-2487.

Schlereth A, Moller B, Liu W, Kientz M, Flipse J, Rademacher EH, Schmid M, Jurgens G, Weijers D. 2010. MONOPTEROS controls embryonic root initiation by regulating a mobile transcription factor. Nature 464: 913-916.

Schnittger A, Weinl C, Bouyer D, Schobinger U, Hulskamp M. 2003. Misexpression of the cyclin-dependent kinase inhibitor ICK1/KRP1 in single- celled Arabidopsis trichomes reduces endoreduplication and cell size and induces cell death. The Plant Cell 15: 303-315.

Schwab R, Palatnik JF, Riester M, Schommer C, Schmid M, Weigel D. 2005. Specific effects of microRNAs on the plant transcriptome. Developmental Cell 8: 517-527.

Schwartz B, Yeung E, Meinke D. 1994. Disruption of morphogenesis and transformation of the suspensor in abnormal suspensor mutants of Arabidopsis. Development 120: 32353245 .

Smith ZR, Long JA. 2010. Control of Arabidopsis apical-basal embryo polarity by antagonistic transcription factors. Nature 464: 423-426.

Sozzani R, Cui H, Moreno-Risueno MA, Busch W, Van Norman JM, Vernoux T, Brady SM, Dewitte W, Murray JA, Benfey PN. 2010. Spatiotemporal regulation of cell-cycle genes by SHORTROOT links patterning and growth. Nature 466: 128-132.

Steinmann T, Geldner N, Grebe M, Mangold S, Jackson CL, Paris S, Galweiler L, Palme K, Jurgens G. 1999. Coordinated polar localization of auxin efflux carrier PIN1 by GNOM ARF GEF. Science 286: 316-318.

Stewart JL, Nemhauser JL. 2010. Do trees grow on money? Auxin as the currency of the cellular economy. Cold Spring Harbor Perspectives in Biology 2: a001420.

Szemenyei H, Hannon M, Long JA. 2008. TOPLESS mediates auxin-dependent transcriptional repression during Arabidopsis embryogenesis. Science 319: 1384-1386.

Takahashi K, Yamanaka S. 2006. Induction of pluripotent stem cells from mouse embryonic and adult fibroblast cultures by defined factors. Cell 126: 663-676.

Terpstra I, Heidstra R. 2009. Stem cells: the root of all cells. Seminars in Cell \& Developmental 
Biology 20: 1089-1096.

Tiwari SB, Hagen G, Guilfoyle T. 2003. The roles of auxin response factor domains in auxinresponsive transcription. Plant Cell 15: 533-543.

Tiwari SB, Wang XJ, Hagen G, Guilfoyle TJ. 2001. AUX/IAA proteins are active repressors, and their stability and activity are modulated by auxin. Plant Cell 13: 2809-2822.

Torres-Ruiz RA, Jurgens G. 1994. Mutations in the FASS gene uncouple pattern formation and morphogenesis in Arabidopsis development. Development 120: 2967-2978.

Turner SR, Somerville CR. 1997. Collapsed xylem phenotype of Arabidopsis identifies mutants deficient in cellulose deposition in the secondary cell wall. The Plant Cell 9: 689-701.

Ubeda-Tomas S, Beemster GT, Bennett MJ. 2012. Hormonal regulation of root growth: integrating local activities into global behaviour. Trends in Plant Science 17: 326-331.

Ueda M, Zhang Z, Laux T. 2011. Transcriptional activation of Arabidopsis axis patterning genes WOX8/9 links zygote polarity to embryo development. Developmental Cell 20: 264-270.

Waki T, Hiki T, Watanabe R, Hashimoto T, Nakajima K. 2011. The Arabidopsis RWP-RK protein RKD4 triggers gene expression and pattern formation in early embryogenesis. Current Biology 21: 1277-1281.

Weigel D, Jurgens G. 2002. Stem cells that make stems. Nature 415: 751-754.

Weijers D, Schlereth A, Ehrismann JS, Schwank G, Kientz M, Jurgens G. 2006. Auxin triggers transient local signaling for cell specification in Arabidopsis embryogenesis. Developmental Cell 10: 265-270.

Yang Z. 2008. Cell polarity signaling in Arabidopsis. Annual Review of Cell and Developmental Biology 24: 551-575.

Yu J, Vodyanik MA, Smuga-Otto K, Antosiewicz-Bourget J, Frane JL, Tian S, Nie J, Jonsdottir GA, Ruotti V, Stewart R et al. 2007. Induced pluripotent stem cell lines derived from human somatic cells. Science 318: 1917-1920.

Zhang Z, Laux T. 2011. The asymmetric division of the Arabidopsis zygote: from cell polarity to an embryo axis. Sexual Plant Reproduction 24: 161-169.

Zhang X, Zhou Y, Ding L, Wu Z, Liu R, Meyerowitz EM. 2013. Transcription repressor HANABA TARANU controls flower development by integrating the actions of multiple hormones, floral organ specification genes, and GATA3 family genes in Arabidopsis. The Plant Cell 25: 83-101. 



\section{Chapter 2}

\section{n 8 \\ Ligation Independent Cloning for plant research}

Jos R. Wendrich, Che-Yang Liao, Willy A.M. van den Berg, Bert De Rybel, and Dolf Weijers

Modified from: Meth Mol Biol. (2015) doi: 10.1007/978-1-4939-2444-8_21
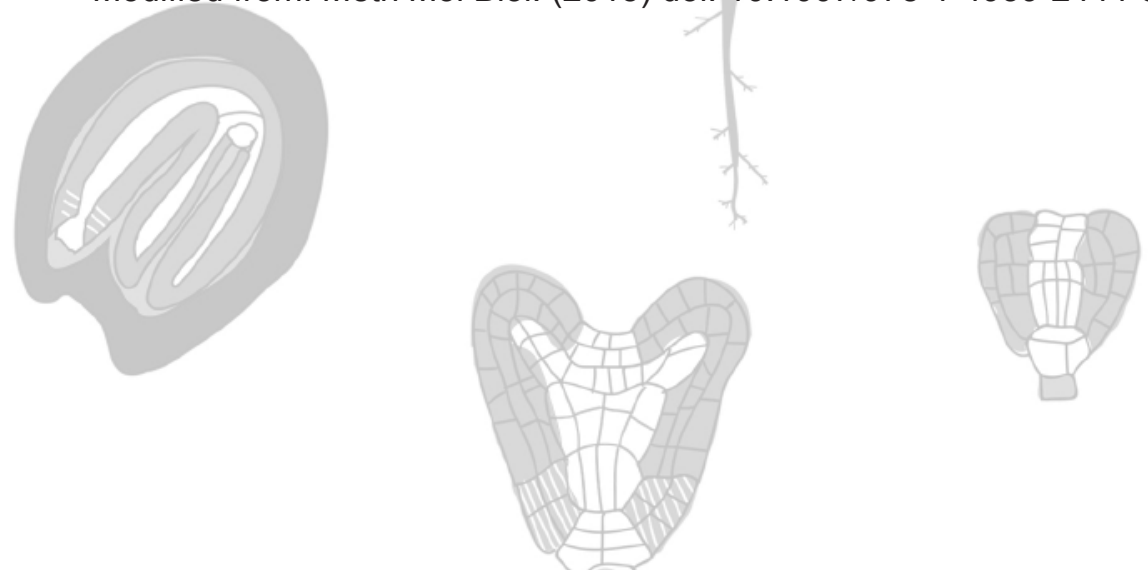

Laboratory of Biochemistry, Wageningen University, Dreijenlaan 3, 6703 HA Wageningen, The Netherlands 



\section{Summary}

Molecular cloning is a vital step in much of today's plant biological research. Particularly, when a species is amenable to transgenic manipulation, cloning enables detailed study of gene and protein function in vivo. Therefore, accurate, consistent and efficient cloning methods have the potential to accelerate biological research. Traditional restriction-enzyme/ligase-based strategies are often inefficient, while novel alternative methods can be less economical. We have recently optimized a method for Ligation Independent Cloning (LIC) that is both efficient and economical. We have developed a large set of LIC-compatible plasmids for application in plant research. These include dedicated vectors for gene expression analysis, protein localization studies and protein misexpression. We describe a detailed protocol that allows the reliable generation of plant transformation-ready constructs from PCR fragments in two to three days. 


\section{Introduction}

Cloning is crucial in molecular biology. The ability to quickly clone a gene of interest (or its promoter) is of vital importance in many areas of research, especially since the emergence of whole-genome analyses. Most cloning techniques are either time consuming (e.g. conventional cloning) or costly (e.g. Gateway cloning) and thus challenging for high-throughput applications. We have previously described an optimized Ligation Independent Cloning (LIC) method in combination with a large set of compatible vectors for use in plant (developmental) research, a procedure that is fast, easy to use, and relatively cheap (De Rybel et al., 2011). LIC uses the 3' to 5' exonuclease activity of commercial T4 DNA polymerase (Tabor and Struhl, 1989) to prepare vectors and inserts with long specific sticky ends (adapters), which can then easily be annealed and directly transformed into bacteria (Eschenfeldt et al., 2009; Li and Elledge, 2007), without the need to enzymatically ligate both together. A graphic, schematic representation of the method is shown in Figure 1 and 2 . This method has been used in various studies (e.g. De Rybel et al., 2011; De Rybel et al., 2012; De Rybel et al., 2013), is compatible with annealing multiple inserts (Li and Elledge, 2007), and is especially useful when a large number of genes need to be cloned into only a few different vectors.

Here we describe a step-by-step protocol for LIC, as we use it in our lab. It describes how to best prepare vectors and inserts for annealing and emphasizes the points critical for high efficiency. A list of available LIC-compatible vectors is described in Figure 3 and Table 1.

A large set of plasmids for plant transformation was described previously (pPLV series; De Rybel et al., 2011). We encountered poor growth of E. coli transformed with some of these plasmids, which led to reduced efficiency of cloning and low plasmid yield. Upon closer inspection, we discovered that a fragment derived from the E. coli LAC gene promoter was present in the pGreenll plasmid backbone (Hellens et al., 2000). Removal of this fragment resulted in improved bacterial growth and increased plasmid yields. The sequences of these improved pPLV plasmids (named pPLVXX_v2; Table 1; Figure 3) have been deposited in Genbank (see Figure 3 for accession numbers). Furthermore, we noticed that a premature start codon was present in the LIC site of pPLV32. This was therefore replaced by another LIC site, generally used for misexpression studies. All original pPLV plasmids have been deposited and are available through the Nottingham Arabidopsis Stock Center (www.arabidopsis.info; stock number N799138). The improved versions (pPLVXX_ v2) are available upon request. 


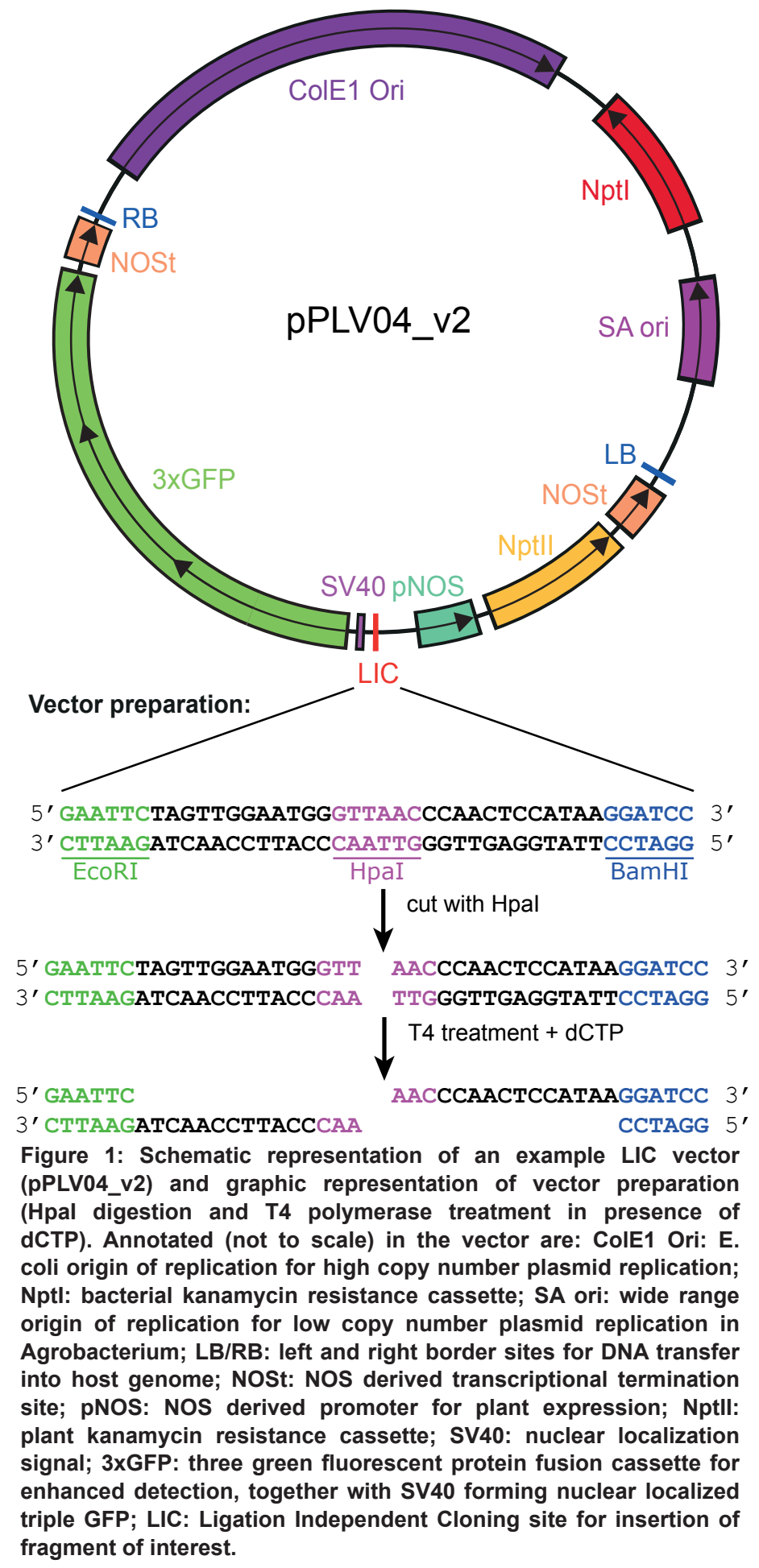


PCR fragment preparation:

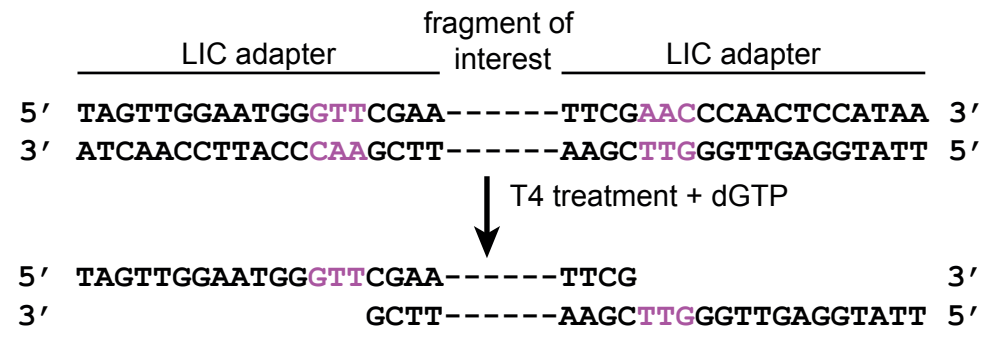

\section{Positive control:}

5' TAGTTGGAATGGGTCGAAGATCGATCGATCGATCGATCAAGC 3'

$$
\begin{aligned}
& \text { |||||||||||||||||||||||||||| } \\
& \text { 3' GCTTCTAGCTAGCTAGCTAGCTAGTTCGTTGGGTTGAGGTATT 5' }
\end{aligned}
$$

Figure 2: Graphic representation of PCR fragment preparation (after PCR amplification, T4 polymerase treatment in presence of dGTP) and positive control used for testing prepared LIC-vector efficiency.

\section{Materials}

1. FastDigest Hpal enzyme (1 FDU/ $\mu \mathrm{L}$, Thermo Scientific)

2. 10x FastDigest buffer (Thermo Scientific)

3. T4 polymerase enzyme $(3 \mathrm{U} / \mu \mathrm{L}, \mathrm{NEB})$

4. 10x T4 DNA polymerase buffer/ 10x NEB Buffer 2 (NEB)

5. $100 \mathrm{mM} \mathrm{dCTP}$

6. $100 \mathrm{mM}$ dGTP

7. $100 \times \mathrm{BSA}(10 \mathrm{mg} / \mathrm{ml}, \mathrm{NEB})$

8. $100 \mathrm{mM}$ DTT

9. $7.5 \mathrm{M} \mathrm{NH}_{4} \mathrm{CH}_{3} \mathrm{COOH}$

10. $70 \%$ and $100 \%$ ethanol

11. $2 x$ Phusion Flash master mix (Thermo Scientific)

12. Thermocycler (e.g. Bio-Rad T100)

13. Table-top microcentrifuge (e.g. Beckman Coulter Microfuge 18 Centrifuge)

14. Thin-wall PCR tubes

15. $37^{\circ} \mathrm{C}$ Incubator

16. Thermoblock for incubation of tubes at, for example $50{ }^{\circ} \mathrm{C}$

17. 1.5-mL microfuge tubes 
Table1. Overview of LIC-compatible vectors. Indicated: Respective use, names, antibiotic resistances, required LIC-adapter sites for forward and reverse primers used to amplify the required fragment (a: Forward 5'-TAGTTGGAATGGGTTCGAA-3', Reverse 5'-TTATGGAGTTGGGTTCGAA-3'; b: Forward 5'-TAGTTGGAATGGGTTCGAA-3', Reverse 5'-TTATGGAGTTGGGTTCGAAC-3'; c: Forward 5'-TAGTTGGAATAGGTTC-3', Reverse 5'-AGTATGGAGTTGGGTTC-3'; d: Forward 5'-TAGTTGAATAGGTTC-3', Reverse 5'-AGTATGGAGTTGGGTTC-3'), for all “_v2” vectors: LAC promoter fragment removed. *: Forward adapter changed to remove ATG.

\begin{tabular}{|c|c|c|c|c|}
\hline Use & pPLV & Vector & Antibiotic resistance & Adapters \\
\hline \multirow[t]{3}{*}{ basic vector for custom use } & pPLV01_v2 & pGIIB-LIC-NOSt & Basta/ppt & a \\
\hline & pPLV02_v2 & pGIIK-LIC-NOSt & Kanamycin & a \\
\hline & pPLV03_v2 & pGIIH-LIC-NOSt & Hygromycin & a \\
\hline \multirow[t]{12}{*}{ promoter analysis } & pPLV04_v2 & pGIIK-LIC-SV40-3xGFP-NOSt & Kanamycin & a \\
\hline & pPLV05_v2 & pGIIB-LIC-SV40-sYFP-NOSt & Basta/ppt & a \\
\hline & pPLV06_v2 & pGIIK-LIC-SV40-sYFP-NOSt & Kanamycin & a \\
\hline & pPLV07_v2 & pGIIB-LIC-SV40-sCFP-NOSt & Basta/ppt & a \\
\hline & pPLV08_v2 & pGIIK-LIC-SV40-sCFP-NOSt & Kanamycin & a \\
\hline & pPLV09 & pGIIH-LIC-SV40-sCFP-NOSt & Hygromycin & a \\
\hline & pPLV10 & pGIIB-LIC-SV40-tdTomato-NOSt & Basta/ppt & a \\
\hline & pPLV11 & pGIIK-LIC-SV40-tdTomato-NOSt & Kanamycin & a \\
\hline & pPLV12 & pGIIH-LIC-SV40-tdTomato-NOSt & Hygromycin & a \\
\hline & pPLV13 & pGIIB-LIC-GUS-NOSt & Basta/ppt & a \\
\hline & pPLV14 & pGIIK-LIC-GUS-NOSt & Kanamycin & a \\
\hline & pPLV15 & pGIIH-LIC-GUS-NOSt & Hygromycin & a \\
\hline \multirow[t]{12}{*}{ protein localization } & pPLV16_v2 & pGIIB-LIC-sYFP-NOSt & Basta/ppt & b \\
\hline & pPLV17_v2 & pGIIK-LIC-sYFP-NOSt & Kanamycin & $\mathrm{b}$ \\
\hline & pPLV18_v2 & pGIIH-LIC-sYFP-NOSt & Hygromycin & $\mathrm{b}$ \\
\hline & pPLV19_v2 & pGIIB-LIC-sCFP-NOSt & Basta/ppt & b \\
\hline & pPLV20_v2 & pGIIK-LIC-sCFP-NOSt & Kanamycin & b \\
\hline & pPLV21_v2 & pGIIH-LIC-sCFP-NOSt & Hygromycin & $\mathrm{b}$ \\
\hline & pPLV22 & pGIIB-LIC-tdTomato-NOSt & Basta/ppt & b \\
\hline & pPLV23 & pGIIK-LIC-tdTomato-NOSt & Kanamycin & b \\
\hline & pPLV24 & pGIIH-LIC-tdTomato-NOSt & Hygromycin & $\mathrm{b}$ \\
\hline & pPLV13 & pGIIB-LIC-GUS-NOSt & Basta/ppt & b \\
\hline & pPLV14 & pGIIK-LIC-GUS-NOSt & Kanamycin & $b$ \\
\hline & pPLV15 & pGIIH-LIC-GUS-NOSt & Hygromycin & $\mathrm{b}$ \\
\hline \multirow[t]{9}{*}{ misexpression } & pPLV25 & pGIIB-p35S-LIC-NOSt & Basta/ppt & c \\
\hline & pPLV26 & pGIIK-p35S-LIC-NOSt & Kanamycin & c \\
\hline & pPLV27 & pGIIH-p35S-LIC-NOSt & Hygromycin & c \\
\hline & pPLV28 & pGIIB-pRPS5a-LIC-NOSt & Basta/ppt & c \\
\hline & pPLV29 & pGIIB-pMP-LIC-NOSt & Basta/ppt & c \\
\hline & pPLV30 & pGIIK-pMP-LIC-NOSt & Kanamycin & $\mathrm{c}$ \\
\hline & pPLV31 & pGIIH-pMP-LIC-NOSt & Hygromycin & c \\
\hline & pPLV32_v2* & pGIIB-UAS-LIC-NOSt & Basta/ppt & d \\
\hline & pPLV33 & pGIIK-UAS-LIC-NOSt & Kanamycin & b \\
\hline
\end{tabular}




\section{Method}

Ligation Independent Cloning (LIC) starts with preparing a LIC-compatible vector by linearization and subsequent T4 DNA polymerase treatment to expose the LIC adapters and enable insertion of a fragment. The fragment of interest is first amplified by PCR and, after purification, also treated with T4 DNA polymerase. T4-treated vector and insert are then combined to allow (spontaneous) annealing and finally transformed into $E$. coli for plasmid ligation and amplification. Fragments up to 8 $\mathrm{kb}$ in size have been successfully cloned into several different vectors using this method. Below, all steps are described in detail as performed in our lab.

\section{LIC vector preparation}

Proper vector preparation is crucial for a successful cloning outcome (see Note 1). One batch of properly prepared vector can be used in many cloning experiments. It is important to start with freshly isolated plasmid DNA, as nicks can be formed in the DNA after prolonged storage in a freezer.

\section{Linearizing vector}

- Digest 2 to $4 \mu \mathrm{g}$ of vector in a total volume of $20 \mu \mathrm{L}$ of $1 \mathrm{x}$ FastDigest buffer containing $1 \mu \mathrm{L}$ of $\mathrm{Hpal}$ enzyme for $1-2$ hours at $37^{\circ} \mathrm{C}$ (see Note 2).

- Run digested vector on a $0.7 \%$ agarose $1 \mathrm{XTAE}$ gel for at least 2 hours at $100 \mathrm{~V}$ (see Note 3), excise and purify the linear vector (for example, using a QIAEXII gel extraction kit [see Note 4])

- After elution following the kit's instructions, precipitate DNA using 0.5 volumes of $7.5 \mathrm{M} \mathrm{NH}_{4} \mathrm{CH}_{3} \mathrm{COOH}$ and 3.75 volumes of $100 \%$ ethanol (example: $20 \mu \mathrm{L}$ eluted DNA, $10 \mu \mathrm{L} 7.5 \mathrm{M} \mathrm{NH}_{4} \mathrm{CH}_{3} \mathrm{COOH}$ and $75 \mu \mathrm{L}$ ethanol) overnight at $-20^{\circ} \mathrm{C}$.

- Centrifuge for 30 minutes at full speed in a table-top microcentrifuge.

- Remove supernatant and wash with $100 \mu \mathrm{L}$ of $70 \%$ ethanol.

- Remove supernatant and wash with $100 \mu \mathrm{L}$ of $100 \%$ ethanol.

- Air-dry the pellet, resuspend it in $20 \mu \mathrm{L}$ of water, and incubate at $50^{\circ} \mathrm{C}$ for 10 minutes to completely dissolve the DNA.

\section{Vector $T 4$ treatment}

- Combine in a 1.5-mL microfuge tube:

- $1.2 \mu \mathrm{g}$ of linearized vector

- $4 \mu \mathrm{L}$ of $10 x \mathrm{~T} 4$ polymerase buffer

- $4 \mu \mathrm{L}$ of $100 \mathrm{mM}$ d $\underline{\mathbf{C} T P}$

- $2 \mu \mathrm{L}$ of $100 \mathrm{mM}$ DTT 
- $0.4 \mu \mathrm{L}$ of $100 x \mathrm{BSA}$

- $0.8 \mu \mathrm{L}$ of T4 DNA polymerase

- up to $40 \mu \mathrm{L}$ of water

- Mix well and centrifuge for 15 seconds at full speed.

- Incubate at $22^{\circ} \mathrm{C}$ for 30 minutes to 2 hours (see Note 5).

- Heat inactivate for 20 minutes at $75^{\circ} \mathrm{C}$.

- Centrifuge for 15 seconds at full speed.

- $\quad$ Store at $4^{\circ} \mathrm{C}$ until use (see Note 6).

LIC insert preparation

\section{Primer design}

PCR primers should be designed to include a LIC adapter site compatible with the intended vector and a 3' gene-specific part of approximately $24 \mathrm{bp}$. Note that for protein localization studies, primers should be designed such that the gene will be in frame with the fluorescent protein.

Typically the following adapter sites are required (see also Table 1):

Expression analysis:

FORWARD: 5' TAGTTGGAATGGGTTCGAA-- 3'

REVERSE: 5' TTATGGAGTTGGGTTCGAA-- 3'

Protein localization:

FORWARD: 5' TAGTTGGAATGGGTTCGAA-- 3'

REVERSE: 5' TTATGGAGTTGGGTTCGAAC-- 3'

Misexpression:

FORWARD: 5' TAGTTGGAATAGGTTC-- 3'

REVERSE: 5' AGTATGGAGTTGGGTTC-- 3'

\section{Insert amplification}

- Combine in a 0.2-mL thin-wall PCR tube:

- $25 \mu \mathrm{L}$ of $2 \mathrm{x}$ Phusion Flash Master mix (see Note 7)

- $2 \mu \mathrm{L}$ of $10 \mu \mathrm{M}$ Forward primer

- $2 \mu \mathrm{L}$ of $10 \mu \mathrm{M}$ Reverse primer

- $\quad x \mu L$ of template DNA (see Note 8)

- up to $50 \mu \mathrm{L}$ of water

- Perform PCR using the following program (see Note 2):

- $98^{\circ} \mathrm{C} \quad 30$ seconds

- $35 \mathrm{x}$ 
- $\quad 98^{\circ} \mathrm{C} \quad 10$ seconds

- $58^{\circ} \mathrm{C} \quad 30$ seconds

- $\quad 72^{\circ} \mathrm{C} \quad 15$ seconds $/ 1 \mathrm{~kb}$ (see Note 9 )

- $72^{\circ} \mathrm{C} \quad 3$ minutes

- $\quad 4^{\circ} \mathrm{C} \quad$ hold

- Run PCR product on a $1 \%$ agarose 1 XTAE gel and purify a band of correct DNA size from the gel (see Note 4), or use a PCR clean-up kit if only one band is visible on the gel.

\section{T4 treatment of inserts}

- Combine in a 1.5-mL microfuge tube:

- 200-400 ng of purified PCR fragment

- $2 \mu \mathrm{L}$ of $10 \mathrm{x}$ T4 polymerase buffer

- $2 \mu \mathrm{L}$ of $100 \mathrm{mM}$ d $\underline{\mathbf{G} T P}$

- $1 \mu \mathrm{L}$ of $100 \mathrm{mM}$ DTT

- $0.2 \mu \mathrm{L}$ of $100 \times \mathrm{BSA}$

- $0.4 \mu \mathrm{L}$ of T4 DNA polymerase

- up to $20 \mu \mathrm{L}$ of water

- Mix well and centrifuge for 15 seconds at full speed in a table-top microcentrifuge.

- Incubate at $22^{\circ} \mathrm{C}$ for 30 minutes to 2 hours (see Note 5)

- Heat inactivate for 20 minutes at $75^{\circ} \mathrm{C}$.

- Centrifuge for 15 seconds at full speed in a table-top microcentrifuge.

- Store at $4^{\circ} \mathrm{C}$ until use (see Note 6 ).

\section{Annealing insert to $L I C$ vector}

Combine T4-treated vector and insert in a 1:3 molar ratio (see Note 10). Incubate at $22^{\circ} \mathrm{C}$ for $1-2$ hours or overnight at $4^{\circ} \mathrm{C}$ (see Note 11).

Transform the entire mixture into competent $E$. coli cells and confirm positive growth by colony PCR, restriction digest and/or sequencing (see Note 12).

\section{General note}

It is of great importance that all DNA isolations result in DNA of high purity and quality, free of contaminants (e.g. RNA and nucleases). Efficiency of LIC cloning depends on this. 


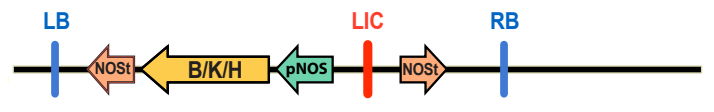

pPLV

Genbank

01_v2 (B) KM062044

02_v2 (K) KM062045

03_v2 (H) KM062046

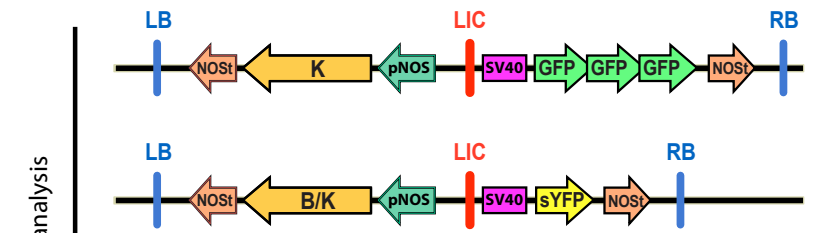

04_v2 (K) KM062047

05_v2 (B) KM062048

06_v2 (K) KM062049

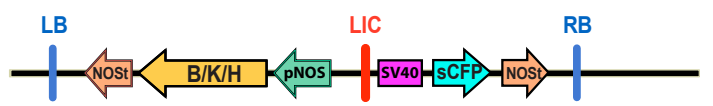

07_v2 (B) KM062050

08_v2 (K) KM062051

$09(\mathrm{H}) \quad J F 909462$

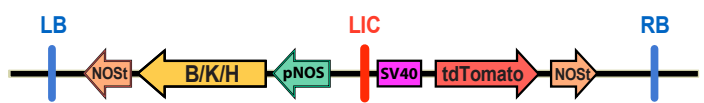

10 (B) JF909463

$11(\mathrm{~K}) \quad$ JF909464

$12(\mathrm{H}) \quad$ JF909465

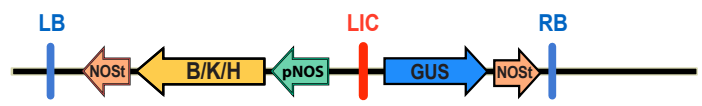

13 (B) J JF909466

$14(\mathrm{~K}) \quad$ JF909467

$15(\mathrm{H}) \quad$ JF909468

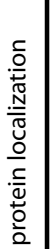

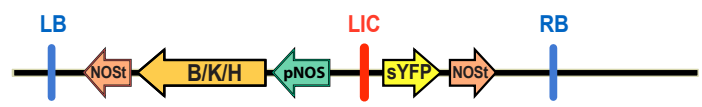

16_v2 (B) KM062052

17_v2 (K) KM062053

18_v2 (H) KM062054

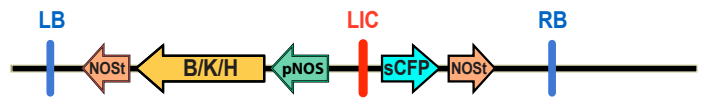

19_v2 (B) KM062055

20_v2 (K) KM062056

21_v2 (H) KM062057

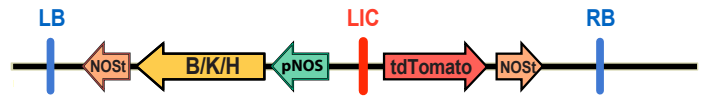

22 (B) JF909475

$23(\mathrm{~K}) \quad \mathrm{JF} 909476$

$24(\mathrm{H}) \quad$ JF909477

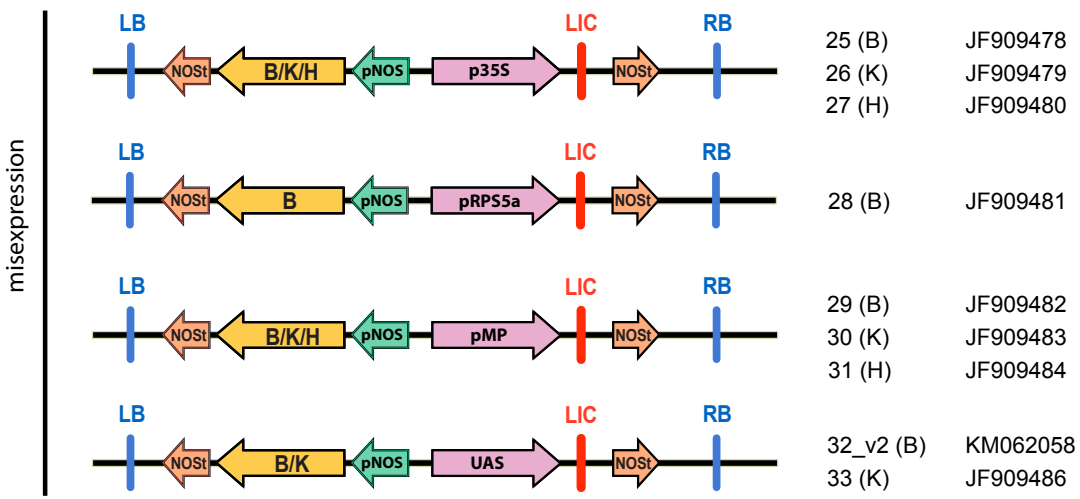

Figure 3: Schematic overview of available LIC compatible vectors. LB/RB: left and right border for DNA transfer into host genome; NOSt: transcriptional terminator; Plant resistance cassettes for Kanamycin (K), Basta/PPT (B), and Hygromycin (H); pNOS: promoter for resistance cassette expression; LIC: Ligation Independent Cloning site; SV40: nuclear localization signal; fluorescent proteins (GFP, sYFP, SCFP, tandemTomato); GUS: beta-glucuronidase; promoters for specific misexpression: 35S, RPS5A, MONOPTEROS (MP), and upstream activating sequence (UAS). pPLV designations and Genebank numbers are also indicated. 


\section{Notes}

1. Quality of a prepared vector can be checked using a custom designed linker generated by hybridizing two complementary primers with the specific LIC overhangs as insert: an example of this positive control is shown in Figure 2. The small size of this insert will result in very high insertion efficiency, making this primer dimer a great positive control.

2. These steps can be performed in duplo if low product yield is expected.

3. Proper separation of the linear vector from the circular form is essential, as any traces of circular plasmid will result in high background in E. coli transformation. Running the DNA on a gel for prolonged times at lower voltage can increase separation, but generally also increases the amount of agarose recovered from the excised gel piece (see next Note)

4. It is very important to minimize the amount of agarose when excising DNA from gel. We have found that use of large amounts of agarose during isolation results in low DNA yields and inhibits annealing later in the protocol.

5. Make sure to keep T4 treatment time under 2 hours, as prolonged treatment will lead to depletion of dCTPs/dGTPs and may result in degradation of the product.

6. Given proper purity, T4 DNA polymerase-treated samples can be stored for more than one year at $4^{\circ} \mathrm{C}$, without any loss in cloning efficiency.

7. Any DNA polymerase with proofreading activity can in principle be used. We have tested several and found Phusion Flash to show good performance in terms of high PCR yield and low error rate.

8. Dependent on the type of template DNA used, different amounts are necessary as input. Typically for a highly pure plant genomic DNA template (100 ng/ $\mu \mathrm{L})$ we use $2 \mu \mathrm{L}$ as input. In contrast, when using a previously amplified fragment of DNA as template, much less (a few ng) is sufficient, as too high input will inhibit proper DNA amplification.

9. Extension time should be adjusted to the specifics of the polymerase used. Some DNA fragments can be difficult to amplify. In these cases it can be worthwhile to lower extension temperature to $66^{\circ} \mathrm{C}$ to allow more time for DNA synthesis. We generally assume two-fold increase of extension time when lowering this temperature.

10. We generally use a total annealing reaction volume of $1-3 \mu \mathrm{L}$. Though not strictly necessary, keeping a molar vector:insert ratio at 1:3 can increase the success rate of annealing. This is usually one of the first things to check when the subcloning of a certain insert does not work. Example: $3 \mathrm{~kb}$ vector 
at concentration of $30 \mathrm{ng} / \mathrm{\mu L} ; 500 \mathrm{bp}$ insert at concentration of $10 \mathrm{ng} / \mathrm{\mu L}$; when using $1 \mu \mathrm{L}$ of vector, $1.5 \mu \mathrm{L}$ of insert should be used to achieve a 1:3 molar ratio.

11. Allowing sufficient time for annealing can increase cloning efficiency. Generally, one to two hours of incubation at $22^{\circ} \mathrm{C}$ result in sufficient efficiency, though when using large fragments a longer incubation may improve the results.

12. Typically $70-100 \%$ of recovered colonies after $E$. coli transformation are positive for both vector and insert. An average of 200 colonies are recovered from each transformation, dependent on the vector used. We generally find 1 in 20 clones to have erroneous bases, when using Phusion Flash. While error rate is highly dependent on insert size and stretches of repetitive bases, sequences of up to 2 $\mathrm{kb}$ in size are usually error-free.

\section{References}

De Rybel, B., W. van den Berg, A. Lokerse, C. Y. Liao, H. van Mourik, B. Moller, C. L. Peris and D. Weijers (2011). "A versatile set of ligation-independent cloning vectors for functional studies in plants." Plant Physiol 156(3): 1292-1299.

De Rybel, B., D. Audenaert, W. Xuan, P. Overvoorde, L. C. Strader, S. Kepinski, R. Hoye, R. Brisbois, B. Parizot, S. Vanneste, X. Liu, A. Gilday, I. A. Graham, L. Nguyen, L. Jansen, M. F. Njo, D. Inze, B. Bartel and T. Beeckman (2012). "A role for the root cap in root branching revealed by the non-auxin probe naxillin." Nat Chem Biol 8(9): 798-805.

De Rybel, B., B. Moller, S. Yoshida, I. Grabowicz, P. Barbier de Reuille, S. Boeren, R. S. Smith, J. W. Borst and D. Weijers (2013). "A bHLH complex controls embryonic vascular tissue establishment and indeterminate growth in Arabidopsis." Dev Cell 24(4): 426437.

Eschenfeldt, W. H., S. Lucy, C. S. Millard, A. Joachimiak and I. D. Mark (2009). "A family of LIC vectors for high-throughput cloning and purification of proteins." Methods Mol Biol 498: 105-115.

Hellens, R. P., E. A. Edwards, N. R. Leyland, S. Bean and P. M. Mullineaux (2000). "pGreen: a versatile and flexible binary Ti vector for Agrobacterium-mediated plant transformation." Plant Mol Biol 42(6): 819-832.

Li, M. Z. and S. J. Elledge (2007). "Harnessing homologous recombination in vitro to generate recombinant DNA via SLIC." Nat Methods 4(3): 251-256.

Tabor, S. and K. Struhl (1989). DNA-Dependent DNA Polymerases. Current Protocols in Molecular Biology. F. M. Ausebel, R. Brent, R. E. Kingston et al. New York, John Wiley \& Sons, Inc. 3.5.10-3.5.12. 



\section{Chapter 3}

\section{Q \\ 9 \\ In vivo identification of plant protein complexes using IP-MS/MS}

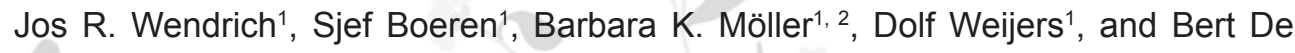
Rybel $^{1,2}$

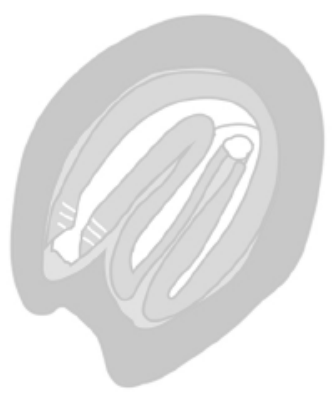

Meth Mol Biol. (in press)

1. Laboratory of Biochemistry, Wageningen University, Dreijenlaan 3, $6703 \mathrm{HA}$ Wageningen, The Netherlands

2. Current address: Department of Plant Systems Biology, VIB, and Department of Plant Biotechnology and Bioinformatics, Ghent University, 9052 Ghent, Belgium 



\section{Summary}

Individual proteins often function as part of a protein complex. The identification of interacting proteins is therefore vital to understand the biological role and function of the studied protein. Here we describe a method for the in vivo identification of nuclear, cytoplasmic and membrane-associated protein complexes from plant tissues using a strategy of immunoprecipitation followed by tandem mass-spectrometry. By performing quantitative Mass Spectrometry measurements on biological triplicates, relative abundance of proteins in GFP-tagged complexes compared to background controls can be statistically evaluated to identify high-confidence interactors. We detail the entire workflow of this approach. 


\section{Introduction}

To understand a biological process, one can focus on the function or activity of the individual proteins that are involved. However, these proteins often perform their function as part of intricate complexes, comprising several and/or different proteins bound and functioning together. Therefore, being able to identify which proteins interact with one another is a very important step towards a thorough understanding of their biological function.

Several methods are currently used to test the interaction of two (or more) selected proteins, including both in vitro and in vivo techniques like, Yeast-Two/ Three-Hybrid (Y2H, Y3H; Ferro and Trabalzini, 2013), Co-Immunoprecipitation (CoIP) followed by Western Blotting (Albrecht et al., 2012), and Förster Resonance Energy Transfer measured by Fluorescence Lifetime Imaging (FRET-FLIM; Bücherl et al., 2014). The drawback of these types of techniques is that they are limited to test the interaction of the selected proteins, and often require prior knowledge regarding the interactions or require all tested proteins to be labeled, limiting the amount of interactions that can be examined and creating a bias in the measurements. Regardless of this, techniques like FRET-FLIM are powerful as a means to characterize individual interactions, as they allow for testing of dynamic interactions at the subcellular level (Bücherl et al., 2014).

Here, we describe an optimized protocol for immunoprecipitation (IP) followed by (label-free) tandem mass-spectrometry (MS/MS) that allows the identification of proteins interacting with a fluorescently labeled bait in a non-biased and (semi-) quantitative fashion. This methodology has been successfully used to identify complexes of multiple types of proteins, including transcription factors and other nuclear proteins (De Rybel et al., 2013; Saiga et al., 2012), membrane associated proteins (Zwiewka et al., 2011), trans-membrane proteins (Zwiewka et al., 2011), and cytosolic proteins (Smaczniak et al., 2012). When considering IP-MS/ MS for the identification of interacting proteins to a protein of interest, it is important to keep in mind that this is not a saturated identification method. Due to the finite amount of peptides that can be measured by the MS per run, not all interacting proteins may be visible. Also some (previously known) interacting proteins may be absent from the results list, due to very low abundance in the sample. It is, therefore, of vital importance to keep contaminations to a minimum, as these will fill the MS with unwanted peptides.

This step-by-step protocol for IP-MS/MS, using anti-GFP coated magnetic beads describes the workflow that is used, from collection of plant material up to the 
final data analysis (see Figure 1) and emphasizes important points for obtaining high purity and efficiency.

\section{Materials}

\section{Plant material}

Homozygous transgenic lines should be generated, expressing the protein of interest tagged with a GFP (or derivative) in the desired tissue. Generally, 3 gram of powdered material is used per replicate in the IP. As a rule of thumb, for three replicates, $1 \mathrm{~mL}$ of seed is needed when studying 6 days old whole seedlings. For the control sample, use either a non-transgenic line or a line expressing only GFP.

\section{Immunoprecipitation}

- Liquid nitrogen

- Mortar and pestle

- Standard $50 \mathrm{~mL}$ Falcon tubes

- Standard $14 \mathrm{~mL}$ Falcon tubes

- Extraction buffer without detergent ( $60 \mathrm{~mL}$ is needed per sample; EB-):

- Tris-HCl; pH7.5; 1M; 5 mL, NaCl; 5M; 3 mL, Protease inhibitor Complete; 2 tablets, $\mathrm{H}_{2} \mathrm{O}$; to $100 \mathrm{~mL}$

- Extraction buffer with $1 \%$ detergent ( $10 \mathrm{~mL}$ needed per sample; $\mathrm{EB}+$ ):

- Nonidet P-40; $0.1 \mathrm{~mL}$, EB-; $9.9 \mathrm{~mL}$

- Needle sonicator

- $50 \mathrm{~mL}$ centrifuge tubes

- Beckman-Coultier Avanti J26 XP - JA 25.50 rotor

- Standard tabletop balance, 0.05 gram accurate

- $40 \mu \mathrm{m}$ cell strainer

- anti-GFP coated magnetic beads ( $\mu$ MACS, Miltenyi)

- Magnetic $\mu$ columns ( $\mu$ MACS, Miltenyi)

- MultiStand ( $\mu$ MACS, Miltenyi)

- $\mu M A C S$ Separator (Miltenyi)

- $A B C$ buffer: $50 \mathrm{mM} \mathrm{NH}_{4} \mathrm{HCO}_{3}$ in $\mathrm{H}_{2} \mathrm{O}$

- Thermoblock

- $0.5 \mathrm{~mL}$ protein low-bind tubes 
Sample preparation mass spectroscopy

- ABC buffer: $50 \mathrm{mM} \mathrm{NH}_{4} \mathrm{HCO}_{3}$ in $\mathrm{H}_{2} \mathrm{O}$

- Dithiotreitol (DTT)

- lodo-acetamide (IAA)

- L-Cystein

- Trypsin, sequencing grade $(0.5 \mu \mathrm{g} / \mu \mathrm{L}$ in $1 \mathrm{mM} \mathrm{HCl})$

- Trifluoroacetic acid (TFA)

- Thermoblock

- C18 Empore membrane

- $1 \mathrm{~mm}$ tissue puncher

- Methanol

- LiChroprep RP-18

- Formic Acid

- Acetonitrile (AcNi)

- $0.5 \mathrm{~mL}$ protein low-bind tubes

- SpeedVac

- Water bath sonicator

- Standard tabletop centrifuge

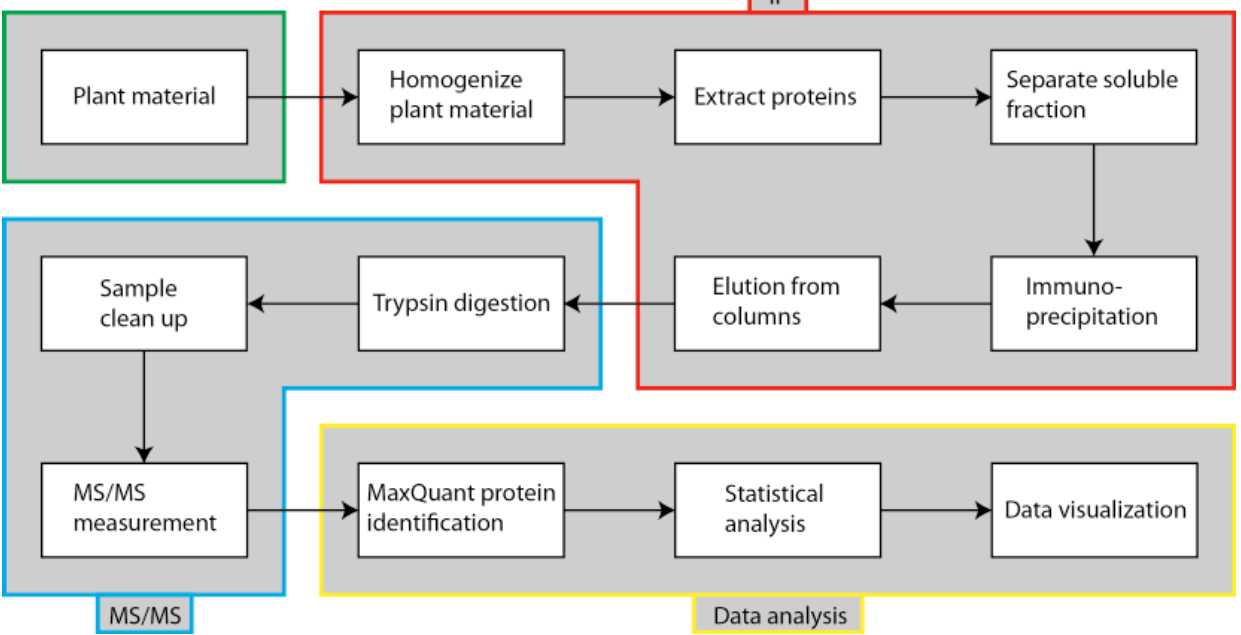

Figure 1: IP-MS/MS workflow. The protocol starts with collecting plant material, then homogenizing it and extracting the proteins. The soluble fraction is then separated and immunoprecipitation is performed. Beads and proteins are subsequently eluted and trypsin digestion of the proteins is done. After cleanup, label-free tandem MS measurements are performed followed by MaxQuant protein identification, statistical analysis and data visualization. 


\section{Method}

\section{Immunoprecipitation}

\section{Day 1:}

1. Thoroughly grind plant material (both transgenic line and the control) in liquid nitrogen with mortar and pestle. Transfer the ground material to a pre-cooled 50 $\mathrm{mL}$ tube and place it in liquid nitrogen.

2. For each of the replicates, weigh the desired amount of plant powder on a scale into a pre-cooled tube (see Note 1).

3. Store in $-80^{\circ} \mathrm{C}$ until next day (see Note 2).

\section{Day 2:}

1. Pre-cool mortars on ice and prepare extraction buffers

2. Add weighed material to mortars and add as little EB+ as possible to solubilize the plant material (see Note 3 ) and grind again very thoroughly with mortar and pestle.

3. Transfer the protein extract to a $14 \mathrm{~mL}$ tube (if you have more than $3 \mathrm{~mL}$ protein extract, divide over several $14 \mathrm{~mL}$ tubes) and sonicate three times for 15 seconds on ice with at least 15 seconds pause in between (see Note 4).

4. Keep the samples on ice for 30 minutes to thoroughly extract the proteins (see Note 5).

5. Dilute the protein extract to $0.2 \%$ NP40 by adding EB- and transfer the protein extract to centrifuge tubes (see Note 6).

6. Centrifuge 15 minutes at $4^{\circ} \mathrm{C}$ at $18.000 \mathrm{rpm}$ (see Note 7). Transfer the supernatant to another centrifuge tube and centrifuge again for 15 minutes at 4 ${ }^{\circ} \mathrm{C}$ at $18.000 \mathrm{rpm}$.

7. Transfer the supernatant through a $40 \mu \mathrm{m}$ cell strainer into a new $50 \mathrm{~mL}$ tube (see Note 8).

8. Add $50-100 \mu \mathrm{L}$ anti-GFP $\mu$ Beads (see Note 9). Mix well by swirling the tube. Rotate for two hours at $4^{\circ} \mathrm{C}$ (see Note 10).

9. Place $\mu$ Column in the magnetic field of the $\mu$ MACS Separator.

10. Add $200 \mu \mathrm{L}$ clean EB+ to the column.

11. Prepare EB with $0.1 \%$ NP40

12. Add $500 \mu \mathrm{L}$ EB with $0.1 \%$ NP40 to the column

13. Apply cell lysate onto the column and let the lysate run through (see Note 11).

14. Prepare $A B C$ Buffer and heat $1 \mathrm{~mL}$ to $95^{\circ} \mathrm{C}$ in a heat block for later use. 
15. Rinse column four times with $200 \mu \mathrm{L}$ EB with $0.1 \%$ NP40

16. Rinse column twice with $500 \mu \mathrm{L}$ ABC Buffer to remove all detergent (see Note 12).

17. Remove the column from the magnet, immediately place a $0.5 \mathrm{~mL}$ low-bind eppendorf tube below the column and add $50 \mu \mathrm{L}$ pre-heated ABC Buffer to the column to transfer the beads into the eppendorf tube (see Note 13).

18. Transfer column into a new Low Bind tube and add another $50 \mu \mathrm{L}$ pre-heated $A B C$ Buffer to the column (second elution with $A B C$, see Note 14) to check whether all beads were transferred in step 17. Combine with the beads in step 17 when beads are visible.

19. Store at $-20^{\circ} \mathrm{C}$.

Sample preparation mass spectrometry

\section{Day 3:}

1. Add $1 \mu \mathrm{L} 500 \mathrm{mM}$ DTT in ABC Buffer to the beads containing eluate and incubate for 2 hours at $60^{\circ} \mathrm{C}$ (see Note 15).

2. Add $1 \mu \mathrm{L} 750 \mathrm{mM}$ IAA in ABC Buffer to the samples. Mix well and incubate 2 hours at room temperature in the dark (see Note 16).

3. Add $1 \mu \mathrm{L} 200 \mathrm{mM} \mathrm{L-Cysteine} \mathrm{in} \mathrm{ABC} \mathrm{Buffer} \mathrm{to} \mathrm{the} \mathrm{samples} \mathrm{(see} \mathrm{Note} \mathrm{17).} \mathrm{Mix}$ well.

4. Add $1 \mu \mathrm{L}$ sequence grade Trypsin, mix well and incubate for 16 hours at $20^{\circ} \mathrm{C}$ (see Note 18).

\section{Day 4:}

1. Using $10 \%$ TFA, adjust the $\mathrm{pH}$ of the samples to approximately 3 ; check the $\mathrm{pH}$ with $0.1 \mu \mathrm{L}$ of sample on a piece of $\mathrm{pH}$ paper (see Note 19).

2. Use a tissue puncher to cut a small $(\sim 1 \mathrm{~mm})$ piece of a C18 Empore membrane and insert it into a polypropylene $200 \mu \mathrm{L}$ pipet tip (Rappsilber et al., 2007).

3. Add $200 \mu \mathrm{L}$ methanol to the tip with membrane (see Note 20).

4. Prepare a $50 \%(\mathrm{v} / \mathrm{v})$ slurry of LiChroprep RP-18 column material in methanol and apply $4 \mu \mathrm{L}$ of the slurry to the tip/ $\mu$ Column in the methanol.

5. Elute the $\mu$ Column and wash once with $100 \mu \mathrm{L}$ Methanol (see Note 21).

6. Equilibrate the $\mu$ Column once with $100 \mu \mathrm{L} 0.1 \%$ Formic Acid (see Note 22).

7. Spin down the beads at full speed for 15 minutes in a standard tabletop centrifuge.

8. Add sample to the $\mu$ Column and elute through (see Note 23).

9. Wash the $\mu$ Column once with $100 \mu \mathrm{L} 0.1 \%$ Formic Acid. 


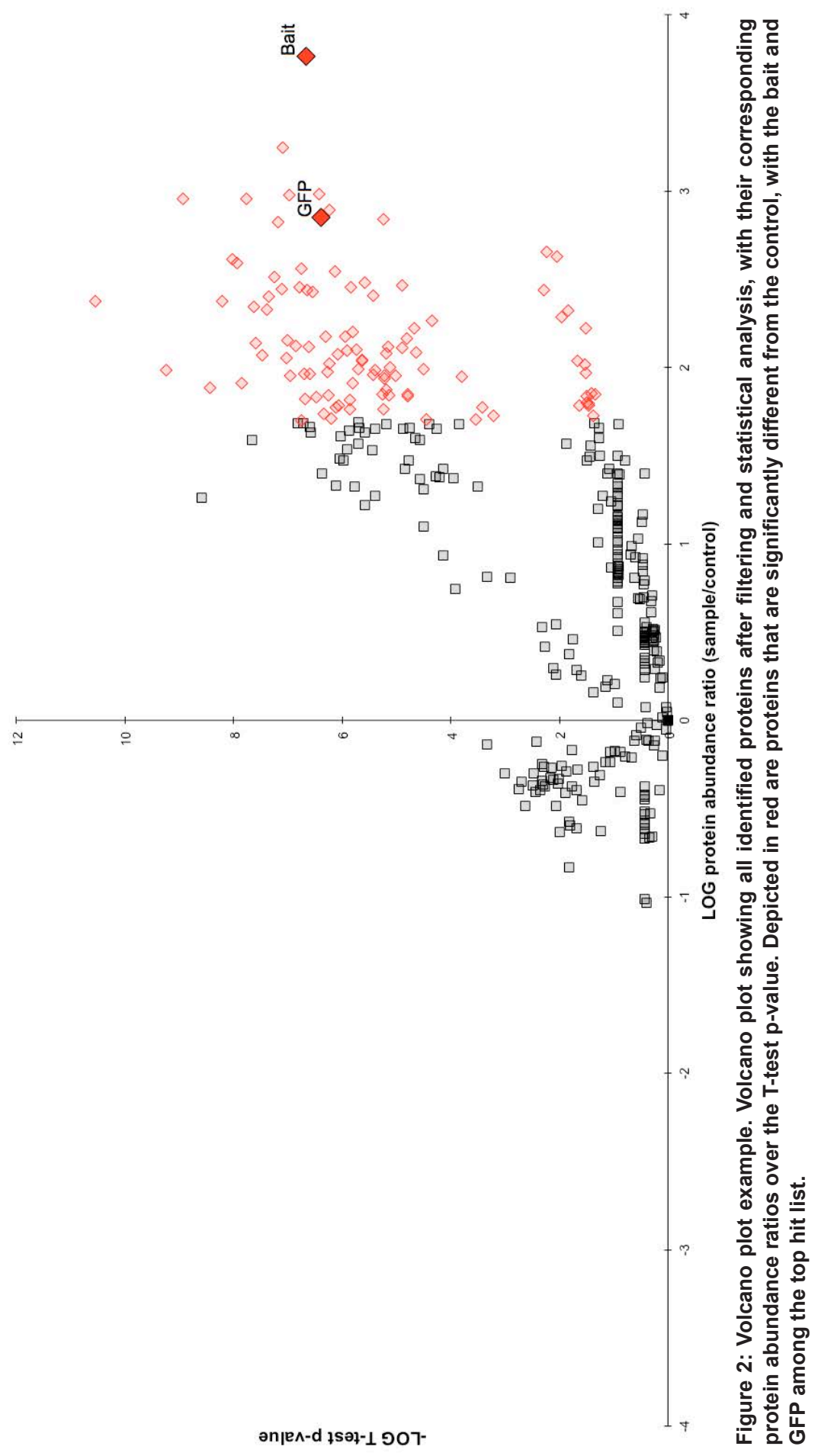


10. Transfer the $\mu$ Column to a $0.5 \mathrm{~mL}$ protein low-bind tube.

11. Add $50 \mu \mathrm{LAcNi} / 0.1 \%$ Formic Acid (1:1) and manually elute the $\mu$ Column directly into the $0.5 \mathrm{~mL}$ protein low-bind tube (see Note 24).

12. For LCMS analysis, reduce the AcNi content by putting the samples with open cap in a SpeedVac at $30-45^{\circ} \mathrm{C}$ for $\sim 2$ hours. The final volume should be well below $10 \mu \mathrm{L}$. Adjust the sample volume to $50 \mu \mathrm{L}$ with $0.1 \%$ Formic Acid (see Note 25).

13. The sample is now ready to be loaded onto an LCMS and can be stored at $-20^{\circ} \mathrm{C}$.

\section{Tandem mass spectrometry}

1. Separate peptides by reversed phase nano liquid chromatography connected to the MS via an electrospray interface.

2. Measure MS spectra on-line by accurate mass Mass Spectrometry (MS) as well as Collision Induce Dissociation fragmented MS-MS spectra according to the settings in Tables 1 and 2 (see Notes 26 and 27).

\section{MaxQuant protein identification and statistical analysis}

1. Analyse all LC-MS/MS runs obtained with all MS/MS spectra with the database search algorithm Andromeda from MaxQuant 1.3.0.5 (Cox and Mann, 2008; Cox et al., 2011) in the "Label Free Quantification" mode with settings described in Table 3 (see Note 28).

2. Normalized quantitative information (Label Free Quantification [LFQ] intensity) is obtained for all protein groups identified when 2 or more peptides could be properly quantified (see Note 29).

3. Group the replicates together. An optional final filtering can be performed in the Perseus filtering and statistics software to improve the statistics by deleting those proteins that are identified in less than half of the replicates (see Table 4 and Note 30).

4. Perform T-tests between groups in Perseus. This not only results in the p-value (column: -Log t-test $p$-value), but also immediately yields the ratio of the groups average LFQ values (column: t-test Difference) when applied to two groups. Significance at a variable false discovery rate (FDR) is judged by both $p$-value and ratio, of which the weight is set by a variable $S_{0}$ value (see Note 31). Both FDR and $S_{0}$ should be optimized to yield no or only a few proteins significantly different on the control side of the volcano plot obtained (see Figure 2).

5. In a successful experiment, the GFP and the bait (tagged) protein are in the top 10 when the list is sorted by ratio (see Note 32 ). The high ratio and low p-value 
should make the difference between sample and control clearly significant. Depending on the starting tissue that is used, some highly abundant proteins like Glyceraldehyde-3-phosphate dehydrogenase and Rubisco can always be observed, but these should give ratio's around one ( 0 on a logarithmic scale).

\section{Notes}

1. Usually about 1-3 grams of ground plant material is used per replicate/sample (for low expressed proteins use 3 grams of tissue and use only tissue where your protein is expressed to limit the amount of background proteins in the sample).

2. This is recommended because it ensures that the mortars are not too cold, which in some cases can lead to complications with fluidity of the sample.

3. Usually $\sim 8-9 \mathrm{~mL}$ of $\mathrm{EB}+$ is needed for 3 gram material. Using less of the buffer in this step will yield more concentrated sample later in the protocol.

4. Sonication is used to breakup cell membranes and release cellular components in the liquid. For the described sonicator, use 3/4 power and middle tune. Optimization might be required depending on the sonicator. It is very important to keep the samples on ice the whole time, especially during sonication, to prevent complex deformation through heat.

5. If desired, a small aliquot can be taken as INPUT sample for Western Blotting.

6. Too high detergent concentrations may increase background proteins and disrupt MS measurements.

7. Make sure the tubes are balanced properly ( \pm 0.05 grams)

8. This ensures any leftover cell debris is filtered out, as these could clog the IP $\mu$ Columns. If desired, a small aliquot can be taken as Supernatant sample for Western Blotting.

9. Use $50 \mu \mathrm{L}$ when 1 gram of material is used and $100 \mu \mathrm{L}$ when 3 grams of material is used. Make sure to resuspend the beads before pipetting with a cut tip.

10. In some cases it can be advisable to speed up the whole protocol. This incubation step can then be decreased to 1 hour.

11. The columns are "flow-stop" and do not run dry. If desired, an aliquot of the flowthrough can be taken as sample for Western Blotting.

12. Any detergent present in the final MS sample may interfere with the chromatography and the MS measurement, as this may cause peak broadening.

13. Make sure the "end" of the column is always in contact with the eluate. This way more beads will be eluted.

14. If desired, a small aliquot can be taken as IP sample for Western Blotting. 
15. DTT reduces disulfide bonds in the proteins, leaving them more exposed for the trypsin digestion later in the protocol.

16. IAA alkylates the proteins, blocking disulfide formation.

17. L-Cysteine stops the alkylation.

18. Do not leave this longer than 16 hours, as this may result in chymotrypsinic cleavages.

19. Lowering the $\mathrm{pH}$ inactivates trypsin, stopping digestion. Avoid a $\mathrm{pH}$ of lower than 2.

20. If some air is trapped between the liquid and the frit/column material, flick the $\mu$ Column to remove.

21. The prepared $\mu$ Columns can be eluted by hand using a $1 \mathrm{~mL}$ syringe with a rubber-lined tip or using a vacuum pump. Whatever method used, do not let the columns run dry.

22. Methanol concentration should be brought below $5 \%$ to allow binding of peptides.

23. Peptides in the sample will bind the column material and detergent and other contaminants will be washed out.

24. Peptides are released from the column material in acetonitrile concentrations above $5 \%, 50 \%$ is used to limit yield losses in this step.

25. If samples are completely dry, resuspend in $50 \mu \mathrm{L} 0.1 \%$ Formic Acid and sonicate several times for 10 seconds, vortexing in between.

26. A high chromatographic resolution as well as high MS resolution, accuracy and sensitivity are required to successfully measure transcription factor interactors.

27. Similar results can be obtained using instruments from suppliers other than mentioned in the tables when they have comparable or improved specifications like some more modern instruments do.

28. MaxQuant internally re-calibrates MS spectra resulting in MS deviations which generally lie below $2 \mathrm{ppm}$. The advantage of using the "Match between runs" option is that the software will search for all peptides identified in all MS runs based on retention time, $\mathrm{m} / \mathrm{z}$ measured and isotopic distribution. This way, quantitative information can be obtained for all peptides identified in all runs even when the peptide may only have been selected for fragmentation in a single run.

29. By default a false discovery rate of $1 \%$ is used.

30 . This will restrict the results table to only those proteins with a high reliability.

31. Significant FDR can be set manually. $S_{0}$ values $<1$ give more weight to the $p$-value and $S_{0}$ values $>1$ give more weight to the ratio, when determining the significance. Generally an $S_{0}$ of 1 is chosen to give both $p$-value and ratio an equal weight. 
32. Sometimes, GFP is found somewhat lower in the list, probably due to its compact folding, making it more difficult to digest with trypsin.

Table 1: Chromatography settings

\begin{tabular}{|c|c|}
\hline Nano LC & Proxeon EASY nLC II \\
\hline Setup & Vented column \\
\hline Pre-concentration column & $\begin{array}{l}0.10 * 32 \mathrm{~mm} \text { Magic C18AQ 200A } 5 \mu \mathrm{m} \text { beads prepared } \\
\text { in house }\end{array}$ \\
\hline Analytical column & $\begin{array}{l}0.10 * 250 \mathrm{~mm} \text { Magic C18AQ 200A } 3 \mu \mathrm{m} \text { beads prepared } \\
\text { in house }\end{array}$ \\
\hline Column temperature & Room temperature \\
\hline Autosampler temperature & $7^{\circ} \mathrm{C}$ \\
\hline $\begin{array}{l}\text { Sample loading volume and } \\
\text { flow }\end{array}$ & $30 \mu \mathrm{L}$ at 270 bar (generally $7-8 \mu \mathrm{L} / \mathrm{min}$ ) with eluent $\mathrm{A}$ \\
\hline Autosampler wash & $\begin{array}{l}2 \text { cycles with } 27 \mu \mathrm{L} \text { of } 50 \%(\mathrm{v} / \mathrm{v}) \text { acetonitril / } 50 \%(\mathrm{v} / \mathrm{v}) 0.1 \% \\
\text { Formic Acid in water, } 100 \mu \mathrm{L} \text { of } 0.1 \% \text { Formic Acid in water }\end{array}$ \\
\hline Eluent A & $5 \mathrm{~mL} / \mathrm{L}$ acetic acid in LCMS grade water \\
\hline Eluent B & $5 \mathrm{~mL} / \mathrm{L}$ acetic acid in LCMS grade acetonitril \\
\hline $\begin{array}{l}\text { Measurement gradient (time } \\
\text { in min }(\% \text { eluent B)) }\end{array}$ & 0 (8), 50 (33), 53 (50), 58 (50). \\
\hline $\begin{array}{l}\text { Cleaning gradient (time in } \min \\
(\% \text { eluent } \mathrm{B}))\end{array}$ & $\begin{array}{l}0(20), 10(80), 15(80) . \text { Run at least one cleaning gradient } \\
\text { after each measurement gradient. }\end{array}$ \\
\hline Injection volume & $\begin{array}{l}18 \mu \mathrm{L} \text { of sample (measurement gradient) or } 15 \mu \mathrm{L} \text { of } 50 \% \\
(\mathrm{v} / \mathrm{v}) \text { acetonitril / } 50 \%(\mathrm{v} / \mathrm{v}) 0.1 \% \text { Formic Acid in water. }\end{array}$ \\
\hline High voltage connection & $\begin{array}{l}\text { Apply an electrospray potential of } 3.5 \mathrm{kV} \text { directly to the } \\
\text { eluent via the stainless steel needle fitted into the vented } \\
\text { waste line of a P777 Upchurch microcross that was } \\
\text { positioned between the pre-concentration and analytical } \\
\text { column. }\end{array}$ \\
\hline Pre-column re-equilibration & $12 \mu \mathrm{L}$ eluent $A$ at 270 bar \\
\hline $\begin{array}{l}\text { Analytical column } \quad \text { re- } \\
\text { equilibration }\end{array}$ & $3 \mu \mathrm{L}$ eluent $\mathrm{A}$ at $270 \mathrm{bar}$ \\
\hline
\end{tabular}


Table 2: Mass spectrometry settings

\begin{tabular}{|c|c|}
\hline MS & LTQ-Orbitrap XL \\
\hline Measurement software & Xcalibur 2.1 \\
\hline Tuning and calibration & $\begin{array}{l}\text { From m/z } 150 \text { to } 2000 \text { by direct infusion of LTQ ESI calibration } \\
\text { solution for positive mode containing Caffeine, peptide } \\
\text { MRFA and Ultramark } 1621 \text { according to instructions of the } \\
\text { manufacturer. }\end{array}$ \\
\hline nESI & $\begin{array}{l}\text { Capillary temperature }=200{ }^{\circ} \mathrm{C} \text {, Capillary voltage }=35 \mathrm{~V} \text {, Tube } \\
\text { Lens voltage }=100 \mathrm{~V} \text {, source voltage }=3.5 \mathrm{kV} \text { (see High } \\
\text { voltage connection in Table } 1 \text { ) }\end{array}$ \\
\hline Tune File Parameters & $\begin{array}{l}\text { FTMS Full Microscans }=1 \text {, Ion Trap MSn Microscans }=1 \text {, } \\
\text { FTMS Full Max Ion Time }=500 \mathrm{~ms} \text {, Ion Trap MSn Max Ion } \\
\text { Time }=100 \mathrm{~ms} \text {, FTMS Full AGC Target }=1,000,000 \text {, Ion Trap } \\
\text { MSn AGC Target }=10,000\end{array}$ \\
\hline $\begin{array}{l}\text { MS detector Acquire time } \\
(\min )\end{array}$ & 58 \\
\hline Start delay (min) & 0 \\
\hline Segments & 1 \\
\hline Scan Events & 2 \\
\hline Event 1 & $\begin{array}{l}\text { Analyzer = FTMS, Mass range }=\text { Normal, Scan Range }=380- \\
1400 \mathrm{~m} / \mathrm{z} \text {, Resolution }=60.000, \text { Scan type }=\text { Full, Polarity }= \\
\text { Positive, Data type = Profile }\end{array}$ \\
\hline Event 2 (Data dependent) & $\begin{array}{l}\text { Analyzer }=\text { Ion Trap, Mass range }=\text { Normal, Scan Rate }= \\
\text { Normal, Data type }=\text { Centroid, Dependent scan On }\end{array}$ \\
\hline Lock mass & Disabled (FTMS is calibrated every day) \\
\hline Global Dynamic Exclusion & $\begin{array}{l}\text { Repeat Count }=1 \text {, Repeat duration }=0 \mathrm{~s} \text {, Exclusion list size }= \\
500, \text { Exclusion duration }=45 \mathrm{~s}, \text { Exclusion mass width Relative } \\
\text { to reference mass }=25 \mathrm{ppm} \text { (low, and high) } \\
\text { Early expiration }=\text { disabled }\end{array}$ \\
\hline Segment & $\begin{array}{l}\text { Preview mode for FTMS master scans }=\text { Enabled, Charge } \\
\text { state screening and Rejection }=\text { Enabled, Monoisotopic } \\
\text { precursor selection }=\text { Enabled, Charge state }+1 \text { and } 4 \text { and up } \\
=\text { Rejected, Unassigned charge state }=\text { Rejected }\end{array}$ \\
\hline
\end{tabular}




\begin{tabular}{|l|l|}
\hline Scan Event & $\begin{array}{l}\text { Minimum MS signal Threshold for MS2 trigger = 5000, Mass } \\
\text { determined from scan event = 1, Nth most intense ion = } \\
\text { Enabled, Analyze top N peaks = 4, Activation type = CID, } \\
\text { Activation Default charge state = 3, Activation Isolation width } \\
(\mathrm{m} / \mathrm{z})=2.0 \text {, Normalized collision energy = 30, Activation } \mathrm{Q}= \\
0.250, \text { Activation time }(\mathrm{ms})=15\end{array}$ \\
\hline $\begin{array}{l}\text { Mass lists and global mass } \\
\text { lists }\end{array}$ & NOT used \\
\hline
\end{tabular}

Table 3: Database search and quantification software settings

\begin{tabular}{|c|c|}
\hline Software & MaxQuant 1.3.0.5. \\
\hline Group specific parameters & $\begin{array}{l}\text { Variable modifications }=\text { Oxidation }(M) \text {, Acetyl (Protein } \\
\text { N-term), Deamidation }(\mathrm{NQ}) \text {, Separate variable modifications } \\
\text { for first search }=\text { disabled, Multiplicity }=1 \text {, Enzyme }= \\
\text { Trypsin/P, First search ppm }=20 \text {, Main search ppm }=6 \text {, } \\
\text { Max number of modifications per peptide }=5 \text {, Max. missed } \\
\text { cleavages }=2 \text {, Max. charge }=7 \text {, individual peptide mass } \\
\text { tolerances }=\text { Enabled, Type }=\text { Standard, Separate enzyme } \\
\text { for first search }=\text { disabled. }\end{array}$ \\
\hline MS/MS sequences & $\begin{array}{l}\text { ITMS MS/MS tolerance = } 0.5 \mathrm{Da} \text {, Include contaminants = } \\
\text { Enabled, } \\
\text { FASTA files = Arabidopsis thaliana Uniprot reference } \\
\text { database, Reverse, Special AAs = KR, Separate file for } \\
\text { first search = a contaminants database with } 60 \text { proteins } \\
\text { including GFP/YFP/CFP/eYFP and BSA (P02769, bovin } \\
\text { serum albumin precursor), Trypsin (P00760, bovin), Trypsin } \\
\text { (P00761, porcin), Keratin K22E (P35908, human), Keratin } \\
\text { K1C9 (P35527, human), Keratin K2C1 (P04264, human) } \\
\text { and Keratin K1Cl (P35527, human). } \\
\text { Fixed modifications = Carbamidomethyl (C) }\end{array}$ \\
\hline Identification \& quantification & $\begin{array}{l}\text { All default with: Deamidation (NQ) added to the Protein } \\
\text { quantification peptide list. } \\
\text { Experimental design file should be made and selected. }\end{array}$ \\
\hline Misc. & $\begin{array}{l}\text { Match between runs }=\text { Enabled }(2 \mathrm{~min}) \text {, Label-free } \\
\text { quantification }=\text { Enabled }(\mathrm{LFQ} \text { min ratio count }=2) \text {, iBAQ } \\
\text { and Log fit = Enabled. }\end{array}$ \\
\hline
\end{tabular}


Table 4: Filtering and statistics on identified protein groups.

\begin{tabular}{|l|l|}
\hline Software & Perseus \\
the result file. & $\begin{array}{l}\text { Expression: all "LFQ_name" rows, Categorical annotation: } \\
\text { Only identified by site, Reverse, Contaminant, Textual } \\
\text { annotation: Protein IDs, Majority protein IDs, Protein names, } \\
\text { Gene names, Fasta headers, (remove "Proteins"); Numerical } \\
\text { annotation: id, Proteins, Peptides, Unique Peptides, iBAQ } \\
\text { and any other info you may need like: sequence coverage } \\
\text { (\%), Mol. Weight [kDa], Sequence length and/or PEP score. }\end{array}$ \\
\hline Extra Filtering & $\begin{array}{l}\text { Filter out 'Reverse' and 'Only identified by site' proteins. } \\
\text { "Only identified by site" marks those proteins that have been } \\
\text { identified by modified peptides only. } \\
\text { Filter out proteins identified by only 1 peptide or no unique } \\
\text { peptide. }\end{array}$ \\
\hline Logarithmic transformation & Transform the LFQ and iBAQ to its logarithmic values \\
\hline Grouping of samples & Group biological replicate measurements \\
\hline Optional extra Filtering 2 & $\begin{array}{l}\text { Filter out those protein groups that have less than } 2 \text { LFQ } \\
\text { values in at least one group }\end{array}$ \\
\hline Replace NaN's & $\begin{array}{l}\text { Replace/imputate missing values by a constant that is } \\
\text { slightly lower than the lowest (Log) value measured. This is } \\
\text { done to make sensible ratio calculation possible. }\end{array}$ \\
\hline Perform a first T-test with FDR = 0.01 and S $=1$ \\
\hline
\end{tabular}




\section{References}

Albrecht, C., F. Boutrot, C. Segonzac, B. Schwessinger, S. Gimenez-lbanez, D. Chinchilla, J. P. Rathjen, S. C. de Vries and C. Zipfel (2012). "Brassinosteroids inhibit pathogenassociated molecular pattern-triggered immune signaling independent of the receptor kinase BAK1." Proc Natl Acad Sci U S A 109(1): 303-308.

Bücherl, C. A., A. Bader, A. H. Westphal, S. P. Laptenok and J. W. Borst (2014). "FRET-FLIM applications in plant systems." Protoplasma 251(2): 383-394.

Cox, J. and M. Mann (2008). "MaxQuant enables high peptide identification rates, individualized p.p.b.-range mass accuracies and proteome-wide protein quantification." Nat Biotechnol 26(12): 1367-1372.

Cox, J., N. Neuhauser, A. Michalski, R. A. Scheltema, J. V. Olsen and M. Mann (2011). "Andromeda: a peptide search engine integrated into the MaxQuant environment." J Proteome Res 10(4): 1794-1805.

De Rybel, B., B. Möller, S. Yoshida, I. Grabowicz, P. Barbier de Reuille, S. Boeren, R. S. Smith, J. W. Borst and D. Weijers (2013). "A bHLH complex controls embryonic vascular tissue establishment and indeterminate growth in Arabidopsis." Dev Cell 24(4): 426437.

Ferro, E. and L. Trabalzini (2013). "The yeast two-hybrid and related methods as powerful tools to study plant cell signalling." Plant Mol Biol 83(4-5): 287-301.

Rappsilber, J., M. Mann and Y. Ishihama (2007). "Protocol for micro-purification, enrichment, pre-fractionation and storage of peptides for proteomics using StageTips." Nat Protoc 2(8): 1896-1906.

Saiga, S., B. Möller, A. Watanabe-Taneda, M. Abe, D. Weijers and Y. Komeda (2012). "Control of embryonic meristem initiation in Arabidopsis by PHD-finger protein complexes." Development 139(8): 1391-1398.

Smaczniak, C., N. Li, S. Boeren, T. America, W. van Dongen, S. S. Goerdayal, S. de Vries, G. C. Angenent and K. Kaufmann (2012). "Proteomics-based identification of lowabundance signaling and regulatory protein complexes in native plant tissues." Nat Protoc 7(12): 2144-2158.

Zwiewka, M., E. Feraru, B. Moller, I. Hwang, M. I. Feraru, J. Kleine-Vehn, D. Weijers and J. Friml (2011). "The AP-3 adaptor complex is required for vacuolar function in Arabidopsis." Cell Res 21(12): 1711-1722. 



\section{Chapter 4}

\section{(19) \\ A set of domain-specific markers in the Arabidopsis embryo}

Jos R. Wendrich ${ }^{1}$, Barbara K. Möller ${ }^{1,2}$, Borhan Uddin ${ }^{1,3,4}$, Tatyana Radoeva ${ }^{1}$, Annemarie S. Lokerse ${ }^{1}$, Bert De Rybel ${ }^{1,2}$, and Dolf Weijers ${ }^{1 *}$

Modified from: Plant Reproduction. (2015) doi: 10.1007/s00497-015-0266-2

1. Laboratory of Biochemistry, Wageningen University, Dreijenlaan 3, $6703 \mathrm{HA}$ Wageningen, The Netherlands

2. Current address: Department of Plant Systems Biology, VIB and Department of Plant Biotechnology and Bioinformatics, Ghent University, Technologiepark 927, 9052 Gent, Belgium

3. Department of Biochemistry and Molecular Biology, Jahangirnagar University, Dhaka, Savar, Bangladesh

4. Current address: Zentrum für Molekulare Biologie der Universität Heidelberg, Im Neuenheimer Feld 282, 69120, Heidelberg, Germany 



\section{Summary}

Multicellular organisms can be defined by their ability to establish distinct cell identities, and it is therefore of critical importance to distinguish cell types. One step that leads to cell identity specification is activation of unique sets of transcripts. This property is often exploited in order to infer cell identity; the availability of good domain-specific marker lines is, however, poor in the Arabidopsis embryo. Here we describe a novel set of domain-specific marker lines that can be used in Arabidopsis (embryo) research. Based on transcriptomic data we selected 12 genes for expression analysis and according to the observed expression domain during embryogenesis we divided them into four categories (1: ground tissue; 2: root stem cell; 3: shoot apical meristem; 4: post-embryonic). We additionally show the use of two markers from the "stem cell" category in a genetic study, where we use the absence of the markers to infer developmental defects in the monopteros mutant background. Finally, in order to judge whether the established marker lines also play a role in normal development, we generated loss-of-function resources. None of the analyzed T-DNA insertion, artificial microRNA, or misexpression lines showed any apparent phenotypic difference from wild-type, indicating that these genes are not non-redundantly required for development, but also suggesting that marker activation can be considered a true output of the patterning process. This set of domain specific marker lines is therefore a valuable addition to the currently available markers, and will help to move towards a generic set of tissue identity markers. 


\section{Introduction}

The establishment of distinct cell identities is a central property of multicellular organisms, and it is therefore of critical importance to distinguish cell types. Typically, cell identity specification involves the activation (or repression) of a unique set of transcripts, followed by the accumulation of proteins and ultimately by cell differentiation events. Cell identity can be inferred at any of these steps, by transcriptional output, molecular composition or morphology and shape. One of the most widely used markers for intrinsic cell identity is transcriptional output, either by in-situ mRNA hybridization or using promoters of cell type specific genes driving a reporter protein that can be visualized using e.g. fluorescence or histological coloring in transgenic plants. Gene expression markers are very powerful, as their activation is one of the first events in cell specification. However, an intrinsic drawback of using gene expression reporters is that each gene is regulated by an intricate network, and even if a gene's pattern reflects a cell identity, it does not define it. Therefore, one would ideally combine several cell identity markers to infer identity.

The Arabidopsis life cycle starts when an egg cell is fertilized and embryogenesis is initiated. During the process of embryogenesis, cells in the embryo undergo several rounds of division and specification events that establish tissue and cell types de novo. It's these de novo specification events that make embryogenesis into an excellent model for studying several developmental processes, as they can teach us how cell and tissue identity is being established (Wendrich and Weijers, 2013). In addition, all these events happen in a relatively short timespan and occur in a very strict and orderly fashion, which makes it easier to infer underlying processes when development is disturbed. One property of Arabidopsis embryogenesis as a model system is still lagging however, the availability of gene expression markers. Some markers have already been well established (e.g. Aida et al., 2004; De Rybel et al., 2013; Haecker et al., 2004), but the amount of markers available is very limited and surely does not result in a saturation of the different possible regions and cell types.

Here we describe the establishment of a novel set of domain-specific markers in the Arabidopsis embryo. Based on both published (Le et al., 2010; Brady et al., 2007) and our own unpublished transcriptomic data from embryonic and root tissues, we have selected 12 genes for expression analysis. Here we report the expression domains of all of them in several stages of embryonic development and in the post-embryonic primary root, as reported by their putative promoters. In addition, we show their usefulness as marker lines in genetic studies. 


\section{Methods}

\section{Plant material and growth conditions}

T-DNA insertion lines WiscDsLox466B7/spt-11 and WiscDsLox386E06/spt-12 were described in Ichihashi et al., (2010), and obtained from the Nottingham Arabidopsis Stock Centre (NASC), along with SALK_103775, FLAG_399C07, SAIL_318_C07 and SALK_068811. Insertions were genotyped using primers listed in Supplementary Table 1.

All Arabidopsis seeds were surface sterilized and grown on $1 / 2$ MS plates either with or without selective antibiotics in standard long day (16/8 hour light/dark) growth conditions at $22^{\circ} \mathrm{C}$ in a growth room. 14-day-old seedlings were transferred to soil and grown further in the same conditions.

\section{Cloning and plant transformation}

Up to $5 \mathrm{~kb}$ upstream of the start codon was cloned into the pPLV04 or pPLV04_v2 vector using Ligation Independent Cloning (De Rybel et al., 2011; Wendrich et al., 2015) and primers described in Supplementary Table 1.

Knockdown lines using artificial microRNA (amiRNA) were constructed as described by Schwab et al (2006) and complete coding sequences were amplified, using primers defined in Supplementary Table 1. Constructed amiRNAs and coding sequences were cloned into the pPLV028 vector (De Rybel et al., 2011) for broad embryonic expression under the RPS5A promoter (Weijers et al., 2001).

All constructs were confirmed by sequencing and transformed into Col-0 wild-type or mp-B4149 heterozygous (Weijers et al., 2006) Arabidopsis plants by simplified floral dipping (De Rybel et al., 2011).

\section{Microscopy}

\section{Differential Interference Contrast (DIC)}

DIC microscopy was performed on isolated ovules or 6-day-old seedling roots as described previously (Llavata-Peris et al., 2013). Briefly: Samples were cleared in a chloral hydrate solution (chloral hydrate, water and glycerol [8:3:1]) and observed with a Leica DMR microscope equipped with DIC optics.

\section{Confocal Laser Scanning Microscopy (CLSM)}

CLSM was performed as described previously (Llavata-Peris et al., 2013) with some modifications. Briefly: Ovules were isolated and fixed in a $4 \%$ paraformaldehyde / 
5\% glycerol in PBS solution containing 1.5\% SCRI Renaissance Stain 2200 (R2200; Renaissance Chemicals, UK) for counterstaining of embryos. Embryos were popped out of the ovules and R2200 and GFP were visualized by excitation at 405 and 488 $\mathrm{nm}$ and detection between $430-470 \mathrm{~nm}$ and $500-535 \mathrm{~nm}$, respectively. For imaging of roots, 6-day-old seedlings were submerged in water containing 1.5\% FM4-64 (Invitrogen) for 1 to 2 minutes and GFP and FM4-64 were visualized by excitation at $488 \mathrm{~nm}$ and detection between $500-535 \mathrm{~nm}$ and $630-700 \mathrm{~nm}$ respectively. All CLSM was performed on a Leica SP5 system equipped with Hybrid Detector.

\section{Results and discussion}

Selection of genes and establishment of marker lines

Based on both publically available (Le et al., 2010; Brady et al., 2007; Supplementary Figure 1) and our own unpublished transcriptome data, collected from misregulation of known factors involved in development, we selected twelve genes (Table 1) that were expected to show local expression in the early embryo (Supplementary Figure 2). In order to utilize the expression of the selected genes as markers for early embryo development, we cloned the putative promoters, up to $5 \mathrm{~kb}$ upstream of the start codon, to drive the expression of a nuclear localized triple green fluorescent protein (n3GFP) and transformed these into Arabidopsis. The n3GFP has high fluorescence intensity and is concentrated in the cell nucleus, which makes it a good tool for expression analyses in Arabidopsis embryos (Takada and Jürgens, 2007; Rademacher et al., 2011). More than three independent transgenic lines were analyzed for each of the 12 constructs, and we here report the representative patterns observed in the majority of lines. Since gene expression is not always accurately represented by promoter fragments, but may also depend on sequences downstream of the transcriptional start site, we do not consider these lines as representatives of gene expression per se. Rather, we consider these as tools that can act as molecular markers for cell or domain identity, irrespective of gene function. Consequently, although the majority of the lines showed an overlapping expression domain compared to the published transcriptomics data (Supplementary Figures 1 and 2), not all lines show a similar expression pattern as was expected. This shows there can be differences between putative promoter activity and detectable transcripts.

Using confocal microscopy, we found that seven of the markers showed expression of n3GFP during embryo development and the remaining five were expressed only later during post-embryonic root development (Supplementary Figure 3; Table 1). Based on these findings we grouped the genes into four different 


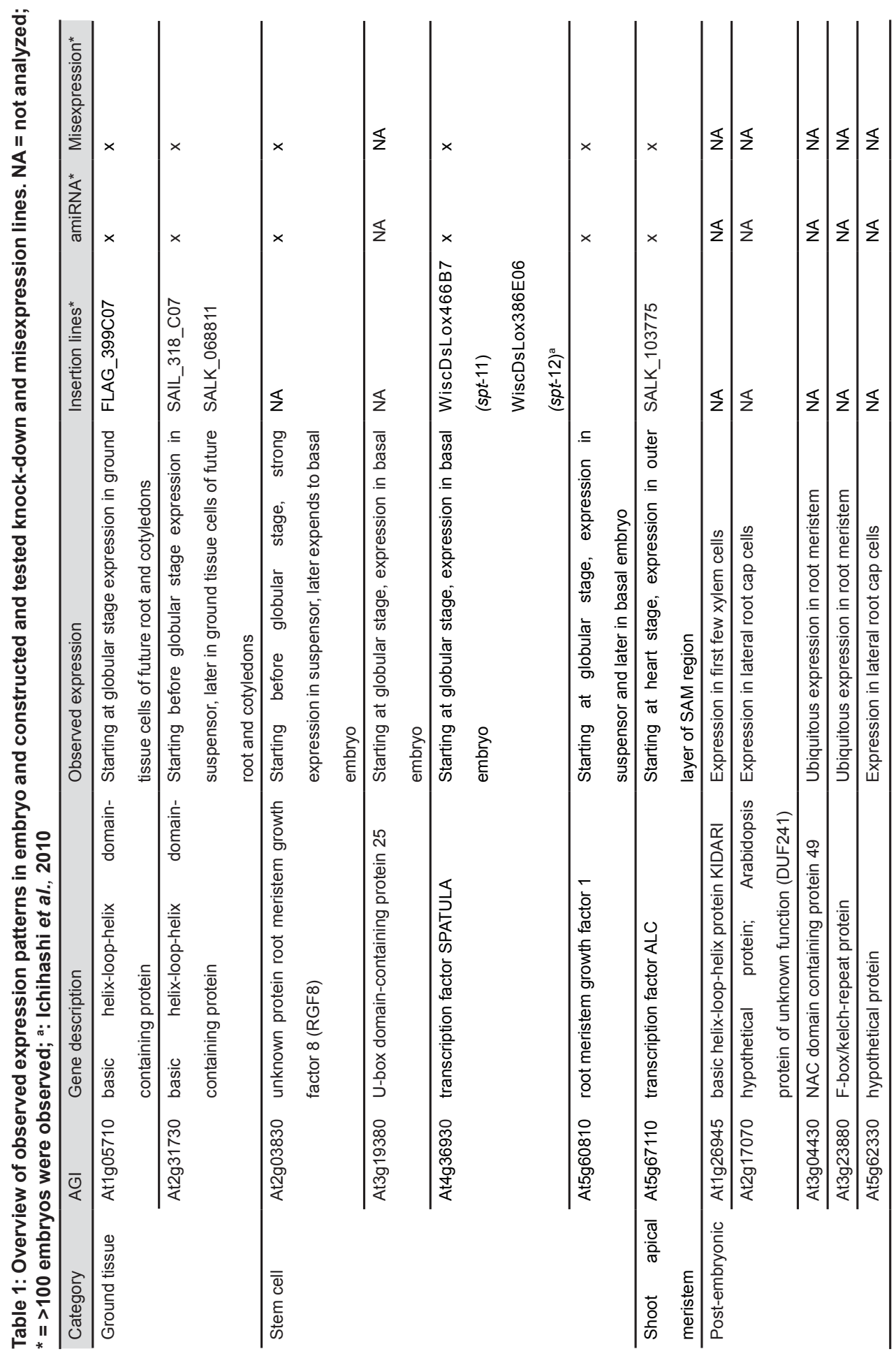


categories, depending on the observed expression pattern in the embryo (1: ground tissue; 2: root stem cell; 3: shoot apical meristem; 4: post-embryonic). Each of the reported patterns is robust, as embryo-to-embryo variation is minimal (Supplementary Figure 4).

\section{Ground tissue lines}

The first category consisted of two genes (At1g05710 and At2g31730), encoding two basic helix-loop-helix (bHLH) transcription factors, that were found expressed (in the case of At2g31730) as early as the 16-cell stage in the suspensor and future hypophysis and later expanded their expression to all cells of the ground tissue (Figure 1). Interestingly, this group of genes is expressed not only in the ground tissue cells of the future root, but also in the ground tissue cells of the hypocotyl and developing cotyledons, i.e. mesophyll precursor cells (Figure 1). In the postembryonic root, these genes showed a similar expression domain as found in embryos, except that weak expression in vascular cells could also be detected (Figure 1). To our knowledge, this is the first demonstration of a "pan-ground tissue" pattern that not only marks endodermis and cortex, but also the mesophyll, in the embryo. This is striking because the ground tissue of root and hypocotyl has a different origin compared to that of the cotyledons. The root and hypocotyl ground tissue derives from 4 precursor cells in the lower half of the pro-embryo that form after periclinal division of the inner cells at 16-cell stage (Yoshida et al., 2014). Indeed, expression of At2g31730 is already detected in this precursor cell (Figure 1). The cotyledon ground

16 cell
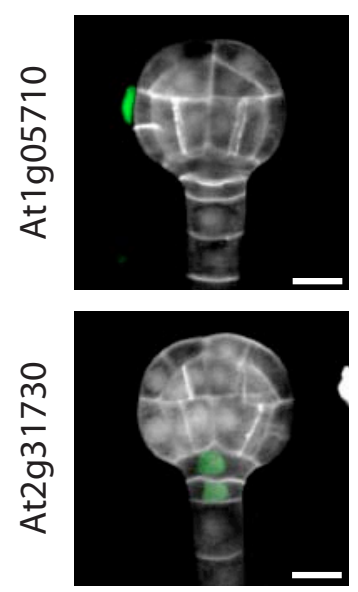

Globular
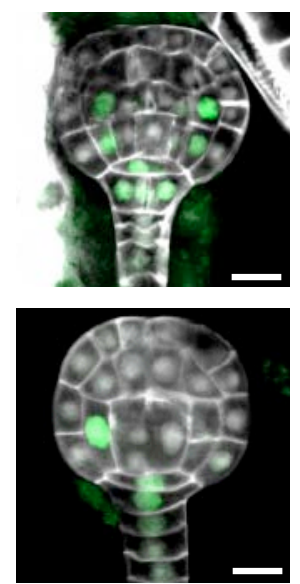

Heart
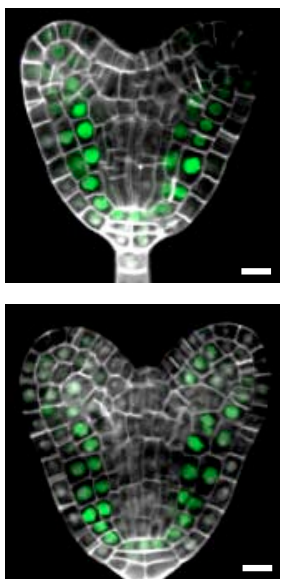

Root
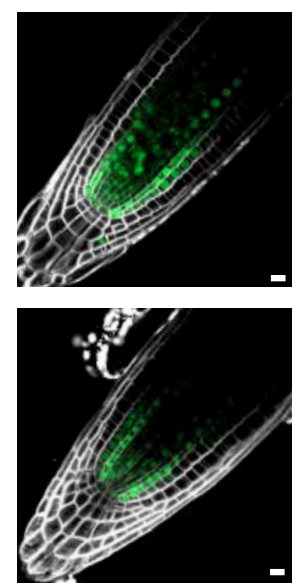

Figure 1: Expression of genes in the ground tissue category, shown in globular and heart stage embryos and in post-embryonic root. Expression was observed in all types of ground tissue cells, i.e. both root and shoot derived. Scale bars $=10 \mu \mathrm{m}$ 
tissue (mesophyll) is instead derived from the upper half of the pro-embryo, in which the ground tissue lineage cannot as easily be predicted. Indeed, no expression of these two ground tissue markers can be detected at globular stage in the upper half of the embryo (Figure 1). Thus, despite having a different ontogeny, the entire ground tissue appears to share expression of at least these two genes. For this reason, we believe that these reporters can serve as generic developing ground tissue markers, which are specific during heart stage embryogenesis.

\section{"Root stem cell" lines}

The second category consisted of four genes (At2g03830, At3g19380, At4g36930, and At5g60810), encoding one bHLH transcription factor (SPATULA [SPT]; At4g36930; Heisler et al., 2001), one PLANT U-BOX domain containing protein (At3g19380), and two peptides (ROOT GROWTH FACTOR1 [RGF1]: At5g60810; RGF8: At2g03830; Matsuzaki et al., 2010), that showed similar expression
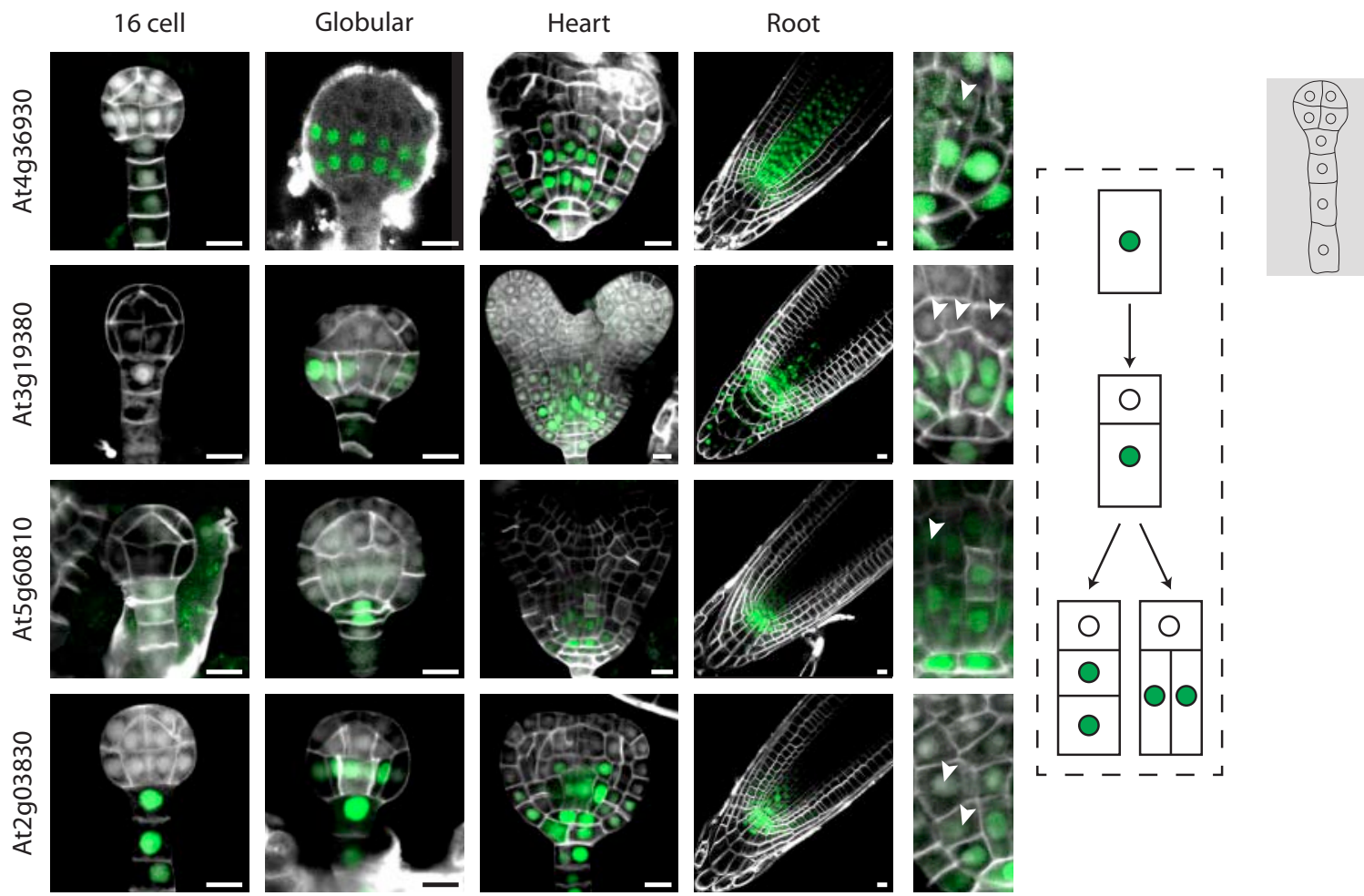

Figure 2: Expression of genes is the "root stem cell" category, shown in 16-cell, globular and heart stage embryos and in post-embryonic root. Expression was observed in the basal part of the embryo, coinciding with the area of stem cells. Arrowheads in the right images indicate loss of expression in daughter cells further displaced from the QC, as is also depicted schematically on the right. Scale bars $=10 \mu \mathrm{m}$ 
patterns, marking the lower half of the globular embryos, and being restricted to a smaller domain of cells surrounding the lens-shaped cell. As the lens-shaped cell is the precursor to the root quiescent center (QC; Scheres et al., 1994), the cells surrounding it are considered stem cells (Bennett and Scheres, 2010). In postembryonic roots, expression of all these 4 genes was found in a zone surrounding the QC, with highest expression directly adjacent to the QC. As the expression of these genes did not appear to be correlated to zones of cell division in general (Burssens et al., 2000; Weijers et al., 2001), nor was there any tissue-specificity, we interpret these genes to mark a property that is related to the stem cells in the root. The moment and location of gene activation of these genes is not identical, nor are the patterns in the root. Nonetheless, these genes share a common pattern at heart stage and collectively mark the youngest cells in the root meristem. Thus, we refer to these genes as potential stem cell markers. An important consideration is that all genes show striking expression dynamics in the basal embryo pole. Upon division, expression is retained in the cells closest to the lens-shaped cell, while it is lost from the daughter that is displaced from the lens-shaped cell (Figure 2). This, to our interpretation, resembles a self-renewal division known for stem cells (Bennett and Scheres, 2010; Wendrich and Weijers, 2013). This implies that genes from this group could be used as markers for the stem cell region during both embryo and root development.

\section{Shoot apical meristem line}

The third category was defined by a single gene, encoding a bHLH transcription factor (ALCATRAZ; At5g67110; Rajani and Sundaresan, 2001) that did not show expression during the earliest steps of embryo development, but whose activity was observed starting around the heart stage of development in the outermost layer of the epidermis (Figure 3). This gene, At5g67110, was specifically expressed in the boundaries between the two cotyledon primordial, but not in the shoot apical meristem. As such, the pattern resembled that of the CUP-SHAPED COTYLEDON (CUC) genes (Aida et al., 1999; Hibara et al., 2003; Vroemen et al., 2003). In the post-embryonic root, expression was observed in the epidermal and lateral root cap layers as well as in differentiating cortex cells (Figure 3). To our knowledge, there is no obvious fate or property common to these three domains (cotyledon boundary, root cap and mature cortex). Hence, this reporter can be used as cotyledon boundary marker in the embryo context, but it should be noted that it does not define this cell type. 


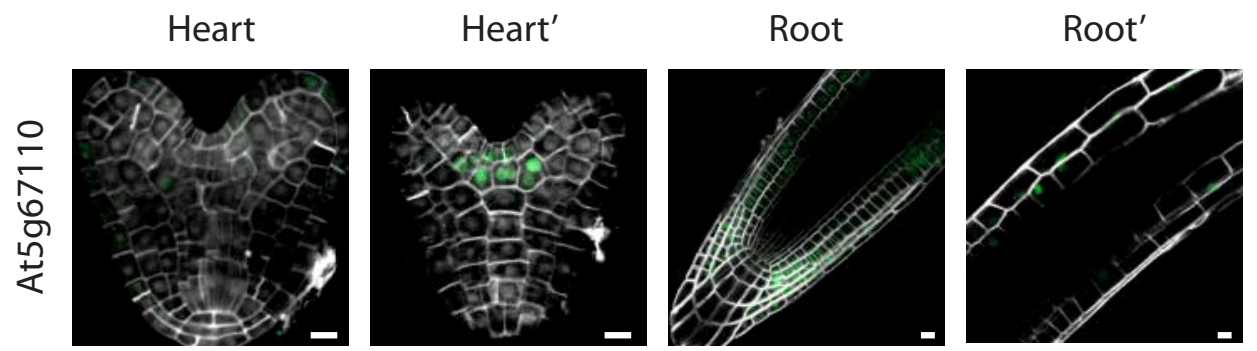

Figure 3: Expression of gene in the apical meristem category, shown in heart stage embryos and in post-embryonic root. Expression was observed in the outermost cell layer at the cotyledon boundary. Scale bars $=10 \mu \mathrm{m}$

\section{Genetic regulation of marker expression}

The purpose of gene expression markers is not only to inform about molecular differences between cells and domains in the wild-type, but importantly also to help interpret mutant defects. We assessed the usefulness of several of the newly established marker lines in genetic studies. For this purpose we used the monopteros mutant ( $m p$; Berleth and Jürgens 1993; Hardtke and Berleth 1998; Weijers et al., 2006), which displays a characteristic rootless phenotype. During embryogenesis, the $m p$ mutant can be identified based on aberrant cell division planes in the hypophysis and the adjacent cells in the pro-embryo (Berleth and Jürgens 1993; Hardtke and Berleth 1998). However, a largely unanswered question is what processes are actually disturbed in the mutant. Individual genes have been shown to be regulated by MP, and consequently are downregulated in the mutant (Schlereth et al., 2010). Yet, these genes are not only expressed in specific patterns in the wild-type, but also themselves required for normal development (De Rybel et al., 2013). Hence, to better understand the developmental role of the MP protein, it will be helpful to analyze the activity of other markers in the mutant. By transformation into a heterozygous $m p$ background, we were able to show that the expression of the two "stem cell" markers At4g36930 and At3g19380 was completely lost in the $m p$ mutant (Figure 4). This finding indicates that 1 ) the markers are under genetic control by a pathway that involves the MP protein, 2) that co-expression of these two genes in wild-type reflects co-regulation by the same pathway, and 3) that MP may control stem cell specification in the Arabidopsis embryo. Loss of PLT1 and PLT2 expression in the mp/arf5 nph4/arf7 double mutant (Aida et al., 2002) had previously suggested that MP is required for aspects of meristem formation. We believe that the loss of expression of these two entirely unrelated genes in the $m p$ mutant lends support to the idea that $m p$ has a significant stem cell specification defect. Especially the latter suggestion could not previously be made due to the absence of markers. 


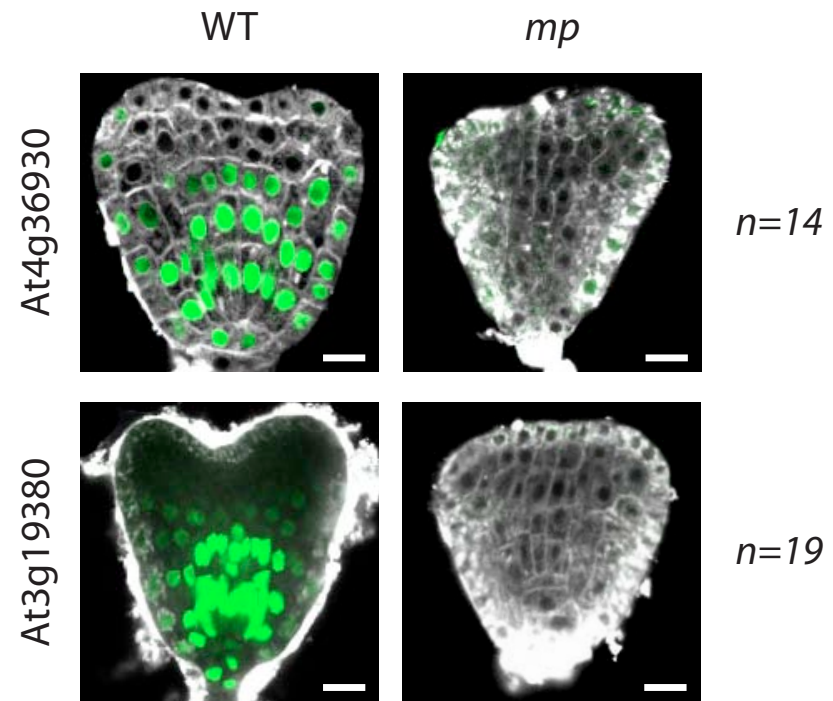

Figure 4: Expression of two genes from the "root stem cell" category in wild-type and in $m p$ background, shown in heart stage embryos. Expression was observed as described before in wild-type, though expression was completely lost in the $m p$ mutant, indicating stem cell specification defects in $m p$. Scale bars $=10 \mu \mathrm{m}$

\section{Gene function of marker lines}

Finally, in order to judge whether the marker lines generated here are only activated as part of the cell/domain specification process, or whether they play an important role in the specification process, we generated loss-of-function resources. We analyzed several T-DNA insertion lines and additionally generated artificial microRNA and misexpression lines (Table 1). No apparent phenotypic difference compared to wildtype was found in any of the analyzed lines, indicating that disruption of expression of these genes does not affect development. While this result demonstrates that none of the genes reflected by the markers is non-redundantly required for normal development, it also suggest that marker activation can be considered a true output of the patterning process. This renders these lines useful proxies for determining cell/domain identity during embryo development.

\section{Conclusion}

In an effort to increase the number of useful cell/domain markers, we have generated a set of marker lines that can be used for (genetic) studies in Arabidopsis embryos. We show four different categories of markers, based on their expression in the 
Arabidopsis embryo: 1: ground tissue; 2: stem cell; 3: shoot apical meristem; 4: post-embryonic. While some of these mark previously described domains (stem cell region, cotyledon boundaries), others mark a novel domain. Good examples are the two ground tissue markers that can be considered pan-ground-tissue markers. These do not only mark both endodermis and cortex, but are also active in the entire ground tissue domain of future cotyledon, hypocotyl and root. The activity of these markers identifies a convergent molecular signature in ground tissue with different cellular ontogeny, and can help to better understand the mechanisms of ground tissue specification.

We used two of the stem cell markers to show that the rootless phenotype displayed by the $m p$ mutant is accompanied by a lack of activation of "stem cell" markers in the basal region of the embryo, which is likely a consequence of the aberrant divisions in early stages of development. Analysis of several lines including multiple strategies for expression disruption, showed no phenotypic alterations during embryo development, supporting the usefulness of these marker lines as output reporters in a developmental context. This set of marker lines is a valuable addition to the currently available set of markers, as it will help to move away from regulation on single genes towards a more generic set of tissue identity markers.

\section{Author contributions}

JRW, BKM, BU, TR, AL and BDR constructed and analyzed promoter reporter lines, JRW and BU constructed and analyzed misexpression and amiRNA lines and analyzed T-DNA insertion lines, BKM and JRW analyzed expression in mutant background, DW conceived the research and JRW and DW wrote the paper with input from all other authors.

\section{Acknowledgements}

The authors would like to acknowledge the MicroSpectroscopy Centre Wageningen for technical support with microscopy. The research was funded by grants from the European Research Council (CELLPATTERN; Contract number 281573), and the Netherlands Organization for Scientific Research (NWO; ALW-VIDI 864.06.012; ALW Open Competition grant 816.02.014; NWO-NSFC grant 846.11.001) to D.W. and from FEBS and Marie Curie (long-term FP7 Intra-European Fellowship IEF2009-252503) to B.D.R. 


\section{References}

Aida, M., D. Beis, R. Heidstra, V. Willemsen, I. Blilou, C. Galinha, L. Nussaume, Y. S. Noh, R. Amasino and B. Scheres (2004). "The PLETHORA genes mediate patterning of the Arabidopsis root stem cell niche." Cell 119(1): 109-120.

Aida, M., T. Ishida and M. Tasaka (1999). "Shoot apical meristem and cotyledon formation during Arabidopsis embryogenesis: interaction among the CUP-SHAPED COTYLEDON and SHOOT MERISTEMLESS genes." Development 126(8): 1563-1570.

Aida, M., T. Vernoux, M. Furutani, J. Traas and M. Tasaka (2002). "Roles of PIN-FORMED1 and MONOPTEROS in pattern formation of the apical region of the Arabidopsis embryo." Development 129(17): 3965-3974.

Bennett, T. and B. Scheres (2010). "Root development-two meristems for the price of one?" Curr Top Dev Biol 91: 67-102.

Berleth, T. and G. Jurgens (1993). "The role of the monopteros gene in organising the basal body region of the Arabidopsis embryo." Development 118(2): 575-587.

Brady, S. M., D. A. Orlando, J. Y. Lee, J. Y. Wang, J. Koch, J. R. Dinneny, D. Mace, U. Ohler and P. N. Benfey (2007). "A high-resolution root spatiotemporal map reveals dominant expression patterns." Science 318(5851): 801-806.

Burssens, S., J. de Almeida Engler, T. Beeckman, C. Richard, O. Shaul, P. Ferreira, M. Van Montagu and D. Inze (2000). "Developmental expression of the Arabidopsis thaliana CycA2;1 gene." Planta 211(5): 623-631.

De Rybel, B., B. Möller, S. Yoshida, I. Grabowicz, P. Barbier de Reuille, S. Boeren, R. S. Smith, J. W. Borst and D. Weijers (2013). "A bHLH complex controls embryonic vascular tissue establishment and indeterminate growth in Arabidopsis." Dev Cell 24(4): 426437.

De Rybel, B., W. van den Berg, A. Lokerse, C. Y. Liao, H. van Mourik, B. Moller, C. L. Peris and D. Weijers (2011). "A versatile set of ligation-independent cloning vectors for functional studies in plants." Plant Physiol 156(3): 1292-1299.

Haecker, A., R. Gross-Hardt, B. Geiges, A. Sarkar, H. Breuninger, M. Herrmann and T. Laux (2004). "Expression dynamics of WOX genes mark cell fate decisions during early embryonic patterning in Arabidopsis thaliana." Development 131(3): 657-668.

Hardtke, C. S. and T. Berleth (1998). "The Arabidopsis gene MONOPTEROS encodes a transcription factor mediating embryo axis formation and vascular development." EMBO J 17(5): 1405-1411.

Heisler, M. G., A. Atkinson, Y. H. Bylstra, R. Walsh and D. R. Smyth (2001). "SPATULA, a gene that controls development of carpel margin tissues in Arabidopsis, encodes a bHLH protein." Development 128(7): 1089-1098.

Hibara, K., S. Takada and M. Tasaka (2003). "CUC1 gene activates the expression of SAMrelated genes to induce adventitious shoot formation." Plant J 36(5): 687-696.

Hyun, Y. and I. Lee (2006). "KIDARI, encoding a non-DNA Binding bHLH protein, represses light signal transduction in Arabidopsis thaliana." Plant Mol Biol 61(1-2): 283-296.

Ichihashi, Y., G. Horiguchi, S. Gleissberg and H. Tsukaya (2010). "The bHLH transcription factor SPATULA controls final leaf size in Arabidopsis thaliana." Plant Cell Physiol 51(2): 252-261.

Le, B. H., C. Cheng, A. Q. Bui, J. A. Wagmaister, K. F. Henry, J. Pelletier, L. Kwong, M. Belmonte, R. Kirkbride, S. Horvath, G. N. Drews, R. L. Fischer, J. K. Okamuro, J. J. Harada and R. B. Goldberg (2010). "Global analysis of gene activity during Arabidopsis seed development and identification of seed-specific transcription factors." Proc Natl Acad Sci U S A 107(18): 8063-8070.

Llavata-Peris, C., A. Lokerse, B. Moller, B. De Rybel and D. Weijers (2013). "Imaging of 
phenotypes, gene expression, and protein localization during embryonic root formation in Arabidopsis." Methods Mol Biol 959: 137-148.

Matsuzaki, Y., M. Ogawa-Ohnishi, A. Mori and Y. Matsubayashi (2010). "Secreted peptide signals required for maintenance of root stem cell niche in Arabidopsis." Science 329(5995): 1065-1067.

Ooka, H., K. Satoh, K. Doi, T. Nagata, Y. Otomo, K. Murakami, K. Matsubara, N. Osato, J. Kawai, P. Carninci, Y. Hayashizaki, K. Suzuki, K. Kojima, Y. Takahara, K. Yamamoto and S. Kikuchi (2003). "Comprehensive analysis of NAC family genes in Oryza sativa and Arabidopsis thaliana." DNA Res 10(6): 239-247.

Rademacher, E. H., B. Moller, A. S. Lokerse, C. I. Llavata-Peris, W. van den Berg and D. Weijers (2011). "A cellular expression map of the Arabidopsis AUXIN RESPONSE FACTOR gene family." Plant J 68(4): 597-606.

Rajani, S. and V. Sundaresan (2001). "The Arabidopsis myc/bHLH gene ALCATRAZ enables cell separation in fruit dehiscence." Curr Biol 11(24): 1914-1922.

Scheres, B., H. Wolkenfelt, V. Willemsen, M. Terlouw, E. Lawson, C. Dean and P. Weisbeek (1994). "Embryonic origin of the Arabidopsis primary root and root meristem initials." Development 120(9): 2475-2487.

Schlereth, A., B. Moller, W. Liu, M. Kientz, J. Flipse, E. H. Rademacher, M. Schmid, G. Jurgens and D. Weijers (2010). "MONOPTEROS controls embryonic root initiation by regulating a mobile transcription factor." Nature 464(7290): 913-916.

Schwab, R., S. Ossowski, M. Riester, N. Warthmann and D. Weigel (2006). "Highly specific gene silencing by artificial microRNAs in Arabidopsis." Plant Cell 18(5): 1121-1133.

Takada, S. and G. Jürgens (2007). "Transcriptional regulation of epidermal cell fate in the Arabidopsis embryo." Development 134(6): 1141-1150.

Vroemen, C. W., A. P. Mordhorst, C. Albrecht, M. A. Kwaaitaal and S. C. de Vries (2003). "The CUP-SHAPED COTYLEDON3 gene is required for boundary and shoot meristem formation in Arabidopsis." Plant Cell 15(7): 1563-1577.

Weijers, D., M. Franke-van Dijk, R. J. Vencken, A. Quint, P. Hooykaas and R. Offringa (2001). "An Arabidopsis Minute-like phenotype caused by a semi-dominant mutation in a RIBOSOMAL PROTEIN S5 gene." Development 128(21): 4289-4299.

Weijers, D., A. Schlereth, J. S. Ehrismann, G. Schwank, M. Kientz and G. Jurgens (2006). "Auxin triggers transient local signaling for cell specification in Arabidopsis embryogenesis." Dev Cell 10(2): 265-270.

Wendrich, J. R., C. Y. Liao, W. A. van den Berg, B. De Rybel and D. Weijers (2015). "Ligationindependent cloning for plant research." Methods Mol Biol 1284: 421-431.

Wendrich, J. R. and D. Weijers (2013). "The Arabidopsis embryo as a miniature morphogenesis model." New Phytol 199(1): 14-25.

Winter, D., B. Vinegar, H. Nahal, R. Ammar, G. V. Wilson and N. J. Provart (2007). "An "Electronic Fluorescent Pictograph" browser for exploring and analyzing large-scale biological data sets." PLoS One 2(8): e718.

Yoshida, S., P. Barbier de Reuille, B. Lane, G. W. Bassel, P. Prusinkiewicz, R. S. Smith and D. Weijers (2014). "Genetic control of plant development by overriding a geometric division rule." Dev Cell 29(1): 75-87. 


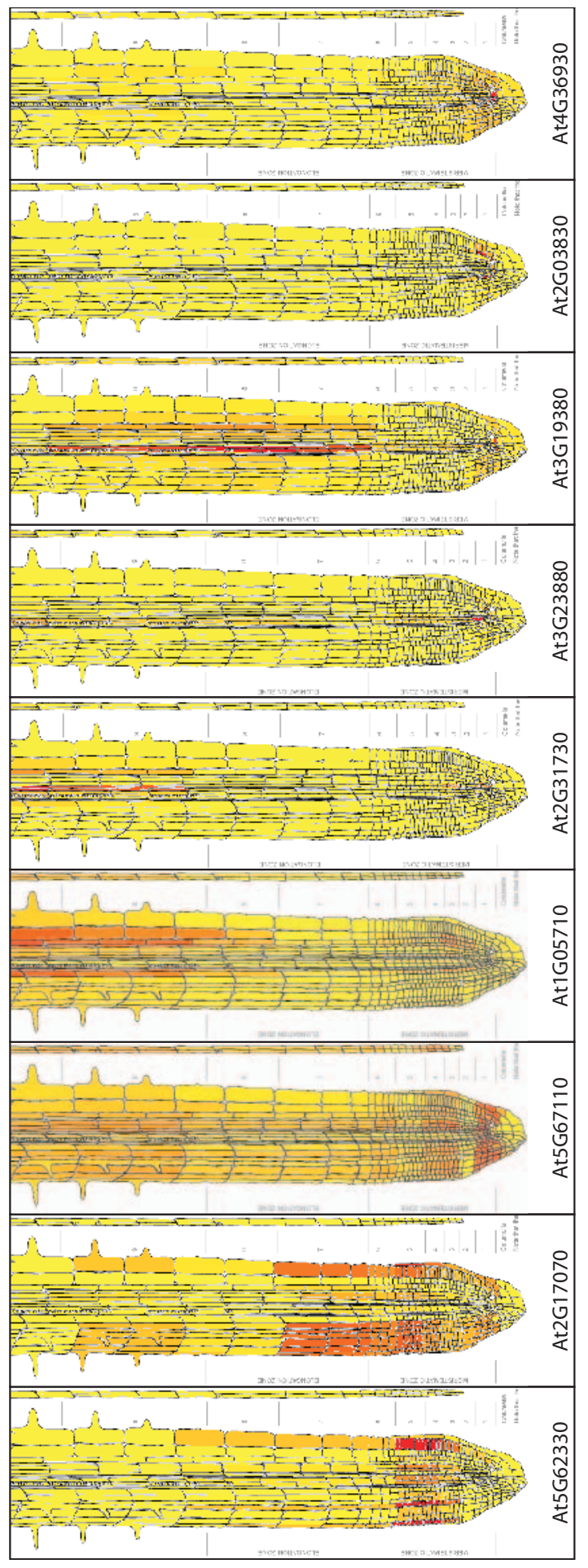




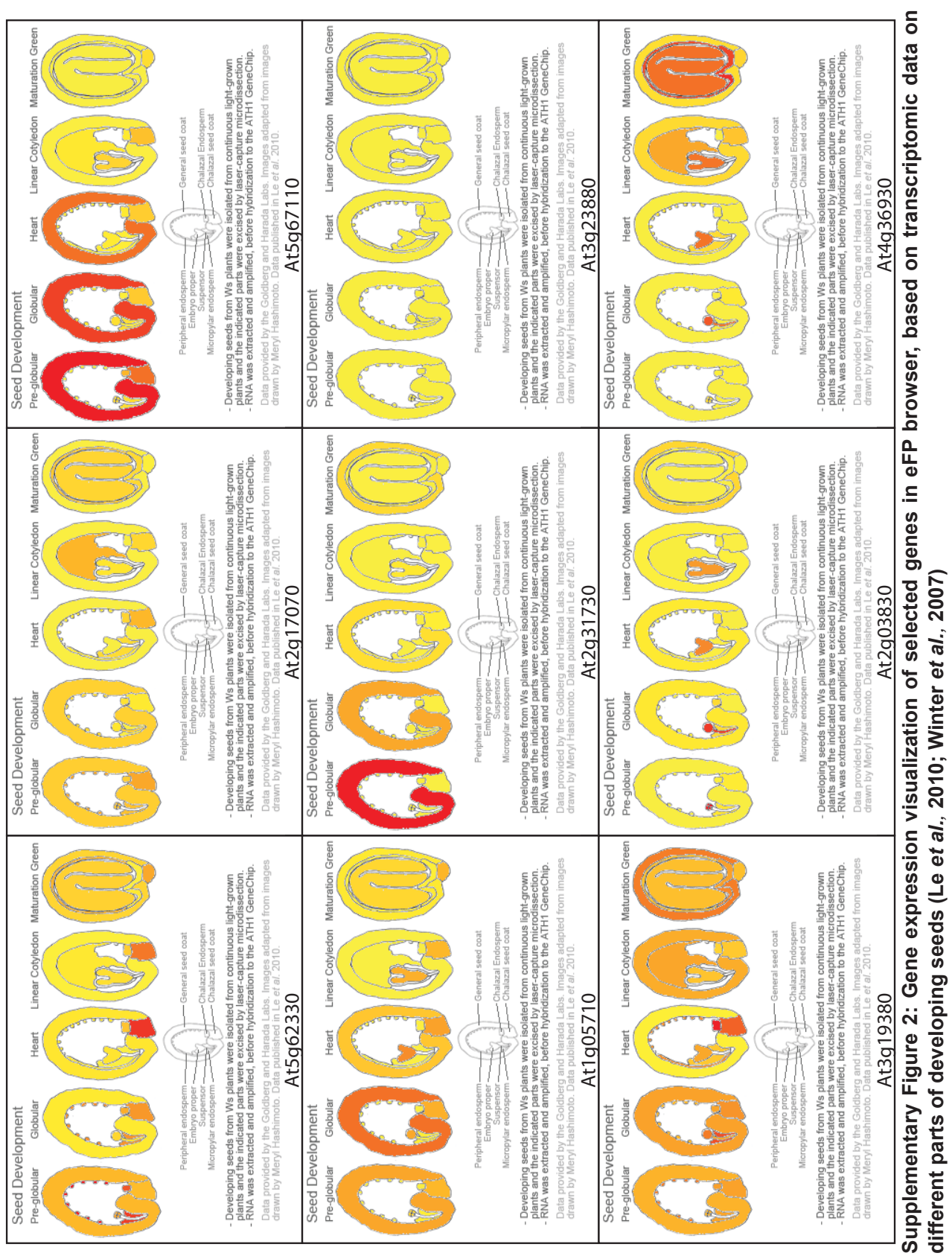



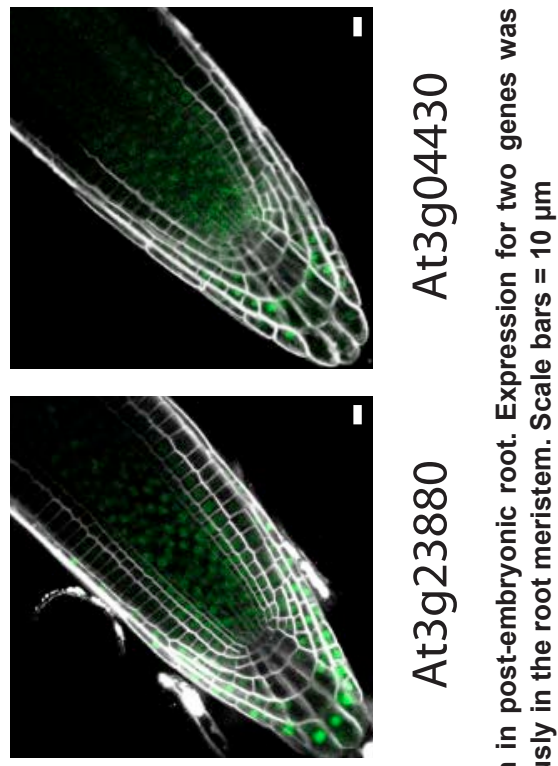

$\circ$ 은

$\infty$ :

m

ชู 흥

艺
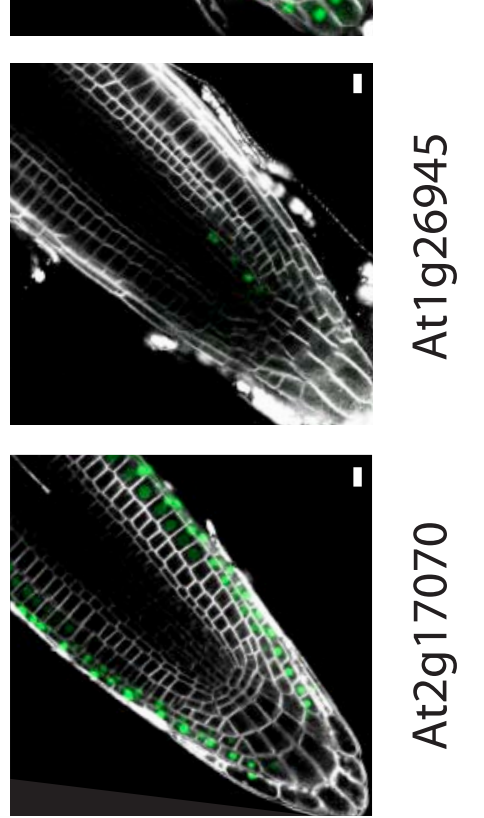

。

응

요원

웡

의

艺

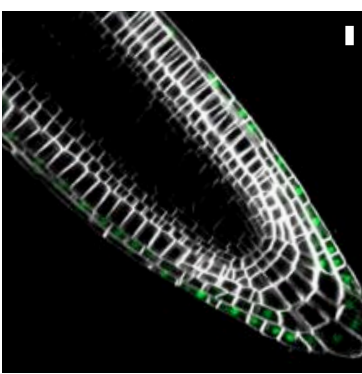

‥

즐

ํํำ

$\frac{5}{w} . \frac{7}{2}$

극

웡

등

을

궁ㅎํ

ํㅠ 음

으

¿

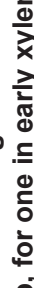

흥 웛

这范

लं 인

m 는

$m$ 흐는

(1) 종

ชา 売

는 웛

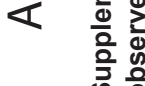



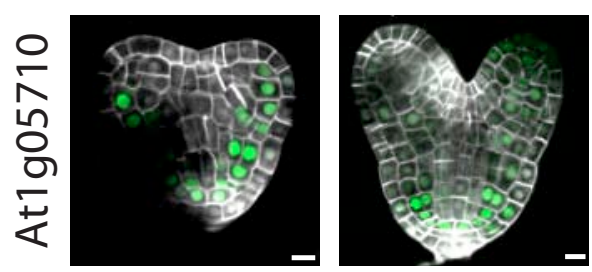

Supplementary Figure 4: Expression of all embryoexpressing lines in wild-type heart stage embryos, shown in different individuals. This indicates the robustness of observed expression patterns. Scale bars $=10 \mu \mathrm{m}$
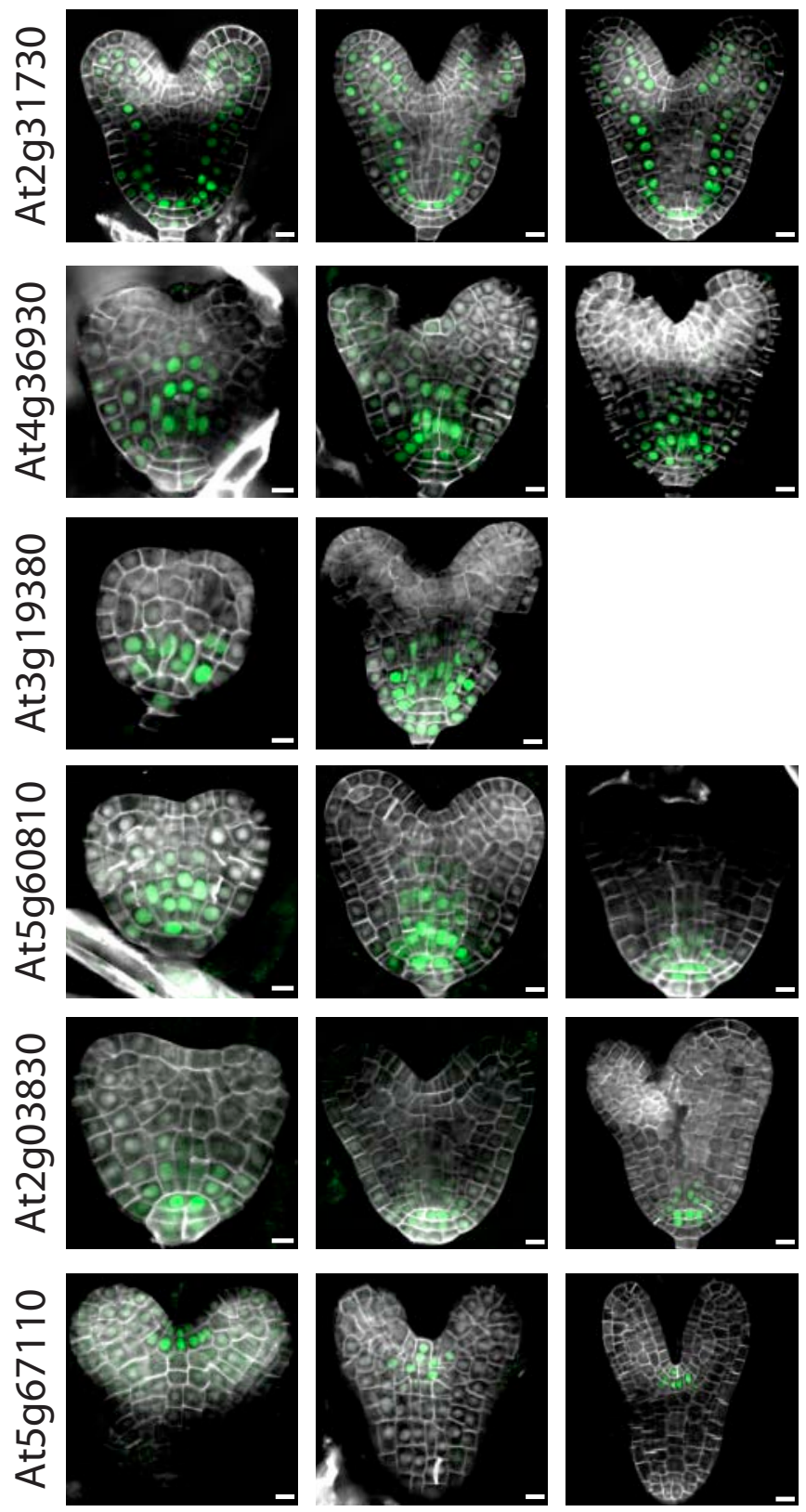
Supplementary Table 1: List of oligonucleotides used in this study

\begin{tabular}{|c|c|c|}
\hline Gene/line & Type & Sequence \\
\hline AT4G36930 & For & 5'- TAGTTGGAATGGGTTCGAAGATTAAAATTAGTAACACTGATTAGGC -3' \\
\hline AT4G36930 & $\operatorname{Rev}$ & 5'- TTATGGAGTTGGGTTCGAATACACCAACAACAAAAAAAAAGC -3' \\
\hline AT5G67110 & For & 5'- TAGTTGGAATGGGTTCGAAGTTTTATCAAGTTTGAAAGATTCCG -3' \\
\hline AT5G67110 & Rev & 5'- TTATGGAGTTGGGTTCGAACTCTCTCTCTCTCTCTCTCTCTGC -3' \\
\hline AT1G05710 & For & 5'- TAGTTGGAATGGGTTCGAACGCAAAGGGTGTAGAATAAGTCAAGG -3' \\
\hline AT1G05710 & Rev & 5'- TTATGGAGTTGGGTTCGAAACCTTTTGTCAATAAGAAATGCGC -3' \\
\hline AT2G31730 & For & 5'- TAGTTGGAATGGGTTCGAACGTTTTAAAAAGACGTGTGAG -3' \\
\hline AT2G31730 & Rev & 5'- TTATGGAGTTGGGTTCGAATCCTTGTCATCAAACAAAACAAAAATG -3' \\
\hline AT5G60810 & For & 5'- TAGTTGGAATGGGTTCGAACCGCTGATTCACGCTAATG -3' \\
\hline AT5G60810 & Rev & 5'- TTATGGAGTTGGGTTCGAACTCGCCTTCCTTTTTTCTCC -3' \\
\hline AT2G03830 & For & 5'- TAGTTGGAATGGGTTCGAAGCTTCAAGTTGTTATAATCGCAAG -3' \\
\hline AT2G03830 & Rev & 5'- TTATGGAGTTGGGTTCGAAATTCTTCAAAGTGATTTTTAGCTATATG -3' \\
\hline AT3G19380 & For & 5'- TAGTTGGAATGGGTTCGAATAAATAGAGACTATTTTCAT -3' \\
\hline AT3G19380 & $\operatorname{Rev}$ & 5'- TTATGGAGTTGGGTTCGAATAAGAAACTTGAGAAACAGA -3' \\
\hline AT3G04430 & For & 5'- TAGTTGGAATGGGTTCGAAAGATGCGTTGTATTTGCCAGG -3' \\
\hline AT3G04430 & Rev & 5'- TTATGGAGTTGGGTTCGAACTCTATTAGCTGAGAGAGACG -3' \\
\hline AT1G26945 & For & 5'- TAGTTGGAATGGGTTCGAAGGCAAATAAATAAAGTATTCAGAAG -3' \\
\hline \multirow[t]{2}{*}{ AT1G26945 } & Rev & 5'- $\quad$ TTATGGAGTTGGGTTCGAACTTCTTTCTTGATATATTATAAGTGTGTTT- \\
\hline & & GTTTGGG -3' \\
\hline AT3G23880 & For & 5'- TAGTTGGAATGGGTTCGAACAAAAAATAATAACAGCCAACC -3' \\
\hline AT3G23880 & $\operatorname{Rev}$ & 5'- TTATGGAGTTGGGTTCGAAGAGCCAGAGCAGAGGAACCAATAG -3' \\
\hline AT5G62330 & For & 5'- TAGTTGGAATGGGTTCGAATGACTACTAATATGTATGGA -3' \\
\hline AT5G62330 & Rev & 5'- TTATGGAGTTGGGTTCGAATGTTTTGTCATGATTGTTGT -3' \\
\hline AT2G17070 & For & 5'- TAGTTGGAATGGGTTCGAATGCCTACAAATTTTGTAGAG -3' \\
\hline AT2G17070 & Rev & 5'- TTATGGAGTTGGGTTCGAATTTTATTGATATTAGACTCT -3' \\
\hline
\end{tabular}

Insertion lines

\begin{tabular}{|lll|}
\hline Gene/line & Type & Sequence \\
\hline WiscDsLox466B7 & For & 5'- TTAGTGTGTCTCACGTGCGACGAGG -3' \\
WiscDsLox466B7 & Rev & 5'- GGAAGAGGGAGCTTCATCAACTACAGC -3' \\
WiscDsLox386E06 & For & 5'- CGGAGATTTCTCTGAGGTTTTAATCG -3' \\
WiscDsLox386E06 & Rev & 5'- GAGGGAAAGGTCCAAAGTGACTGCG -3' \\
SALK_103775.20.25.x & For & 5'-CTTGGTGGTCCAAAAATGCTTTTTTCC -3' \\
\hline
\end{tabular}




\begin{tabular}{|lll|}
\hline \multicolumn{3}{l}{ Supplementary Table 1: Continued } \\
SALK_103775.20.25.x & Rev & 5'- CGGCTAAAGTCTGCATCATGCAG -3' \\
FLAG_399C07 & For & 5'- GATGGAGAATAAGCGGAATGTCTGC -3' \\
FLAG_399C07 & Rev & 5'- GGGAAATCCACGATCATACCTTCAGC -3' \\
SAIL_318_C07 & For & 5'-CAGAAGTTGCTCAAACCAATGGTGC -3' \\
SAIL_318_C07 & Rev & 5'- CTGTTGAGATTTGACAACGGGAACAC -3' \\
SALK_068811.52.05.x & For & 5'-CGTTTACTTGGATCACAATGCAAGAC -3' \\
SALK_068811.52.05.x & Rev & 5'-CGAGACACGCCTACTTATCGAATATC -3' \\
\hline
\end{tabular}

amiRNA

\begin{tabular}{|c|c|c|}
\hline Gene/line & Type & Sequence \\
\hline amiRNA general & A & 5'- TAGTTGGAATAGGTTCCTGCAAGGCGATTAAGTTGGGTAAC -3' \\
\hline amiRNA general & $\mathrm{B}$ & 5'- AGTATGGAGTTGGGTTCGCGGATAACAATTTCACACAGGAAACAG -3' \\
\hline AT4G36930 & 1 & 5'- GATTGGATGAGTTAACGCACCTTTCTCTCTTTTGTATTCC -3' \\
\hline AT4G36930 & II & 5'- GAAAGGTGCGTTAACTCATCCAATCAAAGAGAATCAATGA -3' \\
\hline AT4G36930 & III & 5'- GAAAAGTGCGTTAACACATCCATTCACAGGTCGTGATATG -3' \\
\hline AT4G36930 & IV & 5'- GAATGGATGTGTTAACGCACTTTTCTACATATATATTCCT -3' \\
\hline AT5G67110 & 1 & 5'- GATTTCATAACGGCTAAAGCCTGTCTCTCTTTTGTATTCC -3' \\
\hline AT5G67110 & II & 5'- GACAGGCTTTAGCCGTTATGAAATCAAAGAGAATCAATGA -3' \\
\hline AT5G67110 & III & 5'- GACAAGCTTTAGCCGATATGAATTCACAGGTCGTGATATG -3' \\
\hline AT5G67110 & IV & 5'- GAATTCATATCGGCTAAAGCTTGTCTACATATATATTCCT -3' \\
\hline AT1G05710 & 1 & 5'- GATTAGAGCAAATTACGGACCCGTCTCTCTTTTGTATTCC -3' \\
\hline AT1G05710 & II & 5'- GACGGGTCCGTAATTTGCTCTAATCAAAGAGAATCAATGA -3' \\
\hline AT1G05710 & III & 5'- GACGAGTCCGTAATTAGCTCTATTCACAGGTCGTGATATG -3' \\
\hline AT1G05710 & IV & 5'- GAATAGAGCTAATTACGGACTCGTCTACATATATATTCCT -3' \\
\hline AT2G31730 & I & 5'- GATAATGGGTATTTATGCCACCCTCTCTCTTTTGTATTCC -3' \\
\hline AT2G31730 & II & 5'- GAGGGTGGCATAAATACCCATTATCAAAGAGAATCAATGA -3' \\
\hline AT2G31730 & III & 5'- GAGGATGGCATAAATTCCCATTTTCACAGGTCGTGATATG -3' \\
\hline AT2G31730 & IV & 5'- GAAAATGGGAATTTATGCCATCCTCTACATATATATTCCT -3' \\
\hline AT5G60810 & la & 5'- GATTATAATCGGCAGTTAACCTCTCTCTCTTTTGTATTCC -3' \\
\hline AT5G60810 & lia & 5'- GAGAGGTTAACTGCCGATTATAATCAAAGAGAATCAATGA -3' \\
\hline AT5G60810 & IIla & 5'- GAGAAGTTAACTGCCCATTATATTCACAGGTCGTGATATG -3' \\
\hline AT5G60810 & IVa & 5'- GAATATAATGGGCAGTTAACTTCTCTACATATATATTCCT -3' \\
\hline AT5G60810 & $\mathrm{lb}$ & 5'- GATAATAACCCTTATGGACGCAATCTCTCTTTTGTATTCC -3' \\
\hline AT5G60810 & lib & 5'- GATTGCGTCCATAAGGGTTATTATCAAAGAGAATCAATGA -3' \\
\hline AT5G60810 & IIlb & 5'- GATTACGTCCATAAGCGTTATTTTCACAGGTCGTGATATG -3' \\
\hline
\end{tabular}




\begin{tabular}{|c|c|c|}
\hline \multicolumn{3}{|c|}{ Supplementary Table 1: Continued } \\
\hline AT5G60810 & $\mathrm{IVb}$ & 5'- GAAAATAACGCTTATGGACGTAATCTACATATATATTCCT -3' \\
\hline AT2G03830 & la & 5'- GATCAATAAAATGGCTAGCGCACTCTCTCTTTTGTATTCC -3' \\
\hline AT2G03830 & lia & 5'- GAGTGCGCTAGCCATTTTATTGATCAAAGAGAATCAATGA -3' \\
\hline AT2G03830 & IIla & 5'- GAGTACGCTAGCCATATTATTGTTCACAGGTCGTGATATG -3' \\
\hline AT2G03830 & IVa & 5'- GAACAATAATATGGCTAGCGTACTCTACATATATATTCCT -3' \\
\hline AT2G03830 & $\mathrm{lb}$ & 5'- GATACTAAACTACGTTACTACCATCTCTCTTTTGTATTCC -3' \\
\hline AT2G03830 & lib & 5'- GATGGTAGTAACGTAGTTTAGTATCAAAGAGAATCAATGA -3' \\
\hline AT2G03830 & IIIb & 5'- GATGATAGTAACGTACTTTAGTTTCACAGGTCGTGATATG -3' \\
\hline AT2G03830 & $\mathrm{IVb}$ & 5'- GAAACTAAAGTACGTTACTATCATCTACATATATATTCCT -3' \\
\hline
\end{tabular}

Coding sequence

\begin{tabular}{|c|c|c|}
\hline Gene/line & Type & Sequence \\
\hline AT4G36930 & For & 5'- TAGTTGGAATAGGTTCATGATATCACAGAGAGAAGAAAGAG -3' \\
\hline AT4G36930 & Rev & 5'- AGTATGGAGTTGGGTTCtcaagtaattcgatcttttaggtc -3' \\
\hline AT5G67110 & For & 5'- TAGTTGGAATAGGTTCATGGGTGATTCTGACGTCGGTGATCG -3' \\
\hline AT5G67110 & Rev & 5'- AGTATGGAGTTGGGTTCTCAAAGCAGAGTGGCTGTGGAAAAGC -3' \\
\hline AT1G05710 & For & 5'- TAGTTGGAATAGGTTCATGGAATTCTCTAGAGACGCTGGAATG -3' \\
\hline AT1G05710 & Rev & 5'- AGTATGGAGTTGGGTTCTCATCTAAAGGGTGATTGAGATGTG -3' \\
\hline AT2G31730 & For & 5'- TAGTTGGAATAGGTTCATGGAATACTCTAGAGACTCGGCAG -3' \\
\hline AT2G31730 & Rev & 5'- AGTATGGAGTTGGGTTCTCATTGAAAGGGCGAATTAGAAGACG -3' \\
\hline AT5G60810 & For & 5'- TAGTTGGAATAGGTTCATGGTGTCCATAAGGGTTATTTG -3' \\
\hline AT5G60810 & $\operatorname{Rev}$ & 5'- AGTATGGAGTTGGGTTCTTAGTTATGCCTAGGAGGATGATG -3' \\
\hline AT2G03830 & For & 5'- TAGTTGGAATAGGTTCATGAAGCTAATTAGAGTCACCCTCT -3' \\
\hline AT2G03830 & Rev & 5'- AGTATGGAGTTGGGTTCTCATGGATCAAGAGGTAAAGCC -3' \\
\hline
\end{tabular}





\section{Chapter 5}

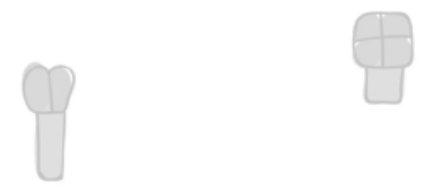

\section{IQ-domain proteins connect auxin and calcium signaling during Arabidopsis development}

Jos R. Wendrich ${ }^{1}$, Pieter Mijnhout ${ }^{1}$, Bert De Rybel ${ }^{1,2}$ and Dolf Weijers ${ }^{1}$
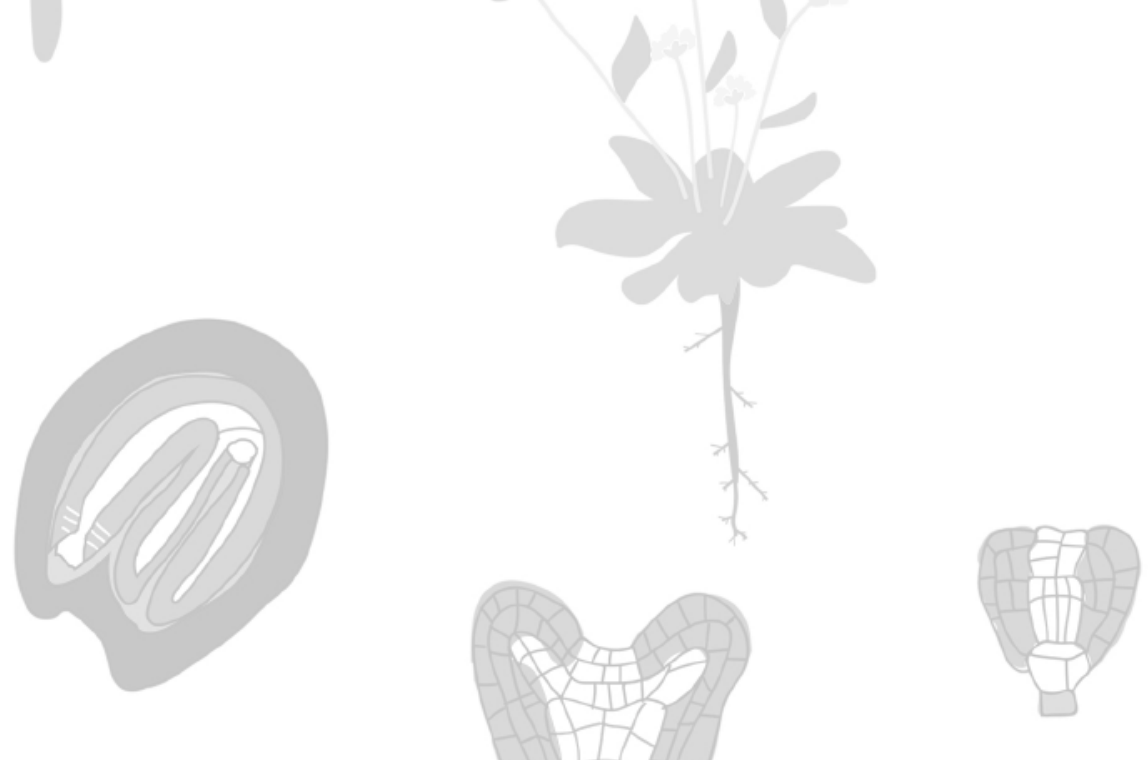

1. Laboratory of Biochemistry, Wageningen University, Dreijenlaan 3, $6703 \mathrm{HA}$ Wageningen, the Netherlands

2. Department of Plant Systems Biology, VIB, and Department of PlantBiotechnology and Bioinformatics, Ghent University, 9052 Ghent, Belgium 



\section{Summary}

Plant development follows a highly coordinated route and many of its processes are controlled by the phytohormone auxin. Embryonic root apical meristem initiation is a key developmental event where auxin plays an important role, mainly through the action of the AUXIN RESPONSE FACTOR5/MONOPTEROS (MP) transcription factor. Disruption of MP function leads to a variety of defects on different levels, ranging from transcriptional responses to disturbed cellular processes. Although a number of downstream targets of MONOPTEROS have been identified and characterized, an open question remains how cellular processes that govern cell shape and function are directed by this transcription factor. By comparing different transcriptomic datasets we have identified a subclade of IQ-domain proteins acting downstream of MP and here we report their molecular and functional characterization. We show that IQD15-18 are transcriptionally controlled by auxin, that they interact with Calmodulins and microtubules in vivo, and that subcellular localization of IQD18 protein is cell cycle-dependent. Both loss- and gain-of-function analyses revealed a role for these proteins in both auxin and calcium signaling. These findings place the IQD15-18 proteins at the hinge between two important signaling pathways and shed light on how cellular processes may be directed by MONOPTEROS. 


\section{Introduction}

Over the course of evolution, plants have been able to colonize the planet, covering it with a variety of shapes and forms and providing nutritional and respiratory functions. The presence of a rigid cell wall prevents plant cells from moving, and enforces mechanical constraints on growth and necessitates strict control of cell division orientation during developmental processes. Both cell division and cell growth are regulated by the phytohormone auxin (Chapter 1 of this thesis). Nuclear auxin signaling occurs through the action of several different components, including AUXIN/INDOLE ACETIC ACID (AuX/IAA) transcriptional co-repressors (Reed, 2011), AUXIN RESPONSE FACTORS (ARFs; Guilfoyle and Hagen, 2007), SKP1CULLIN-F-BOX (SCFTIR1/AFB; Ruegger et al., 1998) ubiquitin ligase complexes, and different molecular species of auxin itself (reviewed in Lokerse and Weijers, 2009). In the absence of auxin, Aux/IAA transcriptional co-repressors bind ARF transcription factors, inhibiting their function (Tiwari et al., 2001, 2003). Auxin on the other hand acts as molecular glue, increasing the affinity of the SCFTIR/AFB ubiquitin ligase complex to Aux/IAA proteins (Gray et al., 2001; Dharmasiri et al., 2005; Kepinski \& Leyser, 2005). This results in rapid degradation of the Aux/IAAs through the $26 \mathrm{~S}$ proteasome, derepressing the ARFs and allowing them to perform their transcriptional control function. Although every stage in development plays an important part in plant survival, the embryonic stage is particularly important for the initial establishment of different tissue types, and defects during embryogenesis often cause lethality (Chapter 1 of this thesis). Auxin plays key roles during different embryonic stages, including the establishment of the embryonic root that will later develop into the root apical meristem (reviewed by Möller and Weijers, 2009). The ARF5/MONOPTEROS (MP) transcription factor is a key regulator of embryonic root formation; $m p$ mutant seedlings show a characteristic rootless phenotype as a result of improper establishment of root cell types and domains in the embryo (Berleth \& Jurgens, 1993; Hardtke \& Berleth, 1998; Weijers et al., 2006). Previous work has focused on the transcriptomic consequences of MP-deficiency and several downstream targets have been identified using different approaches (Schlereth et al., 2010; Möller, 2012). Some of these targets were recently shown to indeed play key roles during development. For example, TARGET OF MONOPTEROS5 (TMO5) is involved in determining vascular bundle size through periclinal cell divisions (De Rybel et al., 2013, 2014), while TMO7 is required for hypophysis specification during the globular stage of embryogenesis (Schlereth et al., 2010). In addition, we have previously described a set of genes that are also transcriptionally regulated 
by MP and mark the region of stem cells in both embryos and roots (Chapter 4 of this thesis). Thus, a transcriptomics approach can indeed identify interesting and important factors for early plant development downstream of MP/ARF5. So far, most of the studied genes and proteins were transcriptional regulators or part of a transcription factor family. A major unanswered question, however, is how hormones and transcription factors direct cellular processes, such as (oriented) cell division and growth that determine shape and function. With the primary focus in auxinand ARF5/MP-dependent transcriptome analysis on transcription factors, the genes mediating downstream cellular functions remain to be identified.

To explore downstream cellular events during embryonic root formation, we analyzed available MP-deficient transcriptomic datasets. While looking for nontranscription factors transcriptionally regulated by MP, a highly represented family of putative calmodulin-binding proteins, the IQ67-domain (IQD) family, drew our attention. This family of 33 members in Arabidopsis was previously identified based on a conserved 67 amino acid domain (the IQ67-domain), that was proposed to facilitate calcium-dependent Calmodulin binding (Abel et al., 2005). Some studies have been done on members of this family, indeed showing in vitro Calmodulin binding through the IQ67-domain, and proposing a role in directing a kinesin-like protein (KLCR1) to microtubules (Bürstenbinder et al., 2013). Although this suggests roles for these proteins in processes in the cell, only limited in vivo work has been performed and functional characterization is lacking for this family of proteins. We therefore set out to functionally characterize a subclade within this family that seemed particularly affected by MP-deficiency (IQD15-18). Here we report that their expression is regulated by auxin during embryo and root development. We also show that they interact with both Calmodulins and microtubules in vivo and that the subcellular localization of IQD18 is cell cycle-dependent. Loss- and gain-of-function analysis revealed possible involvement in both auxin and calcium signaling and places these proteins at the hinge between these two signaling pathways.

\section{Results}

\section{IQ-domain proteins are over-represented in MP-deficient datasets and are evolutionarily conserved in plants}

When looking for non-transcription factors affected by MP-deficiency, we found the IQ67-domain (IQD) family to be highly over-represented (Möller, 2012; Schlereth et al., 2010). In these datasets, 13 of the 33 IQD family members were misregulated 


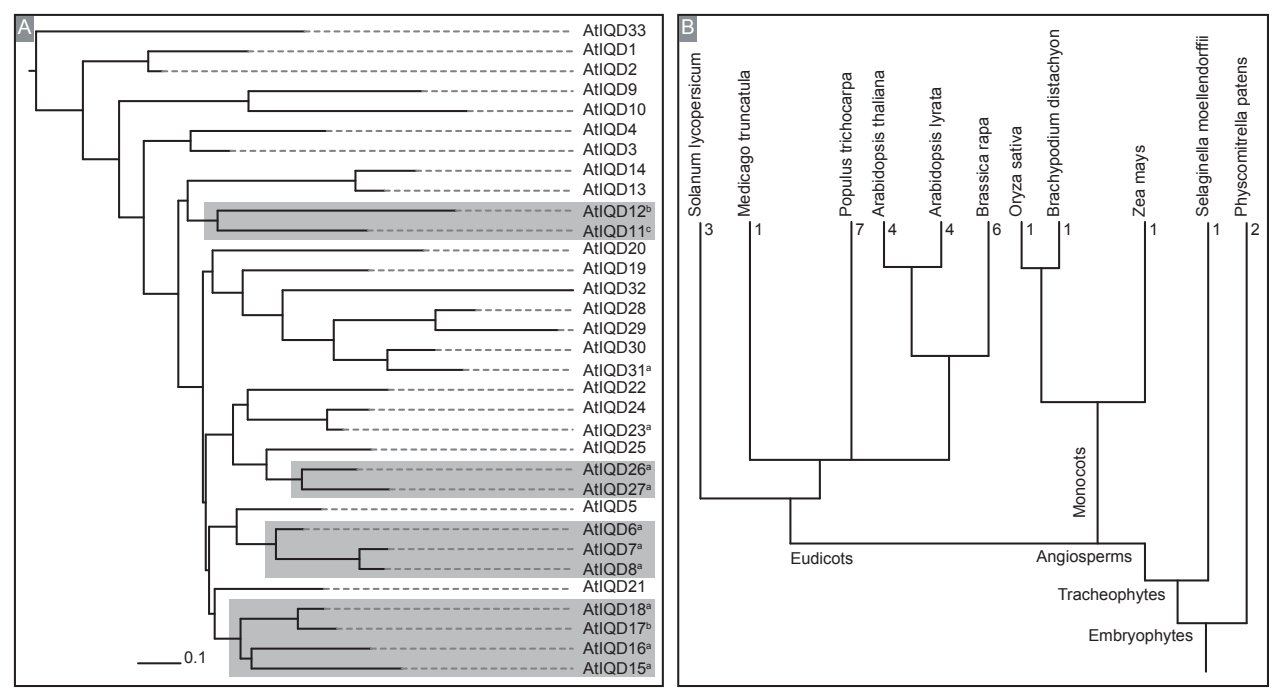

Figure 1: IQD proteins are conserved in evolution and many are misregulated in auxin-associated datasets

A: Phylogenetic tree of all Arabidopsis IQD proteins, rooted to AtIQD33. Grey boxes indicate clades that were misregulated in MONOPTEROS-deficient or auxin datasets. $a=>1.5$ fold down in embryo array (Möller, 2012); b= >1.5 fold down in seedling array (Schlereth et al., 2010); $c=1.2$ fold up in seedling array (Schlereth et al., 2010). B: Number of AtIQD15-18-clade co-orthologs, mapped onto the phylogenetic tree of land plants. Numbers indicate number of co-orthologs.

(Figure $1 \mathrm{~A}$ ). Moreover, most of these appeared to be positively regulated by auxin signaling (Figure 1A). This over-representation suggests a role for these proteins during development of the Arabidopsis embryo, in particular for the establishment of the root stem cell niche. Additionally, it appeared that many of the sub-clades in this family are transcriptionally co-regulated, since they often showed similar behavior in the datasets (as indicated by the grey boxes in Figure 1A). The subclade encompassing AtIQD15-18 was of particular interest since not only were all four members down-regulated in the MONOPTEROS-deficient datasets, they also share ancestry with a single rice co-ortholog (OsIQD14; Abel et al., 2005). To further explore the divergence of these proteins and how they may have been established and maintained during the course of evolution, we explored publicly available genome data from several species. Interestingly, in contrast to the dicot genomes, that all (with the exception of $M$. truncatula) have three or more members within this subclade, all explored monocot genomes (O. sativa, B. distachyon, and Z. mays) encoded only one co-ortholog (Figure 1B). Even though the moss Physcomitrella patens showed two orthologs of this clade, the Lycopodiophyte Selaginella moellendorffii also carried only one ortholog. A plausible explanation for this pattern is that there was one single ancestral gene for this clade, which diverged after the 
monocot/dicot split. Medicago most likely lost some copies, while Physcomitrella likely gained one through a duplication event. Taken together, this suggests that AtIQD15-18 are transcriptionally controlled by auxin signaling and may represent an ancient function. We therefore set out to study the molecular control on and function of the AtIQD15-18 subclade of proteins.

\section{Transcriptional control of IQD15-18 genes}

Since AtIQD15-18 (hereafter referred to as IQD15-18) were identified in transcriptomic analyses of auxin signaling-deficiency, we first tested whether their expression could be altered through exogenous auxin treatments. Arabidopsis seedlings were therefore treated with $1 \mu \mathrm{M}$ synthetic auxin (2-4D) for 15, 60, and 120 minutes. Expression of all four IQD genes was indeed altered by auxin treatment (Figure 2). $I Q D 15$ was rapidly up-regulated within 15 minutes, while IQD17-18 were induced, albeit after 60 and 120 minutes, respectively. IQD16 was not significantly changed at

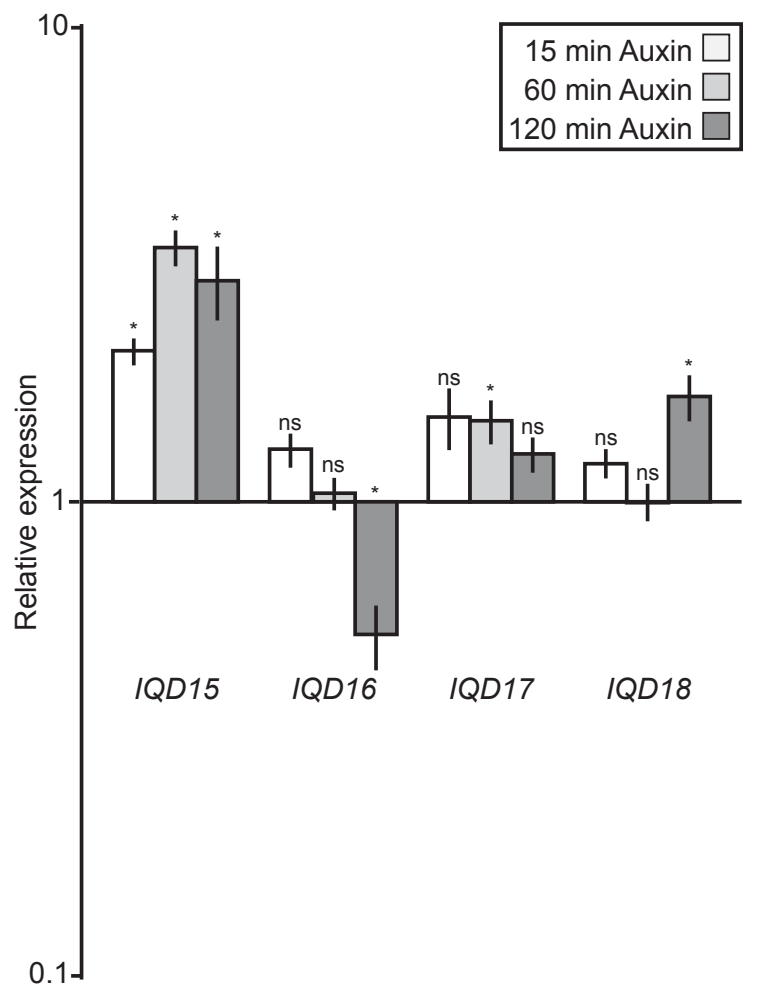

Figure 2: Auxin dependent expression of IQD15-18 Bar diagram showing relative expression of IQD1518 in auxin treated seedlings. $\mathrm{ns}=\mathrm{p}$-value $>0.05$; * = p-value $<0.05$ based on Student's T-test. Error bars indicate standard error of the mean $(n=3)$. 
the early time-points, but was down-regulated after 120 minutes of treatment (Figure 2). These results suggest that $I Q D 15$ is most likely a direct target of auxin signaling, while the other IQD genes may be regulated by factors further down-stream in the pathway.

To understand the spatiotemporal expression of this clade of genes, we analyzed their promoter activity through development. As these genes were identified in embryo- and seedling-specific transcriptomic approaches (Möller, 2012; Schlereth et al., 2010), we focused our analysis on different developmental

Globular
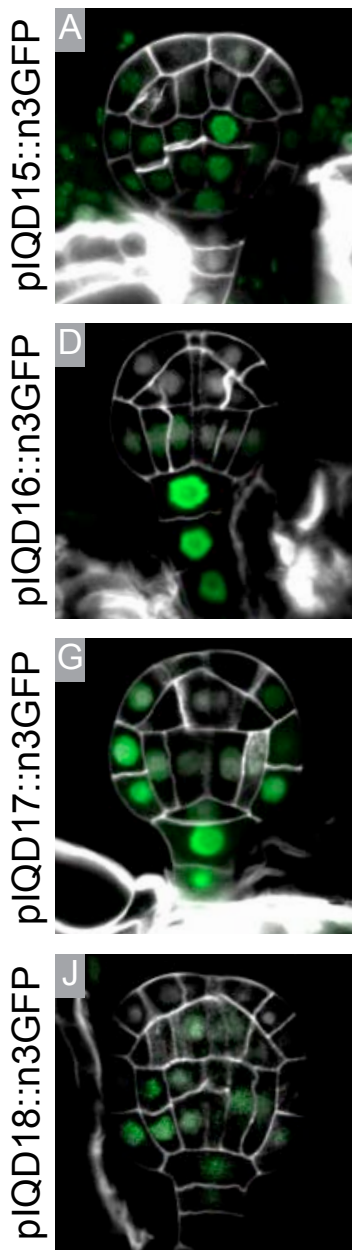

Heart
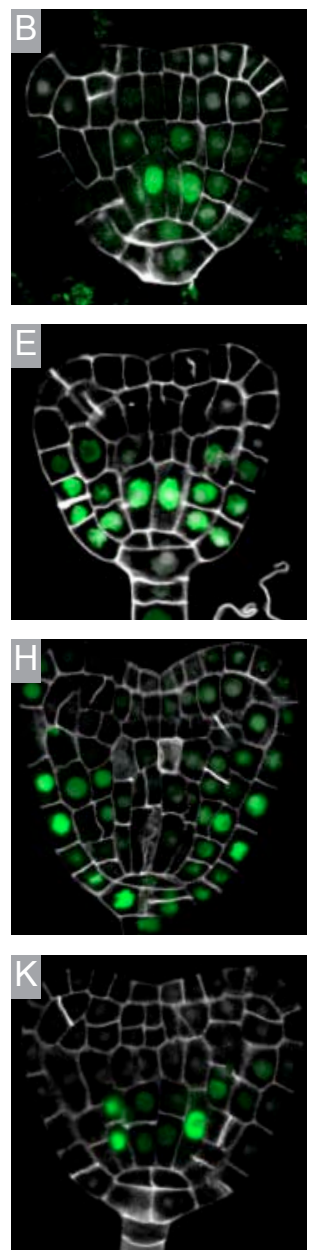

Root
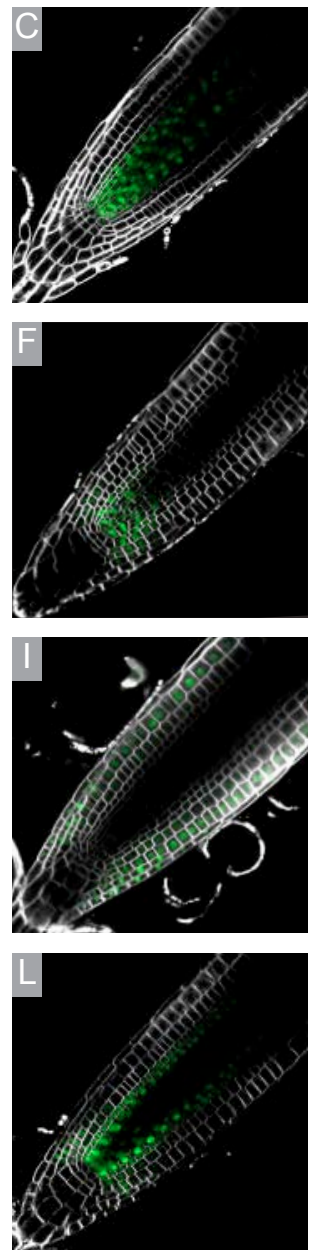

Figure 3: Promoters of IQD15-18 are active early in development at sites of high auxin signaling and developmental importance

Expression of IQD15-18 shown in globular (A,D,G, and J) and heart stage $(B, E, H$, and $K$ ) of embryo development and in five-day-old seedling roots (C,F,I, and L). 
stages of the embryo and the post-embryonic root. Expression of all four IQD genes was observed very early in development in specific regions of the embryo. IQD15 and IQD18 promoter activity was observed from globular stage onwards and most prominently in the early vasculature (Figure $3 \mathrm{~A}, \mathrm{~B}, \mathrm{~J}$, and $\mathrm{K}$ ). This specific expression pattern was also observed in the post-embryonic primary root, although the expression domain expanded to the ground tissue (Figure 3C and L). IQD16 and IQD17 promoter activity was observed in cells of the suspensor, as early as fourcell stage of embryo development (Supplementary Figure 1). Starting at globular stage, expression expanded to the whole basal tier of the proembryo (IQD16; Figure $3 \mathrm{D}$ and $\mathrm{E}$ ) or the outermost cell layers of the epidermis and ground tissue (IQD17; Figure $3 \mathrm{G}$ and $\mathrm{H}$ ). Expression in the post-embryonic root was similar to that in the embryo, where IQD16 was expressed in the whole stem cell niche area and IQD17 predominantly in cells of the epidermis, lateral root cap, and cortex (Figure $3 \mathrm{~F}$ and I).

Interestingly, the observed expression patterns correspond to regions with high auxin response (Liao et al., 2015). Moreover, Möller (2012) has previously shown that expression of IQD15 is reduced in $m p$ embryos. Taken together, these data support the notion that this clade of IQD genes is (at least partially) transcriptionally controlled by auxin response, most likely through the action of MONOPTEROS. The early expression during embryogenesis suggests these genes may have a role during early development.

\section{IQD proteins localize to the cortical microtubules}

Although some members of the large IQD protein family have been shown to reside both in- and outside of the nucleus (Bürstenbinder et al., 2013), it remains unclear what function they perform and whether the localization is similar for all members. We determined the subcellular localization of IQD15, -17, and -18 in stably transformed lines (pIQDXX::IQDXX:sYFP), again focusing on embryo and root development. In all analyzed lines, fusion protein could be detected at the edges of the cell and within the same domain as the promoter activity, both in embryos and in roots (see Figure 4). This indicates that IQD proteins do not move beyond their transcriptional domain. Interestingly, all three IQD fusion proteins appear enriched at the lateral faces of cells in the root meristem (Supplementary Figure 2D, G, and J). IQD15 appeared to have an additional apical polarization (Supplementary Figure 2D), which was not observed for the other IQDs. Although more clearly for IQD17 and IQD18 (Figure $4 \mathrm{H}$ and $\mathrm{L}$ ) than for IQD15, protein could often be observed in strand-like structures near the outer edges of the cell (Figure 4D). These structures highly resemble the structure also observed for (cortical) mictotubules (MT; Supplementary Figure 2A). 

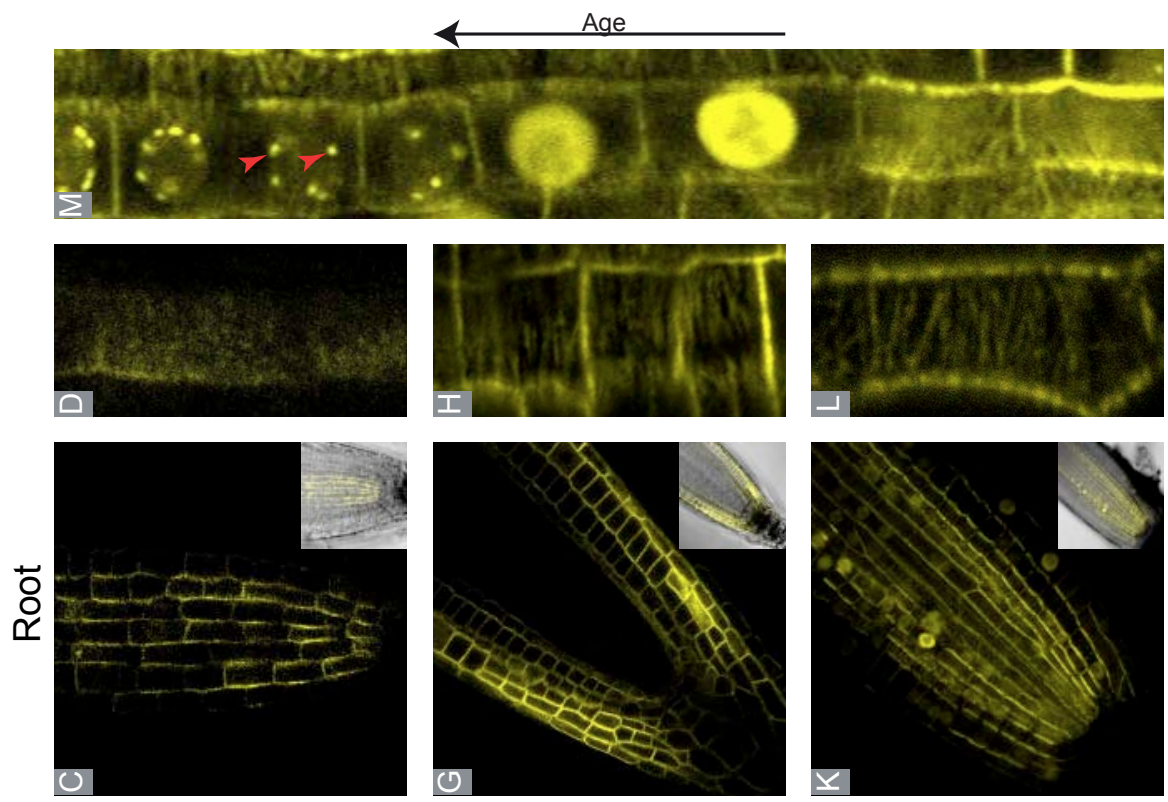

ธับ I

วิำ

든

น" ญ

ตํ 응

옹

范

는

品

c os

읃 인

ㅎํ류
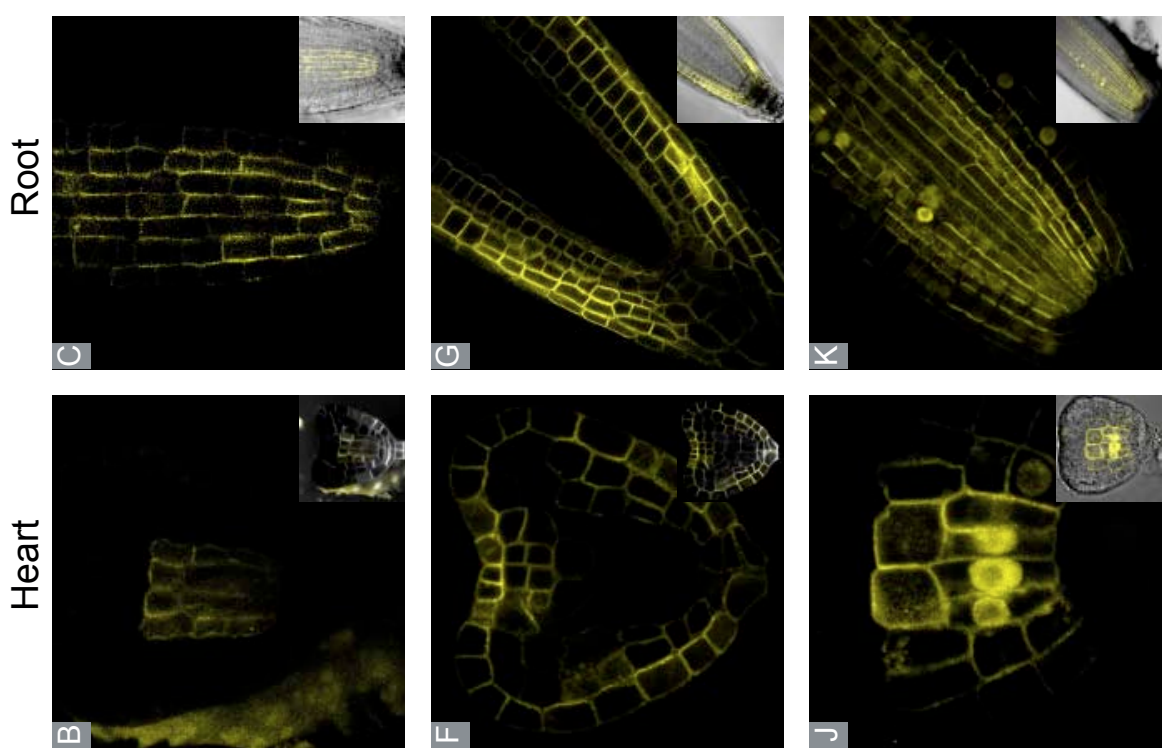

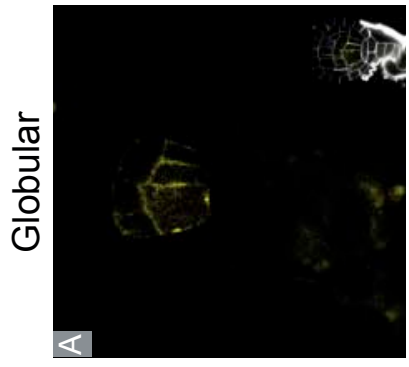

dJ人s:GLOOI::GLOOId

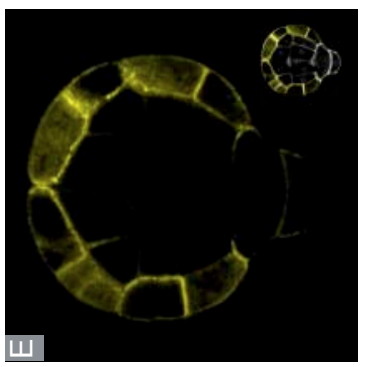

d

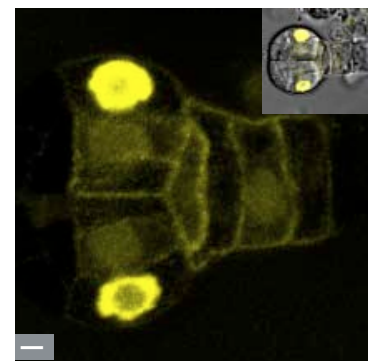

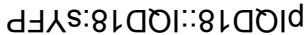

ㄷำ $\leq \frac{5}{\sigma}$ 辛 跑 응 近需包 든 흔 흔 क \& 음 응 웡

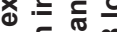
.

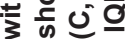
in 0 of \& $\infty$ 웡 $\frac{\infty}{1}$ 의 윽 웡 응 등

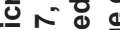
ह 정 능 능 능일 은 엉 엉 o) $\geq$

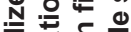
贾 으 듕 돌 등은 흥은 ब. 은 훙응 흔흔응 응 을응 으 흥 ฮ $\ddot{\gamma} \overline{\underline{\Xi}} \mathrm{O}$ 호옹 흥윽 응 은 की 흘 응 
Indeed, localization of all three IQD proteins changed when roots were treated with the MT-destabilizing drug Oryzalin, resulting in patches or diffuse cytosolic signal, rather than the strand-like structures observed in the mock treated sample (Supplementary Figure 2B, E, H, and K).

As previously published data suggests calcium-dependent binding properties for the IQD proteins (Bürstenbinder et al., 2013), we tested the effect of calcium addition or chelation by EGTA treatment (Knight et al., 1997) on the subcellular localization of these proteins. Interestingly, while we did not observe any changes in localization upon calcium treatment, localization was strongly disturbed for all three proteins within one hour of EGTA treatment (Supplementary Figure 2F, $\mathrm{I}$, and L), indeed indicating calcium-dependent localization. A similar response was also observed for the MICROTUBULE ASSOCIATED PROTEIN 65-1 MT marker (Supplementary Figure $2 \mathrm{C}$ ). This suggests that the conserved lateral localization of IQD15, -17, and -18 occurs through binding to cortical MTs and that calcium is crucial for MT stability (Hepler, 2005).

Strikingly, IQD18 fusion protein could also be detected in the nucleus of some cells, in both embryos and roots. The localization of IQD18 depended on the age of cells (Figure 4M). Younger cells, closer to the QC (displayed at the bottom) show cortical localization, while older cells (apically displaced) have nuclear localized protein. Finally, spots of fusion protein (indicated by red arrowheads in Figure 4M) could often be observed in nuclei after division.

Taken together, these data indicate that the IQD proteins within this clade have a conserved property of localizing to cortical microtubules. Specifically for IQD18, the fusion protein showed translocation from lateral sides of the cell to the nucleus and later to nuclear foci, suggesting that IQD18 localization might be dynamically controlled during the cell cycle.

\section{Cell cycle dependent re-localization of IQD18 protein}

In order to determine whether the cell cycle phase was indeed influencing localization of IQD18, we treated five-day-old Arabidopsis roots with hydroxy-urea (HU); a drug commonly used to synchronize plant cell cultures in S-phase (Cools et al., 2010). Indeed, when comparing roots treated for 15 hours with HU (Figure 5B) to untreated roots (Figure 5A), a significant increase in the number of cells with nuclear-localized IQD18 could be observed (Figure $5 C$ ). This strongly suggests that the protein is relocalized to the nucleus before or during S-phase. To further dissect the time and cell cycle component in IQD18 localization, we performed time-lapse imaging on roots. We could observe a reduction of signal at the lateral sides of the cell (white 

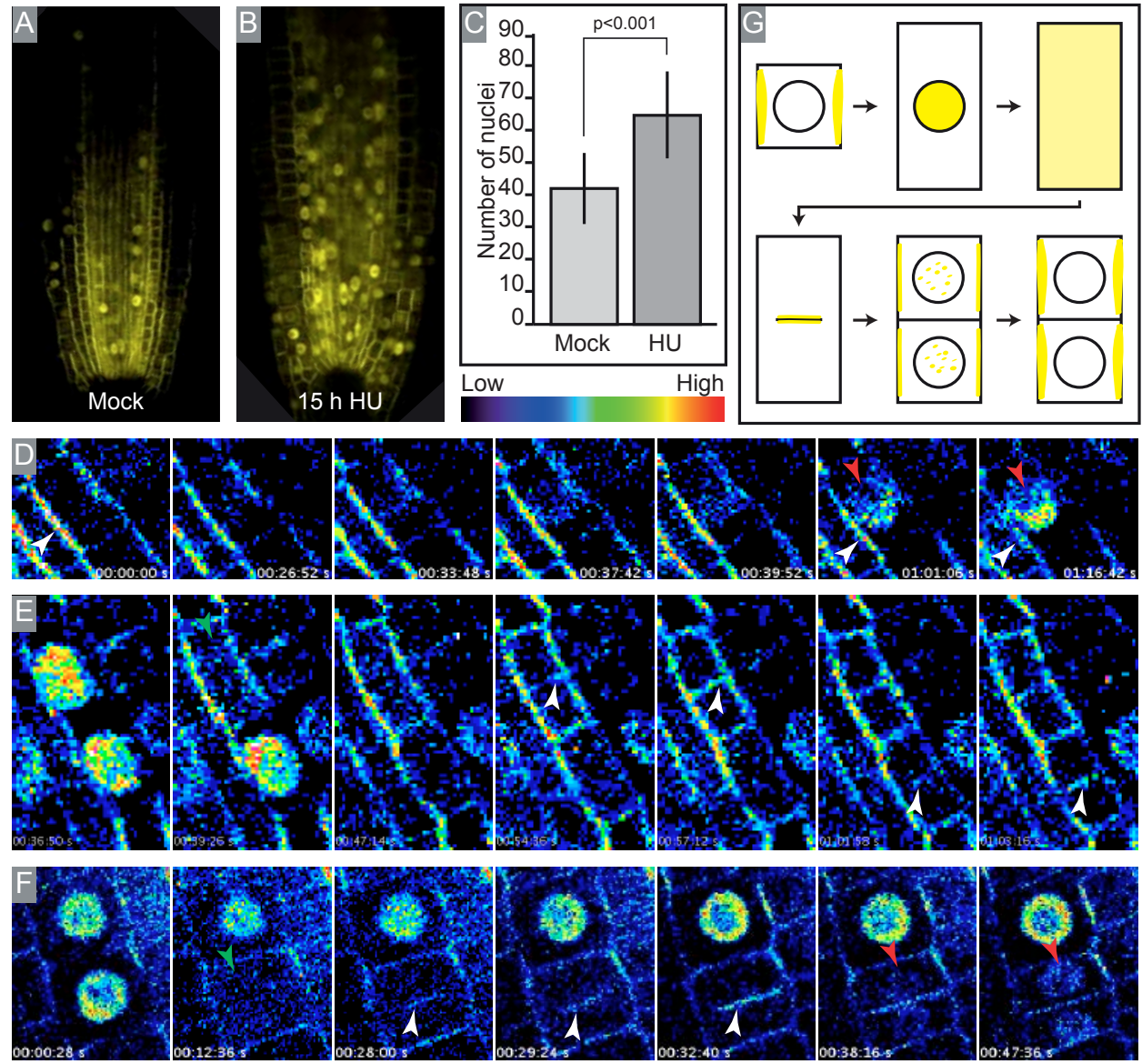

Figure 5: Subcellular localization of IQD18 is cell cycle dependent

$A$ and B: IQD18 localization after mock and hydroxyl urea (HU) treatment; C: quantification of cells with nuclear localized protein. Error bars indicate standard deviation $(n=29)$. D-F: Time-lapse imaging of IQD18 localization becoming nuclear (D) and in endodermal (E) and cortical cells (F) through division. G: Schematic representation of IQD18 localization in a cell undergoing cell division, represented phases: G0/1 phase, S-phase, mitotic-phase, formation of new cell plate, daughter cells just after division and again in $\mathrm{G} 0 / 1$ phase.

arrowheads in Figure 5D), which perfectly coincided with the appearance of nuclear localized protein (red arrowheads in Figure 5D). Although we can not exclude de novo synthesized protein is localized to the nucleus, given that the disappearance of IQD18 fusion protein from the lateral sides of the cell and the appearance in the nucleus occurs within minutes, it is very likely that an active re-localization of protein takes place.

To test what happens to the localization of the fusion protein during completion of the cell cycle, we performed a detailed time-lapse imaging of single 
cells through mitosis. As the nuclear envelop dissolves in (pro)metaphase, the IQD18 fusion protein dissipates throughout the cytoplasm (green arrowheads in Figure $5 \mathrm{E}, \mathrm{F}$ ) and is not returned to the edge completely. Later, during cytokinesis IQD18 localizes to the newly forming cell plate (white arrowheads in Figure 5E, F), and nuclear localization could also be observed when the daughter nuclei had formed (red arrowheads in Figure 5F). The dynamic localization of IQD18 is schematically represented in Figure 5G: IQD18 fusion protein is first seen at the cortical MTs. During S-phase, the protein is re-localized to the nucleus where it stays until the nuclear envelop dissolves and the protein dissipates throughout the cytoplasm. The protein is then focused to the newly forming cell plate and finally regains its original localization after division.

Taken together, these data indicate a cell type independent regulatory mechanism for IQD18 localization and re-localization during the cell cycle and further suggest that IQD18 could be involved in communication between the edges of the cell and the nucleus during the cell cycle. Alternatively, nuclear localization could also be necessary for tempering a yet unknown function at the edges of the cell.

\section{IQD15, -17 and -18 interact with Calmodulins and Tubulins in vivo}

To assign a function to IQD proteins and understand the protein complexes in which they could function, we next determined the interacting proteins. As no other known interaction domains apart from the calmodulin-binding-domain are predicted, we applied an unbiased IP-MS/MS strategy to find interaction partners of IQD15, -17and -18. We performed IP-MS/MS followed by quantitative statistical analysis using MaxQuant (Chapter 3 of this thesis) on plants harboring translational fusions of pIQD15::IQD15:sYFP, pIQD17::IQD17:sYFP and pIQD18::IQD18:sYFP, using both siliques and root tissue for embryo and root contexts, respectively (Supplementary Figure 3). In all cases, both the bait (IQD15, -17, or -18) and the sYFP proteins were among the most abundant protein groups in the sample, which validates the quality of the performed assay. We found additional putative protein interactions, including potential IQD17-IQD18 hetero-dimerization, and several members of the Tubulin and Calmodulin-like protein families for all three IQD proteins (see Figure 6 and Table 1). Moreover, the microtubule association of IQD proteins was further supported by the identification of SPIRAL2 and ANGUSTIFOLIA microtubuleassociated proteins (Kim et al., 2002; Wightman et al., 2013) as putative interactors for IQD17 and IQD18 (Table 1). We also identified an uncharacterized Glycine-rich protein, which appeared only in the root samples, indicating a root specific interaction partner (Table 1). Another two putatively interesting proteins were found to bind 

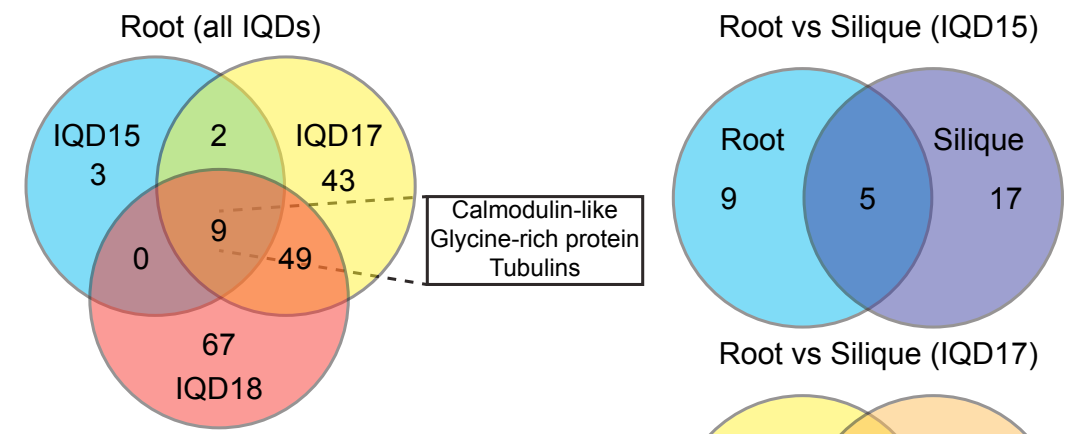

Siliques (all IQDs)
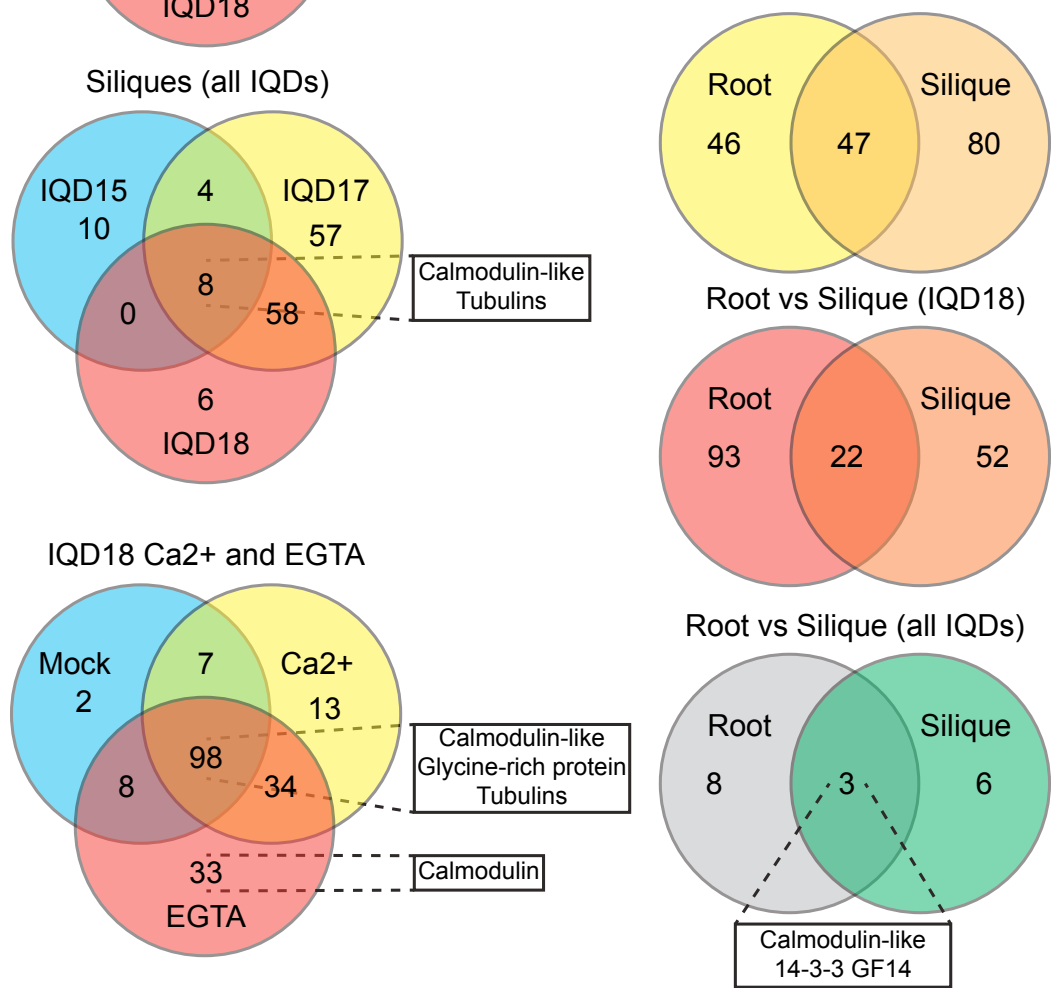

Figure 6: IQD proteins share binding to Calmodulins and Tubulins Venn-diagrams of overlapping and unique protein groups identified through IP-MS on IQD15, -17, and -18 using silique and root tissues.

IQD17 and IQD18 in both roots and siliques, the first is an uncharacterized protein belonging to a Serine/Threonine Protein Kinase family and the second is BIG, a large protein involved in many processes including auxin transport, light response and shade avoidance (Table 1; Gil et al., 2001; Luschnig, 2001). Importantly, most of the identified interactions are of high confidence, as comparison to a database of 86 IP-MS/MS experiments indicated low relative "stickiness" (Table 1). 


\begin{tabular}{|c|c|c|c|c|c|c|c|c|c|c|c|c|c|c|c|c|c|c|c|c|c|}
\hline & & & & 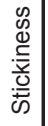 & & 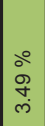 & 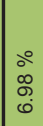 & 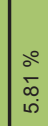 & 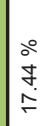 & 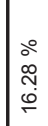 & 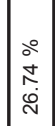 & $\begin{array}{l}\stackrel{\circ}{\circ} \\
\stackrel{9}{9} \\
\text { j) }\end{array}$ & 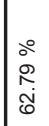 & \begin{tabular}{|l}
$\stackrel{\circ}{\circ}$ \\
$\stackrel{\circ}{\circ}$ \\
$\dot{J}$
\end{tabular} & $\begin{array}{l}\stackrel{0}{0} \\
0 \\
0 \\
\dot{q}\end{array}$ & 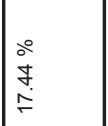 & $\begin{array}{l}\circ \\
\infty \\
\infty \\
0 \\
\dot{0}\end{array}$ & $\begin{array}{l}\stackrel{0}{0} \\
\stackrel{0}{0} \\
\stackrel{0}{0} \\
\stackrel{0}{0}\end{array}$ & 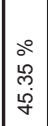 & $\begin{array}{l}\stackrel{\circ}{\circ} \\
\stackrel{2}{\sim} \\
\stackrel{5}{r}\end{array}$ & $\begin{array}{l}\stackrel{0}{\circ} \\
\stackrel{2}{N} \\
\stackrel{N}{ }\end{array}$ \\
\hline & & & & $\begin{array}{l}\frac{0}{2} \\
\frac{\partial}{\pi} \\
\frac{1}{2} \\
\frac{1}{2}\end{array}$ & 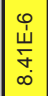 & ₹ & $\begin{array}{l}\stackrel{0}{0} \\
\text { ò } \\
\text { o. } \\
0\end{array}$ & $\begin{array}{l}\text { o } \\
\text { 岁 } \\
\text { م. } \\
\sigma\end{array}$ & $\begin{array}{l}0 \\
\dot{山} \\
\stackrel{m}{j} \\
\text { j. }\end{array}$ & ₹ & z & z & \begin{tabular}{|l|l}
$\infty$ \\
0 \\
0 \\
0 \\
0
\end{tabular} & 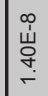 & 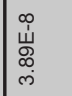 & $\mathrm{z}$ & 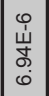 & 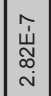 & $\begin{array}{l}\hat{o} \\
\stackrel{0}{0}\end{array}$ & 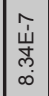 & F. \\
\hline & & & 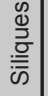 & 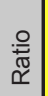 & 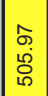 & z & 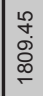 & $\begin{array}{l}\text { N } \\
\text { Oे } \\
\text { Sิ }\end{array}$ & 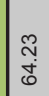 & z & z & $\mathrm{Q}$ & 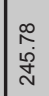 & \begin{tabular}{|l}
$\tilde{N}$ \\
$\tilde{N}$ \\
$\tilde{N}$
\end{tabular} & 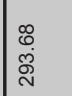 & 之 & $\begin{array}{l}\stackrel{0}{\circ} \\
\stackrel{\circ}{\circ}\end{array}$ & $\mid \begin{array}{l}m \\
\stackrel{\rho}{\sigma} \\
\tilde{\sigma}\end{array}$ & $\begin{array}{l}\hat{\infty} \\
\tilde{\rho} \\
\dot{m}\end{array}$ & 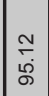 & $\begin{array}{l}\stackrel{\leftrightarrow}{\circ} \\
\stackrel{\leftrightarrow}{\circ}\end{array}$ \\
\hline & & & $\begin{array}{l}* \\
\mathbb{E} \\
心 \\
w\end{array}$ & $\begin{array}{l}\stackrel{\circ}{\circ} \\
\stackrel{\overline{\mathscr{V}}}{\simeq} \\
\end{array}$ & 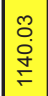 & 只 & 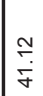 & 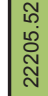 & $\begin{array}{l}\hat{\tilde{m}} \\
0 \\
\stackrel{0}{0} \\
\stackrel{0}{0}\end{array}$ & 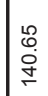 & 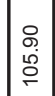 & 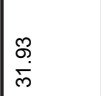 & $\begin{array}{l}R \\
\stackrel{R}{0} \\
\dot{m}\end{array}$ & $\mid \begin{array}{l}\mathcal{N} \\
\infty \\
\stackrel{m}{M}\end{array}$ & 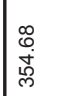 & $\underset{\infty}{\underset{\infty}{\infty}}$ & $\begin{array}{l}\tilde{N} \\
\infty \\
\infty \\
R\end{array}$ & 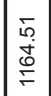 & 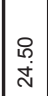 & $\mid \begin{array}{l}0 \\
0 \\
\dot{0} \\
9 \\
\end{array}$ & $\begin{array}{l}\hat{\sigma} \\
\dot{\theta} \\
0\end{array}$ \\
\hline & & & 茎 & 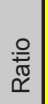 & $\begin{array}{l}\stackrel{8}{\circ} \\
\dot{\bar{q}} \\
\stackrel{-}{-}\end{array}$ & z & z & 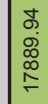 & $\begin{array}{l}\stackrel{0}{0} \\
\dot{0} \\
\stackrel{0}{-}\end{array}$ & 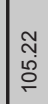 & z & $\mathrm{Q}$ & $\begin{array}{l}\stackrel{0}{0} \\
\stackrel{2}{0}\end{array}$ & $\begin{array}{l}8 \\
\\
\dot{0} \\
\text { ¿ }\end{array}$ & $\begin{array}{l}\infty \\
\stackrel{\infty}{\vdots} \\
\stackrel{N}{N}\end{array}$ & \begin{tabular}{|l} 
o \\
$\stackrel{\tilde{N}}{\text { N }}$
\end{tabular} & 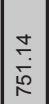 & \begin{tabular}{|l}
$\bar{\infty}$ \\
$\dot{8}$ \\
$\dot{0}$
\end{tabular} & 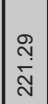 & 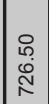 & 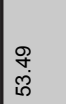 \\
\hline & & $\underset{\frac{1}{4}}{\frac{n}{\infty}}$ & & 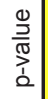 & 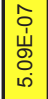 & 只 & $\underset{0}{F}$ & 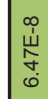 & 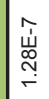 & 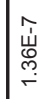 & ₹ & 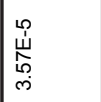 & $\stackrel{m}{0}$ & 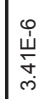 & $\begin{array}{l}\hat{u} \\
\stackrel{\omega}{\omega} \\
\hat{\omega} \\
0\end{array}$ & 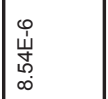 & 苮 & 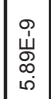 & 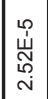 & 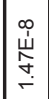 & 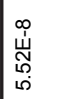 \\
\hline & & $\frac{\bar{\sigma}}{\frac{\sigma}{2}}$ & \begin{tabular}{l}
0 \\
0 \\
0 \\
\hdashline
\end{tabular} & $\begin{array}{l}. \\
\stackrel{0}{\pi} \\
\check{\simeq}\end{array}$ & 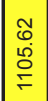 & ₹ & 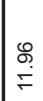 & 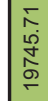 & 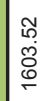 & 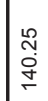 & ₹ & 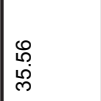 & 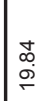 & 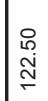 & 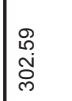 & 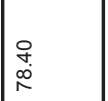 & 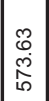 & 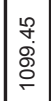 & \begin{tabular}{|l}
$\infty$ \\
$\stackrel{\infty}{\infty}$ \\
$\stackrel{\rho}{\sim}$ \\
$\leftarrow$
\end{tabular} & 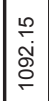 & 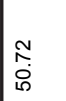 \\
\hline & & & & $\begin{array}{l}\frac{0}{2} \\
\frac{2}{\pi} \\
\frac{1}{1} \\
\frac{1}{2}\end{array}$ & 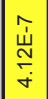 & z & 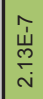 & z & 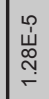 & $\begin{array}{l}\hat{u} \\
\dot{u} \\
\vdots \\
\vdots \\
\infty\end{array}$ & z & 号 & 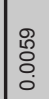 & 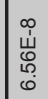 & 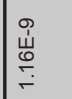 & z & $\underset{0}{\tilde{0}}$ & 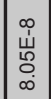 & 它 & 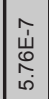 & 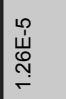 \\
\hline$\sum_{\Sigma}^{\infty}$ & & & 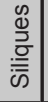 & $\begin{array}{l}\stackrel{\circ}{\bar{T}} \\
\check{\Upsilon}\end{array}$ & $\frac{m}{\stackrel{m}{c}}$ & z & 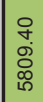 & 号 & 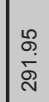 & $\begin{array}{l}\tilde{N} \\
\stackrel{N}{F} \\
\stackrel{F}{2}\end{array}$ & 之 & 之 & 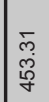 & 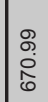 & 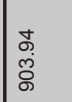 & 之 & $\begin{array}{l}\hat{\stackrel{N}{N}} \\
\stackrel{0}{\circ}\end{array}$ & 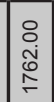 & \begin{tabular}{|l}
$\stackrel{0}{0}$ \\
$\stackrel{0}{0}$ \\
$\stackrel{0}{0}$
\end{tabular} & 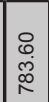 & \begin{tabular}{|l}
0 \\
$\stackrel{\infty}{\infty}$ \\
$\stackrel{\sim}{\sim}$
\end{tabular} \\
\hline $\begin{array}{l}\sum_{1}^{0} \\
\stackrel{1}{1} \\
\underline{\Omega}\end{array}$ & & $\frac{n}{\frac{n}{i}}$ & & $\begin{array}{l}\frac{0}{2} \\
\frac{\partial}{\sigma 0} \\
\stackrel{1}{2} \\
0\end{array}$ & $\begin{array}{l}\frac{0}{8} \\
\bar{\delta} \\
0 \\
0\end{array}$ & २ & 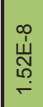 & 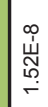 & $\begin{array}{l}\infty \\
\stackrel{\infty}{\Psi} \\
\dot{\omega} \\
\dot{+} \\
\dot{+}\end{array}$ & ₹ & $\frac{0}{0}$ & $\mathrm{Q}$ & $\frac{0}{0}$ & 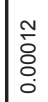 & 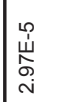 & 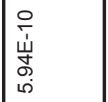 & 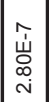 & 莣 & $\frac{1}{\circ}$ & 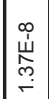 & $\begin{array}{l}\frac{10}{8} \\
\varnothing \\
0 \\
0\end{array}$ \\
\hline 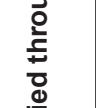 & & $\begin{array}{l}\hat{0} \\
\frac{0}{0} \\
\frac{0}{2}\end{array}$ & $\begin{array}{l}0 \\
0 \\
0 \\
\propto\end{array}$ & 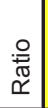 & 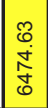 & 号 & 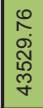 & 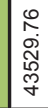 & 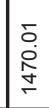 & 令 & $\begin{array}{l}\bar{m} \\
\stackrel{n}{N}\end{array}$ & ₹ & 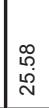 & 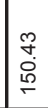 & \begin{tabular}{|l}
$\stackrel{2}{N}$ \\
0 \\
0 \\
0 \\
0
\end{tabular} & 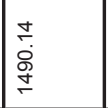 & $\begin{array}{l}\stackrel{\triangle}{\oplus} \\
\stackrel{\sim}{\sim}\end{array}$ & 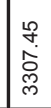 & 年 & 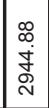 & $\begin{array}{l}\infty \\
\stackrel{0}{\circ} \\
\stackrel{\rho}{\circ}\end{array}$ \\
\hline$\frac{\bar{c}}{0} \frac{0}{0}$ & & & & 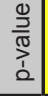 & 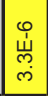 & 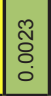 & z & 之 & $\begin{array}{l}\infty \\
\infty \\
o \\
0 \\
0\end{array}$ & 之 & ₹ & 乏 & ָָ & $\begin{array}{l}\frac{m}{\sigma} \\
\bar{o} \\
0\end{array}$ & \begin{tabular}{|l}
$\hat{y}$ \\
0 \\
0
\end{tabular} & 之 & 之 & 之 & 之 & ₹ & 号 \\
\hline 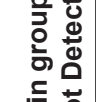 & & & 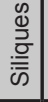 & $\begin{array}{l}. \\
\stackrel{\circ}{\pi} \\
\check{\simeq}\end{array}$ & 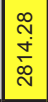 & \begin{tabular}{|l|}
$\bar{\infty}$ \\
$\dot{\delta}$ \\
$\delta$ \\
\end{tabular} & z & z & 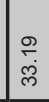 & z & ₹ & z & \begin{tabular}{|l|}
$\infty$ \\
$\infty$ \\
$\stackrel{\infty}{\leftarrow}$
\end{tabular} & 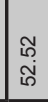 & 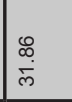 & 之 & ₹ & z & 之 & २ & z \\
\hline 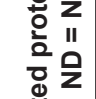 & & $\frac{n}{\frac{0}{i}}$ & & $\begin{array}{l}\frac{0}{2} \\
\frac{\partial}{\pi} \\
\frac{1}{1} \\
\frac{1}{2}\end{array}$ & $\begin{array}{l}0 \\
0 \\
\varnothing \\
\varnothing \\
0 \\
0\end{array}$ & 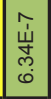 & z & $\mathrm{z}$ & 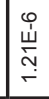 & ₹ & z & ₹ & Q & $\underset{0}{\tilde{O}}$ & $\underset{O}{\tilde{O}}$ & 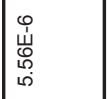 & 之 & z & $\begin{array}{l}0 \\
\text { ọ } \\
0\end{array}$ & z & z \\
\hline 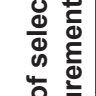 & 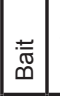 & $\begin{array}{l}\bar{\alpha} \\
\overline{0} \\
\frac{0}{2}\end{array}$ & $\begin{array}{l}0 \\
0 \\
0 \\
\propto\end{array}$ & 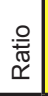 & $\begin{array}{l}\bar{i} \\
\stackrel{\rho}{\rho} \\
\end{array}$ & $\begin{array}{l}\hat{0} \\
\dot{0} \\
\dot{N} \\
\end{array}$ & z & 号 & 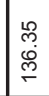 & 之 & z & z & 号 & $\underset{f}{\stackrel{\gamma}{F}}$ & $\begin{array}{l}\stackrel{P}{+} \\
\dot{J}\end{array}$ & $\begin{array}{l}\hat{N} \\
\hat{\theta} \\
\stackrel{\rho}{F}\end{array}$ & 号 & 号 & $\begin{array}{l}\hat{x} \\
0 \\
0\end{array}$ & i & 吕 \\
\hline 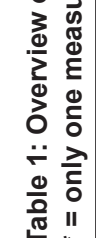 & & & 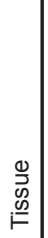 & 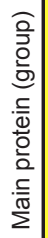 & \begin{tabular}{|l} 
\\
\\
$\frac{0}{1}$ \\
$>$
\end{tabular} & $\stackrel{2}{\frac{0}{\sigma}}$ & $\underline{\hat{\sigma}}$ & $\underline{0}$ & 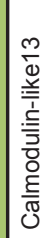 & 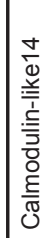 & 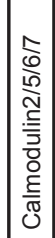 & 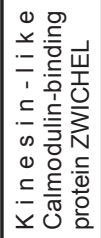 & 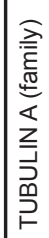 & 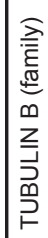 & 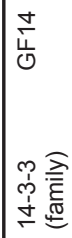 & 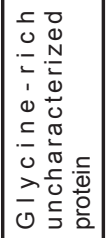 & 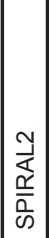 & 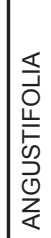 & 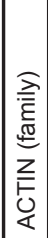 & 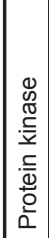 & 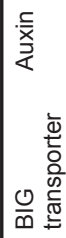 \\
\hline
\end{tabular}


Since we previously established a dramatic change in protein localization in response to calcium chelation we decided to assess the effects of calcium and calcium depletion on the interaction profile of IQD18. We performed IP-MS/MS and treated the protein samples with $100 \mathrm{mM}$ calcium or $20 \mathrm{mM}$ EGTA (see Methods). These results showed a high degree of overlap of interacting proteins between treated and untreated samples (Figure 6), but also showed interesting differences. These included more prominent binding to Calmodulins and another Calmodulinbinding protein, ZWICHEL (Day et al., 2000; Vinogradova et al., 2013; Tian et al., 2015), in the EGTA treated sample. Although, since only a single replicate was performed in this experiment, no statistical analysis could be performed, they do suggest calcium may inhibit binding of IQD18 to several interactors.

In summary, these data confirm that the tested IQD proteins bind Calmodulins, MT and MT-associated proteins. Furthermore, we have also identified other interaction partners that may help define IQD function in development.

\section{IQD mutants suggest involvement in Calcium response}

To understand the biological function of these IQD proteins, we studied loss-offunction mutants. Since this clade of IQD genes showed a high degree of overlap in expression domain and protein localization, they may act redundantly. We first analyzed available homozygous insertion lines (iqd15-1, iqd15-2, iqd16-1, iqd171, iqd17-2, and iqd18-1). To test whether these insertion lines indeed show downregulation of the respective transcripts, we measured expression values in seedling roots. Unfortunately, only iqd17-2 and iqd18-1 showed moderate to strong downregulation of the respective gene, while the other lines showed no down-regulation or even strong up-regulation, especially in the case of iqd16-1 and iqd17-1 (Figure 7A). To generate knock-out mutants, we next developed several CRISPR/Cas9 genome editing approaches and constructs (not shown). Thus far however, these approaches have not yielded mutants in these IQD genes. We decided not to generate higherorder-mutants using the available insertion lines, and continue our analysis only with the iqd17-2 and iqd18-1 lines that show significant transcript down-regulation.

Analysis of different embryonic stages and primary root tips by DIC microscopy, revealed no clear phenotypic difference when compared to the Col-0 wild-type control (data not shown). Moreover, examination of the number of cells in S-phase (i.e. actively dividing cells), through 5-ethynyl-2'-deoxyuridine (EdU) staining showed no qualitative difference between the mutants and the wild-type, in terms of mitotic activity of the root meristem (Figure 7B-D). Although phenotypic differences may not be apparent when plants are grown in optimal conditions, changes could 

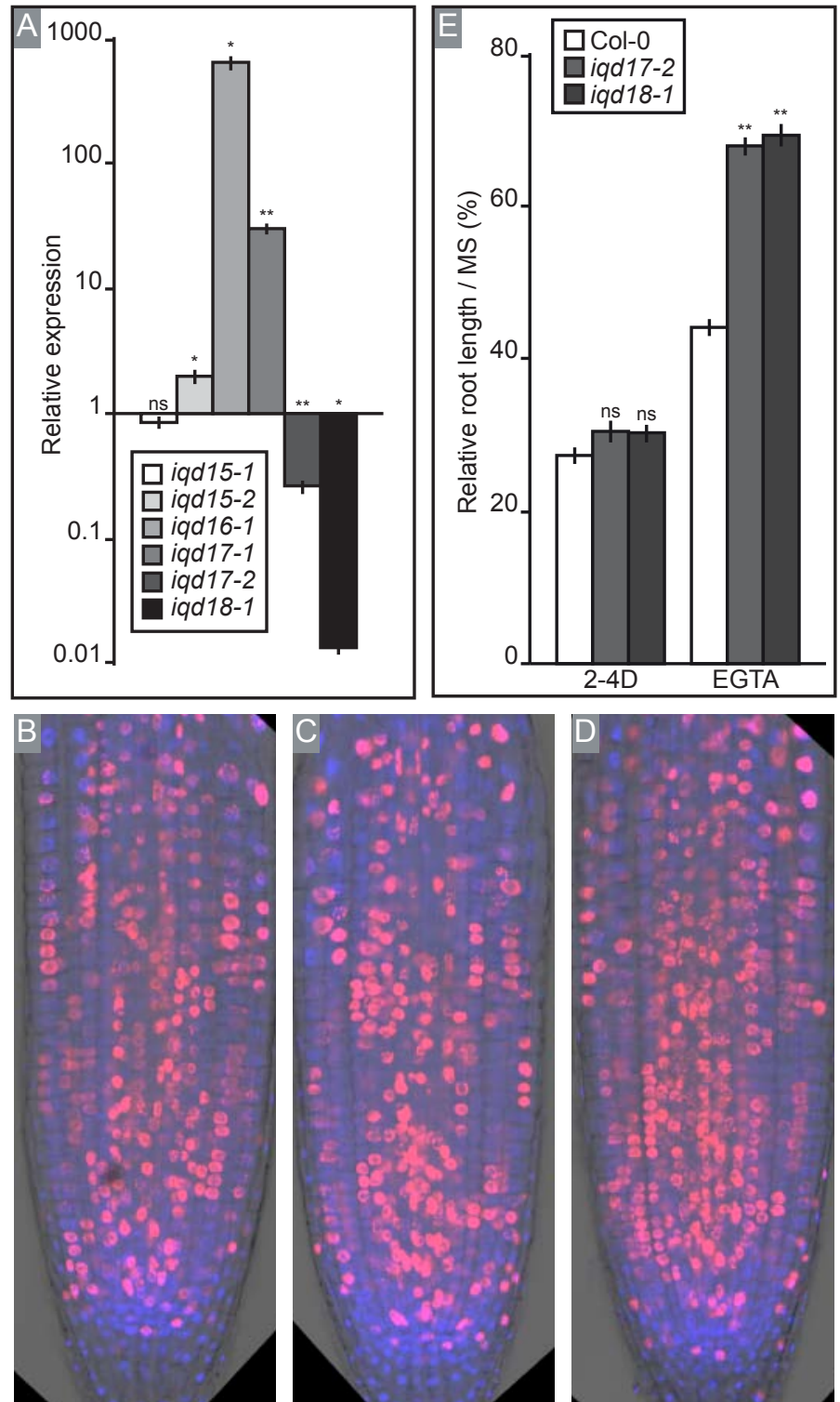

Figure 7: iqd loss-of-function mutants reveal differential EGTA sensitivity

A: Bar diagram showing relative expression of $I Q D$ genes in respective insertion lines. B-D: Division-rate in root tips of Col-0 (B) and iqd17-2, and iqd18-1 (C-D, respectively), shown by EdU staining. E: Bar diagram showing root length (in percentages) of 2-4D and EGTA treated seedlings relative to untreated root lengths $(n>40)$. ns = p-value $>0.05 ;{ }^{*}=p$-value $<0.05 ;{ }^{* *}=p$-value $<0.001$ based on Student's T-test. Error bars indicate standard error of the mean ( $n=3$ for qPCR; $n \geq 59$ for root length assay). 
occur when plants are challenged. As these genes are transcriptionally controlled by auxin, they may be involved in translating auxin input to a growth output. However, when grown on plates containing $40 \mathrm{nM} 2-4 \mathrm{D}$, neither mutant showed a significantly different response compared to the Col-0 wild-type (Figure 7E).

Since the IQ-domain in these proteins has been proposed to mediate calciumdependent Calmodulin binding (Bürstenbinder et al., 2013) and also considering IQD18 seems to more prominently bind Calmodulins in the absence of calcium, we tested whether calcium depletion would have differential effects on root growth in these insertion lines. When grown on plates containing 2 mM EGTA, root length in Col-0 wild-type was highly reduced, to $44 \%$ of the untreated length. Both insertion lines were, on the other hand, more resistant to EGTA treatment, as their roots were significantly longer (Figure $7 \mathrm{l}$ ). This indicates that these proteins indeed may play a key role in regulatory mechanisms that involve calcium. Although indepdendent alleles and/or mutant complementation are required to fortify conclusions, these data indicate that these IQD proteins may mediate calcium responses, perhaps by means of active relocation of proteins during the cell cycle.

\section{Altered subcellular IQD15 and -18 localization impairs auxin and calcium response}

Considering the specific expression domains of both IQD15 and -18, we next assessed the effects of misexpression of these genes. Both proteins were expressed as C-terminal sYFP fusions from the RPS5A promoter that is active in all meristematic tissues and throughout embryogenesis (Weijers et al., 2001). Although misexpression of IQD15 and -18 did not seem to result in any obvious phenotypic abnormalities in either embryos or roots (Figure $8 \mathrm{~A}, \mathrm{~B}, \mathrm{G}, \mathrm{H}$ ), we could observe altered subcellular localization of pRPS5A::IQD15:sYFP (R15). While expression under its native promoter only resulted in localization of IQD15 at the apical and lateral faces of vascular cells, nuclear localization could be observed in the R15 lines (red arrowheads Figure 8A and B). Lateral polarity, similar to pIQD18::IQD18:sYFP (Supplementary Figure $2 \mathrm{~J}$ ), was also observed in ground tissue and epidermal cells in R15 lines (Supplementary Figure 3A), indicating tissue-specific and perhaps dosage-dependent control of localization of this protein. Subcellular localization of pRPS5A::IQD18:sYFP (R18) seemed unchanged compared to pIQD18::IQD18:sYFP (Figure $8 \mathrm{G}$ and $\mathrm{H}$ and Supplementary Figure $3 \mathrm{C}$ ).

Since the subcellular localization of proteins is often a highly regulated process, and specific localizations were indeed consistently observed for these IQD proteins, we tested the effects of altering their subcellular localization. Subcellular 

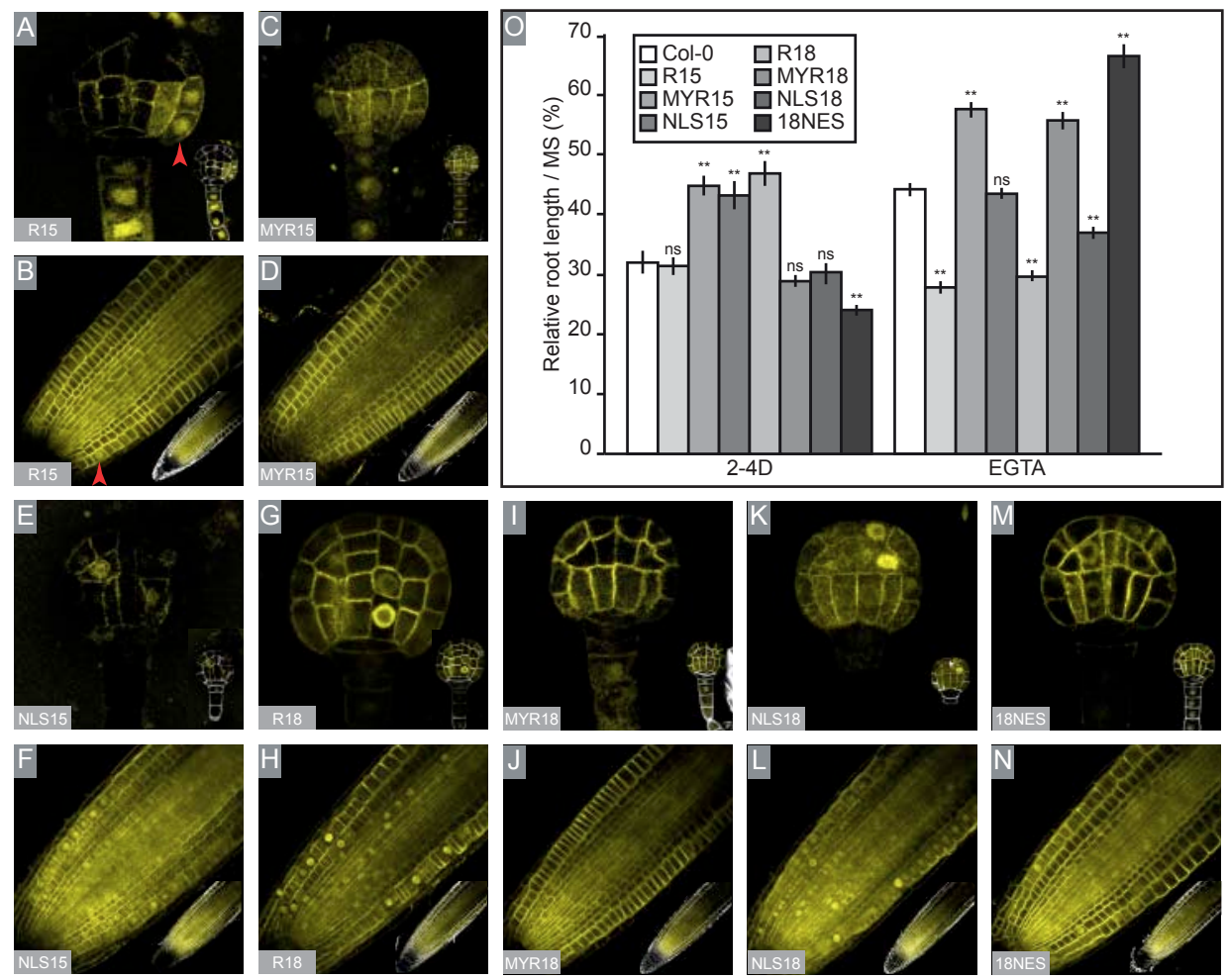

Figure 8: Misexpression and mislocalization of IQD proteins reveals role for nuclear localized protein in calcium signaling

Protein localization of indicated misexpression/mislocaliztion lines in globular stage of embryo development (A,C,E,G,I,K, and $M$ ) and five-day-old seedling roots (B,D,F,H,J,K, and $N)$. O: Bar diagram showing root length (in percentages) of 2-4D and EGTA treated seedlings relative to untreated root lengths. $n s=p$-value $>0.05 ;{ }^{*}=p$-value $<0.05 ;{ }^{* *}=p$-value $<0.001$ based on Student's T-test. Error bars indicate standard error of the mean $(n \geq 40)$.

localization of proteins can easily be changed through use of genetically encoded localization tags. We made use of three such tags: N-terminal myristoylation (MYR) for membrane anchoring (Traverso et al., 2013; pRPS5A::MYR:IQD15:sYFP [MYR15] and pRPS5A::MYR:IQD18:sYFP [MYR18]), N-terminal nuclear localization signal (NLS) for nuclear targeting (Lange et al., 2007; pRPS5A::NLS:IQD15:sYFP [NLS15] and pRPS5A::NLS:IQD18:sYFP [NLS18]), and C-terminal Nuclear Export Signal (NES) for export out of the nucleus (Gallagher and Benfey, 2009; pRPS5A::IQD18:NES-sYFP [18NES]). Addition of localization tags indeed resulted in altered localization of both IQD proteins (Figure 8C-F and I-N), but did not seem to affect the root tip or embryonic appearance. Interestingly, membrane anchoring through the MYR-tag seemed to completely abolish the IQD18 nuclear localization (Figure $8 \mathrm{I}$ and $\mathrm{J}$ ), but seemed to at least partially retain lateral polarity (Supplementary 
Figure 3D), similar to MYR15 (Figure 8C and D and Supplementary Figure 3B). Addition of a nuclear localization signal resulted in increased nuclear localization for both proteins, although localization was not exclusively in the nucleus, as some signal could still be detected in the cytoplasm and at the edges of the cell (Figure 8E, F, I, and J). This type of mislocalization also supports the idea of cell type specific mechanisms of localization, as nuclear protein was more prominently observed in epidermal cells than in any of the inner tissues, for both NLS15 and -18 (Supplementary Figure 3E-H). Although not $100 \%$ effective, addition of a nuclear export signal to the IQD18 protein decreased the amount of nuclear localized protein in $18 \mathrm{NES}$ lines (compare Figure $8 \mathrm{G}-\mathrm{H}$ to $8 \mathrm{M}-\mathrm{N}$ ), but did not affect localization in any other way.

To assess the physiological relevance of protein localization, we tested the response of these transgenic lines to auxin and EGTA in roots. Interestingly, the MYR15, NLS15, and R18 lines were significantly more resistant to auxin treatment, implicating these proteins in mediating auxin responses in the root (Figure 80). Intriguingly, treatment with EGTA revealed a role for nuclear-localized IQD protein in mediating sensitivity to EGTA, as all lines with reduced or abolished nuclear localization (i.e. MYR15, MYR18, and 18NES) also showed increased resistance to EGTA (Figure 80). Conversely, both R15 and R18 showed a reduced EGTA resistance. These results show that, by virtue of their dynamic subcellular localization, IQD proteins mediate auxin and calcium signals in the Arabidopsis root.

\section{Discussion}

This study was aimed at identifying a role for the IQD15-18 subclade of IQD proteins during embryo and root development in Arabidopsis. These proteins were identified based on auxin/ARF-dependent gene regulation, and gain-of-function of IQD15 and 18 indeed resulted in differential auxin sensitivity. This indicates a possible role for these proteins in the auxin-signaling pathway, even though their specific involvement remains elusive. Since we were unable to find knockout lines for IQD15 and 16 in available insertion line collections, the scope of their biological role is unclear at present. Newly developed techniques for genome editing (i.e. CRISPRCas9; Bortesi and Fisher, 2014) should in principle allow us to generate proper lossof-function lines for all four genes in the near future. Extensive effort has already been put into generating these lines; this has, however, not yet resulted in plants with mutated IQD genes (data not shown). Given the phylogenetic patterns of this IQD family subclade, and supported by the similar behavior of the IQD15, -17 and 


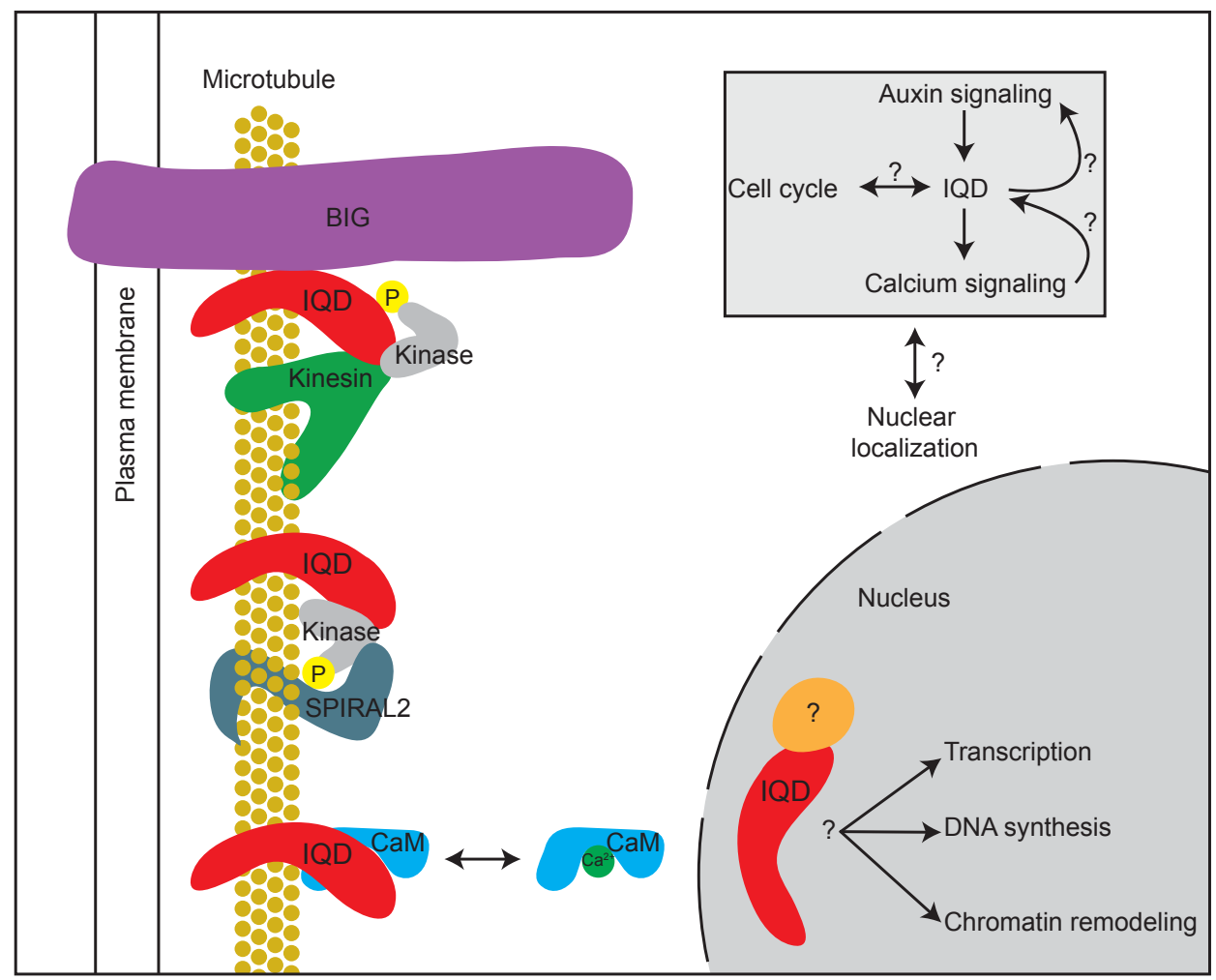

Figure 9: Schematic representation of results and proposed model.

-18 proteins, it is likely that these genes act redundantly. Indeed, preliminary data from a collaborative study characterizing the single rice co-ortholog of AtIQD15-18 (named OsIQD14), showed dramatic phenotypes ranging from smaller seeds to shorter roots and even rootless seedlings (Baojun Yang and Hongwei Xue, personal communication). This supports the hypothesis that AtIQD15-18 may act redundantly and would in fact be contributing to the establishment of the root apical meristem, likely downstream of MONOPTEROS.

A functional aspect that can be deduced from the IP-MS/MS data is a possible role for the IQD proteins directing microtubule orientation, as they were found to interact with SPIRAL2, which was proposed to prevent Katanin-mediated microtubule severing by blocking access to crossover sites (Wightman et al., 2013). SPIRAL2 was also proposed to be phosphorylated, although the functionality of this is currently unknown (Wightman et al., 2013). Given that a protein kinase was robustly found in the IQD complexes, it could be that IQD proteins bring SPIRAL2 and a protein kinase together, functioning as binding hub or docking station at the microtubules, allowing post-translational modifications to occur. Additionally, IQD17 
and IQD18 both interact with the BIG protein. BIG is related to other eukaryotic proteins, like Drosiphila CALOSSIN (Gil et al., 2001; Luschnig, 2001), which is a Calmodulin binding protein involved in directing intracellular vesicle transport. This further supports a role for IQD proteins in calcium- and MT-dependent processes. Although these functional aspects remain speculative, they do give good indications to focus further studies.

Interestingly, further data from the same collaborative study in rice, showed that protein localization of OsIQD14 is similar to that of AtIQD18 and that it also binds microtubules (Baojun Yang and Hongwei Xue, personal communication). This suggests that AtIQD18 has possibly retained ancestral localization properties that have become less prominent in IQD15 and IQD17, and that the localization could be an important feature of the protein. It is of note that when overexpressed, IQD15 localizes like IQD18 protein, suggesting that also IQD15 has retained the same localization capacity. Using genetically encoded tags we were able to mislocalize IQD15 and -18, which strikingly resulted in differential sensitivity to calcium chelation by EGTA. This also supports the idea that localization is important for function, especially nuclear localization, since the lines with reduced nuclear protein also show a reduced sensitivity to EGTA treatment. This somehow links these proteins to response to calcium, perhaps through increased affinity to Calmodulins in low calcium conditions. An open question that remains is whether the relocalization of IQD18 during the cell cycle is caused by fluxes in calcium concentrations. At least two different scenarios could take place where on the one hand IQD18 relocalization could be dependent on the cell cycle and on the other hand the cell cycle could be dependent on IQD18 relocalization. Although the first scenario is perhaps the most plausible, especially since there did not seem to be major effects on division rate in the iqd18 mutant, it will be interesting to test both hypotheses. The mislocalization lines will be helpful tools to dissect the effect of localization, once good (higherorder) loss-of-function mutants are available. Good loss-of-function mutants will also enable us to assess the functionality of all the translational fusion proteins used in this study, through complementation studies. In addition, it would be interesting to assess whether the IQDs bind different proteins at different locations or share the same partners, how the interaction between IQD and microtubules and Calmodulins occurs at the molecular level, and what the contribution of the IQ-domain is to both localization and interaction partners. Since secondary and tertiary protein structures are not easily predicted, especially for proteins without structurally well-characterized domains (like the IQDs), a structural biology approach might shed more light on how these proteins interact with other proteins and what function they might fulfill. 
In conclusion and schematically represented in Figure 9, we have identified auxin regulated IQD proteins that are expressed in regions corresponding with high auxin and key specification events during development. Functional and biochemical characterization suggests a role for these proteins in both auxin and calcium signaling, and by binding to factors involved in both signaling pathways they therefore might form a bridge between these to pathways.

\section{Methods}

\section{Genome mining and phylogenetic tree assembly}

Multiple sequence alignment was performed on protein sequences of all (full length) Arabidopsis IQD proteins, and a phylogenetic tree was assembled using only nongap generating sequences, using MAFFT (Katoh and Standley, 2013) and AtIQD33 was used to root the tree. Protein sequences of AtIQD15-18 were used as query in a BLAST to find related proteins in transcriptome databases of different species. Reciprocal BLAST on Arabidopsis protein database was used to filter the recovered hits and only those hits that resulted in IQD15-18 as top hit were kept.

\section{Plant material and growth conditions}

T-DNA insertion lines (SAIL_71_D08 [iqd15-1], CSHL_GT9529 [iqd15-2], FLAG_392E05 [iqd16-1], FLAG_379B08 [iqd17-1], WiscDsLox477-480A11 [iqd172], SALK_144532 [iqd18-1]) were obtained from the Nottingham Arabidopsis Stock Centre (NASC) and genotyped using primers listed in Supplementary Table 1. Arabidopsis ecotype Col-0 served as wild-type reference in all cases. All seeds were surface sterilized, stratified for at least $24 \mathrm{hrs}$ at $4^{\circ} \mathrm{C}$ and grown on MS plates containing appropriate selective media and grown in a climate chamber in standard long-day (16:8-h light/dark) conditions at $22^{\circ} \mathrm{C}$. Fourteen-day-old seedlings were transferred to soil and grown further in the same conditions.

Chemical and hormone treatments were performed by either germinating seeds on supplemented media or transferring seedlings from normal media to supplemented media and continuing growth for indicated time. Root length assays were performed by germinating seeds on unsupplemented control media or media containing $40 \mathrm{nM} 2-4 \mathrm{D}$ or $2 \mathrm{mM}$ EGTA. Primary roots of five-day-old seedlings were measured using ImageJ software. Relative root length after treatment was calculated based on the average root length of the untreated control and statistics was performed using a Student's t-test, thereby assuming all measured roots as 
independent measurements. Representative data from two biological replicates are shown.

\section{Cloning and plant transformation}

Promoter and whole genomic fusions were prepared by cloning up to $3 \mathrm{~kb}$ upstream of the start codon into the pPLV04 vector or by cloning the promoter fragment including downstream genomic region up to the stop codon into the PPLV16 vector, respectively, using Ligation Independent Cloning (LIC; De Rybel et al 2011; Chapter 2 of this thesis) and primers described in Supplementary Table 1. Misexpression and mislocalization constructs were generated by cloning either the genomic region (IQD15) or coding sequence (IQD18) into a custom made LIC vector containing the RPS5A promoter upstream and a super Yellow Fluorescent Protein (sYFP) downstream of the LIC-site (pPLV43B; Che-Yang Liao, unpublished), for mislocalization, tags were genetically encoded by incorporation into the primer sequence (as listed in Supplementary Table 1). All constructs were confirmed by sequencing and transformed into Arabidopsis using a previously described simplified method for floral dipping (De Rybel et al. 2011). Representative pictures from at least three independent transgenic lines are shown.

\section{RNA extraction and relative expression analysis}

RNA was extracted from five-day-old Arabidopsis seedlings or seedling roots using TriZol (Invitrogen) and subsequently subjected to column purification using an RNeasy Plant Kit (Qiagen) following manufacturers instructions. Concentration and quality of RNA was assessed using a NanoDrop (ThermoScientific) and normalized amounts of RNA were used to generate cDNA using an iScript kit (Bio-Rad). Relative expression was analyzed by quantitative-real-time PCR (qPCR), using $\mathrm{iQ}$ SYBR green mix (Bio-Rad), the primers listed in Supplementary Table 1, and expression values were normalized against two reference genes (i.e. ACTIN2 and EEF1), using qBase software (Hellemans et al., 2007).

\section{Microscopy}

Differential Interference Contrast and Confocal Laser Scanning Microscopy were performed on embryos and roots as previously described (Llavata-Peris et al. 2013; Chapter 4 of this thesis). Additionally, sYFP was visualized by excitation at 514 $\mathrm{nm}$ and detection between 525 and $600 \mathrm{~nm}$. In order to provide proper access for microscopy and enough water and nutrients during time-lapse imaging, five-dayold seedlings were kept in between a large cover slip and a piece of MS media. 
Brightness and contrast were adjusted using ImageJ software.

\section{Immunoprecipitation followed by tandem mass-spectrometry (IP-MS)}

IP-MS was performed, as described in Chapter 3 of this thesis, on up to 3 grams of siliques or five-day-old seedling roots of transgenic Arabidopsis plants harboring translational fusion constructs of pIQD15::gIQD15-sYFP, pIQD17::gIQD17-sYFP or pIQD18::gIQD18-sYFP. The same material from Col-0 wild-type plants was collected as control sample. Each sample was performed in triplicate for follow-up statistics. Calcium and EGTA treatment was performed by respectively adding $100 \mathrm{mM}$ and 20 $\mathrm{mM}$ during the last five minutes of the extraction step.

\section{Analysis of division rate by EdU staining}

The number of mitotically active cells, i.e. cells in S-phase, was determined by accumulation of 5-Ethynyl-2'-deoxyuridine (EdU) using a Click-iT EdU imaging kit (Invitrogen), as previously described (Kotogany et al., 2010). Briefly: five-day-old Arabidopsis seedlings (Col-0, iqd17-2, and iqd18-1) were grown for 2 hours in liquid MS media containing $5 \mu \mathrm{M}$ EdU. Seedlings were fixed in $2 \%$ formaldehyde and $0.1 \%$ TritonX100, and incubated for 30 minutes in Click-iT reaction cocktail containing Alexa555-Fluor and additionally stained with 4',6-diamidino-2-phenylindole (DAPI) stain (ThermoFisher Scientific) for nuclear visualization. Samples were mounted in Fluoromount G (eBioscience) and visualized using a Leica SP5II system, as described above. DAPI and Alexa555 were excited at 405 and $561 \mathrm{~nm}$ and emission was measured between 410 and $500 \mathrm{~nm}$, and 565 and $650 \mathrm{~nm}$, respectively.

\section{Acknowledgements}

The authors would like to thank the following people for support: Che-Yang Liao and Tatyana Radoeva courteously provided unpublished material: the pPLV43B vector and p35S::GFP:MAP65-1 MT marker by C-YL and cDNA of auxin treated seedlings by TR; Evert-Jan Bakker for help with statistics; Jan Willem Borst of Wageningen Microspectroscopy Centre for help with microscopy; Ben Scheres and Wenkun Zhou for help with EdU staining; Sjef Boeren for MS measurements; and Mark Roosjen for help with volcano plots. This work was supported by a Starting Grant from the European Research Council (ERC; CELLPATTERN) to D.W.. 


\section{References}

Abel, S., T. Savchenko and M. Levy (2005). "Genome-wide comparative analysis of the IQD gene families in Arabidopsis thaliana and Oryza sativa." BMC Evol Biol 5: 72.

Berleth, T. and G. Jurgens (1993). "The role of the monopteros gene in organising the basal body region of the Arabidopsis embryo." Development 118(2): 575-587.

Bortesi, L. and R. Fischer (2015). "The CRISPR/Cas9 system for plant genome editing and beyond." Biotechnol Adv 33(1): 41-52.

Burstenbinder, K., T. Savchenko, J. Muller, A. W. Adamson, G. Stamm, R. Kwong, B. J. Zipp, D. C. Dinesh and S. Abel (2013). "Arabidopsis calmodulin-binding protein IQ67-domain 1 localizes to microtubules and interacts with kinesin light chain-related protein-1." J Biol Chem 288(3): 1871-1882.

Cools, T., A. lantcheva, S. Maes, H. Van den Daele and L. De Veylder (2010). "A replication stress-induced synchronization method for Arabidopsis thaliana root meristems." Plant J 64(4): 705-714.

Day, I. S., C. Miller, M. Golovkin and A. S. Reddy (2000). "Interaction of a kinesin-like calmodulin-binding protein with a protein kinase." J Biol Chem 275(18): 13737-13745.

De Rybel, B., M. Adibi, A. S. Breda, J. R. Wendrich, M. E. Smit, O. Novak, N. Yamaguchi, S. Yoshida, G. Van Isterdael, J. Palovaara, B. Nijsse, M. V. Boekschoten, G. Hooiveld, T. Beeckman, D. Wagner, K. Ljung, C. Fleck and D. Weijers (2014). "Plant development. Integration of growth and patterning during vascular tissue formation in Arabidopsis." Science 345(6197): 1255215.

De Rybel, B., B. Moller, S. Yoshida, I. Grabowicz, P. Barbier de Reuille, S. Boeren, R. S. Smith, J. W. Borst and D. Weijers (2013). "A bHLH complex controls embryonic vascular tissue establishment and indeterminate growth in Arabidopsis." Dev Cell 24(4): 426437.

De Rybel, B., W. van den Berg, A. Lokerse, C. Y. Liao, H. van Mourik, B. Moller, C. L. Peris and D. Weijers (2011). "A versatile set of ligation-independent cloning vectors for functional studies in plants." Plant Physiol 156(3): 1292-1299.

Dharmasiri, N., S. Dharmasiri and M. Estelle (2005). "The F-box protein TIR1 is an auxin receptor." Nature 435(7041): 441-445.

Gallagher, K. L. and P. N. Benfey (2009). "Both the conserved GRAS domain and nuclear localization are required for SHORT-ROOT movement." Plant J 57(5): 785-797.

Gil, P., E. Dewey, J. Friml, Y. Zhao, K. C. Snowden, J. Putterill, K. Palme, M. Estelle and J. Chory (2001). "BIG: a calossin-like protein required for polar auxin transport in Arabidopsis." Genes Dev 15(15): 1985-1997.

Gray, W. M., S. Kepinski, D. Rouse, O. Leyser and M. Estelle (2001). "Auxin regulates SCF(TIR1)-dependent degradation of AUX/IAA proteins." Nature 414(6861): 271-276.

Guilfoyle, T. J. and G. Hagen (2007). "Auxin response factors." Curr Opin Plant Biol 10(5): 453-460.

Hardtke, C. S. and T. Berleth (1998). "The Arabidopsis gene MONOPTEROS encodes a transcription factor mediating embryo axis formation and vascular development." EMBO J 17(5): 1405-1411.

Hellemans, J., G. Mortier, A. De Paepe, F. Speleman and J. Vandesompele (2007). "qBase relative quantification framework and software for management and automated analysis of real-time quantitative PCR data." Genome Biol 8(2): R19.

Hepler, P. K. (2005). "Calcium: a central regulator of plant growth and development." Plant Cell 17(8): 2142-2155.

Katoh, K. and D. M. Standley (2013). "MAFFT multiple sequence alignment software version 7: improvements in performance and usability." Mol Biol Evol 30(4): 772-780. 
Kepinski, S. and O. Leyser (2005). "The Arabidopsis F-box protein TIR1 is an auxin receptor." Nature 435(7041): 446-451.

Kim, G. T., K. Shoda, T. Tsuge, K. H. Cho, H. Uchimiya, R. Yokoyama, K. Nishitani and H. Tsukaya (2002). "The ANGUSTIFOLIA gene of Arabidopsis, a plant CtBP gene, regulates leaf-cell expansion, the arrangement of cortical microtubules in leaf cells and expression of a gene involved in cell-wall formation." EMBO J 21(6): 1267-1279.

Knight, H., A. J. Trewavas and M. R. Knight (1997). "Calcium signalling in Arabidopsis thaliana responding to drought and salinity." Plant J 12(5): 1067-1078.

Kotogany, E., D. Dudits, G. V. Horvath and F. Ayaydin (2010). "A rapid and robust assay for detection of S-phase cell cycle progression in plant cells and tissues by using ethynyl deoxyuridine." Plant Methods 6(1): 5.

Lange, A., R. E. Mills, C. J. Lange, M. Stewart, S. E. Devine and A. H. Corbett (2007). "Classical nuclear localization signals: definition, function, and interaction with importin alpha." J Biol Chem 282(8): 5101-5105.

Liao, C. Y., W. Smet, G. Brunoud, S. Yoshida, T. Vernoux and D. Weijers (2015). "Reporters for sensitive and quantitative measurement of auxin response." Nat Methods 12(3): 207-210, 202 p 210.

Llavata-Peris, C., A. Lokerse, B. Moller, B. De Rybel and D. Weijers (2013). "Imaging of phenotypes, gene expression, and protein localization during embryonic root formation in Arabidopsis." Methods Mol Biol 959: 137-148.

Lokerse, A. S. and D. Weijers (2009). "Auxin enters the matrix--assembly of response machineries for specific outputs." Curr Opin Plant Biol 12(5): 520-526.

Luschnig, C. (2001). "Auxin transport: why plants like to think BIG." Curr Biol 11(20): R831833.

Möller, B. and D. Weijers (2009). "Auxin control of embryo patterning." Cold Spring Harb Perspect Biol 1(5): a001545.

Möller, B. K. (2012). Identification of novel MONOPTEROS target genes in embryonic root initiation. Thesis Wageningen University.

Reed, J. W. (2001). "Roles and activities of Aux/IAA proteins in Arabidopsis." Trends Plant Sci 6(9): 420-425.

Ruegger, M., E. Dewey, W. M. Gray, L. Hobbie, J. Turner and M. Estelle (1998). "The TIR1 protein of Arabidopsis functions in auxin response and is related to human SKP2 and yeast grr1p." Genes Dev 12(2): 198-207.

Schlereth, A., B. Moller, W. Liu, M. Kientz, J. Flipse, E. H. Rademacher, M. Schmid, G. Jurgens and D. Weijers (2010). "MONOPTEROS controls embryonic root initiation by regulating a mobile transcription factor." Nature 464(7290): 913-916.

Tian, J., L. Han, Z. Feng, G. Wang, W. Liu, Y. Ma, Y. Yu and Z. Kong (2015). "Orchestration of microtubules and the actin cytoskeleton in trichome cell shape determination by a plant-unique kinesin." Elife 4.

Tiwari, S. B., G. Hagen and T. Guilfoyle (2003). "The roles of auxin response factor domains in auxin-responsive transcription." Plant Cell 15(2): 533-543.

Tiwari, S. B., X. J. Wang, G. Hagen and T. J. Guilfoyle (2001). "AUX/IAA proteins are active repressors, and their stability and activity are modulated by auxin." Plant Cell 13(12): 2809-2822.

Traverso, J. A., C. Micalella, A. Martinez, S. C. Brown, B. Satiat-Jeunemaitre, T. Meinnel and C. Giglione (2013). "Roles of N-terminal fatty acid acylations in membrane compartment partitioning: Arabidopsis h-type thioredoxins as a case study." Plant Cell 25(3): 10561077.

Vinogradova, M. V., G. G. Malanina, J. S. Waitzman, S. E. Rice and R. J. Fletterick (2013). "Plant Kinesin-Like Calmodulin Binding Protein Employs Its Regulatory Domain for 
Dimerization." PLoS One 8(6): e66669.

Weijers, D., M. Franke-van Dijk, R. J. Vencken, A. Quint, P. Hooykaas and R. Offringa (2001). "An Arabidopsis Minute-like phenotype caused by a semi-dominant mutation in a RIBOSOMAL PROTEIN S5 gene." Development 128(21): 4289-4299.

Weijers, D., A. Schlereth, J. S. Ehrismann, G. Schwank, M. Kientz and G. Jurgens (2006). "Auxin triggers transient local signaling for cell specification in Arabidopsis embryogenesis." Dev Cell 10(2): 265-270.

Wightman, R., G. Chomicki, M. Kumar, P. Carr and S. R. Turner (2013). "SPIRAL2 determines plant microtubule organization by modulating microtubule severing." Curr Biol 23(19): 1902-1907.
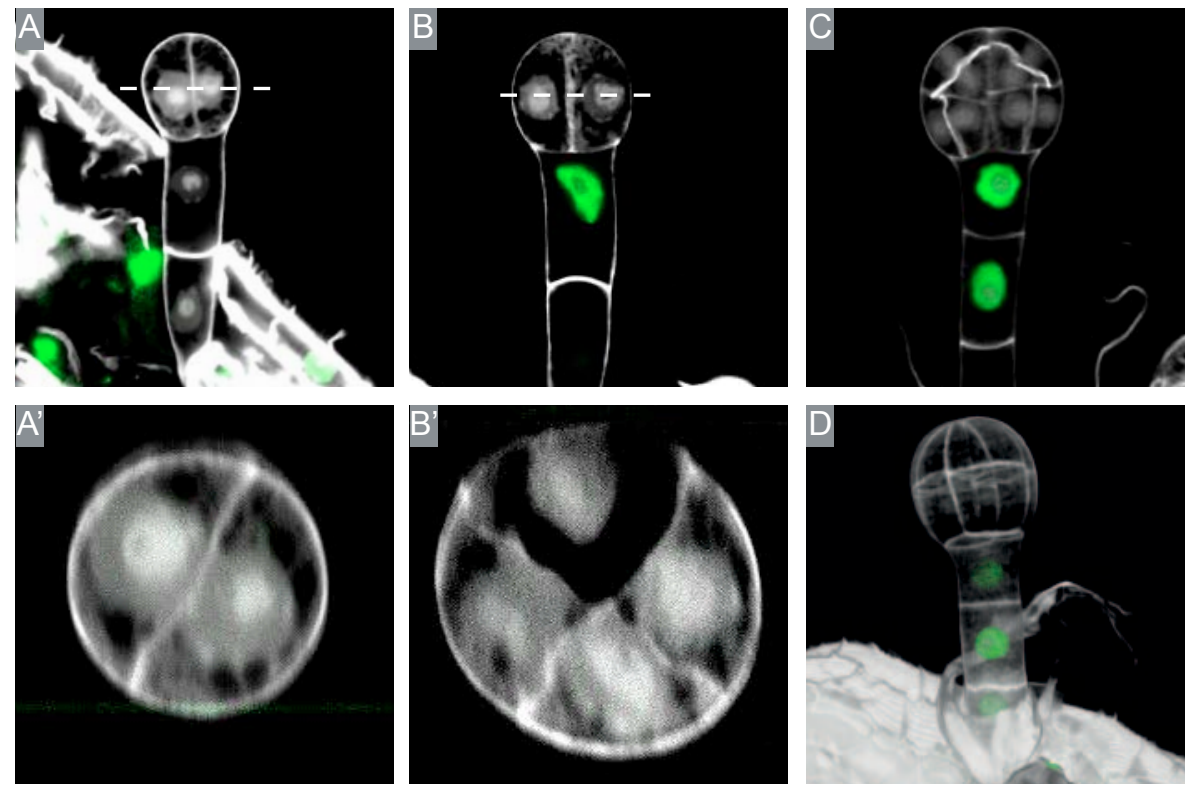

Supplementary Figure 1: Expression of IQD16 starts at four-cell stage of embryo development. A: two-cell stage embryo (cross-section at dashed line [A']) without expression. B: Four-cell stage embryo (cross-section at dashed line [B']) with expression in upper suspensor cell. Expression in suspensor cells of eight-cell (D) and determagen stage (C). 

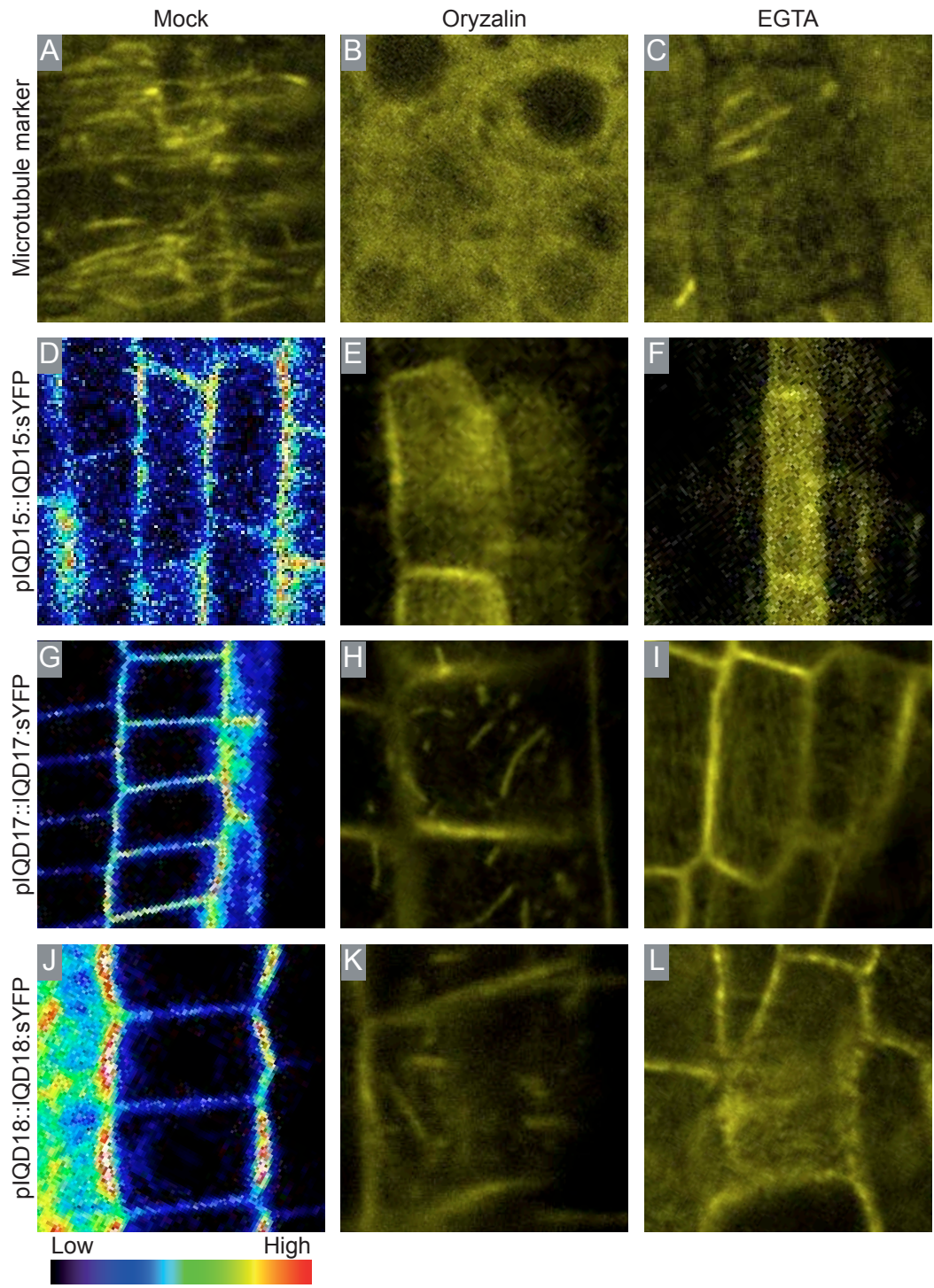

Supplementary Figure 2: IQD proteins are associated to microtubules

Microtubule marker in root cells of mock (A), Oryzalin (B) and EGTA (C) treated roots. False color images of root cells expressing IQD15 (D), $-17(\mathrm{G})$, or $-18(\mathrm{~J})$, showing polarity of protein localization. IQD15 (E and F), -17 ( $\mathrm{H}$ and I), and -18 (K and L) localization after Oryzalin and EGTA treatment. 


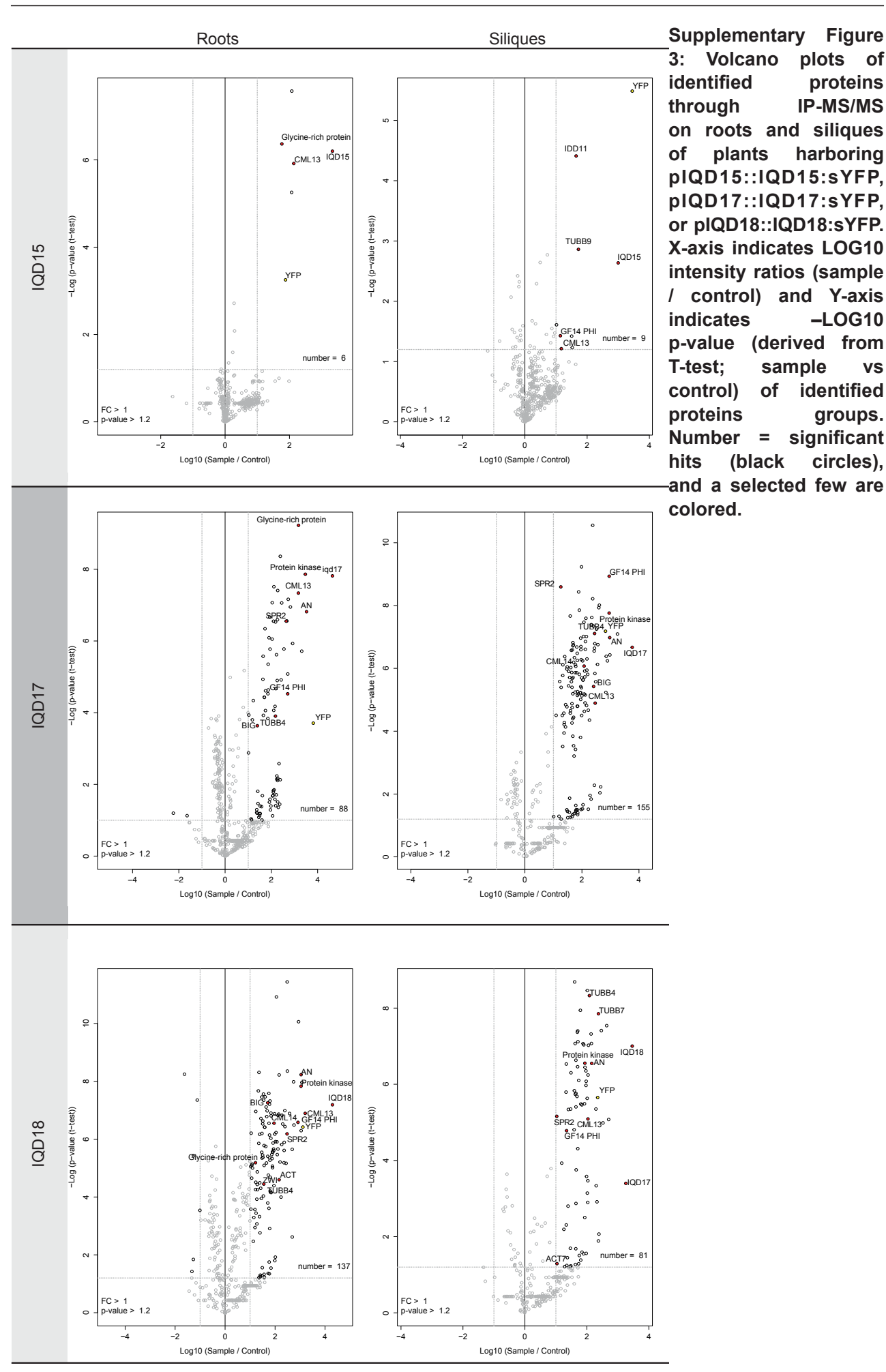



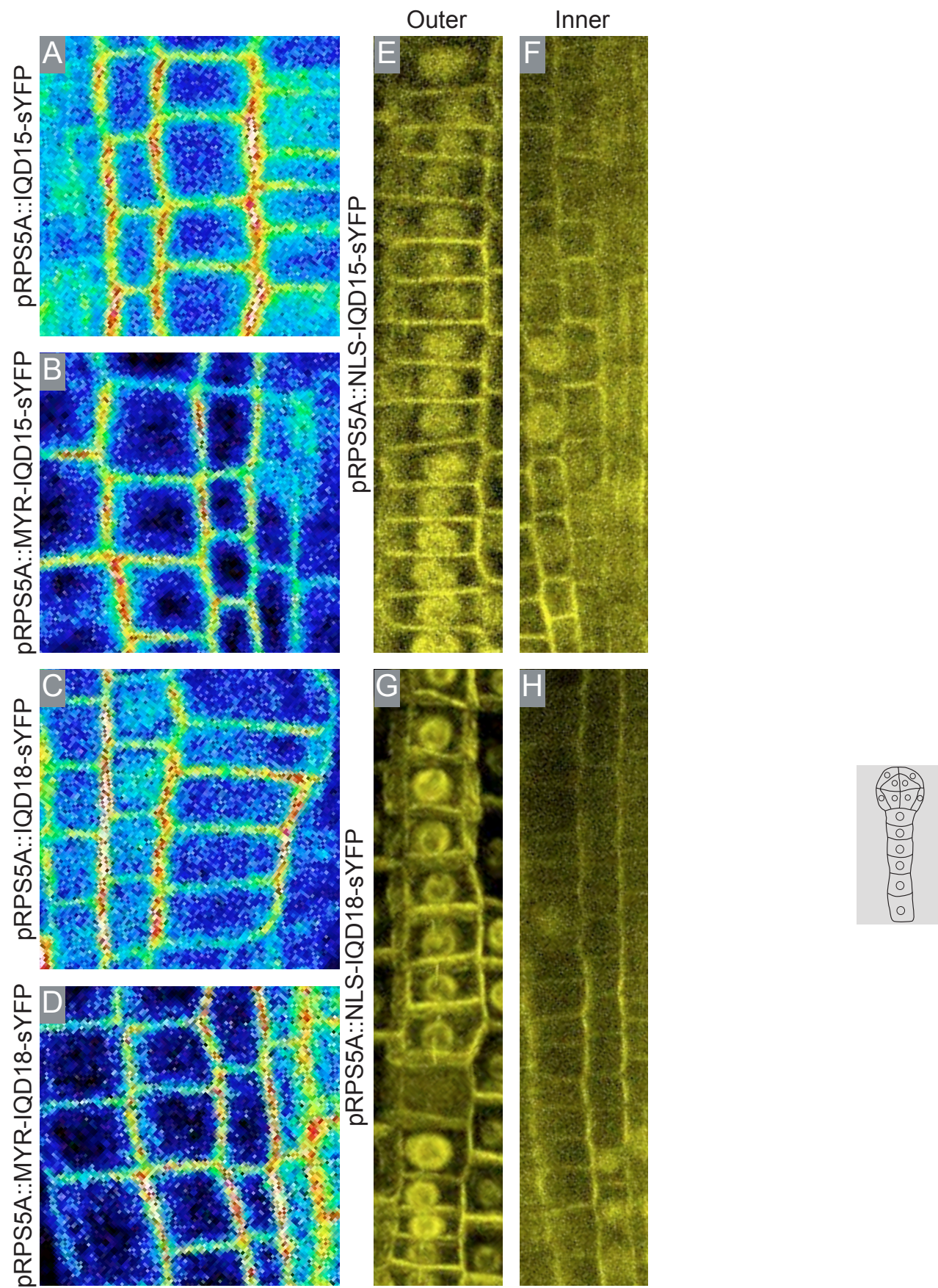

Supplementary Figure 4: Polarity and cell type specific localization of misexpressed IQD proteins Lateral polarity is kept in misexpressed and membrane anchored IQD15 and -18 proteins (A-D). More nuclear localized protein in outer tissues ( $E$ and $G)$ than in inner tissues ( $F$ and $H$ ), for IQD15 and -18 with nuclear localization signal. 
Supplementary Table 1: List of oligonucleotides used in this study

Promoter ( $p)$ and translational fusions ( $t)$

\begin{tabular}{|c|c|c|}
\hline Gene & Sense/Antisense & Sequence \\
\hline IQD15 & Sense & 5'-TAGTTGGAATGGGTTCGAACCGGAGATCTTAAAATTATATAGC-3' \\
\hline IQD15 & Antisense (p) & 5'-TTATGGAGTTGGGTTCGAACAAGATCGATCAACCTCGTCTGC-3' \\
\hline IQD15 & Antisense (t) & 5'-TTATGGAGTTGGGTTCGAACGTACTGAAAATCTTCGTGAGCATTCG-3' \\
\hline IQD16 & Sense & 5'-TAGTTGGAATGGGTTCGAACCGGAGATTTGATTTTTTTATCG-3' \\
\hline IQD16 & Antisense (p) & 5'-TTATGGAGTTGGGTTCGAAATTGAATTAACGTTTTCTAAAAGCG-3' \\
\hline IQD17 & Sense & 5'-TAGTTGGAATGGGTTCGAAGCAAAACCAAGTAATCACAAAAACC-3' \\
\hline IQD17 & Antisense $(p)$ & 5'-TTATGGAGTTGGGTTCGAATGGAGGTTAGGTAGGATTTAAGATTC-3' \\
\hline IQD17 & Antisense (t) & 5'-TTATGGAGTTGGGTTCGAACTCTTAACCATCGCCTATAATCGC-3' \\
\hline IQD18 & Sense & 5'-TAGTTGGAATGGGTTCGAACCTGAAACGATTCAAAAACAG-3' \\
\hline IQD18 & Antisense (p) & 5'-TTATGGAGTTGGGTTCGAAGTGTAATGTGTTTAATTACTTTTGG-3' \\
\hline IQD18 & Antisense (t) & 5'-TTATGGAGTTGGGTTCGAACGTGACTTTAGGAATTGGCTTAGA-3' \\
\hline \multicolumn{3}{|l|}{ qPCR } \\
\hline Gene & Sense/Antisense & Sequence \\
\hline IQD15 & Sense & 5'-CCGACCACAAAGCGTACC-3' \\
\hline IQD15 & Antisense & 5'-AATCTTCGTGAGCATTCGTTCT-3' \\
\hline IQD16 & Sense & 5'-GTAACAACTCATCATCATCAG-3' \\
\hline IQD16 & Antisense & 5'-CACCATAACGGATCTTGA-3' \\
\hline IQD17 & Sense & 5'-TGATGATCTTTGAGATTGGT-3' \\
\hline IQD17 & Antisense & 5'-GAGATTAGTTAGTAAACACTTCC-3' \\
\hline IQD18 & Sense & 5'-GCCAAATCAACTGTCAAGA-3' \\
\hline IQD18 & Antisense & 5'-GAAGTTACAGATCAATAGGTCAA-3' \\
\hline ACTIN2 & Sense & 5'-CTCCATTTGTTTGTTTCA TT -3' \\
\hline ACTIN2 & Antisense & 5'-TCAATTCGATCACTCAGA -3' \\
\hline EEF & Sense & 5'-CTGGAGGTTTTGAGGCTGGTAT -3' \\
\hline EEF & Antisense & 5'-CCAAGGGTGAAAGCAAGAAGA -3' \\
\hline
\end{tabular}

\section{Insertion lines}

\begin{tabular}{lll}
\hline Line & Sense/Antisense & Sequence \\
\hline iqd15-1 / iqd15-2 & Sense & 5'-GCCCTAGTGAGAGGCCATAACGTTCG-3' \\
$i q d 15-1 / i q d 15-2$ & Antisense & 5'-CGAAAACATATAAATTCGACAAGTAC-3' \\
\hline$i q d 16-1$ & Sense & 5'-GGGCTGCCATTATTATTCAGACAGC-3' \\
$i q d 16-1$ & Antisense & 5'-CTGTTTTCCCAATTATCCCCCAAAAG-3' \\
\hline$i q d 17-1 / i q d 17-2$ & Sense & 5'-GCGGTTCTTCTTCTTCTTGGCTCAC-3' \\
$i q d 17-1 / i q d 17-2$ & Antisense & 5'-CCTGGTGAGAGAAAGCTTGTGATATAC-3' \\
\hline$i q d 18-1$ & Sense & 5'-CTTATTCGGTCAGCTAGTCCACGGTG-3' \\
$i q d 18-1$ & Antisense & 5'-GATCTCAAACTTTGTGTTTTCATGGC-3' \\
\hline
\end{tabular}




\section{Supplementary Table 1: Continued}

\section{Misexpression and mislocalization}

\begin{tabular}{|c|c|c|}
\hline Line & Sense/Antisense & Sequence \\
\hline R15 & Sense & 5'-TAGTTGGAATAGGTTCATGGGGAAAACCGACGGAAGCTCATGG-3' \\
\hline R15 & Antisense & 5'-AGTATGGAGTTGGGTTCTTGTACTGAAAATCTTCGTGAGCATTCG-3' \\
\hline \multirow[t]{2}{*}{ MYR15 } & Sense & 5'-TAGTTGGAATAGGTTCATGGGAGGATGCTTCTCTAAGAAGGG- \\
\hline & & GAAAACCGACGGAAGCTCATGG-3' \\
\hline MYR15 & Antisense & 5'-AGTATGGAGTTGGGTTCTTGTACTGAAAATCTTCGTGAGCATTCG-3' \\
\hline \multirow[t]{2}{*}{ NLS15 } & Sense & 5'-TAGTTGGAATAGGTTCATGCCTAAGAAGAAGAGGAAGGTTGG- \\
\hline & & GAAAACCGACGGAAGCTCATGG-3' \\
\hline NLS15 & Antisense & 5'-AGTATGGAGTTGGGTTCTTGTACTGAAAATCTTCGTGAGCATTCG-3' \\
\hline R18 & Sense & 5'-TAGTTGGAATAGGTTCATGGGGAAAAAGAACGGCTCTTCTTC-3' \\
\hline R18 & Antisense & 5'-AGTATGGAGTTGGGTTCTTTCTAAGCCAATTCCTAAAGTCACTAG-3' \\
\hline \multirow[t]{2}{*}{ MYR18 } & Sense & 5'-TAGTTGGAATAGGTTCATGGGAGGATGCTTCTCTAAGAAGGG- \\
\hline & & GAAAAAGAACGGCTCTTCTTCTTGG-3' \\
\hline MYR18 & Antisense & 5'-AGTATGGAGTTGGGTTCTTTCTAAGCCAATTCCTAAAGTCACTAG-3' \\
\hline \multirow[t]{2}{*}{ NLS18 } & Sense & 5'-TAGTTGGAATAGGTTCATGCCTAAGAAGAAGAGGAAGGTTGG- \\
\hline & & GAAAAAGAACGGCTCTTCTTCTTGG-3' \\
\hline NLS18 & Antisense & 5'-AGTATGGAGTTGGGTTCTTTCTAAGCCAATTCCTAAAGTCACTAG-3' \\
\hline 18NES & Sense & 5'-TAGTTGGAATAGGTTCATGGGGAAAAAGAACGGCTCTTCTTC-3' \\
\hline \multirow[t]{2}{*}{ 18NES } & Antisense & 5'-AGTATGGAGTTGGGTTCTTATCAAGAGTAAGTCTTTCAAGAGGAG- \\
\hline & & GAAGTTGAAGTCTAAGCCAATTCCTAAAGTCACTAG-3' \\
\hline
\end{tabular}





\section{Chapter 6}

\section{Organization of the Arabidopsis root meristem by opposing transcriptional gradients}

Jos R. Wendrich ${ }^{1}$, Barbara K. Möller ${ }^{1,2}$, Rosangela Sozzani ${ }^{3,4}$, Bert De Rybel ${ }^{1,5}$, Philip N. Benfey ${ }^{3}$ and Dolf Weijers ${ }^{1}$

1. Laboratory of Biochemistry, Wageningen University, Dreijenlaan 3, $6703 \mathrm{HA}$ Wageningen, the Netherlands

2. Current address: Department of Plant Systems Biology, VIB, and Department of Plant Biotechnology and Bioinformatics, Ghent University, 9052 Ghent, Belgium

3. Department of Biology and Howard Hughes Medical Institute, Duke University, 124 Science Drive, Durham, NC, 27708, USA.

4. Current address: Department of Plant and Microbial Biology, North Carolina State University, Raleigh, NC, United States

5. Department of Plant Systems Biology, VIB, and Department of PlantBiotechnology and Bioinformatics, Ghent University, 9052 Ghent, Belgium 



\section{Summary}

Stem cells are at the heart of continued growth in multicellular organisms. The question of how stem cells are specified and maintained throughout development has inspired research for many years. In plants, stem cells are kept in niches, called meristems at the apical ends of the plant. In search of genes that confer stem cell identity, we started this study at the point in development where stem cells are first established: during embryogenesis. We observed that genes expressed in the embryonic root stem cell precursors were not restricted to the proposed stem cells in the post-embryonic root. Rather than being restricted to those cells surrounding the QC, expression of these genes was found in a graded profile that was high close to the $Q C$ and gradually decreased in expression level when farther displaced from the QC. Using these gradient markers as tool, coupled to a differential cell sorting approach, we separated the root meristem into three ontogenetic cell populations, based on their distance from the QC. Subsequent transcriptomics and clustering analysis revealed that the most abundant group of genes was expressed in a graded profile and also showed a large number of genes expressed in an opposite gradient that was low near the QC and gradually increased in expression. Gene ontology enrichment revealed that genes expressed in a gradient that was high at the QC and lower further displaced from the QC were associated with development and cell division. Strikingly, genes expressed in a gradient that was low near the $\mathrm{QC}$ and higher farther away from the QC were found to associate with cell differentiation processes. In contrast, no clear functions were associated with genes expressed only near the $\mathrm{QC}$, nor did any known stem cell regulator follow this pattern. The promoter activity of a number of selected genes was found to match transcript profiles. Importantly, expression gradients are genetically controlled rather than simply an output of meristem length, and disruption of endogenous graded transcript profiles can lead to altered root development. Taken together, we propose an extended model for stem cell organization in the root apical meristem that includes two opposing gradients, one of "stemness" that gradually increases and one of differentiation that gradually increases. 


\section{Introduction}

Development and growth of multicellular organisms is dependent on continuous renewal and replenishment of cells in each tissue. This replenishment of cell occurs through action of self-renewing stem cells that by definition stay in an undifferentiated state, also referred to as "stemness", and are capable of generating multiple (differentiating) daughter cells upon division, while retaining their stemness (Scheres, 2007). Plants contain niches of stem cells, also called meristems that are maintained throughout plant life, and that elaborate body architecture post-embryonically (Duclercq et al., 2011). The two first meristems (Shoot- and Root Apical Meristem [respectively SAM and RAM]) are first established while other (lateral) meristems are established later (e.g. during development of lateral roots and shoot branches, as well as in vascular cambium) (De Rybel et al., 2016; Duclercq et al., 2011). The precise organization of stem cells in the meristems has been the subject of many years of research and much has been learned about a number of genes that are important for proper establishment and maintenance (e.g. Drisch and Stahl, 2015). The Arabidopsis RAM is highly organized with clearly distinguishable cell types and it has served as an easily accessible model system to study stem cell organization. The RAM generates cells to simultaneously extend both the "proximal" cell types (vascular tissue, ground tissue and epidermis and lateral root cap), and the "distal" central root cap. These proximal and distal meristem zones are separated by the organizing quiescent center (QC; reviewed by Bennett and Scheres, 2010). The distal meristem has clearly distinguishable cellular properties: one cell layer of stem cells, directly adjacent to the QC, and further layers of cells with clear differentiation markers, e.g. starch-granules. These differentiation markers are also present in the stem cells upon ablation of the $Q C$, which ultimately results in re-specification of the both QC and stem cells at a different position (van den Berg et al., 1997). This shows that at least for the distal root cap meristem, the QC is crucial for maintaining the stem cells. Properties of the proximal meristem have mostly been extrapolated from findings in the distal meristem, but are in fact more difficult to define. Clonal analysis revealed that, strictly operationally speaking, the only possible stem cells reside directly adjacent to the QC (Scheres et al., 1994), as only these gave rise to large clonal sectors. These combined data have resulted in a currently widely used model for the organization of stem cells in the RAM, schematically represented in Figure 1. So far however, it has not been demonstrated that these operational stem cells, contacting the QC, are indeed functionally and measurably different from their distal daughter cells. While several genes are known to mark cells of the QC or the root cap 


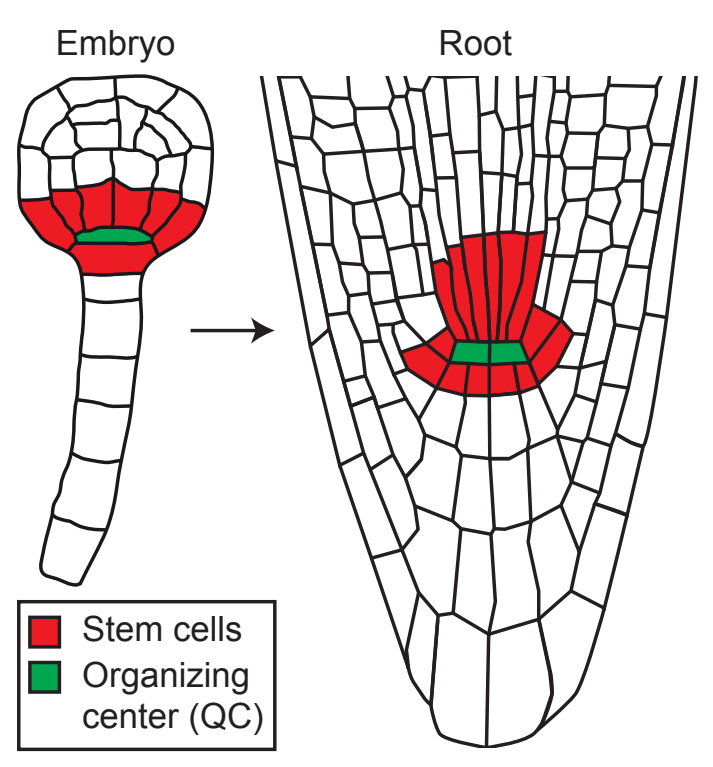

Figure 1: Currently used model for stem cell organization in the Arabidopsis root apical meristem; stem cells surround the organizing center (both specified during embryogenesis).

stem cells, no such genes are currently known that mark only those cells surrounding the QC in the proximal meristem. This makes it very difficult to infer identity of the stem cells in this system and raises the question of whether the plant makes a distinction between stem cells and non-stem cells in the proximal meristem, and if so, where the boundaries are. Interestingly, the de novo specification of root stem cells can be traced back to the embryonic development of Arabidopsis (Scheres et al., 1994). As discussed in Chapter 1 of this thesis, the first establishment of stem cells is apparent during the globular stage of embryogenesis, hallmarked by appearance of the three major tissue types (epidermis, ground tissue and vasculature) and perhaps more importantly, later also by the first asymmetric divisions of these tissue types (Yoshida et al., 2014; Chapter 4 of this thesis). This stage of development therefore functions as a great model to study the organization of stem cells in the root, in general. A key regulator of embryonic RAM establishment is the auxin response factor ARF5/MONOPTEROS (MP). Absence of this transcription factor results in erroneous divisions during the globular stage of embryo development and ultimately leads to rootless seedlings (Berleth \& Jurgens, 1993; Hardtke \& Berleth, 1998; Weijers et al., 2006). We have previously shown that this phenotype coincides with a loss of expression of genes that mark the stem cell precursors during this stage of development (Chapter 4 of this thesis), indicating MP may be involved in the specification of stem cells, or the definition of the stem cell zone. 
In this study we address how stem cells are organized and may be specified in the RAM. When analyzing the post-embryonic expression of MP-dependent genes expressed in the stem cell zone precursors in the embryo, we noticed that none were solely expressed in the cells surrounding the QC. Instead, all were expressed in a graded expression profile in the post-embryonic root, meaning that while these genes mark the stem cell precursors in early stages, conforming to the current model of stem cell organization, they did not do so post-embryonically. This gave rise to the following questions: (I) are there genes qualitatively distinguishing stem cells from other cells, (II) are more genes expressed in a gradient fashion, and (III) what type of genes would be expressed like this? To address these questions, we employed cell sorting coupled to a genome-wide approach to reveal genes expressed in different ontogenetic cell populations in the root apical meristem.

\section{Results}

Genes marking stem cell precursors are expressed in a gradient postembryonically

To molecularly characterize the organization of stem cells in the (developing) Arabidopsis RAM, we analyzed marker lines of genes expressed in the basal tier of the embryo, i.e. in the embryonic stem cell precursors. We have previously shown that the origin of the rootless phenotype seen in monopteros $(m p)$ mutants coincides with a loss of markers expressed in this region (Chapter 4 of this thesis). We thus focused our analysis on MP target genes expressed in the basal tier of the embryo, during early development (Figure 2A,D,G,J). Interestingly, while expression of these genes in the embryo follows behavior expected from stem cell factors (white arrowheads Figure $2 A, D, G, J$; Chapter 4 of this thesis), their expression in the post-embryonic root was not restricted to the cells directly surrounding the QC. Instead, these rather showed graded expression peaking near the $Q C$ and gradually decreasing in expression (Figure 2B,E,H,K). This transcriptional output corresponded with protein levels, as measured by translational fusions of the same genes to GFP or YFP (Figure 2C,F,I). Thus, the observed gradient does not appear to be due to stability of the GFP protein used for visualization in promoter-n3GFP lines. The observation that these genes are specific to stem cell precursors in the embryonic but not in the post-embryonic root indicates either of the following options: (I) these genes only mark stem cells in the embryo and are less specific in the post-embryonic root or (II) these genes are specific for the property of stemness in the post-embryonic root but this property is 

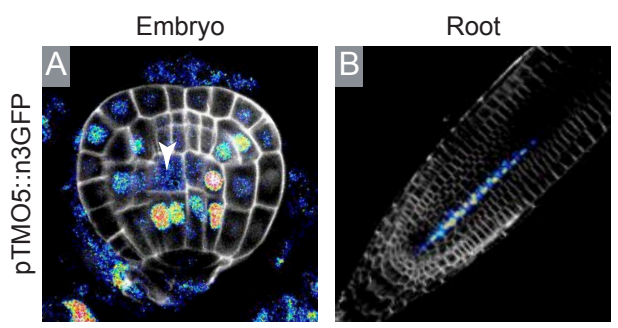

Translational fusion
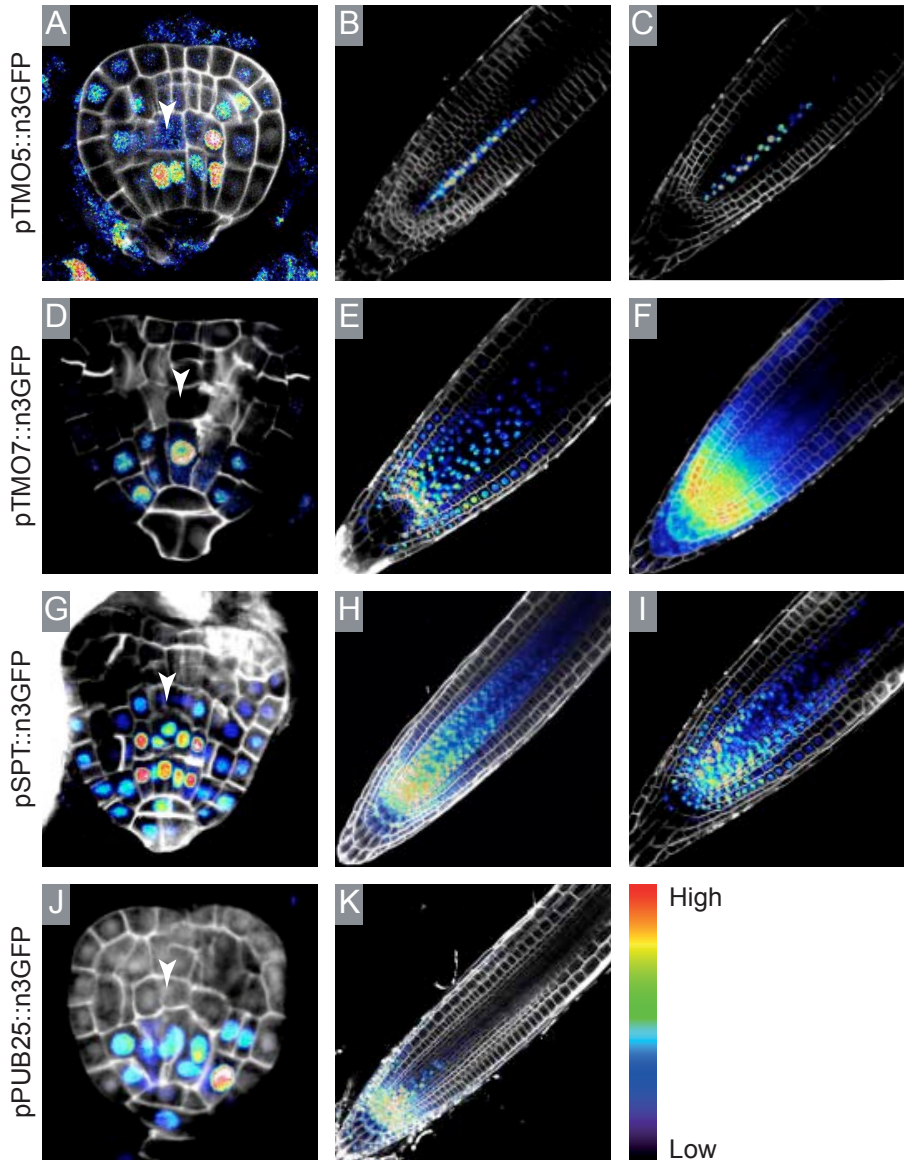

Figure 2: Genes expressed in embryonic stem cell precursors are expressed in gradients in the post-embryonic root

Expression of pTMO5::n3GFP, pTMO7::n3GFP, pSPT::n3GFP, and pPUB25::n3GFP in embryos (A, D, G, and J) and roots (B, E, H, and K); expression of pTM05::TMO5:3GFP, PTM07::TM07:GFP and pSPT::SPT:sYFP in roots (C, F, and I); fluorescence intensity is shown by indicated false coloring.

not restricted to the cells directly surrounding the QC. The first scenario predicts the existence of genes expressed only in the cells surrounding the QC, capable of conferring a stem cell identity to those cells. In the second scenario, there may not be such genes, but genes conferring stemness will be expressed in gradients.

\section{Intensity-based cell sorting can separate cell populations along gradients}

We aimed to determine the organization of the entire transcriptome in the proximal 


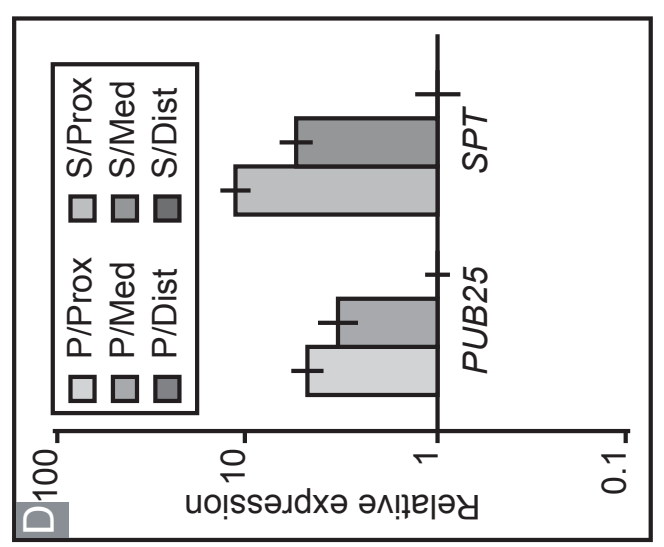

둥

के 高

등

นึ้

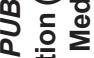

䨔

흥 핮

पु 응

는 웅

高焉

ڤ II

苞 苋

壱

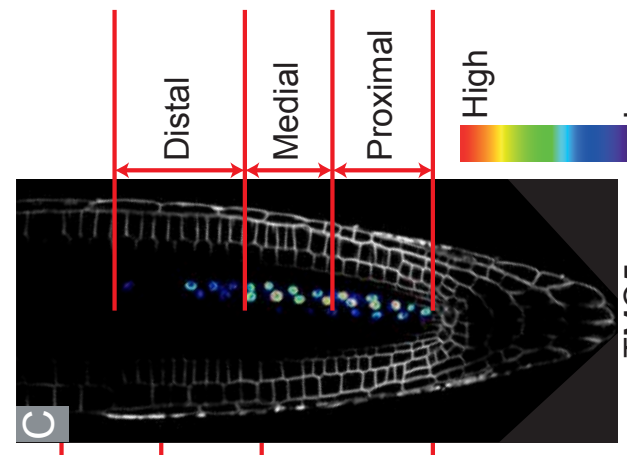

ब.

흥

बㅎํㅇ

츤 인

䓠。高

늘

:

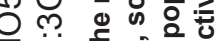

$\sum$ i

○约

을 인용

莞

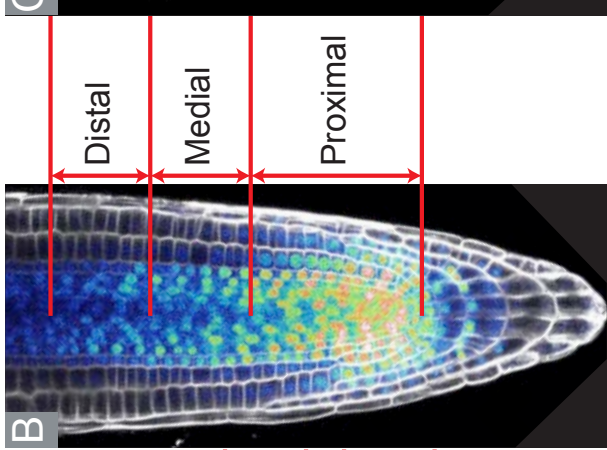

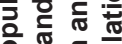

ํํำ음 응

$\overline{\bar{\delta}}$

的㐫

这文

은 这交焉

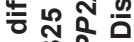

츈 向용

웡뉴

क क त 중

ऽ 잉 ฮ

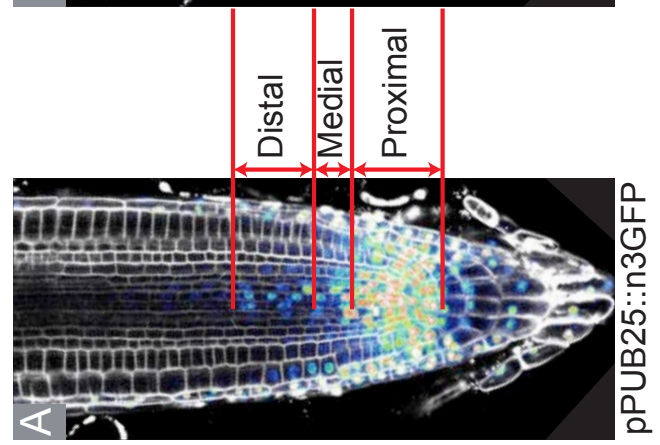

ํํำ

는 至 $\frac{E}{x}$

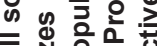

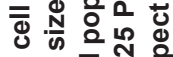

증 웡 品

部

屯

告 응

м $\overline{\mathrm{s}}$

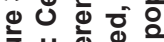

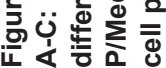


root meristem. Previous studies have generated genome-wide maps of mRNA expression in sorted cell populations in the root, but these lack resolution to address this issue. The first (Birnbaum et al., 2003) sampled 5 different cell types in three zones. However, the entire gradients of the genes reported here (Figure 2) are sampled in the most proximal segment. The second study (Brady et al., 2007) increased the number of cell types (markers) to 19, and in a separate experiment dissected two roots in small zones to capture temporal dynamics. While these offer a high resolution after computational integration of cell types and zones, the robustness of data is limited with two roots sampled for the developmental zones. We therefore designed a new experiment to specifically sample cell populations along expression gradients.

We employed a differential cell sorting method, where the strength of GFP signal in the cells was used to separate the root into three different populations: Proximal to the QC (with high GFP signal), Medial (with intermediate GFP signal) and Distal to the QC (with low GFP signal), schematically represented in Figure 3AC. When coupled to transcriptome profiling this would enable generating a genomewide view of which genes are expressed in what population, depending on distance from the QC. Sorting was performed on pPUB25::n3GFP (Figure 3A), pSPT::n3GFP (Figure $3 \mathrm{~B}$ ), and pTMO5::TMO5:3GFP (Figure $3 \mathrm{C}$ ), as together these lines generate complementary datasets with one cell type-specific line (TMO5), and two general gradient lines with either a short/steep (PUB25) or a long/stretched (SPT) gradient. Following differential sorting, transcript levels of PUB25 and SPT were checked in each of the samples by qPCR. As shown in Figure 3D, these were found to mirror levels of GFP signal in the root (Supplementary Figure 1), with both levels being about 10-fold higher in the "Proximal" population compared to the "Distal" population. This further validates the use of GFP level as a proxy for transcript levels, and also demonstrates that the differential cell sorting was successful.

\section{Transcriptome profiling reveals opposing gradients of stemness and differentiation}

After cell sorting, we used isolated RNA for transcriptome profiling by Illumina RNAsequencing. Data was analyzed using the Tuxedo suite analysis package (Ghosh and Chan, 2016), revealing between $12.3-19.5$ million reads per sample that could be mapped to the reference (Col-0) genome and between 10.000-12.000 genes expressed over 5 fragments per kilobase of exon per million fragments (fpkm) in each population (Table 1). Similar to GPCR results (Figure 3D), transcript levels of PUB25, SPT, and TMO5 were found to gradually decrease in the cell populations 
Table 1: Overview of RNA-sequencing samples showing number of cells isolated, mapped RNA-sequencing reads proportional to total amount of reads for that sample and genes with expression $>5$ fragments per kilobase of exon per million fragments.

\begin{tabular}{|c|c|c|c|c|}
\hline Sample & \# isolated cells & \# mapped reads & $\%$ of total reads & $\#$ genes $>5$ fpkm \\
\hline PUB25 Proximal 1 & 50,000 & $18.6 \mathrm{E} 6$ & $87.1 \%$ & \multirow{3}{*}{11,990} \\
\hline PUB25 Proximal 2 & 50,000 & $15.4 \mathrm{E} 6$ & $86.1 \%$ & \\
\hline PUB25 Proximal 3 & 50,000 & 17.1E6 & $85.8 \%$ & \\
\hline PUB25 Medial 1 & 50,000 & 16.5E6 & $84.1 \%$ & \multirow{3}{*}{12,003} \\
\hline PUB25 Medial 2 & 50,000 & $14.8 \mathrm{E} 6$ & $83.3 \%$ & \\
\hline PUB25 Medial 3 & 50,000 & 18.1E6 & $87.0 \%$ & \\
\hline PUB25 Distal 1 & 50,000 & 16.2E6 & $83.8 \%$ & \multirow{3}{*}{11,993} \\
\hline PUB25 Distal 2 & 50,000 & 18.1E6 & $85.7 \%$ & \\
\hline PUB25 Distal 3 & 50,000 & 16.7E6 & $85.4 \%$ & \\
\hline SPT Proximal 1 & 50,000 & 18.3E6 & $85.9 \%$ & \multirow{3}{*}{11,768} \\
\hline SPT Proximal 2 & 27,500 & 17.2E6 & $82.5 \%$ & \\
\hline SPT Proximal 3 & 50,000 & $17.9 \mathrm{E} 6$ & $84.1 \%$ & \\
\hline SPT Medial 1 & 50,000 & $16.1 \mathrm{E} 6$ & $81.5 \%$ & \multirow{3}{*}{12,022} \\
\hline SPT Medial 2 & 50,000 & 12.3E6 & $83.8 \%$ & \\
\hline SPT Medial 3 & 50,000 & 16.0E6 & $82.2 \%$ & \\
\hline SPT Distal 1 & 50,000 & $14.5 \mathrm{E} 6$ & $83.9 \%$ & \multirow{3}{*}{11,676} \\
\hline SPT Distal 2 & 51,000 & $15.0 \mathrm{E} 6$ & $82.8 \%$ & \\
\hline SPT Distal 3 & 50,000 & 17.5E6 & $85.6 \%$ & \\
\hline TMO5 Proximal 1 & 22,300 & $19.4 \mathrm{E} 6$ & $85.5 \%$ & \multirow{2}{*}{10,123} \\
\hline TMO5 Proximal 2 & 32,200 & 17.3E6 & $85.7 \%$ & \\
\hline TMO5 Medial 1 & 28,600 & $19.2 \mathrm{E} 6$ & $86.6 \%$ & \multirow{2}{*}{9,995} \\
\hline TMO5 Medial 2 & 18,420 & 17.9E6 & $84.0 \%$ & \\
\hline TMO5 Distal 1 & 29,900 & $19.5 \mathrm{E} 6$ & $86.2 \%$ & \multirow{2}{*}{10,826} \\
\hline TMO5 Distal 2 & 28,900 & 15.9E6 & $85.6 \%$ & \\
\hline
\end{tabular}

farther displaced from the QC in the RNA-sequencing datasets (Figure 4A-C). This validated that the RNA-sequencing produced reliable results and was technically sound. When we performed hierarchical clustering on all datasets, we found that the xylem-specific TMO5 dataset formed a separate cluster, while the SPTProximal samples clustered together with all three PUB25 populations (Figure 4D). This indicates that the cell type-specific dataset is indeed different from the broad datasets of PUB25 and SPT and that sampling of similar cell-populations from different gradient lengths resulted in similar datasets. Interestingly, when we performed a QT-clustering (Heyer et al., 1999) of all genes expressed over $5 \mathrm{fpkm}$ in at least one of the populations, we noticed that six expression profiles were enough to cluster the behavior of all genes (Supplementary Figures 2, 3, and 4). Additionally, 
we found that most of the genes (between 45-65\%) showed a graded expression profile and that this gradient could go in either direction (either $P>D$ or $P<D$ ). Since there were no clear clusters resembling an expression profile restricted to the cells surrounding the QC, we directly investigated what functions could be associated to genes expressed $>1 \mathrm{fpkm}$ in the proximal region and $<1 \mathrm{fpkm}$ in the other regions (Figure 4E). While this resulted in a large number of genes (between 185-715 genes, 1,152 in total over all datasets), the only significantly enriched gene ontology terms in all datasets were related to ribosomal RNA processes (Supplementary Table 1), and none were related to biological processes we would expect for genes conferring stemness or stem cell identity (e.g. development, transcriptional regulation, cell division, chromatin). More importantly, none of the genes showing this expression profile has previously been implicated in developmental processes involving the proximal meristem. However, in this set of genes we did find a number of factors involved in root cap meristem development and genes known to be expressed in the QC (e.g. ARR15, ERF115, FEZ, and NTT [Crawford et al., 2015; Heyman et al., 2013; Müller and Sheen, 2008; Willemsen et al., 2008]). Thus, enrichment in the proximal domain can be a consequence of specific gene expression in the QC rather than the first proximal cells. This further suggests that the number of genes, whose expression is restricted to the cells in the proximal meristem surrounding the $Q C$, is likely very limited.

In contrast, a larger number of genes (1,530 genes in total over all datasets) showed a graded expression profile that was higher in the proximal population and significantly reduced in further populations $(P>M>D$; Figure 4F). Importantly the enriched gene ontology terms were related to gene expression, development, and the cell cycle (Supplementary Table 1). Considering that asymmetric cell division and cell replenishment are core features of stem cells, these terms may indeed relate to stemness or stem cell identity. Indeed, when looking at expression profiles of genes known to be of importance for root meristem development (e.g. PLT1, PLT2, AHP6, SHR, ARF6, and LOG3 [Aida et al., 2004; De Rybel et al., 2014; Helariutta et al., 2000; Mähönen et al., 2006]) we found their expression matched the graded profile expected from this type of genes (i.e. high in proximal populations and gradually decreasing; Figure 5). The clustering analysis also identified a large number of genes (1,247 genes in total over all datasets; Figure 4G) showing a graded expression profile in the opposite direction. Strikingly, genes in this category were found to associate most with biological processes related to cell differentiation and maturation (Supplementary Table 1). These included the ACL5, BFN1, COB, IRX1, and XCP2 genes (Figure 5), that are known to control aspects of (terminal) differentiation (Avci 

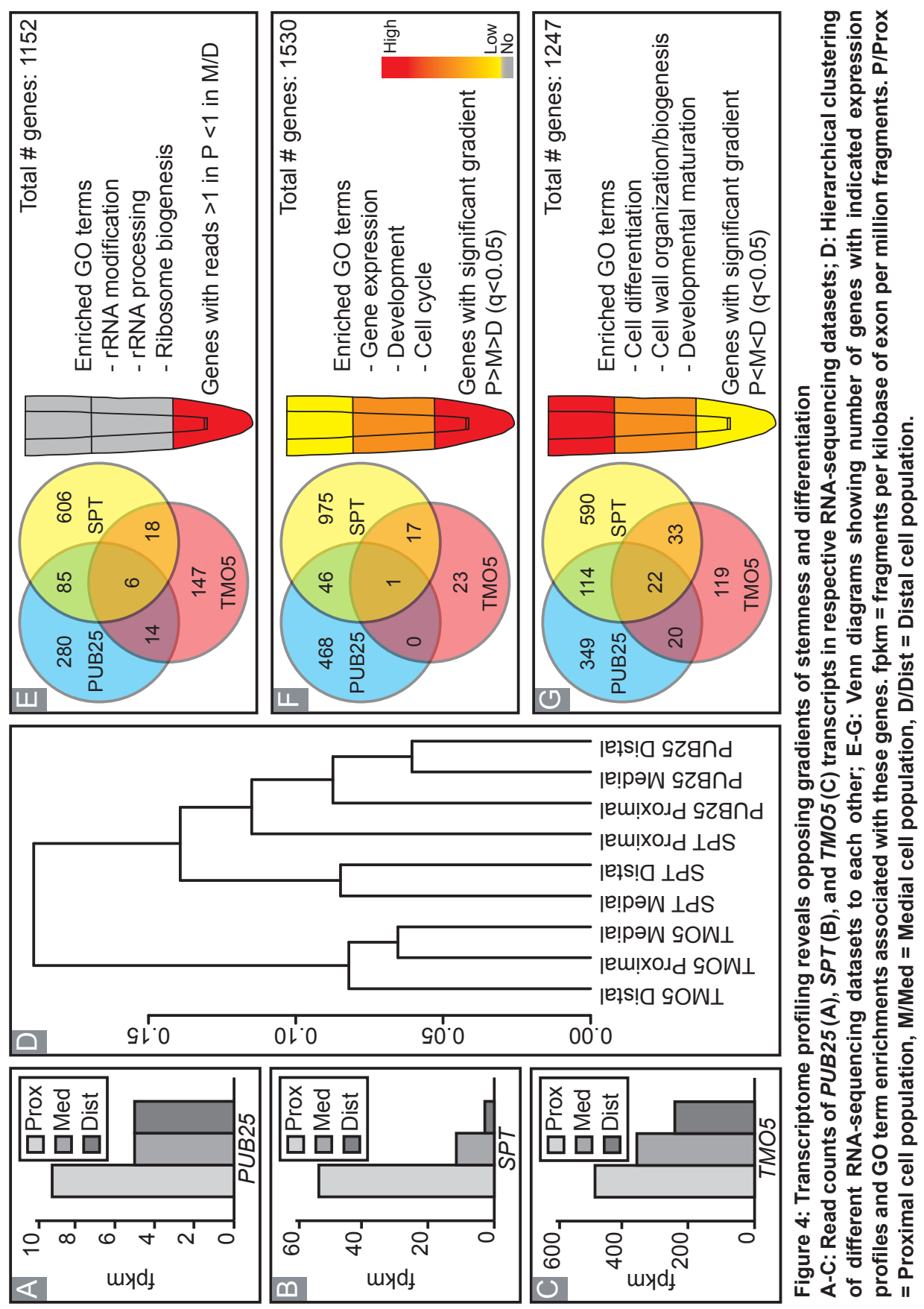


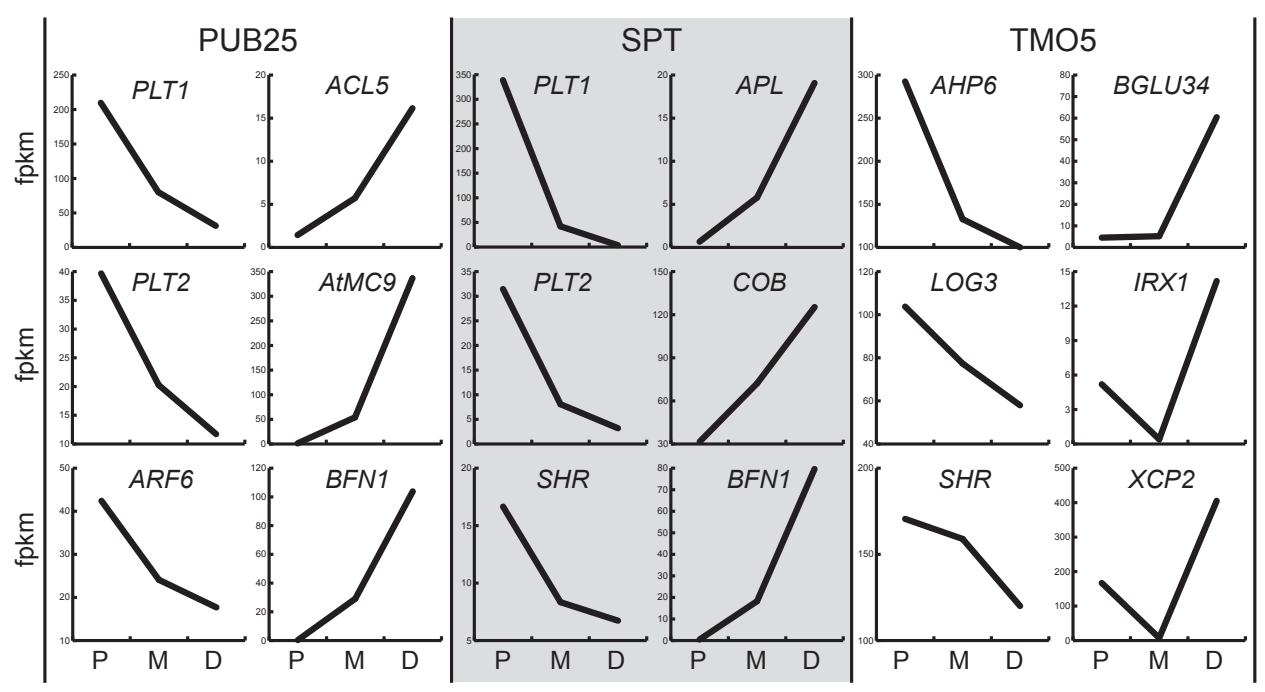

Figure 5: Genes known to be involved in development or differentiation show opposing graded expression profile

Expression profiles of genes in different datasets are shown in line diagrams. fpkm $=$ fragments per kilobase of exon per million fragments. $P=$ Proximal cell population, $M=$ Medial cell population, $\mathrm{D}=$ Distal cell population.

et al., 2008; Clay and Nelson, 2005; Pérez-Amador et al., 2000; Roudier et al., 2005; Taylor et al., 2000). As the criteria for the inclusion in this expression pattern includes detectable expression in all three zones, this finding suggests that genes associated with differentiation are expressed in very young meristematic cells, and increase in expression level as cells progress towards differentiation. Thus, instead of discrete zones of stem cells, division and differentiation, at molecular level there appear to be opposing gradients of stemness and differentiation potential.

\section{Gradient genes mark embryonic stem cell precursors}

To further explore the biological significance of the observed profiles, we focused on the cell type-specific TMO5 dataset. This dataset was combined with a second low-resolution TMO5 dataset. This second dataset was generated independently of the high-resolution dataset using the same pTMO5::TM05:3GFP line, but separating cells into two, rather than three populations (one with high GFP and the other with low GFP intensity). Subsequent microarray analysis of transcript levels resulted in a high degree of overlap between the two datasets. Of those genes above 1.5 fold more highly expressed in the proximal compared to the distal population, or visa versa, $66-86 \%$ shared the same expression profile in the highresolution dataset (Supplementary Figure 5). Since a high number of genes $(2,777$ 

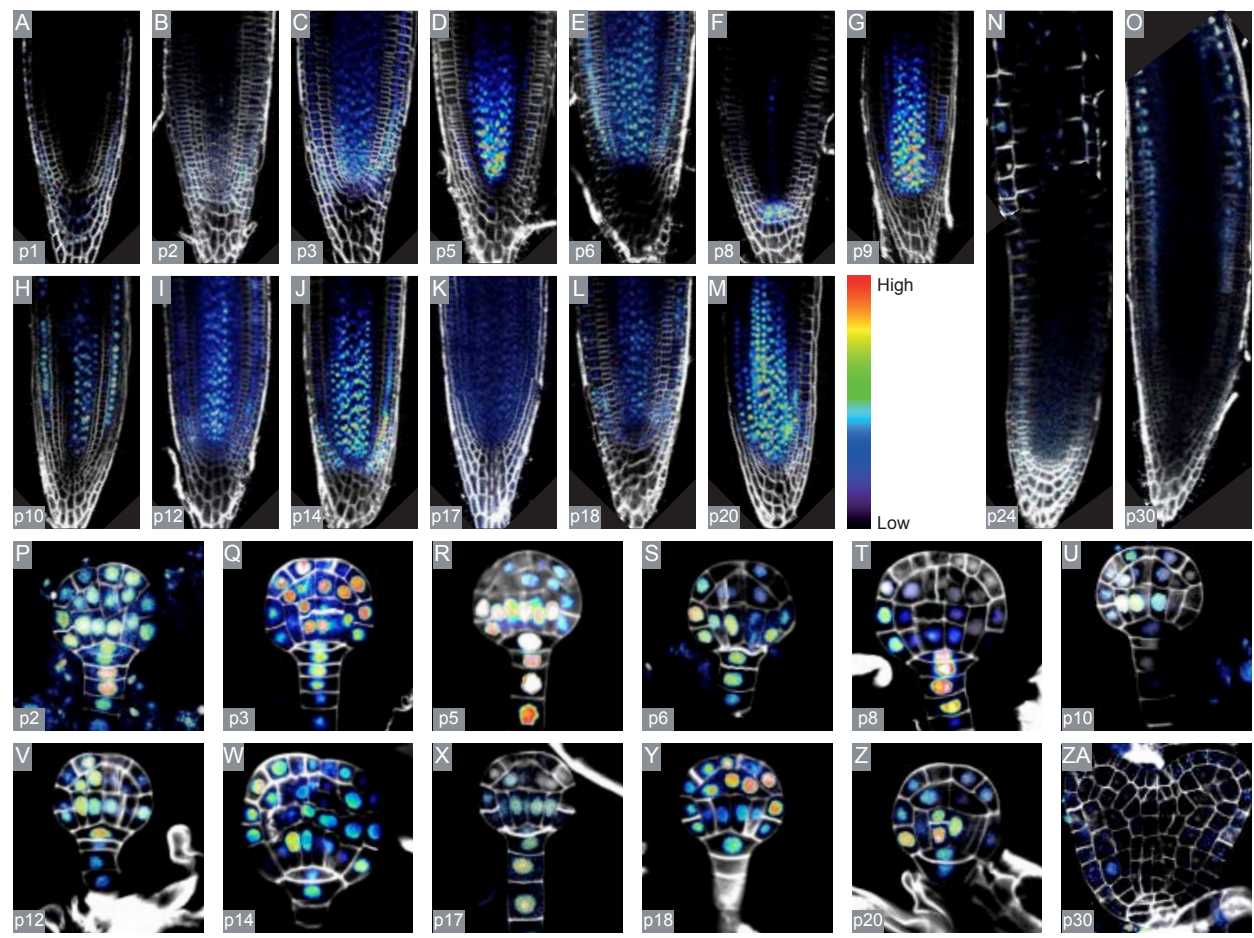

Figure 6: Gradient genes mark embryonic stem cell precursors

A-ZA: Promoter activity of selected genes shown in post-embryonic root (A-O) and embryos (PZA). $\mathrm{p \# \#} \mathrm{=} \mathrm{Promoter} \mathrm{+} \mathrm{number} \mathrm{of} \mathrm{selected} \mathrm{gene;} \mathrm{fluorescence} \mathrm{intensity} \mathrm{is} \mathrm{shown} \mathrm{by} \mathrm{indicated}$ false coloring.

genes in total; Figure $4 \mathrm{~F}$ and $\mathrm{G}$ ) were found in a graded expression profile, we used a selection of these to validate whether the measured transcript levels match observable expression domains. A number of criteria were used for the selection: (I) Expression was either higher or lower in the proximal population compared to the distal population in both high- and low-resolution datasets, and (Ila) gene encoded a predicted nuclear protein or transcription factor or (Illb) gene encoded an unknown protein (Supplementary Figure 6). 15 genes were selected to validate the RNA-sequencing profiles, by generating promoter reporter lines. One gene (\#33; AT2G43680/IQD14) was not visibly expressed in the root and another (\#1; AT1G14350/FOUR LIPS) was observed only in the lateral root cap and columella. While expression of the other 13 genes was found to resemble the transcript profile identified through RNA-sequencing, including gradients in both directions (Figure $6 \mathrm{~A}-\mathrm{O}$ and Table 2), this was most apparent for \#3, 5, 9, and 14. These showed very clear graded expression profiles in the root (Figure 6C,D,G,J). This indicates that the transcript profiles measured in the RNA-sequencing are most likely generated by 


\begin{tabular}{|c|c|c|c|c|c|c|c|c|c|c|c|c|c|c|c|c|c|c|c|c|}
\hline 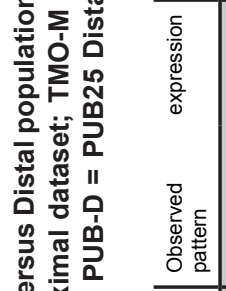 & 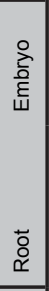 & 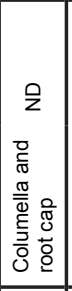 & 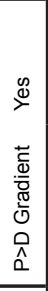 & 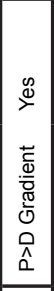 & 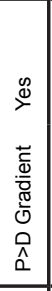 & 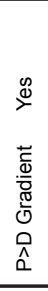 & 只 & 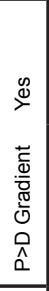 & 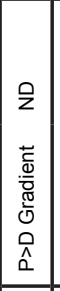 & 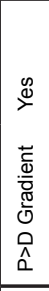 & 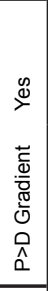 & 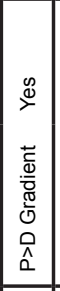 & 只 & 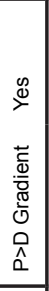 & 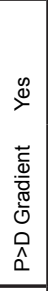 & 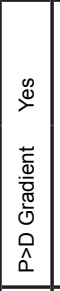 & z & 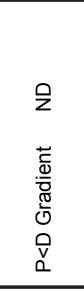 & 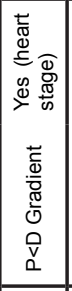 & 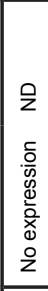 \\
\hline 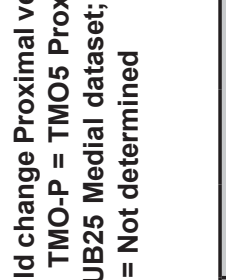 & $\begin{array}{l}\frac{9}{1} \\
\frac{1}{0} \\
\sum_{1} \\
\frac{1}{0} \\
\infty \\
\frac{0}{5} \\
\frac{0}{0}\end{array}$ & 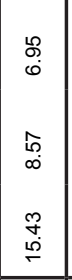 & 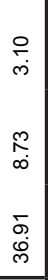 & 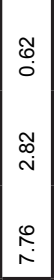 & 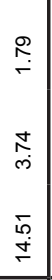 & $\begin{array}{l}\underset{\sigma}{\sigma} \\
\stackrel{\infty}{N} \\
\stackrel{N}{N}\end{array}$ & 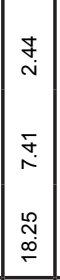 & 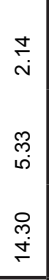 & 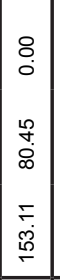 & 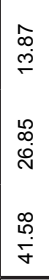 & 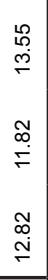 & 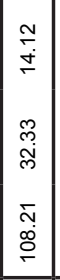 & $\begin{array}{l}\underset{m}{\forall} \\
\stackrel{\varpi}{\infty} \\
\infty \\
\infty \\
\infty\end{array}$ & 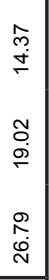 & 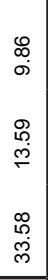 & 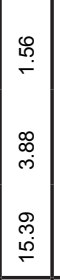 & $\underset{i \infty}{N}$ & 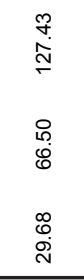 & 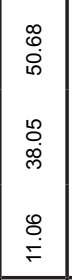 & 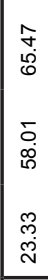 \\
\hline 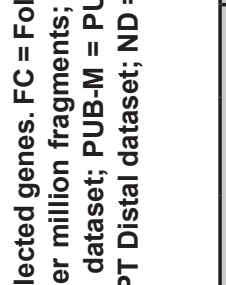 & 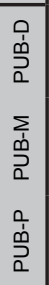 & 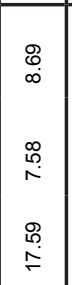 & 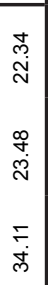 & 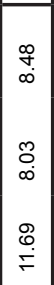 & 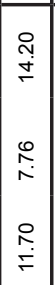 & 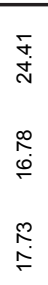 & 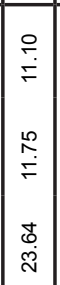 & $\begin{array}{l}\underset{\infty}{R} \\
\\
\stackrel{\sim}{2} \\
\stackrel{+}{F}\end{array}$ & 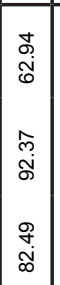 & $\begin{array}{l}\infty \\
\infty \\
\stackrel{\infty}{\infty} \\
\mathbb{N} \\
\underset{N}{ }\end{array}$ & 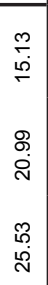 & 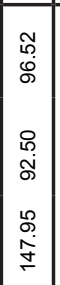 & 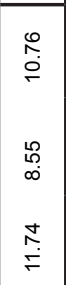 & 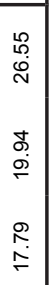 & 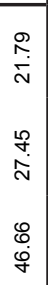 & 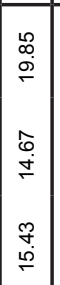 & $\underset{⿱}{*}$ & 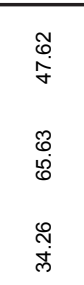 & 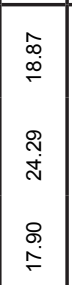 & $\stackrel{\infty}{\stackrel{\infty}{\Gamma}}$ \\
\hline 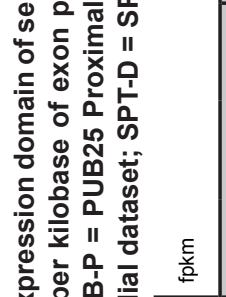 & 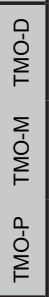 & 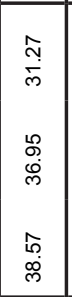 & 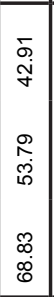 & 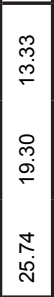 & 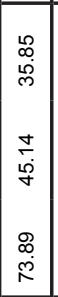 & 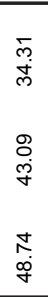 & 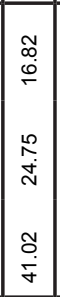 & $\begin{array}{l}\stackrel{8}{0} \\
\dot{m} \\
\dot{m}\end{array}$ & 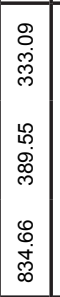 & 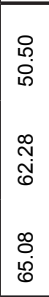 & $\begin{array}{l}\bar{\phi} \\
\stackrel{\omega}{j}\end{array}$ & 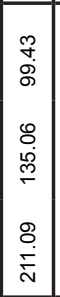 & 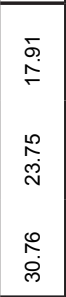 & 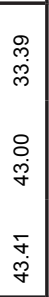 & $\begin{array}{l}\stackrel{\bullet}{0} \\
\stackrel{m}{\infty}\end{array}$ & 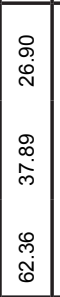 & 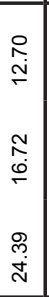 & $\begin{array}{l}\stackrel{\infty}{=} \\
\stackrel{\circ}{\circ} \\
\stackrel{\circ}{\circ} \\
\stackrel{\circ}{\circ}\end{array}$ & $\underset{\widetilde{N}}{\stackrel{\widetilde{n}}{ }}$ & 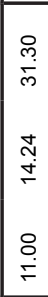 \\
\hline 0 & 足 & $\stackrel{\text { to }}{\leftarrow}$ & $\stackrel{\overbrace{}}{\leftarrow}$ & $\begin{array}{l}: \\
\text { i } \\
\end{array}$ & 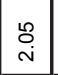 & $\stackrel{\hbar \omega}{\leftarrow}$ & $\stackrel{\square}{\square}$ & 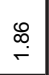 & న్ & $\stackrel{\text { }}{\stackrel{\leftrightarrow}{\circ}}$ & $\underset{i}{\stackrel{d}{*}}$ & & & م્ & $\stackrel{\text { in }}{\text { Ni }}$ & & $\stackrel{\leftrightarrow}{\leftrightarrow}$ & $\stackrel{\infty}{\stackrel{\leftarrow}{\leftarrow}}$ & $\stackrel{\infty}{\leftarrow}$ & ্ָণ \\
\hline 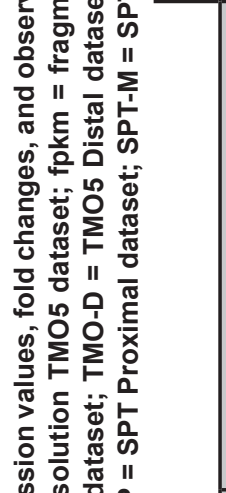 & 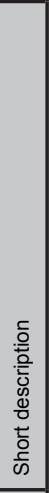 & 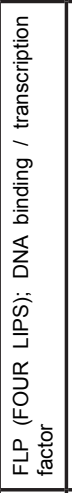 & 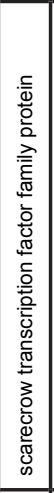 & 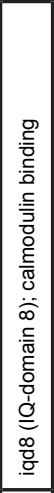 & 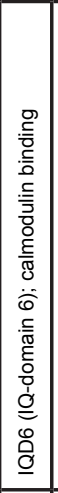 & 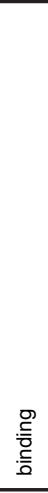 & 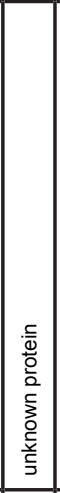 & 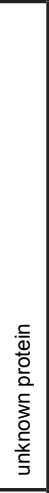 & 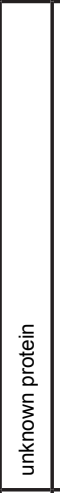 & 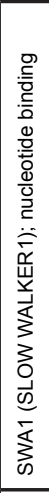 & 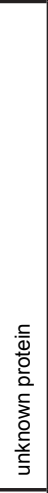 & 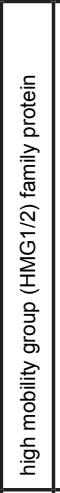 & 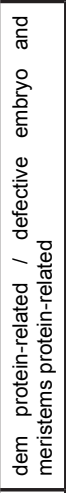 & 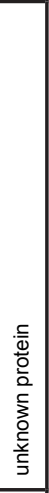 & 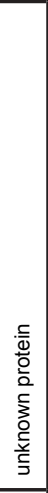 & 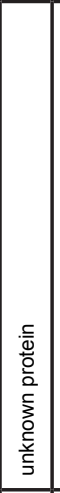 & 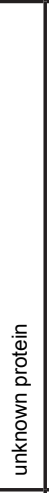 & 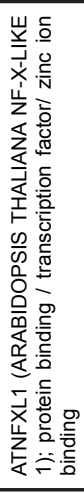 & 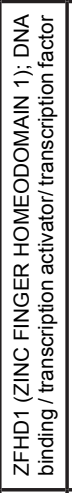 & 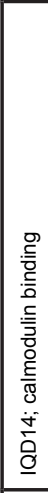 \\
\hline 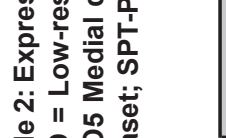 & হ & 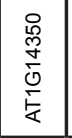 & $\begin{array}{l}8 \\
\frac{0}{8} \\
0 \\
0 \\
\frac{0}{<}\end{array}$ & \begin{tabular}{|l|}
$\stackrel{0}{0}$ \\
$\stackrel{0}{N}$ \\
0 \\
\multirow{2}{*}{} \\
\end{tabular} & 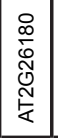 & 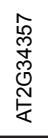 & 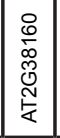 & 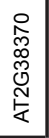 & 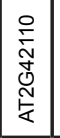 & 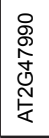 & 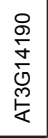 & 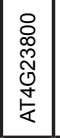 & 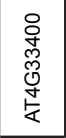 & 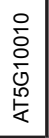 & 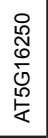 & 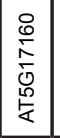 & $\begin{array}{l}\stackrel{8}{0} \\
\stackrel{0}{0} \\
0 \\
0\end{array}$ & $\begin{array}{l}0 \\
\stackrel{0}{0} \\
\frac{0}{0} \\
\frac{0}{2} \\
\frac{1}{4}\end{array}$ & $\begin{array}{l}\text { 영 } \\
\stackrel{\circ}{0} \\
0 \\
\\
\end{array}$ & 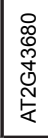 \\
\hline & $\#$ & - & $N$ & $m$ & $\curvearrowleft$ & 0 & $n$ & $\infty$ & $\infty$ & & 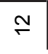 & $\stackrel{\nabla}{\square}$ & $\stackrel{6}{\leftarrow}$ & -1 & $\stackrel{\infty}{\sim}$ & i & $\stackrel{\widetilde{N}}{\sim}$ & I & pి & $\ddot{m}$ \\
\hline
\end{tabular}


promoter activity of the associated genes. Interestingly, all of the genes that showed expression were also strongly expressed early during embryogenesis (Figure 6PZA) and in most cases expression was found to be strongest in the basal tier of the embryo (e.g. Figure $6 \mathrm{Q}, \mathrm{R}, \mathrm{U}, \mathrm{Z}$ ). While we started this study with genes expressed in the basal tier of the embryo that were found to have a graded expression in the root, it now appears that the opposite is also true. This suggests that there could be a common property among genes expressed in the early embryo, to have a gradual expression in the postembryonic root. Furthermore, these data imply that cells in the post-embryonic RAM share properties with the embryonic stem cell precursors and that these properties are condensed in the embryo and "spread out" over multiple cells in the root. Now that a large number of genes with a graded RAM expressed profile are identified, an open question remains how these gradients are regulated and how relevant they are for development.

\section{Gradient expression can be uncoupled from meristem growth}

To find out more about the regulation on these graded expression profiles we analyzed what the effect on these gradients would be when the size of the meristem is changed. Two scenarios are most likely, either the observed gradients are a simple output of growth and meristem size, which would predict that the size of the gradient proportionally scales with meristem size. Alternatively, the observed gradients are actively regulated and controlled by mechanism independent of growth. In this case, gradients may not change proportional to the meristem (Supplementary Figure 7A). We first looked for hormones or chemicals that robustly alter meristem size. Of the compounds known in literature, brassinolide $(\mathrm{BL})$ and trans-Zeatin $(\mathrm{tZ})$ produced stable and easily measurable meristem reduction (Figure 7A); therefore these two treatments were used. The fluorescent gradient in different promoter lines ( $p 2, p 5$, p6, p9, p14, p24, and p30) was imaged in treated and untreated root tips and length of the gradient was subsequently measured. We measured the length of the gradient as expressed by the length to reach $50 \%$ of maximum fluorescence (from maximum to half fluorescence) in each root (Supplementary Figure 7B). While two of the lines indeed showed a reduction of gradient length proportional to the reduction in meristem length (i.e. p6 and p24, only when treated with $\mathrm{tZ}$ ), none of the other five tested lines showed this for either treatment (Figure 7B-I). In several lines (i.e. p5, $\mathrm{p} 14$, and $\mathrm{p} 30$ ), gradient lengths were completely unaltered after treatment (Figure 7C, F, H, I). Interestingly, in some cases (i.e. for p2, p6, and p9) gradient lengths were even increased upon $\mathrm{BL}$ treatment. This indicates that the second postulated scenario is likely true and that the observed gradients are not simply an output of 

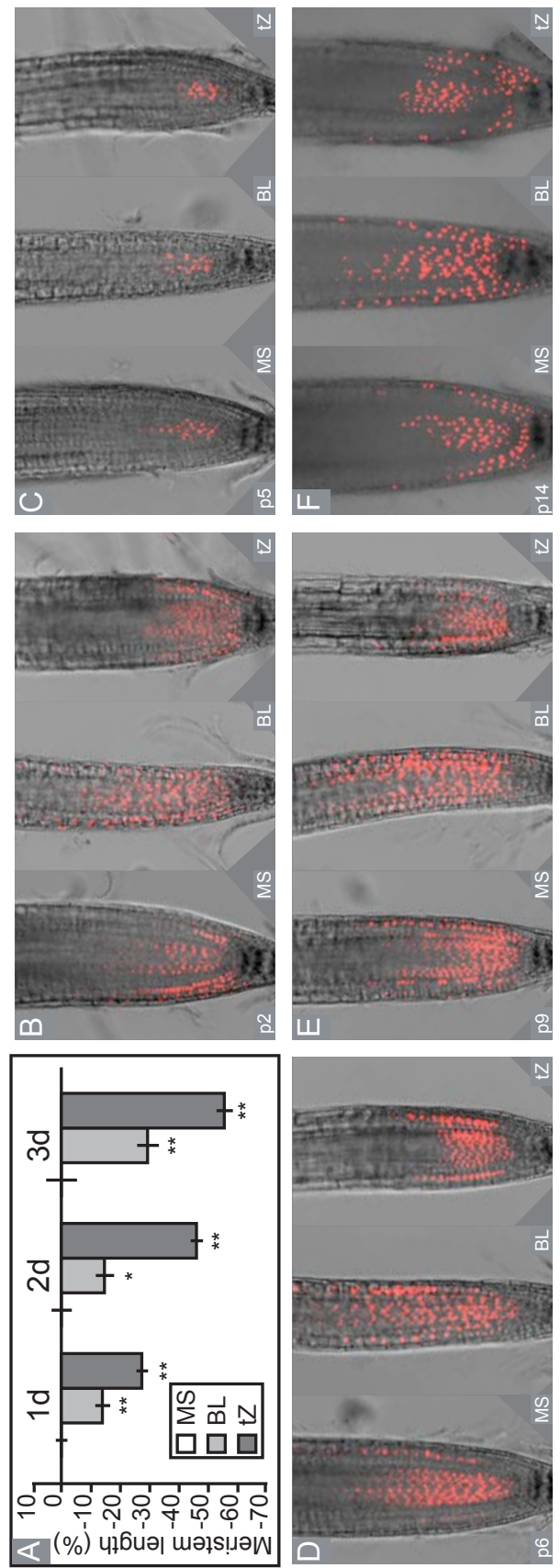
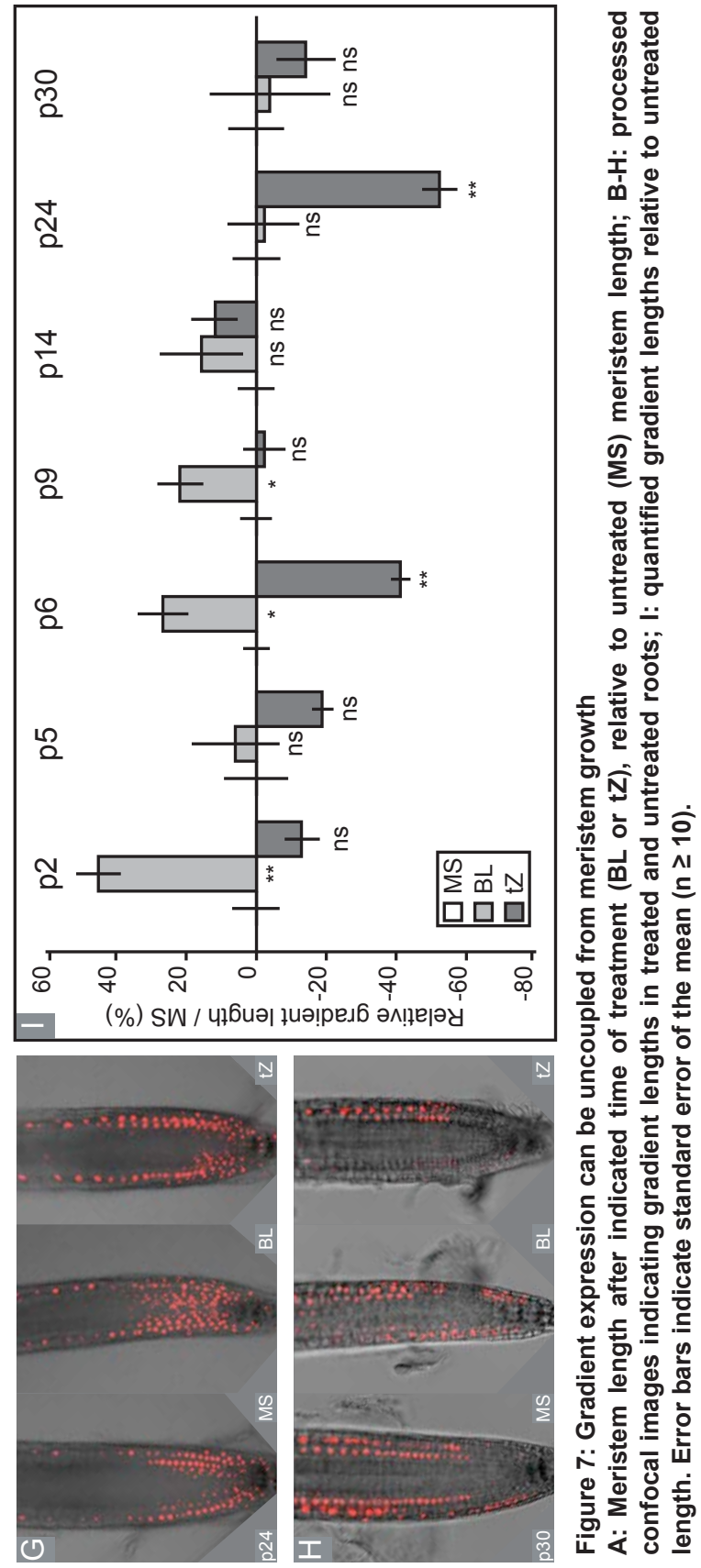

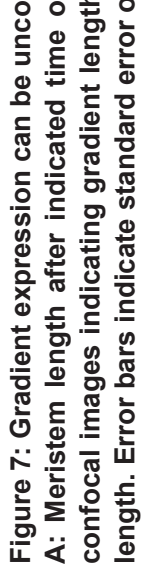

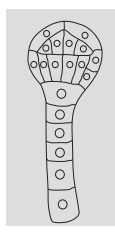


spatial context or meristem size, but are actually genetically controlled and more complex regulatory mechanisms may play a role in generating these gradients.

\section{Disrupting transcription gradient leads to growth defects}

Since the observed gradients seem to be tightly regulated, we next employed a misexpression approach to test whether this would result in alterations in root growth. Expression under control of the strong $35 \mathrm{~S}$ promoter results in ectopic expression throughout the plant, thereby disrupting the endogenous graded profile of these genes. Using qPCR, we first confirmed that the introduced constructs indeed led to higher levels of expression. All 21 lines harboring an $\mathrm{m} 5, \mathrm{~m} 7, \mathrm{~m} 9$ or $\mathrm{m} 23$ construct had stable over-expression of at least 10 -fold (Figure $8 \mathrm{~A}$ ), indicating these genes can relatively easily be over-expressed. Plants harboring an $\mathrm{m} 15$ construct, however, showed a variable expression level between five independently transformed lines (Figure $8 \mathrm{~A}$ ), suggesting that $\mathrm{m} 15$ is under more tight transcriptional control. When
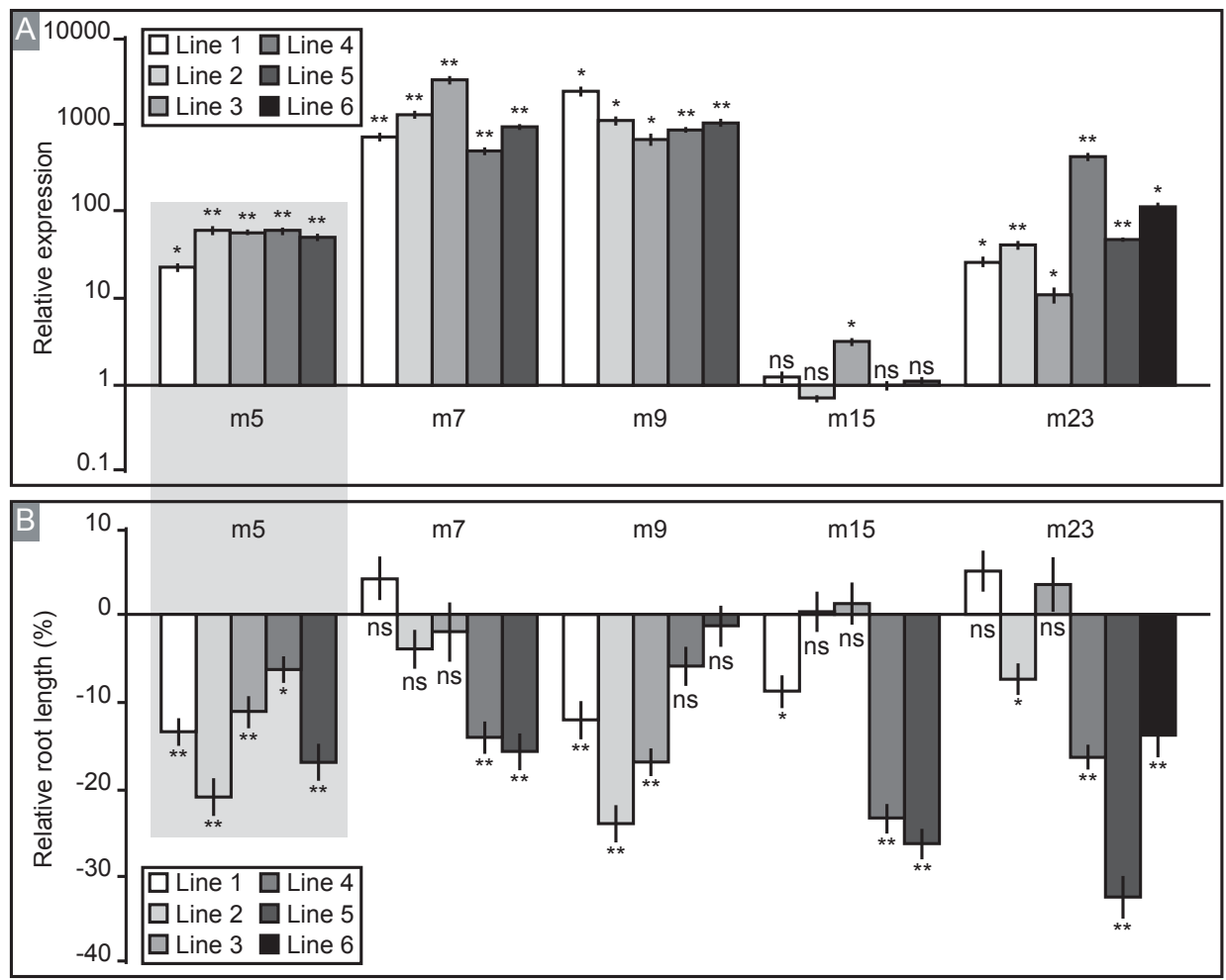

Figure 8: Disrupting transcription gradient leads to growth defects

A: relative expression measured by qPCR of selected genes in multiple independent transgenic misexpression lines; B: root length of multiple misexpression lines of selected genes, relative to Col-0 wild-type root length. Error bars indicate standard error of the mean ( $n=3$ for qPCR; $\mathrm{n} \geq \mathbf{4 5}$ for root length assay); $\mathrm{m \# \#} \mathrm{=} \mathrm{misexpression} \mathrm{+} \mathrm{number} \mathrm{of} \mathrm{selected} \mathrm{gene.}$ 
we analyzed root lengths of five-day-old seedlings, we noticed a variety of differential root lengths in the lines (Figure 8B). While there was quite some difference between different lines of the same construct, most lines showed a reduction in root length, though this was only clearly correlated to expression levels in the case of m5/IQD6 (grey box Figure 8). All lines harboring an $\mathrm{m} 5$ over-expression construct showed a significant reduction in root length, indicating that endogenous graded expression of this gene is required for normal root growth. Although less prominent, a similar trend could also be observed for $\mathrm{m} 9$, encoding an unknown protein, implying endogenous expression of this gene may also be required for normal root growth. These data indicate that disruption of the endogenous transcriptional gradient can, at least in these isolated cases, lead to reduced root growth, showing that this gradient is indeed important in normal developmental processes.

\section{Discussion}

In this study we have taken an unbiased genome-wide approach to search for genes that may confer stem cell identity to a cell. The stem cells in the proximal meristem can be operationally defined as the cells directly surrounding the QC. Evidence for this comes from the observation that only these cells can give rise to large clonal sectors (Scheres et al., 1994) and through logic reasoning: owing to the nature of cell divisions and the fixed position of plant cells due to the cell walls, all cells would eventually be pushed out of the meristem, except (to a large extent) these cells surrounding the QC. Whether or not these operational stem cells are also characterized by unique cellular properties, as reflected by a specific transcriptome, remained an open question. This is in part due to the impossibility to transplant cells and test for potential, an approach that has been used extensively in animal stem cell research (e.g. Huch et al., 2013). Going back into development to the moment of de novo stem cell specification enabled us to analyze cells that can unequivocally be considered precursors to the functional stem cells. Since at the globular stage of embryogenesis there is only a single cell layer and this layer gives rise to all cells in the root, by definition, these cells must be the stem cell precursors. Genes expressed in these embryonic stem cell precursors, although showing typical stem cell factor behavior in the embryo (Chapter 4 of this thesis) did not show this behavior in the post-embryonic root but were expressed in gradients, rather than being restricted to the cells surrounding the QC. Transcriptome analysis of different ontogenetic cell populations revealed that the cell population closest to the QC does not uniquely express genes associated with development that are restricted 
to this population. This provides, to our knowledge, the first direct evidence that on the basis of expressed genes, the plant may not qualitatively distinguish the cells closest to the QC as stem cells relative to other cells in the same file. This raises the question of whether the currently used model for the organization of stem cells in the root is complete. Nonetheless, since there were also many unknown and uncharacterized genes identified with an expression profile that was restricted to the cells surrounding the QC, it is still possible that we missed an important factor in this analysis, and follow-up in-depth characterization may yet reveal a factor that can qualitatively distinguish functional stem cells. Alternatively, in our analysis we also identified a large group of genes expressed in a graded profile of high expression closer to the QC that gradually decreases and many genes, known for their involvement in development, were actually found among this group. Additionally, perhaps the most striking finding was that an opposing gradient of differentiationassociated genes is present in the root meristem as well. Moreover, as we have shown that these gradients are transcriptionally regulated and important for normal root growth, we propose an alternative extended model for the organization of stem cells in the root apical meristem, schematically represented in Figure 9. In this model, stemness is a quantitative property that is highest close to the QC and gradually decreases when farther displaced from the QC. Opposing this gradient of stemness, is a differentiation gradient that is already present close to the QC and gradually increases. Since we have shown that the observed gradients are not a mere output of meristem size and in fact seem transcriptionally controlled, an open question that still remains is how these gradients are controlled and whether there is a common "gradient-regulator" or different gradients are regulated by different mechanisms. A possible candidate for common gradient-regulator could be auxin that, perhaps through downstream regulation by PLETHORAs (PLTs), generates a gradient framework for gene expression and development. It would therefore be interesting to test whether gradient lengths are altered in different PLT mutant and overexpression backgrounds. Another open question is whether the expression levels of gradient genes are informative for development, as dosage-dependency has been shown for the PLETHORAs (Galinha et al., 2007; Mähönen et al., 2014), this could also be the case for other gradient genes. Indeed thresholds of expression could result in different developmental outputs, although this would have to be accompanied by a very sensitive and finely tuned mechanism. Differences in expression levels, between neighboring cells, especially close to the $\mathrm{QC}$, are small (e.g. for p5 and p9; Supplementary Figure 8). Another interesting point will be to study whether the observed differentiation gradient is, in addition to being present, 


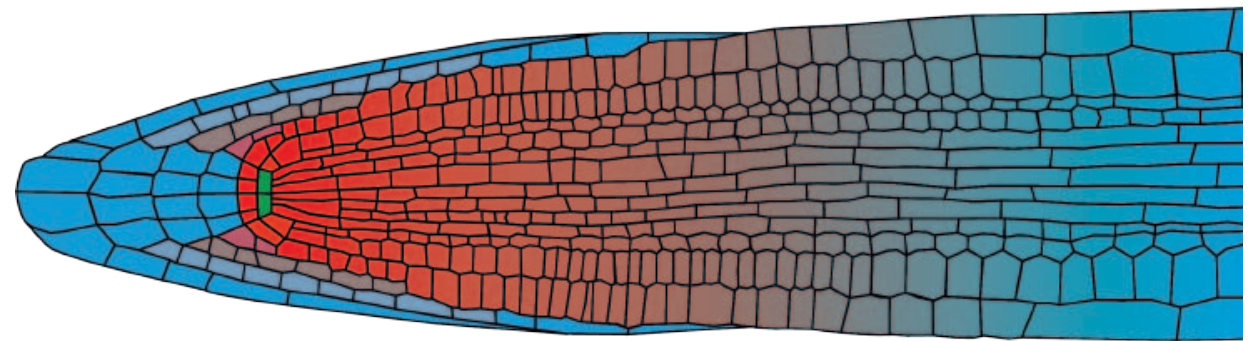

Stemness

Differentiation

Figure 9: Schematic representation of proposed alternative model for stem cell organization in the Arabidopsis root apical meristem

also actively promoting differentiation close to the QC. Moreover, it will be interesting to see whether an interaction exists between the two opposing gradients; i.e. if they are also antagonistic to each other. The opposite gradient of differentiation could in principle be generated by a dose-dependent repression by for example PLTs; this would mean that the differentiation gradient is a read-out of the stemness gradient and that the latter would be enough to generate both gradients. Alternatively, both gradients could be generated by separate mechanisms, acting independent of each other. Specific analysis of downstream target genes and dose-dependent binding sites of master regulators involved in these processes (e.g. PLTs) would shed more light on these questions.

\section{Methods}

\section{Plant material and growth conditions}

PreviouslydescribedreporterlinesforTMO5(pTMO5::n3GFP;pTMO5::TMO5:3xGFP), TMO7 (pTMO7::n3GFP; pTMO7::TMO7:GFP), SPT (pSPT::n3GFP), and PUB25 (pPUB25::n3GFP) were used (Schlereth et al. 2010; Chapter 4 of this thesis). Seeds were surface sterilized and grown on MS plates under standard long day growth conditions $\left(22^{\circ} \mathrm{C}, 16: 8\right.$-h light/dark cycles) following a one to four-day stratification at $4^{\circ} \mathrm{C}$. Arabidopsis ecotype Columbia- 0 was used as wild-type control in all cases. Hormone treatments were performed by transferring seedlings to plates containing either $5 \mathrm{nM}$ of $\mathrm{BL}$ or $1 \mu \mathrm{M}$ of $\mathrm{tZ}$.

\section{Cloning and plant transformation}

Promoter fragments (up to $3 \mathrm{~kb}$ upstream of start codon) and coding sequences (CDS) from selected genes were amplified from genomic DNA (promoter) or root 
cDNA (CDS) using PCR and Phusion Flash master mix (Thermo Scientific) and the primers described in Supplementary Table 2. PCR products were cloned into the LIC pPLV4_v2 (promoter) or pPLV26 (CDS) vector using Ligation Independent Cloning (De Rybel et al. 2011; Chapter 2 of this thesis). Translational fusion construct of SPT (pSPT::SPT:sYFP), was generating by cloning the whole genomic region, including $3 \mathrm{~kb}$ upstream promoter into the pPLV16 vector using Ligation Independent Cloning (De Rybel et al. 2011; Chapter 2 of this thesis). All constructs were confirmed by sequencing, and subsequently transformed into Arabidopsis Col-0 wild-type plants through Agrobacterium mediated transformation. At least three independent transformants were checked and representative pictures are shown.

\section{Microscopic analysis}

Confocal Laser Scanning Microscopy (CLSM) was performed as previously described (Llavata-Peris et al. 2013; Chapter 4 of this thesis) using a Leica SP5. Briefly: fiveday-old seedling roots were stained using FM4-64 dye (Invitrogen) and visualised using the following wavelengths: $488 \mathrm{~nm}$ excitation and 500-535 nm detection for GFP and $514 \mathrm{~nm}$ excitation and 600-700 nm detection for FM4-64 dye. For observation of embryos, ovules were isolated and fixed in $4 \%$ paraformadehyde/5\% glycerol solution, stained with SCRI Renaissance Stain 2200 (R2200; Renaissance Chemicals, UK) and visualized using the following wavelengths: $488 \mathrm{~nm}$ excitation and $500-535 \mathrm{~nm}$ detection for GFP and $405 \mathrm{~nm}$ excitation and 430-470 nm detection for R2200. Measurements were performed and brightness and contrast were adjusted using Leica Application Suite Advanced Fluorescence and ImageJ software.

\section{Fluorescence Activated Cell Sorting}

Fluorescence Activated Cell Sorting (FACS) of plant protoplasts was performed as described in lyer-Pascuzzi and Benfey (2010). Briefly: Root tips of 6 days old seedlings were cut and incubated in protoplasting Solution $B(1.5 \%[\mathrm{w} / \mathrm{v}]$ cellulysin and $0.1 \%[\mathrm{w} / \mathrm{v}]$ pectolyase in Solution $\mathrm{A}$ [600 mM mannitol, $2 \mathrm{mM} \mathrm{MgCl} 2,0.1 \%\{\mathrm{w} / \mathrm{v}\}$ BSA, $2 \mathrm{mM} \mathrm{CaCl}$, $2 \mathrm{mM}$ MES, $10 \mathrm{mM} \mathrm{KCl}$, pH 5.5]) for $1 \mathrm{hr}$ at room temperature. Cells were spun down at $200 \times \mathrm{g}$ for 6 minutes and resuspended in Solution A. Cells were sorted on a MoFlo Astrios (Beckmann), based on strength of GFP signal at 488 $\mathrm{nm}$ excitation. Cells were collected in RLT buffer from a QIAGEN RNeasy Micro kit and directly frozen.

RNA isolation and RNA-sequencing library preparation

Total RNA from sorted cells was isolated using a QIAGEN RNeasy Micro kit, RNA 
concentration was measured using a Life Technologies Qubit 2.0 fluorometer and RNA integrity was measured using an Agilent 2100 bioanalyzer plant RNA 6000 pico kit, all following manufacturer's instructions. $10 \mathrm{ng}$ of total RNA was used for amplification in an Ovation RNA-Seq System V2 (NuGEN). $\sim 3 \mu \mathrm{g}$ of amplified cDNA was fragmented to $200 \mathrm{bp}$ on a Covaris Sonication system. $100 \mathrm{ng}$ was subsequently used to prepare libraries for Illumina RNA-seq, using Ovation Ultralow Library Systems (NuGEN), following manufacturer's instructions.

\section{Quantitative RT-PCR and RNA-sequencing}

Quantitative RT-PCR (qPCR) was performed as described previously (De Rybel et al., 2013). Poly(dT) cDNA prepared from $10 \mathrm{ng}$ of total RNA using an Invitrogen SuperScript III or Bio-Rad iScript kit and manufacturer's instructions, followed by qPCR using SYBR Green Master Mix (Applied Biosystems) or iQ SYBR green mix (Bio-Rad). All reactions were performed in triplicate, using primers designed in Beacon designer 8.0 (Primier Biosoft International; Supplementary Table 2) and data were analyzed using the qBase program (Hellemans et al., 2007). Signals were normalized against expression of PP2A or ACTIN2 and EEF1a4 (Czechowski et al., 2005).

RNA-sequencing was performed using Illumina HiSeq 50SE (Duke IGSP Genome Sequencing \& Analysis Core Resource, Duke University, NC, USA). Data were analyzed and visualized using the Tuxedo suite (Bowtie2, Tophat2, Cufflinks, and cummeRbund; Ghosh and Chan, 2016). QT-Clustering was performed using MultiExperiment Viewer software (Heyer et al., 1999). GO term enrichment analysis was performed using the Cytoscape software with BiNGO plugin (Maere et al., 2005; Shannon et al., 2003).

\section{Acknowledgements}

The authors would like to thank Heather Belcher, Manuel Valdes, and Masashi Yamada for help with protoplasting and RNA-sequencing library preparations, Lynn Martinek of the Duke Concer Institute Flow Cytometry service for performing cell sorting, Song Li for help with statistical analysis of RNA-sequencing data, Peter Schaap for providing server capacity for RNA-sequencing data analysis. This work was supported by a Starting Grant from the European Research Council (ERC; CELLPATTERN) to D.W., a Netherlands Organization for Scientific Research (NWO; VIDI864.13.001) grant to B.D.R. and by an EMBO short-term fellowship (ASTF 4272013) to J.R.W. 


\section{References}

Aida, M., D. Beis, R. Heidstra, V. Willemsen, I. Blilou, C. Galinha, L. Nussaume, Y. S. Noh, R. Amasino and B. Scheres (2004). "The PLETHORA genes mediate patterning of the Arabidopsis root stem cell niche." Cell 119(1): 109-120.

Avci, U., H. E. Petzold, I. O. Ismail, E. P. Beers and C. H. Haigler (2008). "Cysteine proteases $\mathrm{XCP} 1$ and XCP2 aid micro-autolysis within the intact central vacuole during xylogenesis in Arabidopsis roots." Plant J 56(2): 303-315.

Bennett, T. and B. Scheres (2010). "Root development-two meristems for the price of one?" Curr Top Dev Biol 91: 67-102.

Berleth, T. and G. Jurgens (1993). "The role of the monopteros gene in organising the basal body region of the Arabidopsis embryo." Development 118(2): 575-587.

Birnbaum, K., D. E. Shasha, J. Y. Wang, J. W. Jung, G. M. Lambert, D. W. Galbraith and P. N. Benfey (2003). "A gene expression map of the Arabidopsis root." Science 302(5652): 1956-1960.

Brady, S. M., D. A. Orlando, J. Y. Lee, J. Y. Wang, J. Koch, J. R. Dinneny, D. Mace, U. Ohler and P. N. Benfey (2007). "A high-resolution root spatiotemporal map reveals dominant expression patterns." Science 318(5851): 801-806.

Clay, N. K. and T. Nelson (2005). "Arabidopsis thickvein mutation affects vein thickness and organ vascularization, and resides in a provascular cell-specific spermine synthase involved in vein definition and in polar auxin transport." Plant Physiol 138(2): 767-777.

Crawford, B. C., J. Sewell, G. Golembeski, C. Roshan, J. A. Long and M. F. Yanofsky (2015). "Plant development. Genetic control of distal stem cell fate within root and embryonic meristems." Science 347(6222): 655-659.

Czechowski, T., M. Stitt, T. Altmann, M. K. Udvardi and W. R. Scheible (2005). "Genome-wide identification and testing of superior reference genes for transcript normalization in Arabidopsis." Plant Physiol 139(1): 5-17.

De Rybel, B., M. Adibi, A. S. Breda, J. R. Wendrich, M. E. Smit, O. Novak, N. Yamaguchi, S. Yoshida, G. Van Isterdael, J. Palovaara, B. Nijsse, M. V. Boekschoten, G. Hooiveld, T. Beeckman, D. Wagner, K. Ljung, C. Fleck and D. Weijers (2014). "Plant development. Integration of growth and patterning during vascular tissue formation in Arabidopsis." Science 345(6197): 1255215.

De Rybel, B., A. P. Mähönen, Y. Helariutta and D. Weijers (2016). "Plant vascular development: from early specification to differentiation." Nat Rev Mol Cell Biol 17(1): 30-40.

De Rybel, B., B. Möller, S. Yoshida, I. Grabowicz, P. Barbier de Reuille, S. Boeren, R. S. Smith, J. W. Borst and D. Weijers (2013). "A bHLH complex controls embryonic vascular tissue establishment and indeterminate growth in Arabidopsis." Dev Cell 24(4): 426437.

De Rybel, B., W. van den Berg, A. Lokerse, C. Y. Liao, H. van Mourik, B. Moller, C. L. Peris and D. Weijers (2011). "A versatile set of ligation-independent cloning vectors for functional studies in plants." Plant Physiol 156(3): 1292-1299.

Drisch, R. C. and Y. Stahl (2015). "Function and regulation of transcription factors involved in root apical meristem and stem cell maintenance." Front Plant Sci 6: 505.

Duclercq, J., B. Sangwan-Norreel, M. Catterou and R. S. Sangwan (2011). "De novo shoot organogenesis: from art to science." Trends Plant Sci 16(11): 597-606.

Galinha, C., H. Hofhuis, M. Luijten, V. Willemsen, I. Blilou, R. Heidstra and B. Scheres (2007). "PLETHORA proteins as dose-dependent master regulators of Arabidopsis root development." Nature 449(7165): 1053-1057.

Ghosh, S. and C. K. Chan (2016). "Analysis of RNA-Seq Data Using TopHat and Cufflinks." Methods Mol Biol 1374: 339-361. 
Hardtke, C. S. and T. Berleth (1998). "The Arabidopsis gene MONOPTEROS encodes a transcription factor mediating embryo axis formation and vascular development." EMBO J 17(5): 1405-1411.

Helariutta, Y., H. Fukaki, J. Wysocka-Diller, K. Nakajima, J. Jung, G. Sena, M. T. Hauser and P. N. Benfey (2000). "The SHORT-ROOT gene controls radial patterning of the Arabidopsis root through radial signaling." Cell 101(5): 555-567.

Hellemans, J., G. Mortier, A. De Paepe, F. Speleman and J. Vandesompele (2007). "qBase relative quantification framework and software for management and automated analysis of real-time quantitative PCR data." Genome Biol 8(2): R19.

Heyer, L. J., S. Kruglyak and S. Yooseph (1999). "Exploring expression data: identification and analysis of coexpressed genes." Genome Res 9(11): 1106-1115.

Heyman, J., T. Cools, F. Vandenbussche, K. S. Heyndrickx, J. Van Leene, I. Vercauteren, S. Vanderauwera, K. Vandepoele, G. De Jaeger, D. Van Der Straeten and L. De Veylder (2013). "ERF115 controls root quiescent center cell division and stem cell replenishment." Science 342(6160): 860-863.

Huch, M., C. Dorrell, S. F. Boj, J. H. van Es, V. S. Li, M. van de Wetering, T. Sato, K. Hamer, N. Sasaki, M. J. Finegold, A. Haft, R. G. Vries, M. Grompe and H. Clevers (2013). "In vitro expansion of single Lgr5(+) liver stem cells induced by Wnt-driven regeneration." Nature.

lyer-Pascuzzi, A. S. and P. N. Benfey (2010). "Fluorescence-activated cell sorting in plant developmental biology." Methods Mol Biol 655: 313-319.

Llavata-Peris, C., A. Lokerse, B. Möller, B. De Rybel and D. Weijers (2013). "Imaging of phenotypes, gene expression, and protein localization during embryonic root formation in Arabidopsis." Methods Mol Biol 959: 137-148.

Maere, S., K. Heymans and M. Kuiper (2005). "BiNGO: a Cytoscape plugin to assess overrepresentation of gene ontology categories in biological networks." Bioinformatics 21(16): 3448-3449.

Mähönen, A. P., A. Bishopp, M. Higuchi, K. M. Nieminen, K. Kinoshita, K. Tormakangas, Y. Ikeda, A. Oka, T. Kakimoto and Y. Helariutta (2006). "Cytokinin signaling and its inhibitor AHP6 regulate cell fate during vascular development." Science 311(5757): 94-98.

Mähönen, A. P., K. ten Tusscher, R. Siligato, O. Smetana, S. Diaz-Trivino, J. Salojarvi, G. Wachsman, K. Prasad, R. Heidstra and B. Scheres (2014). "PLETHORA gradient formation mechanism separates auxin responses." Nature 515(7525): 125-129.

Müller, B. and J. Sheen (2008). "Cytokinin and auxin interaction in root stem-cell specification during early embryogenesis." Nature 453(7198): 1094-1097.

Perez-Amador, M. A., M. L. Abler, E. J. De Rocher, D. M. Thompson, A. van Hoof, N. D. LeBrasseur, A. Lers and P. J. Green (2000). "Identification of BFN1, a bifunctional nuclease induced during leaf and stem senescence in Arabidopsis." Plant Physiol 122(1): 169-180.

Roudier, F., A. G. Fernandez, M. Fujita, R. Himmelspach, G. H. Borner, G. Schindelman, S. Song, T. I. Baskin, P. Dupree, G. O. Wasteneys and P. N. Benfey (2005). "COBRA, an Arabidopsis extracellular glycosyl-phosphatidyl inositol-anchored protein, specifically controls highly anisotropic expansion through its involvement in cellulose microfibril orientation." Plant Cell 17(6): 1749-1763.

Scheres, B. (2007). "Stem-cell niches: nursery rhymes across kingdoms." Nat Rev Mol Cell Biol 8(5): 345-354.

Scheres, B., H. Wolkenfelt, V. Willemsen, M. Terlouw, E. Lawson, C. Dean and P. Weisbeek (1994). "Embryonic origin of the Arabidopsis primary root and root meristem initials." Development 120(9): 2475-2487.

Schlereth, A., B. Möller, W. Liu, M. Kientz, J. Flipse, E. H. Rademacher, M. Schmid, G. 
Jurgens and D. Weijers (2010). "MONOPTEROS controls embryonic root initiation by regulating a mobile transcription factor." Nature 464(7290): 913-916.

Shannon, P., A. Markiel, O. Ozier, N. S. Baliga, J. T. Wang, D. Ramage, N. Amin, B. Schwikowski and T. Ideker (2003). "Cytoscape: a software environment for integrated models of biomolecular interaction networks." Genome Res 13(11): 2498-2504.

Taylor, N. G., S. Laurie and S. R. Turner (2000). "Multiple cellulose synthase catalytic subunits are required for cellulose synthesis in Arabidopsis." Plant Cell 12(12): 2529-2540.

van den Berg, C., V. Willemsen, G. Hendriks, P. Weisbeek and B. Scheres (1997). "Shortrange control of cell differentiation in the Arabidopsis root meristem." Nature 390(6657): 287-289.

Weijers, D., A. Schlereth, J. S. Ehrismann, G. Schwank, M. Kientz and G. Jurgens (2006). "Auxin triggers transient local signaling for cell specification in Arabidopsis embryogenesis." Dev Cell 10(2): 265-270.

Willemsen, V., M. Bauch, T. Bennett, A. Campilho, H. Wolkenfelt, J. Xu, J. Haseloff and B. Scheres (2008). "The NAC domain transcription factors FEZ and SOMBRERO control the orientation of cell division plane in Arabidopsis root stem cells." Dev Cell 15(6): 913-922.

Yoshida, S., P. Barbier de Reuille, B. Lane, G. W. Bassel, P. Prusinkiewicz, R. S. Smith and D. Weijers (2014). "Genetic control of plant development by overriding a geometric division rule." Dev Cell 29(1): 75-87. 

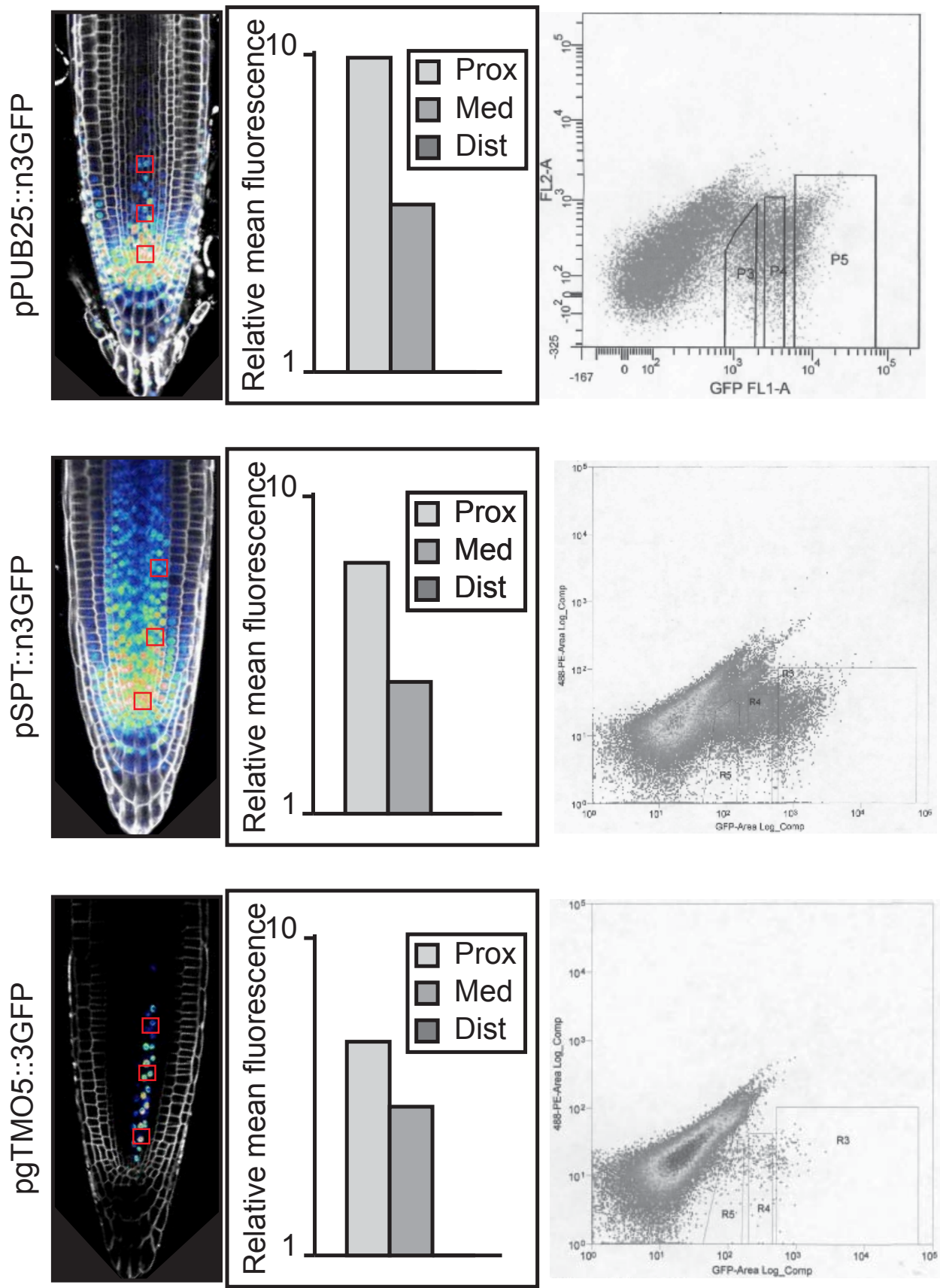

Supplementary Figure 1: Relative fluorescence intensity at indicated positions and gating used in fluorescence activated cell sorting of PUB25, SPT and TMO5 lines. 

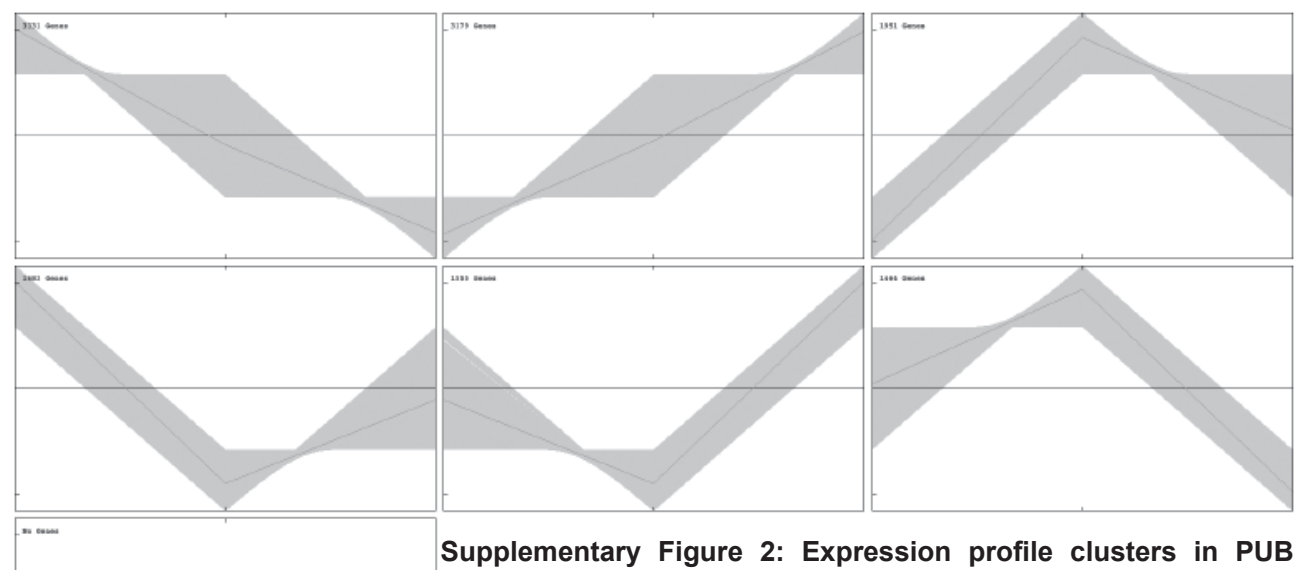
datasets; X-axis: Proximal, Medial, and Distal dataset.
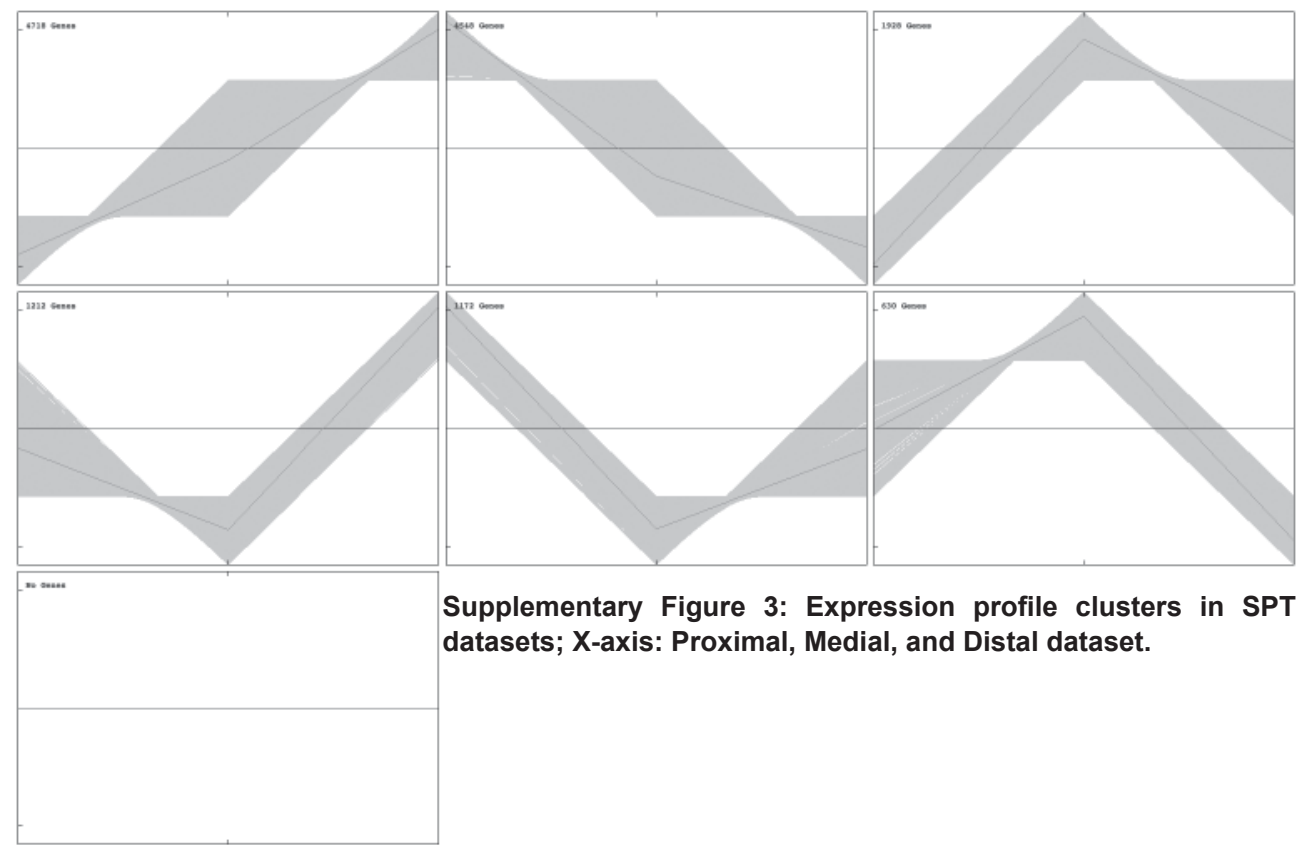

Supplementary Figure 3: Expression profile clusters in SPT datasets; X-axis: Proximal, Medial, and Distal dataset. 


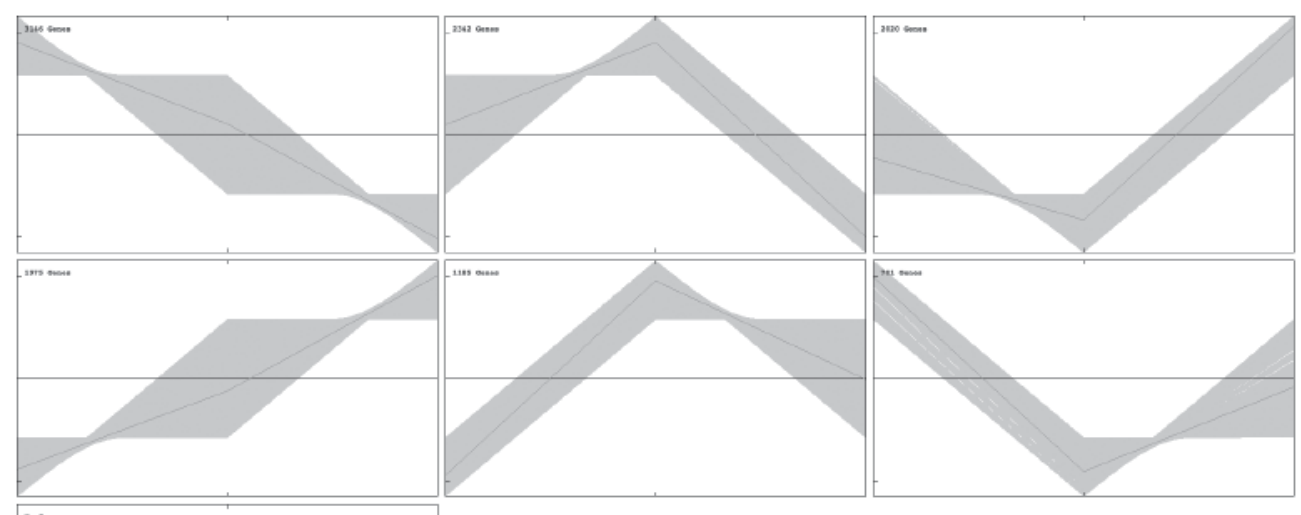

Supplementary Figure 4: Expression profile clusters in TMO5 datasets; X-axis: Proximal, Medial, and Distal dataset.

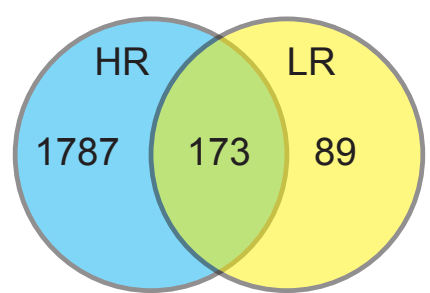

\# genes with $\mathrm{FC}>1.5$ comparing

Proximal versus Distal in Highand Low-resolution dataset

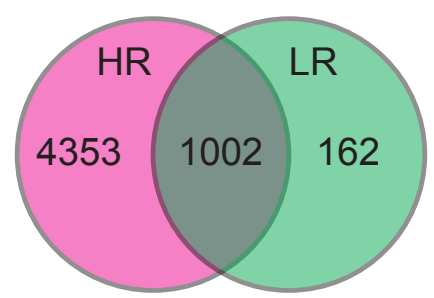

\# genes with $\mathrm{FC}<-1.5$ comparing

Proximal versus Distal in Highand Low-resolution dataset

Supplementary Figure 5: Comparison of number of identified genes with fold change $>1.5$ or $<-1.5$ in high- and low-resolution TMO5 datasets. 


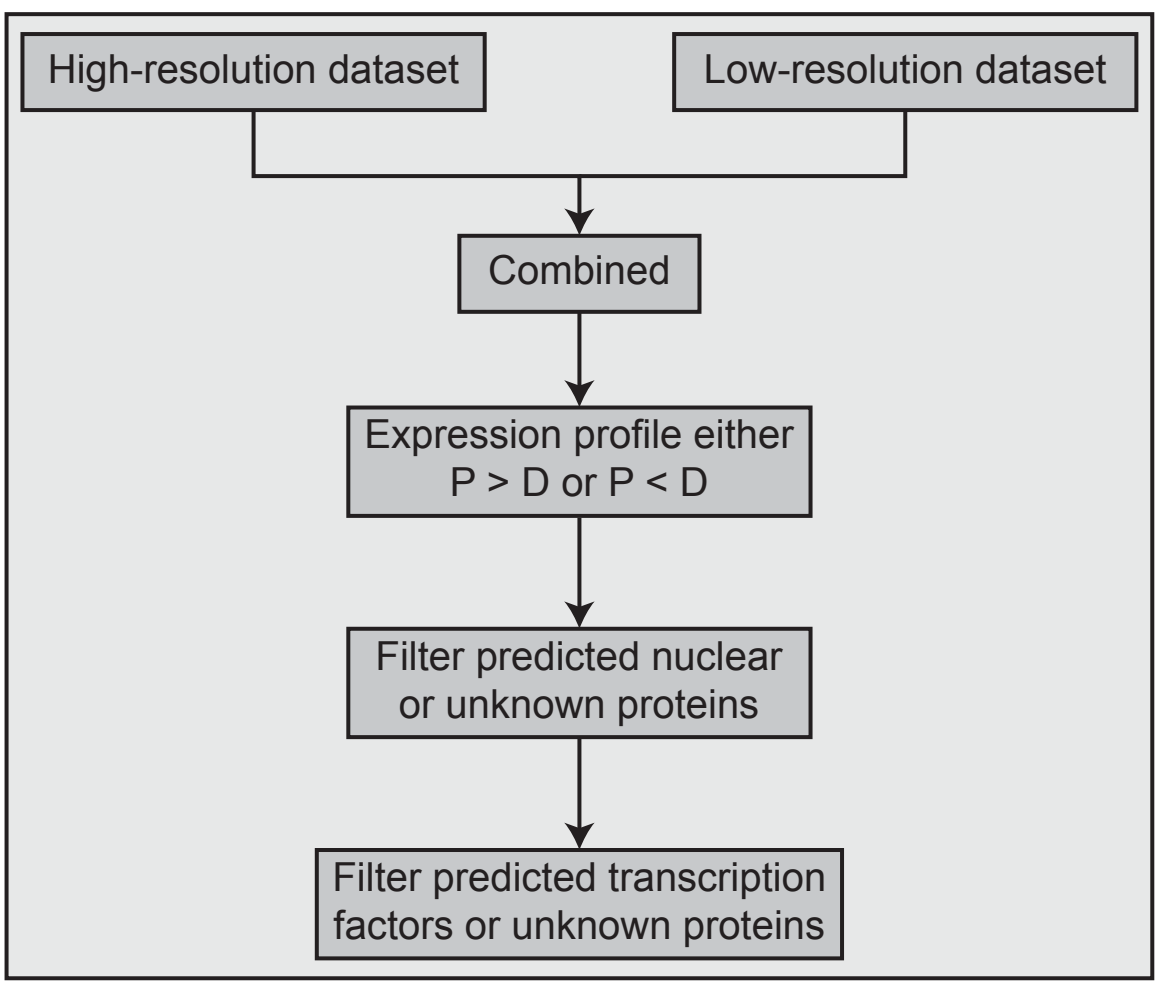

Supplementary Figure 6: Flow chart indicating gene selection procedure. $\mathrm{P}=$ Proximal, $\mathrm{D}=$ Distal 

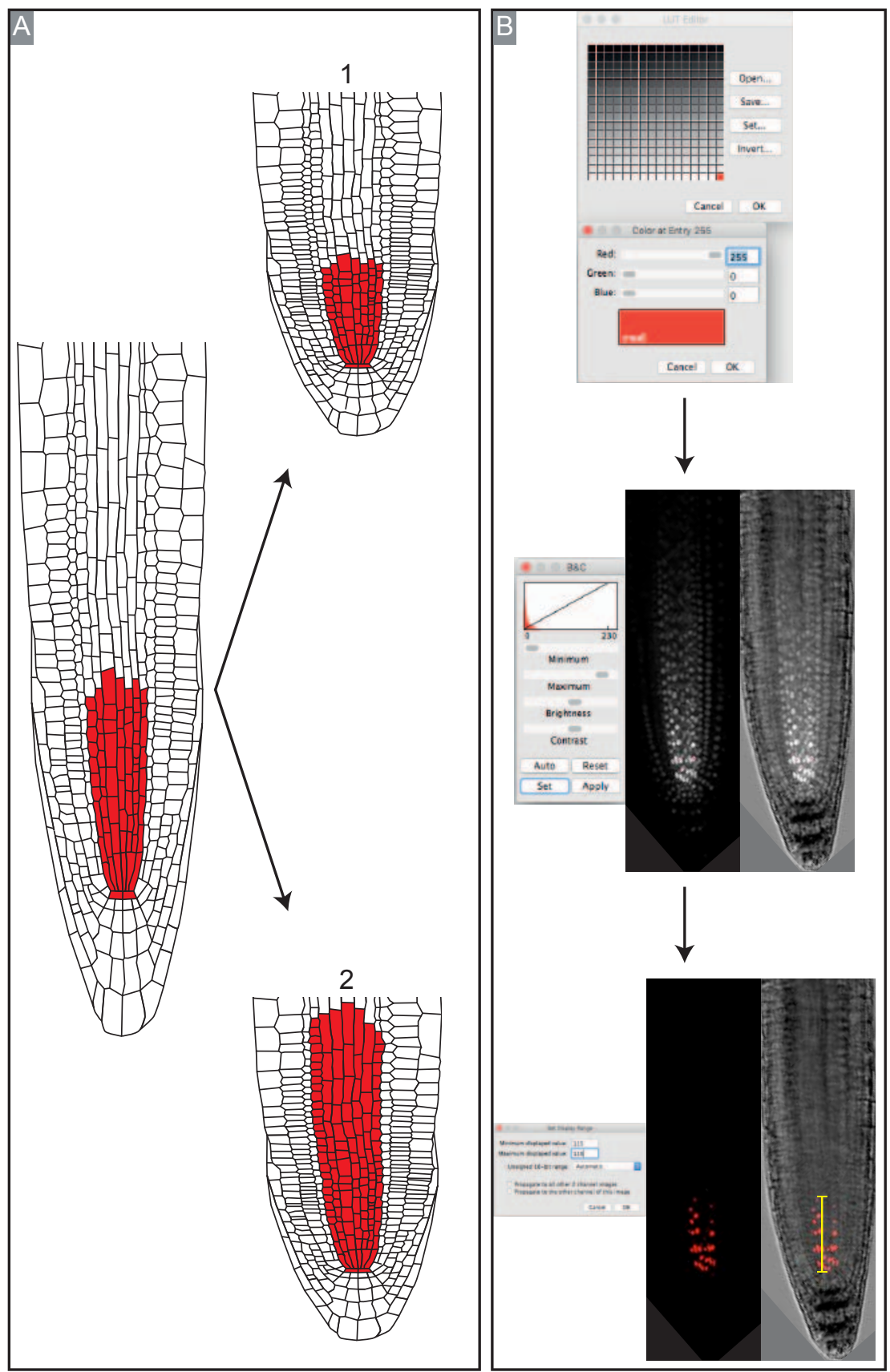

Supplementary Figure 7: (A) Hypotheses of gradient lengths after treatments 1: Gradients scale proportional to the meristem or 2: gradients do not scale proportional to the meristem. (B) Image processing procedure for gradient length measurements: Look-up table is set to indicate red at highest exposure level; Maximum exposure sites are determined; Minimum and maximum displayed values are set to half of maximum exposure level and remaining fluorescence from the QC is measured. 


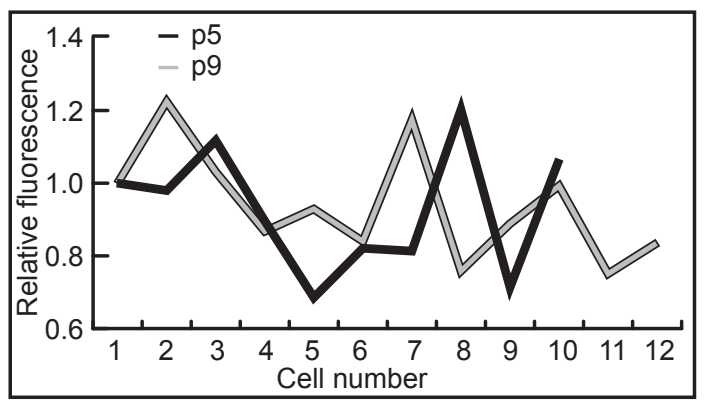

Supplementary Figure 8: Fluorescence intensity measured in a single cell file (see Figure 6D and $\mathrm{G})$, relative to previous cell in $\mathrm{p} 5$ and $\mathrm{p} 9$ promoter lines. $\mathrm{X}$-axis indicates cell number from QC.

Supplementary Table 1: Selected results from GO term enrichment analysis

\begin{tabular}{|c|c|c|c|c|c|c|}
\hline \multicolumn{7}{|c|}{ ontology: namespace } \\
\hline \multicolumn{7}{|c|}{ curator: bingo } \\
\hline \multicolumn{7}{|c|}{ Selected ontology file : jar:file:/Users/Jos/.cytoscape/2.8/plugins/BiNGO.jar!/GO_Biological_Process } \\
\hline \multicolumn{7}{|c|}{ Selected annotation file : jar:file:/Users/Jos/.cytoscape/2.8/plugins/BiNGO.jar!/A_thaliana_default } \\
\hline \multicolumn{7}{|c|}{ Discarded evidence codes : } \\
\hline \multicolumn{7}{|c|}{ Overrepresentation } \\
\hline \multicolumn{7}{|c|}{ Selected statistical test : Hypergeometric test } \\
\hline \multicolumn{7}{|c|}{ Selected correction : Benjamini \& Hochberg False Discovery Rate (FDR) correction } \\
\hline \multicolumn{7}{|c|}{ Selected significance level : 0.05} \\
\hline \multicolumn{7}{|c|}{ Testing option : Use whole annotation as reference set } \\
\hline \multicolumn{7}{|c|}{ PUB P>D } \\
\hline GO-ID & corr p-value & $\mathrm{x}$ & $\mathrm{n}$ & $\mathrm{x}$ & $\mathrm{N}$ & Description \\
\hline 50896 & 1.49E-09 & 118 & 3207 & 434 & 22304 & response to stimulus \\
\hline 6950 & 3.14E-06 & 70 & 1853 & 434 & 22304 & response to stress \\
\hline 50794 & $2.28 \mathrm{E}-04$ & 78 & 2448 & 434 & 22304 & regulation of cellular process \\
\hline 45449 & $4.90 \mathrm{E}-04$ & 52 & 1468 & 434 & 22304 & regulation of transcription \\
\hline 50789 & $5.64 \mathrm{E}-04$ & 84 & 2783 & 434 & 22304 & regulation of biological process \\
\hline 10468 & $1.81 \mathrm{E}-03$ & 54 & 1642 & 434 & 22304 & regulation of gene expression \\
\hline 48364 & $2.63 \mathrm{E}-03$ & 14 & 230 & 434 & 22304 & root development \\
\hline 48513 & 4.29E-02 & 24 & 719 & 434 & 22304 & organ development \\
\hline 48731 & 4.33E-02 & 24 & 720 & 434 & 22304 & system development \\
\hline 32502 & 4.57E-02 & 50 & 1820 & 434 & 22304 & developmental process \\
\hline
\end{tabular}


Organization of the Arabidopsis root meristem by opposing transcriptional gradients

\begin{tabular}{|c|c|c|c|c|c|c|}
\hline \multicolumn{7}{|c|}{ SPT $P>D$} \\
\hline GO-ID & corr p-value & $x$ & $\mathrm{n}$ & $x$ & $\mathrm{~N}$ & Description \\
\hline 10467 & $1.28 \mathrm{E}-71$ & 224 & 1578 & 817 & 22304 & gene expression \\
\hline 6412 & $6.10 \mathrm{E}-60$ & 173 & 1112 & 817 & 22304 & translation \\
\hline 32502 & 7.43E-07 & 112 & 1820 & 817 & 22304 & developmental process \\
\hline 33205 & 1.19E-05 & 8 & 22 & 817 & 22304 & cell cycle cytokinesis \\
\hline 51301 & 4.89E-05 & 13 & 75 & 817 & 22304 & cell division \\
\hline 8283 & 3.05E-04 & 8 & 34 & 817 & 22304 & cell proliferation \\
\hline 7049 & $1.46 \mathrm{E}-03$ & 16 & 152 & 817 & 22304 & cell cycle \\
\hline 15031 & 3.56E-03 & 25 & 325 & 817 & 22304 & protein transport \\
\hline 51726 & $6.00 \mathrm{E}-03$ & 12 & 111 & 817 & 22304 & regulation of cell cycle \\
\hline 48364 & $1.28 \mathrm{E}-02$ & 18 & 230 & 817 & 22304 & root development \\
\hline \multicolumn{7}{|c|}{ TMO P>D } \\
\hline GO-ID & corr p-value & $\mathrm{x}$ & $\mathrm{n}$ & $x$ & $\mathrm{~N}$ & Description \\
\hline 51225 & $9.23 \mathrm{E}-07$ & 3 & 3 & 36 & 22304 & spindle assembly \\
\hline 7017 & 1.23E-06 & 6 & 101 & 36 & 22304 & microtubule-based process \\
\hline 51726 & 1.37E-06 & 6 & 111 & 36 & 22304 & regulation of cell cycle \\
\hline 7049 & $5.95 \mathrm{E}-06$ & 6 & 152 & 36 & 22304 & cell cycle \\
\hline 22402 & 4.43E-05 & 5 & 122 & 36 & 22304 & cell cycle process \\
\hline 7010 & $3.54 \mathrm{E}-04$ & 4 & 97 & 36 & 22304 & cytoskeleton organization \\
\hline 51301 & 3.38E-03 & 3 & 75 & 36 & 22304 & cell division \\
\hline 10252 & 4.80E-03 & 2 & 18 & 36 & 22304 & auxin homeostasis \\
\hline 16043 & $6.95 \mathrm{E}-03$ & 7 & 935 & 36 & 22304 & cellular component organization \\
\hline 48509 & 2.68E-02 & 2 & 61 & 36 & 22304 & regulation of meristem development \\
\hline \multicolumn{7}{|c|}{$P U B P<D$} \\
\hline GO-ID & corr p-value & $x$ & $\mathrm{n}$ & $x$ & $\mathrm{~N}$ & Description \\
\hline 71554 & 7.33E-07 & 22 & 260 & 420 & 22304 & cell wall organization or biogenesis \\
\hline 71555 & 1.67E-06 & 17 & 165 & 420 & 22304 & cell wall organization \\
\hline 16049 & $2.41 \mathrm{E}-06$ & 20 & 240 & 420 & 22304 & cell growth \\
\hline 8361 & $4.72 \mathrm{E}-06$ & 20 & 254 & 420 & 22304 & regulation of cell size \\
\hline 48856 & $3.45 \mathrm{E}-05$ & 53 & 1392 & 420 & 22304 & anatomical structure development \\
\hline 42545 & $3.50 \mathrm{E}-05$ & 13 & 128 & 420 & 22304 & cell wall modification \\
\hline 30154 & $3.69 \mathrm{E}-04$ & 18 & 296 & 420 & 22304 & cell differentiation \\
\hline 48513 & $9.53 \mathrm{E}-04$ & 30 & 719 & 420 & 22304 & organ development \\
\hline
\end{tabular}


Chapter 6

\begin{tabular}{|c|c|c|c|c|c|c|}
\hline 9913 & $2.24 \mathrm{E}-03$ & 10 & 123 & 420 & 22304 & epidermal cell differentiation \\
\hline 43067 & 3.30E-03 & 5 & 29 & 420 & 22304 & regulation of programmed cell death \\
\hline \multicolumn{7}{|c|}{ SPT P<D } \\
\hline GO-ID & corr $p$-value & $x$ & $\mathrm{n}$ & $\mathrm{X}$ & $\mathrm{N}$ & Description \\
\hline 50896 & $3.00 \mathrm{E}-07$ & 147 & 3207 & 627 & 22304 & response to stimulus \\
\hline 71554 & 3.00E-07 & 29 & 260 & 627 & 22304 & cell wall organization or biogenesis \\
\hline 6950 & 4.76E-06 & 94 & 1853 & 627 & 22304 & response to stress \\
\hline 9651 & 8.98E-05 & 29 & 360 & 627 & 22304 & response to salt stress \\
\hline 9628 & 2.06E-04 & 62 & 1168 & 627 & 22304 & response to abiotic stimulus \\
\hline 71555 & 3.93E-04 & 17 & 165 & 627 & 22304 & cell wall organization \\
\hline 46034 & 3.93E-04 & 10 & 59 & 627 & 22304 & ATP metabolic process \\
\hline 9260 & 4.13E-04 & 11 & 75 & 627 & 22304 & ribonucleotide biosynthetic process \\
\hline 9664 & $1.85 \mathrm{E}-03$ & 10 & 78 & 627 & 22304 & plant-type cell wall organization \\
\hline 42546 & $2.20 \mathrm{E}-02$ & 8 & 79 & 627 & 22304 & cell wall biogenesis \\
\hline \multicolumn{7}{|c|}{ TMO P<D } \\
\hline GO-ID & corr p-value & $x$ & $\mathrm{n}$ & $\mathrm{x}$ & $\mathrm{N}$ & Description \\
\hline 50896 & 3.33E-21 & 79 & 3207 & 170 & 22304 & response to stimulus \\
\hline 71554 & $1.38 \mathrm{E}-04$ & 11 & 260 & 170 & 22304 & cell wall organization or biogenesis \\
\hline 48469 & $2.54 \mathrm{E}-04$ & 5 & 41 & 170 & 22304 & cell maturation \\
\hline 9987 & $2.66 \mathrm{E}-04$ & 83 & 7393 & 170 & 22304 & cellular process \\
\hline 21700 & 6.77E-04 & 5 & 52 & 170 & 22304 & developmental maturation \\
\hline 65008 & $1.31 \mathrm{E}-03$ & 14 & 569 & 170 & 22304 & regulation of biological quality \\
\hline 30154 & 3.60E-03 & 9 & 296 & 170 & 22304 & cell differentiation \\
\hline 8361 & $5.46 \mathrm{E}-03$ & 8 & 254 & 170 & 22304 & regulation of cell size \\
\hline 32502 & $1.50 \mathrm{E}-02$ & 25 & 1820 & 170 & 22304 & developmental process \\
\hline 52386 & 3.37E-02 & 2 & 19 & 170 & 22304 & cell wall thickening \\
\hline \multicolumn{7}{|c|}{ PUB on off } \\
\hline GO-ID & corr p-value & $x$ & $\mathrm{n}$ & $x$ & $\mathrm{~N}$ & Description \\
\hline 154 & $3.45 \mathrm{E}-08$ & 12 & 72 & 282 & 22304 & rRNA modification \\
\hline 16072 & $3.45 \mathrm{E}-08$ & 13 & 94 & 282 & 22304 & rRNA metabolic process \\
\hline 6364 & $3.45 \mathrm{E}-08$ & 13 & 94 & 282 & 22304 & rRNA processing \\
\hline 42254 & $7.28 \mathrm{E}-08$ & 14 & 123 & 282 & 22304 & ribosome biogenesis \\
\hline 22613 & $1.22 \mathrm{E}-07$ & 14 & 130 & 282 & 22304 & ribonucleoprotein complex biogenesis \\
\hline
\end{tabular}


Organization of the Arabidopsis root meristem by opposing transcriptional gradients

\begin{tabular}{|c|c|c|c|c|c|c|}
\hline 9451 & $1.53 \mathrm{E}-06$ & 12 & 111 & 282 & 22304 & RNA modification \\
\hline 34470 & $1.77 \mathrm{E}-06$ & 13 & 138 & 282 & 22304 & ncRNA processing \\
\hline 34660 & 1.03E-04 & 13 & 198 & 282 & 22304 & ncRNA metabolic process \\
\hline 6396 & $1.67 \mathrm{E}-03$ & 15 & 337 & 282 & 22304 & RNA processing \\
\hline 44085 & 1.27E-02 & 16 & 454 & 282 & 22304 & cellular component biogenesis \\
\hline \multicolumn{7}{|c|}{ SPT on off } \\
\hline GO-ID & corr p-value & $x$ & $\mathrm{n}$ & $x$ & $\mathrm{~N}$ & Description \\
\hline 6396 & 7.37E-05 & 26 & 337 & 536 & 22304 & RNA processing \\
\hline 6139 & 3.35E-04 & 53 & 1104 & 536 & 22304 & $\begin{array}{l}\text { nucleobase, nucleoside, nucleotide and } \\
\text { nucleic acid metabolic process }\end{array}$ \\
\hline 6259 & 8.59E-03 & 20 & 311 & 536 & 22304 & DNA metabolic process \\
\hline 16070 & $9.32 \mathrm{E}-03$ & 27 & 510 & 536 & 22304 & RNA metabolic process \\
\hline 34470 & $9.32 \mathrm{E}-03$ & 12 & 138 & 536 & 22304 & ncRNA processing \\
\hline 6974 & $1.08 \mathrm{E}-02$ & 13 & 163 & 536 & 22304 & response to DNA damage stimulus \\
\hline 154 & $1.98 \mathrm{E}-02$ & 8 & 72 & 536 & 22304 & rRNA modification \\
\hline 16072 & $2.25 \mathrm{E}-02$ & 9 & 94 & 536 & 22304 & rRNA metabolic process \\
\hline 6364 & 2.25E-02 & 9 & 94 & 536 & 22304 & rRNA processing \\
\hline 22613 & 4.83E-02 & 10 & 130 & 536 & 22304 & ribonucleoprotein complex biogenesis \\
\hline \multicolumn{7}{|c|}{ TMO on off } \\
\hline GO-ID & corr p-value & $x$ & $\mathrm{n}$ & $x$ & $\mathrm{~N}$ & Description \\
\hline 154 & $2.42 \mathrm{E}-02$ & 5 & 72 & 125 & 22304 & rRNA modification \\
\hline 16072 & 2.87E-02 & 5 & 94 & 125 & 22304 & rRNA metabolic process \\
\hline 6364 & 2.87E-02 & 5 & 94 & 125 & 22304 & rRNA processing \\
\hline 9451 & 4.66E-02 & 5 & 111 & 125 & 22304 & RNA modification \\
\hline 6396 & 4.97E-02 & 8 & 337 & 125 & 22304 & RNA processing \\
\hline 42254 & 4.97E-02 & 5 & 123 & 125 & 22304 & ribosome biogenesis \\
\hline
\end{tabular}


Supplementary Table 2: List of oligonucleotides used in this study

\begin{tabular}{|c|c|c|}
\hline Gene & Sense/Antisense & Sequence \\
\hline m5/AT2G26180 & Sense & 5'-AAGTCCTGGTTATGAGTT-3' \\
\hline m5/AT2G26180 & Antisense & 5'AGAGTTATCTGAAACAAGTC-3' \\
\hline m7/AT2G38160 & Sense & 5'-TGCTAGACCTGTCTCAAC-3' \\
\hline m7/AT2G38160 & Antisense & 5'-GAGTCCCCATCAACACAG-3' \\
\hline m9/AT2G42110 & Sense & 5'-CTTGTTGTTATCACAGAGACTA-3' \\
\hline m9/AT2G42110 & Antisense & 5'-AACTTACGGAGCAATTCG-3' \\
\hline m15/AT4G33400 & Sense & 5'-TGGTCTGGATAACAATAGG-3' \\
\hline m15/AT4G33400 & Antisense & 5'-TATTCGCAGTAGCAAGAT-3' \\
\hline m23/AT5G67390 & Sense & 5'-CCCTTGGTCCCTCGTGTT-3' \\
\hline m23/AT5G67390 & Antisense & 5'-АCTCCCGTCCATCATCTCC-3' \\
\hline PUB25_FOR1 & Sense & 5'-CAGCCAAGTGGTCCCTTT-3' \\
\hline PUB25_REV1 & Antisense & 5'-ТТСТТСТТСАСАТСТТТССАТСАА-3' \\
\hline SPT_FOR & Sense & 5'-GATGGACAACCTGACCTA-3' \\
\hline SPT_REV & Antisense & 5'-TTATGGCTTGCGTTCTAAG-3' \\
\hline EEF & Sense & 5'-CTGGAGGTTTTGAGGCTGGTAT -3' \\
\hline EEF & Antisense & 5'-CCAAGGGTGAAAGCAAGAAGA -3' \\
\hline ACT2 & Sense & 5'-CTCCATTTGTTTGTTTCA TT -3' \\
\hline ACT2 & Antisense & 5'-TCAATTCGATCACTCAGA -3' \\
\hline
\end{tabular}

\begin{tabular}{lll} 
Cloning & & \\
\hline Gene & Sense/Antisense & 'sequence \\
\hline SPT & Sense & 5'-TAGTTGGAATGGGTTCGAAGATTAAAATTAGTAACACTGATTAGGC-3' \\
SPT & Antisense & 5'-TTATGGAGTTGGGTTCGAACAGTAATTCGATCTTTTAGGTCAGG-3' \\
\hline p1/AT1G14350 & Sense & 5'-TAGTTGGAATGGGTTCGAAGACATGCACTTGTCAGCAATGC-3' \\
p1/AT1G14350 & Antisense & 5'-TTATGGAGTTGGGTTCGAATTTTCTTCTTCTTCTTTCTTACTAC-3' \\
\hline p2/AT1G63100 & Sense & 5'-TAGTTGGAATGGGTTCGAACAACCGCTTTTCGCATTATGTC-3' \\
p2/AT1G63100 & Antisense & 5'-TTATGGAGTTGGGTTCGAACCTCTACAAAATCTACCTAACCC-3' \\
\hline p3/AT1G72670 & Sense & 5'-TAGTTGGAATGGGTTCGAAGTTCTTCAGAGAGTGTGGAAAAC-3' \\
p3/AT1G72670 & Antisense & 5'-TTATGGAGTTGGGTTCGAATTGCTCAAATTTGAAACCCTTTTG-3' \\
\hline p5/AT2G26180 & Sense & 5'-TAGTTGGAATGGGTTCGAACCGTCACCATACGGCCCAATTCC-3' \\
p5/AT2G26180 & Antisense & 5'-TTATGGAGTTGGGTTCGAAAGATTAAAAAGTTTCGATCTTTTTGG-3' \\
\hline p6/AT2G34357 & Sense & 5'-TAGTTGGAATGGGTTCGAAGAGAGAATAAACACGAAATGG-3' \\
p6/AT2G34357 & Antisense & 5'-TTATGGAGTTGGGTTCGAAAACTAGGTTCCGTTCCTTGAC-3' \\
\hline
\end{tabular}


Organization of the Arabidopsis root meristem by opposing transcriptional gradients

\section{Supplementary Table 2: Continued}

\begin{tabular}{|c|c|c|}
\hline p8/AT2G38370 & Sense & 5'-TAGTTGGAATGGGTTCGAAGGAGAGGGCAGAGCTGTATTAGC-3' \\
\hline p8/AT2G38370 & Antisense & 5'-TTATGGAGTTGGGTTCGAATGAAGCAGAAGAAGACGAGTCTTC-3' \\
\hline p9/AT2G42110 & Sense & 5'-TAGTTGGAATGGGTTCGAAGAGTTTTTGCAATTGAAGCAGG-3' \\
\hline p9/AT2G42110 & Antisense & 5'-TTATGGAGTTGGGTTCGAAATTCTCGGTAATGTAAGAAAGAC-3' \\
\hline p10/AT2G47990 & Sense & 5'-TAGTTGGAATGGGTTCGAAGAAGCGCATGTGGAGAATCTCAC-3' \\
\hline p10/AT2G47990 & Antisense & 5'-TTATGGAGTTGGGTTCGAATATTCTAGAGTACAAGCAGAGAGC-3' \\
\hline p12/AT3G14190 & Sense & 5'-TAGTTGGAATGGGTTCGAACCACTGCCACCGAAAGAAGCAGC-3' \\
\hline p12/AT3G14190 & Antisense & 5'-TTATGGAGTTGGGTTCGAAATGGTTTTAACTGTGAATCATC-3' \\
\hline p14/AT4G23800 & Sense & 5'-TAGTTGGAATGGGTTCGAACATAAGAATGTGCTTCTCATCAAG-3' \\
\hline p14/AT4G23800 & Antisense & 5'-TTATGGAGTTGGGTTCGAATTCTAAAGTCGAAAATGAGAGAG-3' \\
\hline p17/AT5G10010 & Sense & 5'-TAGTTGGAATGGGTTCGAAGATCAAGTACTCTACTCCTCTTAC-3' \\
\hline p17/AT5G10010 & Antisense & 5'-TTATGGAGTTGGGTTCGAATGCCACAGTACTCTACCAACG-3' \\
\hline p18/AT5G16250 & Sense & 5'-TAGTTGGAATGGGTTCGAACGAGTCCATACGGGTCAACGCTAC-3' \\
\hline p18/AT5G16250 & Antisense & 5'-TTATGGAGTTGGGTTCGAAGATGAGTTTTGAGTTTTTGAAAATTT-3' \\
\hline p20/AT5G17160 & Sense & 5'-TAGTTGGAATGGGTTCGAAGTACGTAGACAACCTTTTACAAGG-3' \\
\hline p20/AT5G17160 & Antisense & 5'-TTATGGAGTTGGGTTCGAATTCCGCGAAATCGAGAGAGAGTG-3' \\
\hline p24/AT1G10170 & Sense & 5'-TAGTTGGAATGGGTTCGAAGCTGCACCGGAACTGAAAGAATG-3' \\
\hline p24/AT1G10170 & Antisense & 5'-TTATGGAGTTGGGTTCGAAATTCTGCCTTGACTCCACAAACAC-3' \\
\hline p30/AT1G69600 & Sense & 5'-TAGTTGGAATGGGTTCGAAGCTCGATGATTAAAGTTAAATCC-3' \\
\hline p30/AT1G69600 & Antisense & 5'-TTATGGAGTTGGGTTCGAAAGCTTTTGTTTAGTTCTGTCTTTATAG-3' \\
\hline p33/AT2G43680 & Sense & 5'-TAGTTGGAATGGGTTCGAACGACCAAAGATTAATCCATATTAG-3' \\
\hline p33/AT2G43680 & Antisense & 5'-TTATGGAGTTGGGTTCGAATTTGCCAACATCACTTTCCTTACC-3' \\
\hline m5/AT2G26180 & Sense & 5'-TAGTTGGAATAGGTTCATGGGTGCTTCAGGGAAATGGG-3' \\
\hline m5/AT2G26180 & Antisense & 5'-AGTATGGAGTTGGGTTCTTACCTCTCGGCTTCTCGAATC-3' \\
\hline m7/AT2G38160 & Sense & 5'-TAGTTGGAATAGGTTCATGGAGAATGTGGTGGTGGTTCG-3' \\
\hline m7/AT2G38160 & Antisense & 5'-AGTATGGAGTTGGGTTCTTCGATGACTCGTTTTTGTCC-3' \\
\hline m9/AT2G42110 & Sense & 5'-TAGTTGGAATAGGTTCATGGATCTTGTTGTTATCACAGAG-3' \\
\hline m9/AT2G42110 & Antisense & 5'-AGTATGGAGTTGGGTTCTTAACGACGTCGTTGGTGAGAC-3' \\
\hline m15/AT4G33400 & Sense & 5'-TAGTTGGAATAGGTTCATGGGAGCATCTCACAGTCATG-3' \\
\hline m15/AT4G33400 & Antisense & 5'-AGTATGGAGTTGGGTTCTTTCGCTTGCTGGATAAGCTG-3' \\
\hline m23/AT5G67390 & Sense & 5'-TAGTTGGAATAGGTTCATGGAGAAGCTTCTTAATCCGTAC-3' \\
\hline m23/AT5G67390 & Antisense & 5'-AGTATGGAGTTGGGTTCTTAATAACATTCAAGGTCAATG-3' \\
\hline
\end{tabular}





\section{Chapter 7}

\section{, \\ General discussion}

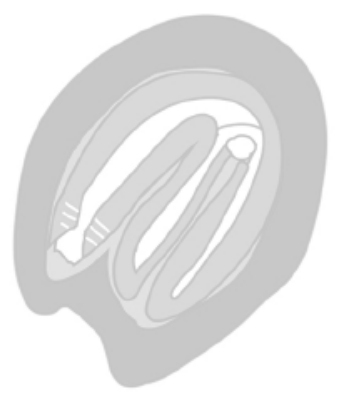

Jos R. Wendrich
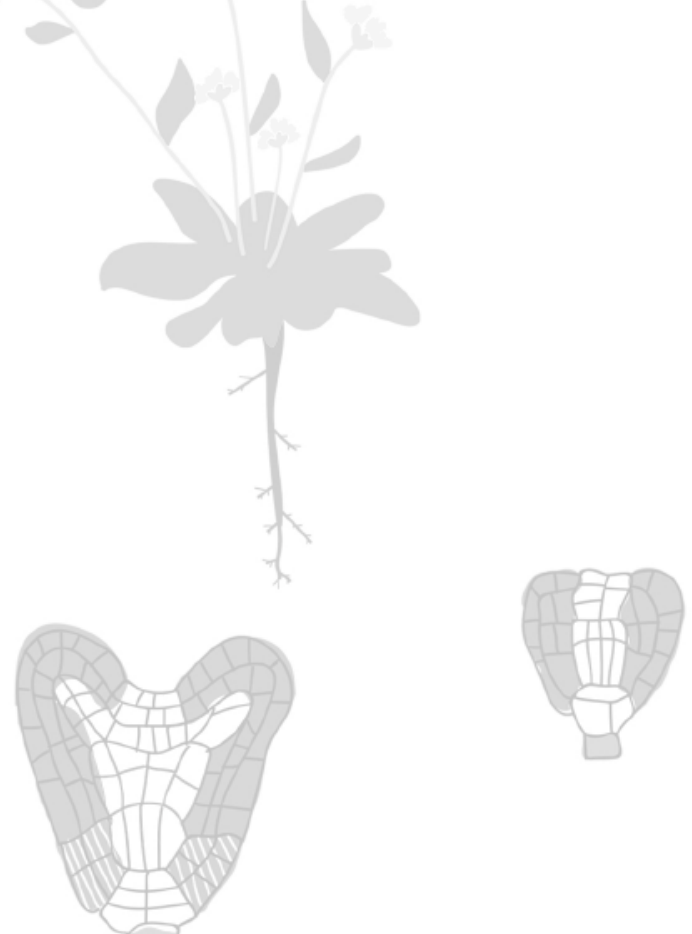

Laboratory of Biochemistry, Wageningen University, Dreijenlaan 3, 6703 HA Wageningen, the Netherlands 

Stem cells are at the core of multicellular development as they provide new cells to growing tissue, through their ability to self-renew and produce differentiating daughter cells. In plants, they are typically found in niches, which are part of meristems that remain active throughout the life of the plant to continuously produce new organs and tissues. The meristems that are first established are the Shoot- and Root Apical Meristem (SAM and RAM, respectively), which reside at the tips of the plant. The SAM produces all the aboveground tissues, like stems and leaves. The RAM, on the other hand, produces the belowground root-tissues. Additional (lateral) meristems, like flower and lateral root meristems and the vascular cambium, are formed later during development. Questions of how stem cells are established and what factors are involved in this process have inspired generations of scientists. Although much has already been learned about several key components involved, many gaps still remain and in this thesis we have aimed to fill some of these gaps. As discussed in Chapter 1, all the components that shape the plant are condensed during embryonic development of Arabidopsis. In addition, embryogenesis in Arabidopsis occurs in a very ordered and predictable way, which makes it an ideal model to study key developmental events, such as the establishment of stem cells. In the work presented in this thesis, we have taken an integrated approach to dissect the action of a key transcription factor involved in the establishment of the root apical meristem, MONOPTEROS (MP). This AUXIN RESPONSE FACTOR (ARF), acts very early during development and is required to orchestrate key developmental and morphogenetic events. In this chapter I will discuss the novel findings of this thesis, connect different chapters and make suggestions for future research directions.

\section{Cell identity as inferred by transcriptional composition}

Underlying the question of how stem cells are established is the question of how a cell can distinguish itself from others, i.e. have a unique identity. The specification of cell identity involves the activation or repression of a unique set of transcripts, followed by the accumulation of proteins and ultimately by cell differentiation processes. The identity of a cell can be inferred at any of these levels, but the most widely used method is by looking at the transcriptional composition of a cell. Especially young cells often lack clear signs of differentiation and testing for accumulation of proteins regularly requires elaborate staining and detection techniques. Although staining methods for transcripts, e.g. by in situ mRNA hybridization, are still relatively elaborate techniques, the transcriptional activity of a gene can easily be inferred by the activity of the associated promoter driving a reporter protein. Promoter activity is 
often a good proxy for mRNA accumulation as we were for example able to show by the extremely high overlap between in situ mRNA hybridization and promoter activity of two LONELY GUY genes (LOG3 and LOG4; De Rybel et al., 2014). The use of gene expression makers to infer cell identity is very powerful, especially since this is one of the first events that take place upon specification of cell identity. A basic drawback of using expression markers is, however, that complex networks regulate the expression of each gene, and even if the expression of a gene correlates with a cell's identity, it does not define it. One would, therefore, ideally combine several markers to infer identity, independent of the dedicated transcriptional control of a single gene. The availability of identity markers in the Arabidopsis embryo is, however, poor and does not cover all possible regions and cell types. In Chapter 4 we describe a set of promoter marker lines that mark different regions in the embryo. This set of lines helps to move away from measuring the regulation of single genes, and towards a more generic set of tissue identity markers. The selection of these genes was based on several transcriptomic datasets, including a microarray experiment where MP activity was locally inhibited in the innermost cells of the embryo (Möller, 2012). Interestingly, all the selected genes that were identified as downstream targets of MP were found to mark the embryonic stem cell precursors in globular stage embryos (Chapters 4 and 6). The expression of these genes additionally reflected typical stem cell behavior, especially at the transition from early- to late globular stage. Expression after division could often be found in the basal daughter cell and not in the apical daughter. This indicates two things: (I) divisions taking place at this stage of development are asymmetric, not only at the level of cell morphology (Yoshida et al., 2014) but also at the level of transcriptional composition; and (II) stem cell properties can, in the embryo, be inferred by marker lines. Functional characterization of these genes did, however, not reveal a specific role for any of them during this stage of development (Chapter 4). Nonetheless their expression seems to be linked to stem cell identity, even though it does not define it. Another interesting finding was that in the absence of a functional copy of MP, the genes marking these embryonic stem cell precursors were completely absent from the region they were normally expressed (Chapter 4 ). This indicates that these genes are indeed under transcriptional control by MP and further suggests that MP is involved in the establishment of stem cells at this stage of development. We, in addition, identified a pair of genes specifically expressed in cells of the ground tissue. Expression was initially restricted to the Cortex/Endodermis Initial precursor, in the basal tier of the globular embryo, but interestingly later expanded to ground tissue cells of the developing cotyledons (Chapter 4). This suggests that although 
these two lineages are derived from different cellular ancestors (apical vs. basal tier), they do share common properties at the level of gene expression. Furthermore, these two lines are, to our knowledge, the first that mark all the developing ground tissue at this stage.

While expression domains of single genes can be very informative, true cell identity is a complex mixture all the molecular components, like transcripts and proteins, in that cell. This mixture ultimately leads to unique cellular responses defining identity. To further grasp the differences between each cell on the molecular basis, one would ideally like to know the exact molecular composition of each individual cell. Although this is still beyond our reach, recent advances have been made in transcriptomics and especially in the isolation of single cell types from complex tissues. This enables us to fill a big piece of that puzzle by deciphering the transcriptomes of single cell types in the Arabidopsis embryo. A project currently running in our lab (Palovaara et al., unpublished) utilizes such a technique, called Isolation of Nuclei TAgged in specific Cell Types (INTACT), originally developed by Deal and Henikoff (2010). This technique makes use of a two-component tagging system, composed of a Biotin-ligase protein (BirA) and a Nuclear Tagging Factor (NTF) that contains a Biotin-acceptor peptide and is targeted to the nuclear envelope. When both components are expressed in the same cell, BirA will biotinylate the NTF and tagged nuclei can then easily be isolated from a crude nuclear preparation, using streptavidin-beads. By expressing both components from different (cell type specific) promoters, we were able to isolate nuclei from all the different cell types in the basal tier of the embryo. In addition, through a hand-pollination strategy we were able to isolate nuclei from embryos in a specific stage of development. This allowed us to determine the transcriptome of specific cell types in the embryo, through development. Approaches like these have great potential to further our knowledge of what defines a cell and its identity.

\section{Cellular responses controlled by MP}

So far, most the downstream targets of MP that have been characterized were themselves transcription factors or part of families of transcriptional regulators. Some of them (e.g. TMO5, TMO7; De Rybel et al., 2013, 2014; Schlereth et al., 2010) have been shown to play an important role in embryo development. An open question that still remains is how hormones and transcription factors, like MP, can orchestrate different cellular processes that determine cell shape and function. In search for nontranscription factors regulated by MP, we identified a group of IQD genes (IQD15- 
18) that was particularly affected by MP inhibition (Chapter 5). IQD proteins were initially identified based on a conserved IQ67-domain that was proposed to facilitate calcium-dependent Calmodulin binding (Abel et al., 2005). Further analysis on this subclade showed that these IQD genes are indeed transcriptionally regulated by auxin and that they bind microtubules (MT) and Calmodulins in vivo (Chapter 5). The latter was also shown for another member of this family, IQD1, by in vitro binding assays and transient expression in tobacco leaves (Bürstenbinder et al., 2013). Still an open question is whether these IQD proteins directly bind MT or if they require an additional binding partner to bind MT. Binding to Calmodulins most likely occurs directly through the IQ-domain, but no other functional domains are known for these proteins. This suggests that either unknown domains play a role in IQD binding to MT or perhaps this occurs through other proteins. As calcium and Calmodulins have been shown to both be required for MT depolymerization (Hepler, 2016), the IQD proteins could be involved in this as well. There is a so-called DOMAIN OF UNKNOWN FUNCTION (DUF4005) present in 64\% of all Arabidopsis IQD proteins, including IQD15-18, and it will be interesting to find out what the function of this domain is and if it is involved in specific localization or protein-protein interactions of IQD proteins.

We were, in addition, able to show that the subcellular localization of IQD18 is cell cycle-dependent (Chapter 5). While localized to the cortical MT in interphase, the protein moves to the nucleus during S-phase, where it resides for the remainder of the cell cycle. Furthermore, during cytokinesis, IQD18 localizes to the newly forming cell plate and afterwards returns to its original position at the cortical MT. This cell cycle-dependent localization suggests that IQD18 may be involved in processes governing the cell cycle. Interestingly, loss- and gain-of-function lines of IQD18 showed an opposite response to treatment with the calcium-chelator EGTA (Chapter 5). Also, while the iqd18 loss-of-function mutant did not show a significantly altered response upon auxin treatment, the gain-of-function misexpression line was significantly more resistant to auxin-induced root growth inhibition (Chapter 5). This implies that this protein may be necessary for proper auxin- and calcium-signaling, bridging these two signaling pathways. A link between these two signaling pathways has been shown before, for example through rapid calcium peaks and upregulation of Calmodulin expression after auxin treatment (Di et al., 2015; Monshausen et al., 2011; Monshausen, 2012) and regulation of PIN-polarity by calcium (Zhang et al., 2011). The precise molecular components of this link have, however, remained elusive. From the findings presented in Chapter 5, is seems that IQD proteins may meet the requirements to indeed bridge these signaling pathways for several reasons: (I) 
they are transcriptionally regulated by auxin; (II) they bind proteins involved in auxin homeostasis and signaling; (III) they bind proteins involved in calcium signaling; and importantly (IV) disrupting their expression (positively or negatively) results in altered auxin and calcium outputs. Exactly what molecular function these proteins perform is still unclear, and remains speculation. One could imagine that through interactions with different proteins in different conditions, these proteins are able to assist in the regulation of several processes. An example for this could be the interaction with the Kinesin-like protein ZWICHEL (Chapter 5). Studies on a similar Kinesin-like protein (KINESIN-LIKE CLACIUM BINDING PROTEIN; KCBP) suggest that calcium might have an inhibitory role for the motor activity of this protein. In low calcium conditions this protein would bind and move over MT, while in high calcium conditions it would bind Calmodulin or KCBP-INTERACTING CALCIUM BINDING PROTEIN (KIC), which block MT binding and motor activity (Hepler, 2016; Vinogradova et al., 2008, 2009). Interestingly, IQD1 has been proposed to direct yet another Kinesin protein towards MT (Büstenbinder et al., 2013). A similar mode of action could take place in the case of the IQD15-18 subclade, where part of their role could be to direct Kinesin binding to MT and perhaps promote their motor activity by binding to Calmodulins, thereby freeing the Kinesin from its interference. Support for this can also be found in the preliminary IP-MS/MS data on IQD18, in the presence of EGTA, indicating more prominent Calmodulin binding in the absence of calcium (Chapter 5). This can be further supported by in vitro binding analysis and colocalization studies, also showing more prominent binding between the single rice co-ortholog of this Arabidopsis subclade, OsIQD14, and with OsCaM1-1 (Baojun Yang and Hongwei Xue, personal communication). Since the rice and Arabidopsis IQD proteins show identical subcellular localization (i.e. cortical MT and nuclear localization; Baojun Yang and Hongwei Xue, personal communication), this is likely a conserved type of localization, and their function may also be conserved, perhaps even down to the ancestral IQD protein. Considering the rootless phenotype observed in osiqd14 mutants, it is very likely that the Arabidopsis IQD15-18 subclade also plays a vital role in the establishment of the root meristem downstream of MP.

Interestingly, other experiments indicate a more general role for IQD proteins in auxin-mediated development. An example of this is a gene within the IQD6-8 subclade, IQD6. This gene was not only found as a gradient marker in Chapter $\mathbf{6}$, but also identified as downstream target of MP in globular stage embryos (Möller, 2012) and extremely affected in auxin signaling-deficient 8-cell stage embryos (De Zeeuw et al., unpublished). Although in-depth functional analysis has not yet been performed, ectopic expression of this gene did result in reduced root length (Chapter 
6), indicating a potential function in root development. Remarkably, although the entire IQD6-8 subclade lacks the DUF4005 domain found in many other IQD proteins, they do seem to be transcriptionally regulated by auxin. This suggests that they may have distinct function and uncouples the DUF4005 domain from auxin-regulation. It will be interesting to study the differences and similarities between the IQD6-8 and IQD15-18 clade and find out why their expression appears so tightly regulated.

Taken together, these data strongly suggest a general role for IQD proteins in cellular responses directed by auxin and MP. Perhaps by modulating auxin- and calcium-signaling, the IQD proteins could be involved in fine-tuning responses to both these signaling pathways during development and maybe in stem cell specification or maintenance.

\section{Stem cell organization in the Arabidopsis root}

The organization of stem cells within meristems is subject to many studies and although much has been learned already, many gaps still remain to be filled. A currently widely used model for the organization of stem cells in the root apical meristem shows the organizing quiescent center (QC), that separates a proximal and a distal meristem zone. The organizing role for the QC is most apparent for the distal meristem zone, which generates the central root cap. There is very clear evidence that shows the $\mathrm{QC}$ and signals from the $\mathrm{QC}$ prevent the adjacent columella stem cells (CSC) from differentiating (van den Berg et al., 1997). A factor that has been found to be important for this function of the $\mathrm{QC}$ is the homeo-domain transcription factor WOX5. WOX5 is specifically expressed in the QC and the protein has been shown to move to the adjacent CSC, which is necessary for its role in maintaining the CSC population (Pi et al., 2015). Furthermore, other pathways (i.e. RETINOBLASTOMA-RELATED, SOMBRERO, FEZ, ARF10 and ARF16) have been shown to determine the CSC population in parallel to WOX5 (Bennett et al., 2014). Together these pathways control the number of stem cells and ensure that cells enter differentiation at the right moment. While this clearly defines the molecular players involved in the organization of the distal meristem zone, the proximal meristem has proven much more difficult to dissect. The clear role that the QC plays in the organization of the distal meristem is less apparent in the proximal meristem. For example, ablation of the QC has severe effects on the distal meristem zone, but organization of the proximal meristem appears unaffected (van de Berg et al., 1997). A similar effect is seen in for example the wox 5 mutant, which shows defects in CSC maintenance but has no obvious effect on the proximal meristem (Sarkar et al., 2007). 
Stem cells in the proximal meristem may therefore be controlled differently from the distal meristem stem cells. Nonetheless, clonal analysis revealed that the only possible proximal stem cells reside directly adjacent to the QC, strictly operationally speaking (Scheres et al., 1994). The lack of gene expression markers specific for only these cells however urges the question of whether the plant makes a qualitative distinction between stem cells and non-stem cells in the proximal meristem. Since clear morphological differentiation markers only appear outside the meristem, e.g. casparian-strip formation in endodermal cells (Geldner, 2013), it is also unclear where the boundaries between stem cells and differentiation are and how these are established.

As discussed above, MP plays a key role during de novo stem cell specification events that take place during the globular stage of embryogenesis. We have shown that downstream target genes of MP are often expressed in these embryonic stem cell precursors (Chapters 4 and 6). While all of them showed typical stem cell factor behavior in the embryo, post-embryonically they were all expressed in a graded profile that was highest close to the QC (Chapters 4 and 6). Using three such marker lines (PUB25, SPT and TMO5), we were able to generate the first cell type-specific transcriptome from systematically obtained ontogenetic cell populations in the root meristem (Chapter 6). We were able to overcome the drawbacks of previously obtained datasets that either covered much larger zones in the root (Birnbaum et al., 2003) or sampled only two individual roots with high spatial resolution (Brady et al., 2007). Our data enabled us to test several scenarios regarding stem cell organization in the proximal meristem.

We first tested which genes were associated with an expression profile that was restricted to only the cells close to the QC. Analysis revealed that this population of cells does not uniquely express genes associated with development (Chapter 6). This suggests that the plant indeed may not qualitatively distinguish stem cells from non-stem cells in the proximal meristem.

Secondly, as an alternative, we identified many genes with a graded profile of high expression close to the QC that gradually decreases. These genes were in fact associated with developmental functions (Chapter 6). Among this group of genes were many that are known for their role in proximal meristem development, such as PLETHORA1 and -2, SHORT-ROOT, and ARABIDOPSIS HISTIDINE PHOSPHOTRANSFER PROTEIN 6 (Aida et al., 2004; Helariutta et al., 2000; Mähönen et al., 2006). These prevailing graded expression patterns of meristem regulators suggests an alternative mode for stem cells organization in the proximal meristem. In this case stemness would not be a qualitative property restricted to 
the cells directly surrounding the QC, but rather a quantitative one that is highest in those cells and gradually decreases. This does raise a question as to how we currently define stem cells and what this stemness property exactly is. If indeed we cannot find unique sets of qualitative molecular properties that define a stem cell, perhaps these properties are not unique and we should reconsider the stem cell definition. We could, for example, consider stemness purely as a property of the meristem, rather than restricted to particular cells, as was also suggested by Lander (2009). Such a scenario would not require unique properties of the stem cells, but rather place them into the larger context of the meristem that has more general properties allowing it to sustain a steady production of new cells and tissues.

Thirdly, and to our surprise, we also identified a large group of genes with an opposite graded expression profile. This group consisted of many genes known for their involvement in differentiation processes, like ACAULIS5, COBRA, and IRREGULAR XYLEM1 (Clay and Nelson, 2005; Roudier et al., 2005; Taylor et al., 2000). While these genes increased in expression when further displaced from the QC, their expression was not absent close to the QC (Chapter 6). This strongly suggests that differentiation potential is present already in very young cells and that a gradient of differentiation is opposing the gradient of stemness in the proximal meristem. Taken together we propose an extended model for stem cell organization in the proximal meristem, where both stemness and differentiation are quantitative properties that oppose each other in gradients in the root (Chapter 6). The interaction between these two gradients still remains an open question. One could imagine that the observed differentiation gradient is established through transcriptional repression by genes following the stemness gradient. In addition, as cells in the meristem lack clear signs of differentiation, it is unclear whether the differentiation processes are already started in these young cells or whether these are somehow blocked, for example by post-translational modifications. The latter could result in a sharp switch to differentiation, but this remains to be investigated.

Further analysis on the identified gradients also revealed some interesting findings. Expression, as visualized by promoter activity, of the majority of the selected genes mirrored that of the transcript profiles identified using RNA-sequencing. We, in addition, observed a strong correlation between a graded expression in the root and strong expression in the embryonic stem cell precursors (Chapter 6 ). This suggests that it could be a common property of genes expressed in the embryonic root stem cell precursors to be expressed in gradients in the post-embryonic root. This further indicates that these cells in the lower tier of the embryo have similar properties to their descendants in the root. One could speculate that, due to the limited number 
of cells at this stage of development, these properties are condensed into a single cell layer. This is later stretched over more cells as development progresses and more cells are added to the tissue. The factor that generates the gradients in the root would in that case most likely already be present early during development of the embryo. This supports the use of the Arabidopsis embryo as a model system to study the specification of stem cells and the generation of developmental gradients. How exactly these gradients are generated remains an open question. Of course, the concept of gradients is not new to biology and gradients have been shown for other factors, like for example morphogens. Morphogens are secreted signaling molecules that dose-dependently organize an area of cells into patterns (Gurdon and Bourillot, 2001). In fact, transcriptional gradients in the root could be an output of morphogen action. Morphogen-gradients, however, often scale proportional to tissue size (Rogers and Schier, 2011). This was, for example, shown for Decapentaplegic gradients in growing Drosophila wing imaginal discs (Wartlick et al., 2011). Since we have shown that the length of the identified transcriptional gradients does not scale proportional to the meristem size, in most cases (Chapter 6), it is unlikely that they are a direct output of a morphogen or special context. The gradients are more likely the result of active transcriptional control and finding out exactly what factors are involved will be very interesting. A possibility could be that master regulators, like for example the PLTs, are responsible for generating these transcriptional gradients. It would therefore be very interesting to find out whether there is an overlap between these gradient genes and target genes of master regulators like PLTs. In addition, since many of the MP target genes are expressed in gradients in the root (Chapters $\mathbf{4}, \mathbf{5}$, and 6), it would be interesting to find out whether there is a more common connection between MP targets and genes expressed in a gradient. Alternatively, highly stable transcripts and a dilution effect after division could also generate a gradient. A gene would then only be actively transcribed in a single or a few cell layers and the protein or transcript is divided over the two daughter cells after division. This would result in a gradual decrease of protein or transcript abundance after a few rounds of cell division. This has, for example, been shown for PLT gradients. In this case a combination of local expression, transcript and protein stability and protein diffusion results in a gradient of PLT protein in the root meristem (Mähönen et al., 2014). While this seems a very elegant mechanism to establish a gradient, such a system would probably be coupled to growth speeds and tissue size. It will be interesting to find out how transcript stability can contribute to gradient formation and whether the mechanism shown for the PLTs is utilized more often. 
In conclusion, this thesis describes efforts to dissect the control of MP on the specification and organization of stem cells in the Arabidopsis (embryonic) root. Through multidisciplinary approaches we have been able to identify a role for MP in the specification of embryonic stem cell precursors, a mode for how MP may affect cellular processes, through the action of IQD proteins, and a new mode for the organization of stem cells in the Arabidopsis root meristem. The latter indicates a different mode of control on the proximal meristem than on the distal meristem. Interestingly, when we compare the two main apical meristems (SAM and RAM) to each other, it would appear they are quite alike. Especially the molecular players involved in maintenance of both the distal root meristem and the organizing center and central zone of the shoot meristem seem highly associated (Friedman et al., 2004). It would therefore be interesting to test whether a comparable stem cell organization can also be found between the proximal root meristem and the rib meristem of the shoot. Since Arabidopsis may not be a representative species for meristem organization principles, it will also be interesting to study how this type of organization has evolved and whether the gradient-type organization has been adopted in other systems and species as well. It could, in addition, be possible that a gradient-type organization is present in all (plant) meristems, but that this is somehow masked, for example due to the single cell layer between QC and differentiating columella cells. Testing mutants or species with multiple CSC layers, may yet reveal gradients that govern these meristems. 


\section{References}

Abel, S., T. Savchenko and M. Levy (2005). "Genome-wide comparative analysis of the IQD gene families in Arabidopsis thaliana and Oryza sativa." BMC Evol Biol 5: 72.

Aida, M., D. Beis, R. Heidstra, V. Willemsen, I. Blilou, C. Galinha, L. Nussaume, Y. S. Noh, R. Amasino and B. Scheres (2004). "The PLETHORA genes mediate patterning of the Arabidopsis root stem cell niche." Cell 119(1): 109-120.

Bennett, T., A. van den Toorn, V. Willemsen and B. Scheres (2014). "Precise control of plant stem cell activity through parallel regulatory inputs." Development 141(21): 4055-4064.

Birnbaum, K., D. E. Shasha, J. Y. Wang, J. W. Jung, G. M. Lambert, D. W. Galbraith and P. N. Benfey (2003). "A gene expression map of the Arabidopsis root." Science 302(5652): 1956-1960.

Brady, S. M., D. A. Orlando, J. Y. Lee, J. Y. Wang, J. Koch, J. R. Dinneny, D. Mace, U. Ohler and P. N. Benfey (2007). "A high-resolution root spatiotemporal map reveals dominant expression patterns." Science 318(5851): 801-806.

Burstenbinder, K., T. Savchenko, J. Muller, A. W. Adamson, G. Stamm, R. Kwong, B. J. Zipp, D. C. Dinesh and S. Abel (2013). "Arabidopsis calmodulin-binding protein IQ67-domain 1 localizes to microtubules and interacts with kinesin light chain-related protein-1." J Biol Chem 288(3): 1871-1882.

Clay, N. K. and T. Nelson (2005). "Arabidopsis thickvein mutation affects vein thickness and organ vascularization, and resides in a provascular cell-specific spermine synthase involved in vein definition and in polar auxin transport." Plant Physiol 138(2): 767-777.

De Rybel, B., M. Adibi, A. S. Breda, J. R. Wendrich, M. E. Smit, O. Novak, N. Yamaguchi, S. Yoshida, G. Van Isterdael, J. Palovaara, B. Nijsse, M. V. Boekschoten, G. Hooiveld, T. Beeckman, D. Wagner, K. Ljung, C. Fleck and D. Weijers (2014). "Plant development. Integration of growth and patterning during vascular tissue formation in Arabidopsis." Science 345(6197): 1255215.

De Rybel, B., B. Moller, S. Yoshida, I. Grabowicz, P. Barbier de Reuille, S. Boeren, R. S. Smith, J. W. Borst and D. Weijers (2013). "A bHLH complex controls embryonic vascular tissue establishment and indeterminate growth in Arabidopsis." Dev Cell 24(4): 426437.

Deal, R. B. and S. Henikoff (2010). "A simple method for gene expression and chromatin profiling of individual cell types within a tissue." Dev Cell 18(6): 1030-1040.

Di, D. W., C. Zhang and G. Q. Guo (2015). "Involvement of secondary messengers and small organic molecules in auxin perception and signaling." Plant Cell Rep 34(6): 895-904.

Friedman, W. E., R. C. Moore and M. D. Purugganan (2004). "The evolution of plant development." Am J Bot 91(10): 1726-1741.

Geldner, N. (2013). "The endodermis." Annu Rev Plant Biol 64: 531-558.

Gurdon, J. B. and P. Y. Bourillot (2001). "Morphogen gradient interpretation." Nature 413(6858): 797-803.

Helariutta, Y., H. Fukaki, J. Wysocka-Diller, K. Nakajima, J. Jung, G. Sena, M. T. Hauser and P. N. Benfey (2000). "The SHORT-ROOT gene controls radial patterning of the Arabidopsis root through radial signaling." Cell 101(5): 555-567.

Hepler, P. K. (2016). "The Cytoskeleton and Its Regulation by Calcium and Protons." Plant Physiol 170(1): 3-22.

Lander, A. D. (2009). "The 'stem cell' concept: is it holding us back?" J Biol 8(8): 70.

Mähönen, A. P., A. Bishopp, M. Higuchi, K. M. Nieminen, K. Kinoshita, K. Tormakangas, Y. Ikeda, A. Oka, T. Kakimoto and Y. Helariutta (2006). "Cytokinin signaling and its inhibitor AHP6 regulate cell fate during vascular development." Science 311(5757): 94-98.

Mähönen, A. P., K. ten Tusscher, R. Siligato, O. Smetana, S. Diaz-Trivino, J. Salojarvi, G. 
Wachsman, K. Prasad, R. Heidstra and B. Scheres (2014). "PLETHORA gradient formation mechanism separates auxin responses." Nature 515(7525): 125-129.

Möller, B. K. (2012). Identification of novel MONOPTEROS target genes in embryonic root initiation. Thesis Wageningen University.

Monshausen, G. B. (2012). "Visualizing $\mathrm{Ca}(2+)$ signatures in plants." Curr Opin Plant Biol 15(6): 677-682.

Monshausen, G. B., N. D. Miller, A. S. Murphy and S. Gilroy (2011). "Dynamics of auxindependent $\mathrm{Ca} 2+$ and $\mathrm{pH}$ signaling in root growth revealed by integrating high-resolution imaging with automated computer vision-based analysis." Plant J 65(2): 309-318.

Pi, L., E. Aichinger, E. van der Graaff, C. I. Llavata-Peris, D. Weijers, L. Hennig, E. Groot and T. Laux (2015). "Organizer-Derived WOX5 Signal Maintains Root Columella Stem Cells through Chromatin-Mediated Repression of CDF4 Expression." Dev Cell 33(5): 576-588.

Rogers, K. W. and A. F. Schier (2011). "Morphogen gradients: from generation to interpretation." Annu Rev Cell Dev Biol 27: 377-407.

Roudier, F., A. G. Fernandez, M. Fujita, R. Himmelspach, G. H. Borner, G. Schindelman, S. Song, T. I. Baskin, P. Dupree, G. O. Wasteneys and P. N. Benfey (2005). "COBRA, an Arabidopsis extracellular glycosyl-phosphatidyl inositol-anchored protein, specifically controls highly anisotropic expansion through its involvement in cellulose microfibril orientation." Plant Cell 17(6): 1749-1763.

Sarkar, A. K., M. Luijten, S. Miyashima, M. Lenhard, T. Hashimoto, K. Nakajima, B. Scheres, R. Heidstra and T. Laux (2007). "Conserved factors regulate signalling in Arabidopsis thaliana shoot and root stem cell organizers." Nature 446(7137): 811-814.

Scheres, B., H. Wolkenfelt, V. Willemsen, M. Terlouw, E. Lawson, C. Dean and P. Weisbeek (1994). "Embryonic origin of the Arabidopsis primary root and root meristem initials." Development 120(9): 2475-2487.

Schlereth, A., B. Möller, W. Liu, M. Kientz, J. Flipse, E. H. Rademacher, M. Schmid, G. Jurgens and D. Weijers (2010). "MONOPTEROS controls embryonic root initiation by regulating a mobile transcription factor." Nature 464(7290): 913-916.

Taylor, N. G., S. Laurie and S. R. Turner (2000). "Multiple cellulose synthase catalytic subunits are required for cellulose synthesis in Arabidopsis." Plant Cell 12(12): 2529-2540.

van den Berg, C., V. Willemsen, G. Hendriks, P. Weisbeek and B. Scheres (1997). "Shortrange control of cell differentiation in the Arabidopsis root meristem." Nature 390(6657): 287-289.

Vinogradova, M. V., G. G. Malanina, A. S. Reddy and R. J. Fletterick (2009). "Structure of the complex of a mitotic kinesin with its calcium binding regulator." Proc Natl Acad Sci U S A 106(20): 8175-8179.

Vinogradova, M. V., G. G. Malanina, V. S. Reddy, A. S. Reddy and R. J. Fletterick (2008). "Structural dynamics of the microtubule binding and regulatory elements in the kinesinlike calmodulin binding protein." J Struct Biol 163(1): 76-83.

Wartlick, O., P. Mumcu, A. Kicheva, T. Bittig, C. Seum, F. Julicher and M. Gonzalez-Gaitan (2011). "Dynamics of Dpp signaling and proliferation control." Science 331(6021): 1154-1159.

Yoshida, S., P. Barbier de Reuille, B. Lane, G. W. Bassel, P. Prusinkiewicz, R. S. Smith and D. Weijers (2014). "Genetic control of plant development by overriding a geometric division rule." Dev Cell 29(1): 75-87.

Zhang, J., S. Vanneste, P. B. Brewer, M. Michniewicz, P. Grones, J. Kleine-Vehn, C. Lofke, T. Teichmann, A. Bielach, B. Cannoot, K. Hoyerova, X. Chen, H. W. Xue, E. Benkova, E. Zazimalova and J. Friml (2011). "Inositol trisphosphate-induced Ca2+ signaling modulates auxin transport and PIN polarity." Dev Cell 20(6): 855-866. 


\section{Summary}

Growth of plant tissues and organs depends on continuous production of new cells, by niches of stem cells. Stem cells typically divide to give rise to one differentiating daughter and one non-differentiating daughter. This constant process of self-renewal ensures that the niches of stem cells or meristems stay active throughout plant-life. Specification of stem cells occurs very early during development of the emrbyo and they are maintained during later stages. The Arabidopsis embryo is a highly predictable and relatively simple model to study several developmental processes. Chapter 1 discusses the Arabidopsis embryo as a model for development and morphogenesis and describes the currently known factors involved in these processes.

Molecular cloning is a vital technique of today's plant biological research. The ability to quickly produce reliable constructs for follow-up analyses can greatly accelerate biological research. In Chapter 2, we describe the optimization of a highly efficient Ligation Independent Cloning method. This method makes use of sticky overhangs that enable in vivo ligation of cloning products. We present a step-by-step protocol that enables generating plant transformation-ready constructs in a semi-highthroughput manner, within two to three days. This method can for example facilitate follow-up analysis of genome-wide approaches.

Proteins regularly function as part of larger protein-complexes and their interaction partners can often be indicative of functionality. Unbiased, in vivo analysis of protein complexes can therefore be very informative for the functional characterization of a protein of interest. In Chapter 3, we describe an optimized method for immunoprecipitation followed by tandem mass-spectrometry. By performing mass-spectrometry measurements on at least three biological replicates, relative abundance of proteins in GFP-tagged sample compared to background controls can be statistically evaluated to identify high-confidence interactors. In this step-bystep protocol we detail the entire procedure from plant material to data analysis and visualization.

The establishment of distinct cellular identities is of critical importance for multicellular organisms. The first step that leads to cell identity is the activation of a unique set of transcripts and this often exploited in order to infer cell identity. In Chapter 4, we have generated 12 gene expression marker lines and describe their expression domain in the Arabidopsis embryo. We divided them into four different categories based 
on their expression domain: (I) ground tissue; (II) root stem cell; (III) shoot apical meristem; and (IV) post-embryonic. In addition, we used two stem cell markers to show their use as marker lines in genetic studies.

A central player in development of the Arabidopsis root meristem is the AUXIN RESPONSE FACTOR5/MONOPTEROS (MP). Several downstream targets of this transcription factor have been characterized, but the main focus has been on targets that were themselves transcription factors. An open question remains, therefore, how MP can orchestrate cellular responses during development. Chapter 5 describes the in-depth functional and biochemical characterization of a group of IQ-domain proteins. We show that their expression is regulated by the hormone auxin and that they bind microtubules and Calmodulins, in vivo. In addition, we show that the subcellular localization of IQD18 is cell cycle dependent. Loss- and gain-of-function analysis resulted in differential auxin- and calcium-signaling output, suggesting these proteins may form a bridge between these two major signaling pathways. Furthermore, this indicates a mode for how MP may be affecting cellular responses, during root development.

In Chapter 6, we take a step back and re-evaluate the currently prevailing model for stem cell organization in the Arabidopsis (embryonic) root. Using different gene expression markers, we were able to generate non-cell type specific and cell type specific transcriptomic datasets from systematically obtained ontogenetic cell populations in the root meristem. Follow-up analyses give support for an extended model for stem cell organization in the root.

Finally, in Chapter 7, we discuss the novel findings of this thesis and suggestions are made for future research directions. 


\section{Samenvatting}

De groei van (planten-) weefsels en organen is afhankelijk van een doorlopende productie van nieuwe cellen. Deze nieuwe cellen worden aangemaakt door niches van stamcellen. Een typische stamceldeling resulteert in een dochtercel die verder differentieert en een dochtercel die niet differentieert en stamcel blijft. Dit proces van continue zelfvernieuwing zorgt ervoor dat de niches van stamcellen, ook wel meristemen genoemd, gedurende het gehele leven van de plant actief kunnen blijven. Stamcellen worden heel vroeg tijdens de ontwikkeling van het embryo gespecificeerd en worden gedurende de verdere ontwikkeling steeds onderhouden. Het embryo van de plant Arabidopsis thaliana ontwikkelt zich op een zeer voorspelbare manier en leent zich uitstekend als een relatief simpel model om verschillende ontwikkelingsprocessen te bestuderen, waaronder de specificatie van stamcellen. Hoofdstuk 1 bediscussieerd het Arabidopsis embryo als model voor ontwikkeling en morfogenese en bespreekt wat er momenteel bekend is over factoren die hier een rol bij spelen.

Moleculair kloneren is een cruciale techniek in het hedendaagse (plant biologisch) onderzoek. De mogelijkheid om op een snelle manier betrouwbare DNA-constructen te maken kan biologisch onderzoek enorm versnellen. In Hoofdstuk 2 beschrijven we de optimalisatie van een zeer efficiënte kloneringsmethode, Ligation Independent Cloning (LIC) genaamd. Deze methode maakt gebruik van lange enkelstrengs DNAuiteinden die het mogelijk maken om verschillende stukken DNA in de bacteriën te combineren zonder dat daar een enzymreactie voor nodig is. We presenteren een stap-voor-stap protocol die het mogelijk maakt om binnen drie dagen, op een semihigh-throughput manier, constructen te maken die klaar zijn om getransformeerd te worden in planten. Deze methode kan bijvoorbeeld zeer nuttig zijn bij vervolgstudies na een genoom-brede aanpak.

Eiwitten functioneren zelden alleen, maar zijn vaak onderdeel van een groter complex met meerdere eiwitten. Een manier om erachter te komen wat de functie van een eiwit is, is te onderzoeken met welke andere eiwitten een interactie wordt aangegaan. Door te onderzoeken welke eiwitten kunnen binden aan een eiwit van interesse, is het mogelijk nieuwe functies te achterhalen voor dit eiwit. In Hoofdstuk 3 wordt een dergelijke methode beschreven voor immuun-precipitatie gevolgd door tandem massa-spectrometrie. Door massa-specrometrische metingen uit te voeren op tenminste drie biologische herhalingen, is het mogelijk om relatieve hoeveelheden van eiwitten in GFP-gelabelde monsters te vergelijken met achtergrond controles en deze statistisch te testen. Op deze manier kunnen bindende eiwitten met een hoge zekerheid geïdentificeerd worden. Dit stap-voor-stap protocol beschrijft de gehele 
procedure vanaf plantenmateriaal tot en met data-analyse en visualisatie.

De aanleg van de specifieke identiteit van cellen is zeer belangrijk voor meercellige organismen. De eerste stap die leidt tot een cellulaire identiteit is de activatie van een unieke set aan genen en derhalve wordt genexpressie in het onderzoek vaak gebruikt om de identiteit van een cel te bepalen. In Hoofdstuk $\mathbf{4}$ hebben we een collectie van 12 genexpressie merker-lijnen gemaakt en beschrijven we de domeinen van expressie tijdens de ontwikkeling van het Arabidopsis embryo. De collectie is opgedeeld in vier verschillende categorieën, afhankelijk van het expressiedomein: (I) steunweefsel, (II) wortelstamcellen, (III) scheutmeristeem en (IV) post-embryonaal. Naast een beschrijving van de expressiedomeinen laten we een voorbeeld zien van hoe twee stamcelmerker-lijnen gebruikt kunnen worden in genetisch onderzoek.

Een centrale speler binnen de ontwikkeling van het Arabidopsis embryo en wortelmeristeem is AUXIN RESPONSE FACTOR5/MONOPTEROS (MP). Verschillende doelgenen van deze transcriptiefactor zijn in het verleden gekarakteriseerd, echter lag er een nadruk op genen die zelf ook coderen voor transcriptiefactoren. Een onbeantwoorde vraag is daarom hoe MP op cellulair niveau in staat is om veranderingen teweeg te brengen. Hoofdstuk $\mathbf{5}$ behandeld een gedetailleerde functionele en biochemische studie van een groep van IQdomein eiwitten. Hierin laten we zien dat de expressie van deze genen gereguleerd wordt door het auxine hormoon en dat de eiwitten kunnen binden aan microtubuli en Calmodulines, in vivo. Daarnaast laten we zien dat de lokalisatie van IQD18 in de cel verandert tijdens de celcyclus. Analyse van auxine- en calcium-signalering in planten met verminderde of juist vermeerderde functie van deze eiwitten resulteerde in een veranderd effect op beide signaalroutes. Dit suggereert dat deze eiwitten een brug zouden kunnen vormen tussen deze twee belangrijke signaalmoleculen. Bovendien laat dit zien hoe MP een effect zou kunnen hebben op cellulaire veranderingen tijdens de wortelontwikkeling.

In Hoofdstuk 6 nemen we een stap terug om het huidige model voor stamcelorganisatie in de Arabidopsis (embryo-)wortel te evalueren. Door gebruik te maken verschillende genexpressie merker-lijnen, waren we in staat om zowel nietcel-specifieke als cel-specifieke transcriptoom data te genereren van systematisch verkregen ontogenetische celpopulaties in het wortelmeristeem. Verdere analyse van de data en genen die daaruit naar voren kwamen, vormen de basis van een hernieuwd model voor de organisatie van stamcellen in de wortel.

Tot slot worden in Hoofdstuk 7 de nieuwgevonden resultaten verder bediscussieerd en suggesties gedaan voor vervolgonderzoek. 


\section{Dankwoord}

Vier jaar lang naar een promotie toe werken is natuurlijk niet iets wat je alleen doet. Tijdens de afgelopen jaren heb ik het voorrecht gehad om met een geweldige groep mensen samen te werken en te ontmoeten. Hierbij zou ik dan ook iedereen, die op wat voor manier ook heeft bijgedragen aan dit hele proces, van harte willen bedanken! Er zijn een aantal mensen die ik in het bijzonder nog wil benoemen:

Allereerst Dolf, mijn promotor, dankjewel voor je toegewijde, gemotiveerde, optimistische, praktische en inspirerende begeleiding de afgelopen jaren. Dit heb ik altijd zeer gewaardeerd en heeft mij ook erg veel geleerd. De manier waarop jij je aandacht weet te verdelen over alle mensen in het lab en toch op de hoogte blijft van de voortgang van alle projecten is zeker bewonderingswaardig. Jouw deur staat altijd open voor een goed gesprek of even een grapje, dankjewel daarvoor. Ik hoop dat we elkaar in de toekomst nog vaak tegen zullen komen en de goede band die we opgebouwd hebben voort kunnen zetten.

Bert, bedankt voor alle praktische en op z'n tijd emotionele steun die je gegeven hebt. Jouw consciëntieuze aanpak is van onschatbare waarde geweest en heeft mij ook veel geleerd. Ik ben erg blij dat we jouw rol tijdens mijn promotie hebben kunnen uitbreiden tot co-promotor. We hebben samen ook het nodige kattenkwaad uitgehaald, ik herinner me bijvoorbeeld nog een "incident" met een prullenbak en vloeibare stikstof en die keer dat we een mooi verschillend-gekleurd agar-kunstwerk voor Dolf zijn verjaardag hadden gemaakt (alleen kwam hij er later pas achter dat we ook zijn trackpad daarin verstopt hadden...). Kortom goede tijden, die we zeker gaan voortzetten in Gent. Ik kijk er erg naar uit om daar samen met jou aan de slag te gaan!

Next I would like to thank Joakim and Shunsuke. Working together with you on the INTACT project was a great joy! The many hours we spent in the growth room emasculating and pollinating (all beware of the POLLINATOR!) surely created a strong bond. Thanks guys for all the fun and good discussions we had in (and outside) the office! I hope we can continue them in the future.

Bedankt ook Willy, dè go-to-guy voor alle praktische oplossingen in het lab. Zonder jouw waardevolle inbreng en expertise zou het lab zeker een stuk minder functioneren. Daarnaast ben je ook altijd wel in voor een geintje en draag je bij aan 
de goede atmosfeer binnen en buiten het lab.

Thanks also to all other Plant Development lab members (old and new) for creating such a nice working atmosphere. Ale, Colette, Cristina, Diaa, Hiro, Keita, Kuan-JuJoppie, Liao, Margo (Marjon), Maritza, Mark, Nicole, Sebastien, Sumanth, Tanya, Thijs and Wouter: Working alongside you was surely a great pleasure and I hope you weren't too annoyed by my singing and weird outbursts in the lab. All the poker nights, beer and whiskey tastings, group weekends and other fun stuff made the last years extra enjoyable! I hope we keep seeing each other in the future!

I am also very thankful for the greatly talented students I supervised during my PhD, in particular Borhan, Emiel and Pieter. Your hard work has been a great help to move the different projects forward, which is much appreciated!

Veel dank gaat ook uit naar Sacco, als hoofd van de afdeling faciliteerde je een prettige werkomgeving. Ik vond het erg leuk om onder andere met jou de PhD-trip naar Engeland te organiseren, waar we onder het genot van lauwe pils een zeer interessante en vooral leuke week gehad hebben ( $\mathrm{hmm}$ dat doet me aan een liedje denken...).

Een speciaal woord gaat uit naar Laura. Dankjewel dat je altijd weer het pad door het bureaucratische doolhof van declaraties, uren-schrijven en alle regeltjes weet te belichten. Ondanks dat we het toch steeds weer net niet helemaal goed lijken te doen, ben jij er altijd om stralend de weg te wijzen.

Jan Willem, erg bedankt voor alle hulp omtrent de microscopen en de leuke discussies die we gehad hebben over al dan niet werk gerelateerde onderwerpen.

Sjef bedankt voor de hulp met de optimalisaties van de IP experimenten en de MS metingen.

Also all other Biochemistry members, Adrie, Antsje, Carlo, Cathy, Gudrun, Jacques, Joseline, Mieke, Tom, Walter and Willem, thanks for the lively discussions and fun at the lunch table, during 'borrels', lab-outings, or barbecues! 
In the beginning of 2014, I spent two months at Duke University in North Carolina, USA. I would like to sincerely thank Philip for allowing me to come to his lab and do some fascinating experiments.

Also many thanks to all members of the Benfey lab, in particular Colleen, Erin, Heather, Jamie, Masashi and Polly, for making me feel very welcome and helping me with all kinds of things. Thanks Colleen and Joe, and Sophia and Adam, for taking me along for some very welcome social distraction during those months. I hope to see you all again soon!

Daarnaast wil ik graag mijn vrienden en familie bedanken voor alle liefde en gezellige momenten die jullie gegeven hebben de afgelopen jaren. Ook hier wil ik graag een paar mensen in het bijzonder bedanken:

Dylan en Evert, mijn partners-in-crime, dank voor alle leuke, gezellige, beschonken, actieve, luie, wetenschappelijke, doldwaze, serieuze, idiote, geweldige avonden, weekenden en vakanties die we beleefd hebben (en gaan beleven)! We zijn met z'n drieën op het HBO aan dit wetenschapsleven begonnen en ik ben erg blij dat we bij elkaar gebleven zijn en elkaar door dik en dun zijn blijven steunen. Anderhalf jaar geleden als mijn getuigen tijdens de bruiloft, nu als paranimfen aan mijn zijde, jullie zijn echt geweldig!

Elysa, Janna, Joost, Sjoerd en Wouter, dank voor alle muzikale momenten en gezellige etentjes! Drie jaar geleden begonnen we aan een prachtige reis door de wereld van de ensemble muziek en ik denk dat we in de afgelopen jaren erg naar elkaar toe gegroeid zijn. Deze regelmatige repetitieavonden en ook concerten zijn altijd een hoogtepunt in de week en ik hoop dat we dat nog lang kunnen blijven doen! Canzone!

Ook iedereen van Vivavoce en de Koorschool Midden-Gelderland, bedankt voor de fijne tonen die we samen hebben geproduceerd en de prachtige muziek die we uitgevoerd hebben!

Uiteraard wil ik ook graag mijn lieve ouders en stiefouders bedanken voor jullie liefde, dat jullie altijd in mij geloofd hebben en er altijd op aangedrongen hebben dat ik iets moest gaan doen wat ik leuk vind. Dat is zeker gelukt en daar ben ik jullie erg dankbaar voor! 
Lieve Pien en David, bedankt voor jullie hartelijkheid en warmte. Ik heb me vanaf het begin (nu zo'n tien jaar geleden alweer) direct thuis gevoeld bij jullie. Dankjewel!

Lieve Lotte, ik vind het super leuk dat je mijn cover zo mooi ontworpen hebt. Dankjewel! De etentjes met jou en Wilfried zijn ook altijd een welkome afleiding en herinneren mij eraan om te blijven genieten.

Tot slot, waar is een man zonder zijn vrouw? Lieve Annelien, dankjewel voor al je steun, geduld en liefde en dat je altijd voor me klaarstaat. We hebben inmiddels al best wat meegemaakt samen, sommige dingen leuk, andere niet. Ik weet dat mijn promotie niet altijd positief heeft bijgedragen aan de situatie, maar jij bent er altijd voor me geweest om me te ondersteunen en bij te staan. Ik zie ons daar al naast elkaar wandelen op de overtoom... Samen kunnen wij alles! Ik hou van jou! 


\section{Curriculum Vitae}

Jos Ruurd Wendrich was born on the $22^{\text {nd }}$ of January 1988 , in a town called Eelde, the Netherlands. At the age of 13 he moved to Almere, where he completed his higher general secondary education degree (HAVO) in 2005 at Het Baken Lyceum. Directly after, he started his Bachelor of Applied Sciences at the Hogeschool Utrecht, studying Life Sciences with a specialization in Molecular Biology. During these studies he completed two internships: the first at Plant Research International in Wageningen, under supervision of Dr Ruud

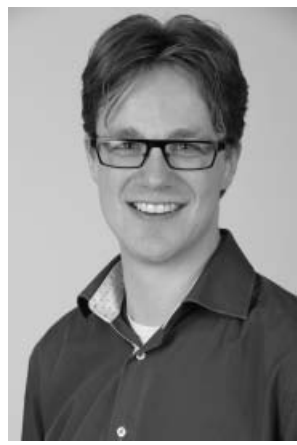
de Maagd, was focused on the analysis of MADS-box proteins in tomato. Jos next sought out more distant lands and performed his second internship at Griffith University in Queensland, Australia. Under supervision of Associate Professor Victoria Korolik he studied several genes involved in saccharide biosynthesis in the pathogenic bacterium Campylobacter jejuni and their role in the infectiousness and pathogenicity of this bacterium. The report he wrote on this last internship was nominated for the "Gouden Spatel 2009" (KNCV). After receiving his degree, Jos decided to further his studies in the academic world and started a master program in Molecular Life Sciences at Wageningen University in 2009. During this program he focused more on Plant Sciences and completed an internship at the laboratory of Professor Ben Scheres at Utrecht University. During this internship he studied the role of Retinoblastoma-related and PURalpha proteins in Arabidopsis root development. Jos finished his masters degree with a thesis on the role of bHLH transcription factors in Arabidopsis embryogenesis, under supervision of Professor Dolf Weijers. With their mutual interest in studying plant development at the molecular level, Jos next started a PhD program also under supervision of Professor Dolf Weijers, at the Laboratory of Biochemistry, Wageningen University. The work he performed between 2012 and 2016, dissecting stem cell specification and organization during Arabidopsis development, resulted in this thesis. He was awarded an EMBO shortterm fellowship to visit the laboratory of Professor Philip Benfey (Duke University, USA) for two months, which laid the foundation for the work presented in Chapter 6 of this thesis and more intense collaboration between the two labs. Jos intents to pursue a career in academic science, starting with a post-doc in the group of Dr Bert De Rybel at the Flemish Institute for Biotechnology in Ghent, Belgium. 


\section{Publications}

Palovaara, J. ", Saiga, S. ${ }^{*}$, Wendrich, J.R., van Schayck, P., van 't Wout Hofland, N., Sjollema, J., Boekschoten, M., Hooiveld, G., and Weijers, D. (in preparation) "A highresolution gene expression atlas of tissue initiation in the early Arabidopsis embryo" * These authors contributed equally

Radoeva, T.*, Lokerse, A.S. ${ }^{*}$, Llavata-Peris, C.I., Wendrich, J.R., Xiang, D., Liao, C-Y., Borst, J.W., Vlaar, L., Boekschoten, M., Hooiveld, G., Datla, R., and Weijers, D. (under revision) "A novel ARF/bHLH module regulates extra-embryonic identity during Arabidopsis embryogenesis"

* These authors contributed equally

Wendrich, J.R., Boeren, S., Möller, B.K., Weijers, D., and De Rybel, B. (in press) "In vivo identification of plant protein complexes using IP-MS/MS" Meth Mol Biol.

Wendrich, J.R., Möller, B.K., Uddin, B., Radoeva, T., Lokerse, A.S., De Rybel, B., and Weijers, D. (2015) "A set of domain-specific markers in the Arabidopsis embryo" Plant Reproduction. doi: 10.1007/s00497-015-0266-2

Wendrich, J.R., Liao, C-Y, van den Berg, W.A.M., De Rybel, B., and Weijers, D. (2015) "Ligation Independent Cloning for plant research" Meth Mol Biol. doi: 10.1007/978-1-4939-2444-8_21

De Rybel, B.*, Adibi, M.*, Breda, A.S., Wendrich, J.R., Smit, M.E., Novak, O., Yamaguchi, N., Yoshida, S., Van Isterdael, G., Palovaara, J., Nijsse, B., Boekschoten, M.V., Hooiveld, G., Beeckman, T., Wagner, D., Ljung, K., Fleck, C., and Weijers, D. (2014) "Integration of growth and patterning during vascular tissue formation in Arabidopsis" Science. doi: 10.1126/science.1255215

* These authors contributed equally

Wendrich, J.R. and Weijers, D. (2013) "The Arabidopsis embryo as a miniature morphogenesis model” New Phytologist. doi: 10.1111/nph.12267 

Education Statement of the Graduate School Experimental Plant Sciences

\author{
Issued to: Jos Wendrich \\ Date: $\quad 3$ June 2016 \\ Group: Laboratory of Biochemistry \\ University: Wageningen University \& Research Centre
}

1) Start-up phase

- First presentation of your project

Characterization of cellular processes underlying plant stem cell specification

- Writing or rewriting a project proposal

- Writing a review or book chapter

Transley review: The Arabidopsis embryo as a miniature morphogenesis model, New Phytologist (2013) 199: pp 14-25
MSc courses

- Laboratory use of isotopes

Subtotal Start-up Phase $\quad 7.5$ credits* $^{*}$

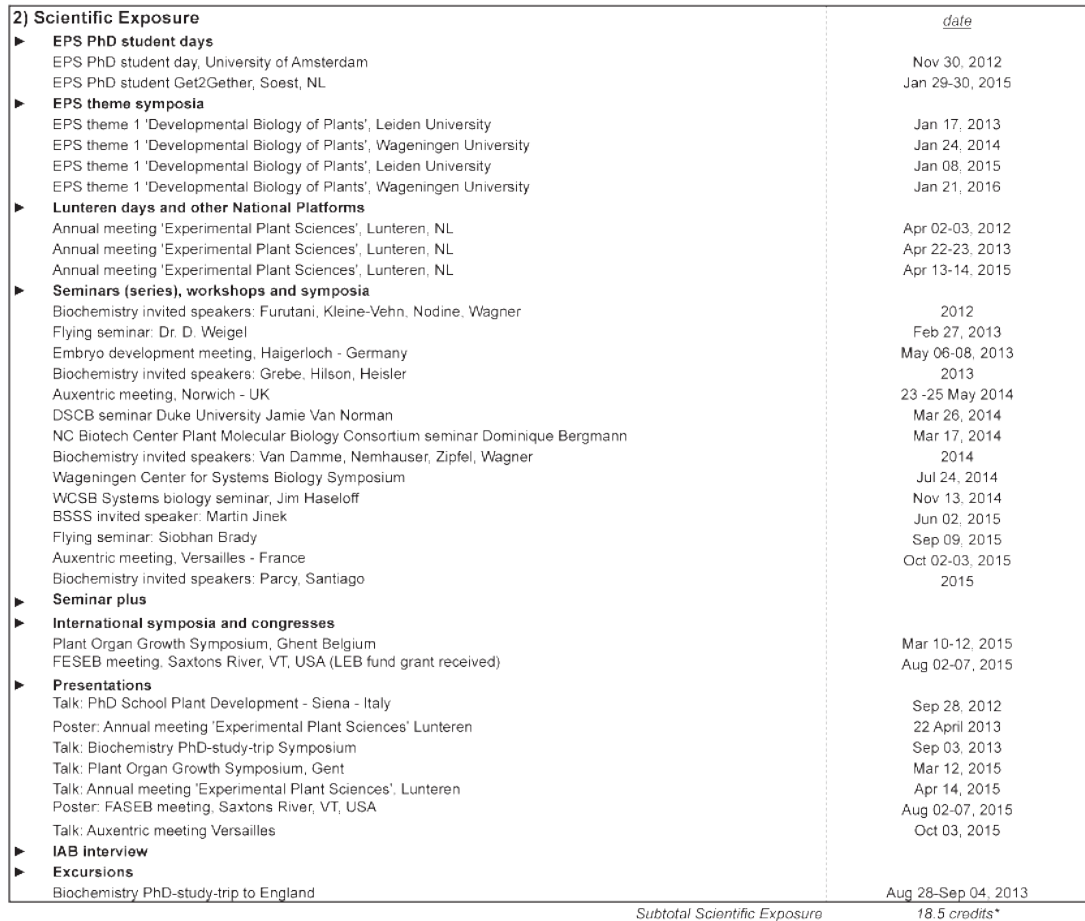

Biochemistry PhD-study-trip to England

\title{
3) In-Depth Studies
}

PhD School Plant Development - Siena - Italy (COST grant received)

EPS course: Transcription Factors and Transcriptional Regulation

EPS course: Microscopy and Spectroscopy in Food and Plant Sciences

Journal club

Participation in weekly journal club (Dolf Weijers Group)

- Individual research training

FACS and RNAseq in lab of Philip Benfey - two months (EMBO Short Term Fellowship received)

\begin{tabular}{c|c}
$\underline{\text { date }}$ \\
Sep 25-28, 2012 \\
Dec 17-19, 2013 \\
May 06-09, 2014 \\
$2012-2015$
\end{tabular}

Subtotal in-Depth Studies

Mar-Apr 2014

4) Personal development

- Skill training courses

WGS course Competence Assessment

WGS course Techniques for Writing and Presenting a Scientific Paper

WGS course Career Perspectives

Advanced course Guide to Scientific Artwork

Advanced course

- Organisation of PhD students day, course or conference

Organisation of Biochemistry PhD-study-trip to England

- Membership of Board, Committee or PhD council

9.5 credits* $^{*}$

\begin{tabular}{|rc|}
\hline & 5.8 credits* $^{*}$ \\
\hline TOTAL NUMBER OF CREDIT POINTS & $\mathbf{4 1 . 2}$ \\
\hline
\end{tabular}

Herewith the Graduate School declares that the PhD candidate has complied with the ed
Educational Committee of EPS which comprises of a minimum total of 30 ECTS credits

- A credit represents a normative study load of 28 hours of study. 
Research presented in this thesis was performed at the Laboratory of Biochemistry, Wageningen University, and was financially supported by the European Research Council (ERC_CELLPATTERN) and European Molecular Biology Organization (EMBO; ASTF 427-2013).

Financial support from the Laboratory of Biochemistry for printing this thesis is gratefully acknowledged.

Cover design by Lotte Wendrich

Layout by Jos Wendrich

Printed by Proefschriftmaken.nl, Digiforce B.V., Den Haag, the Netherlands 